2. To: (Receiving Organization)

Support Services \& Business Improvements

5. Proj-/Prog./Dept./Div.:

Tank Farm Trnsn Proj/TWRS

8. Originator Remarks:

KEY WORDS: S/RID, Phase 2, Compliance Assessment, Requirements Management.

11. Receiver Remarks:
3. From: (originating organization) Support Services \& Business Improvements

6. Cog. Engr.:

E. Biebesheimer
4. Related EDT No.:

$614254 / 619336 / 619337$

7. Purchase order No.:

N/A

9. Equip./Component No.:

N/A

10. System/Bldg./Facility:

N/A / N/A / TF Trnsn Proj

12. Major Assm. Dwg. No.: N/A

13. Permit/Permit Application No.: $N / A$

14. Required Response Date: $N / A$

DESIGN BASELINE DOFS 9127196

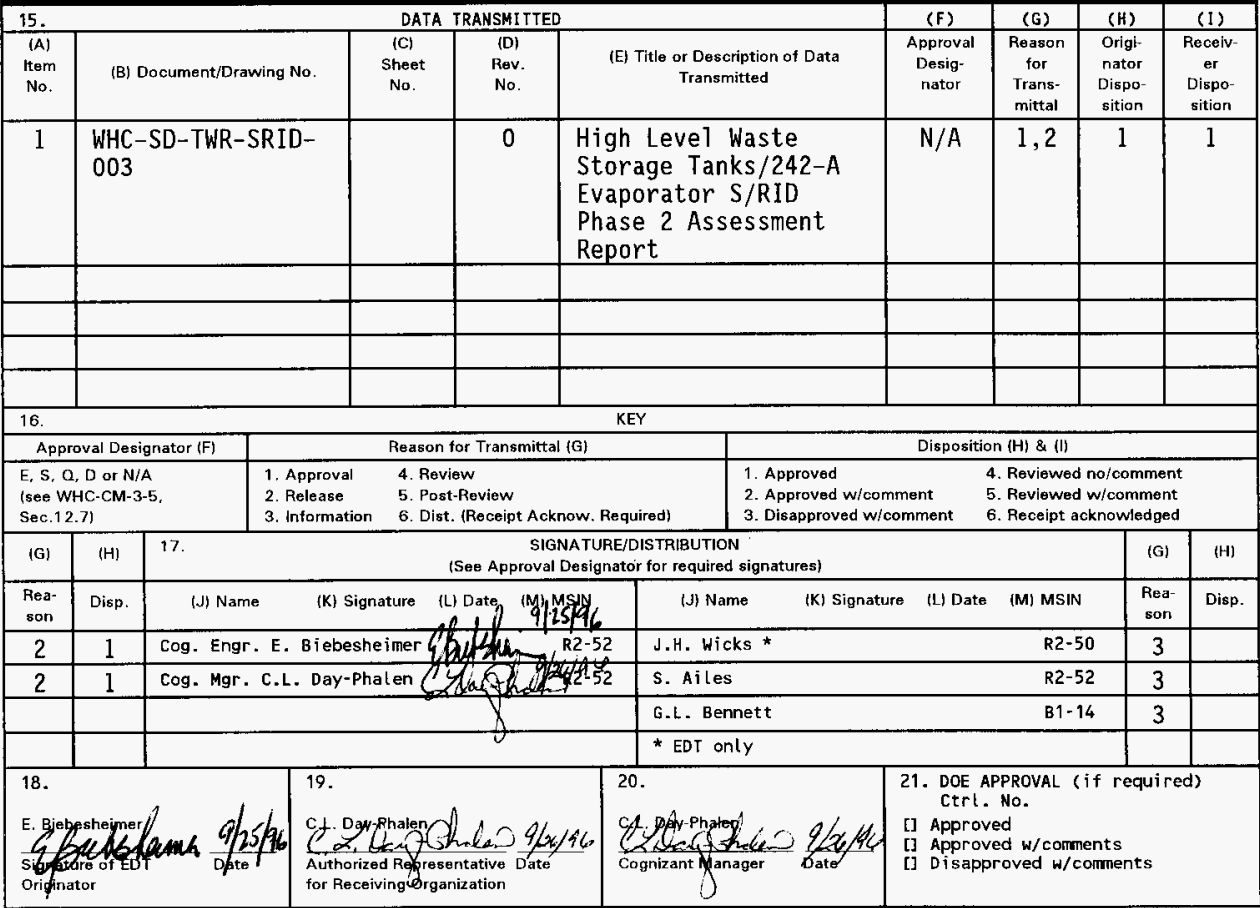




\title{
High Level Waste Storage Tank Farms/242-A Evaporator Standards/Requirements Identification Document Phase 2 Assessment Report
}

\author{
E. Biebesheimer \\ Westinghouse Hanford Company, Richland, WA 99352 \\ U.S. Department of Energy Contract DE-AC06-87RL10930
}

$\begin{array}{llll}\text { EDT/ECN: } & 619342 & \text { UC: } 2030 \\ \text { Org Code: } & 77850 & \text { Charge Code: } & \text { N1569 } \\ \text { B\&R Code: } & \text { EW3120071 } & \text { Total Pages: } 284\end{array}$

Key Words: S/RID, Phase 2, Compliance Assessment, Requirements Management.

Abstract: This document, the Standards/Requirements Identification Document (S/RID) Phase 2 Assessment Report for the subject facility, represents the results of a Performance Assessment to determine whether procedures containing S/RID requirements are fully implemented by field personnel in the field. It contains a summary report and three attachments; an assessment schedule, performance objectives, and assessments for selected functional areas.

TRADEMARK DISCLAIMER. Reference herein to any specific comercial product, process, or service by trade name, trademark, manufacturer, or otherwise, does not necessarily constitute or imply its endorsement, recomendation, or favoring by the United States Government or any agency thereof or $i$ ts contractors or subcontractors.

Printed in the United States of America. To obtain copies of this document, contact: WHC/BCS Document Control Services, P.O. Box 1970, Mailstop H6-08, Richland WA 99352, Phone (509) 372-2420; Fax (509) $376-4989$.
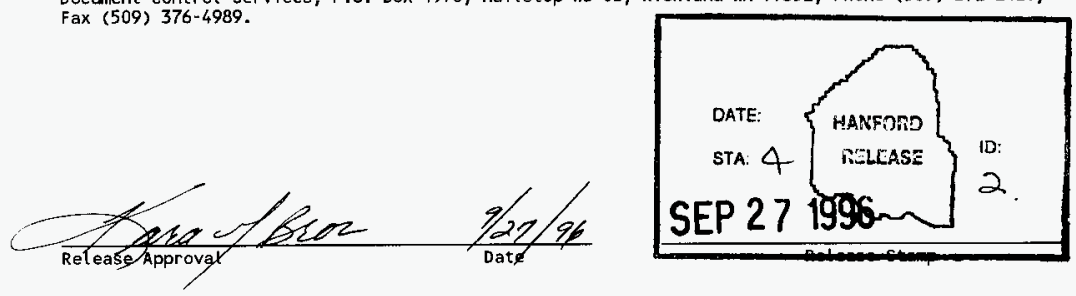

Approved for Public Release 
WHC-SD-TWR-SRID-003, Rev. 0

September 30, 1996

Page $i i$ of $i i$

\section{CONTENTS}

The High-Level Waste Storage Tank Farms/242-A Evaporator Standards/Requirements Identification Document (S/RID) Phase 2 Assessment Report covers selected functional areas. The S/RID is comprised of 20 functional areas; three of which have no requirements at this time.

An assessment summary report with three attachments are provided in this supporting document.

Attachment Description

1.

Assessment Schedule

2. Performance Objectives

3. Assessments for Selected Functional Areas 
WHC-SD-TWR-SRID-003

September 30, 1996

Rev. 0

\author{
High Level Storage Tank Farms/242-A Evaporator \\ Standards/Requirements Identification Document \\ Phase 2 Assessment Report \\ DOE Milestone T21-96-617 \\ September 30,1996
}

\title{
1.0 Introduction
}

This report documents the results of a performance assessment of procedural conformance in twenty functional areas in response to the Defense Nuclear Facility Safety Board (DNFSB) Recommendation 90-2. The implementing procedures evaluated, implement the requirements contained in the High Level Storage Tank Farms/242-A Evaporator Standards/Requirements Identification Document (hereafter, Tank Farm S/RID). The Tank Farm S/RID is controlled as a supporting document (WHC-SD-MP-SRID-001).

The DNFSB Recommendation 90-2 requested that the Department of Energy (DOE) identify specific standards applicable to the design, construction, operation, and decommissioning of defense nuclear

facilities; assess the adequacy of these standards for ensuring public health and safety; and then assess the extent to which these standards have been implemented.

The DNFSB Recommendation 90-2 is being implemented through a Tank Farms S/RID program comprised of four elements: 1) requirements development; 2) phase 1 assessment; 3 ) phase 2 assessment; and 4) requirements maintenance.

The first element has been accomplished through the development and approval of the Tank Farm S/RID (approved by RL March 1996); a compilation of appropriate environmental, safety, and health requirements. The phase $l$ assessment, performed to assess and identify the implementing procedures for the Tank Farm S/RID, provides the second element. The third element, or phase 2 assessment, is designed to be performed to provide evidence that controlled procedures are being used to implement the requirements contained in the Tank Farm S/RID. The last element, dealing with requirements management, is the implementation of periodic reassessments and requirement changes necessitated by newly promulgated requirements or mission changes.

This report addresses the third element, Phase 2 assessment, and documents the results for completion to meet milestone T21-96-617 from the Fiscal Year 1995 Multi-Year Program Plan.

\subsection{Summary}

DOE Milestone T21-96-617 requires issuing a revised assessment schedule to address the recent revision of the Tank Farms S/RID (Attachment 1),

Rpt. - 1 
WHC-SD-TWR-SRID-003

September 30, 1996

Rev. 0

development of performance objectives for new S/RID requirements (Attachment 2), and completion of assessments for selected functional areas (Attachment 3) by September 30, 1996. The intent of the milestone is to ensure that Tank Farms not only demonstrates that policies and procedures are in $\mathrm{place}$ to implement DOE S/RID requirements, but that the procedures are effectively implemented (resultant actions or activities produce the required results).

\subsection{Strategy}

Efforts to meet the T21-96-617 milestone were contained in a three-phase approach. The first approach attempted to determine the effectiveness of existing controls by analyzing a sample of S/RID requirements previously evaluated in the initial Phase 2 Assessment. This approach provided no meaningful results. When the early S/RID requirements were compared with the current requirements there were less than $10 \%$ of the requirements that remained the same.

The second approach was to glean the results of other appraisal and assessment activities conducted for all functional areas in FY96 to maximize assessment coverage. As illustrated in Attachment 3, 394 requirements were assessed, 573 procedures reviewed ( 392 compliant and 72 non-compliant), with 109 continuous improvement checks against operational activities.

The last component of the FY96 three-phase effort supports the future intent to integrate the conformance Management Assessment Program activities with Phase 2 S/RID Assessment activities. PIans are to integrate these assessment activities beginning in FY 1997. To achieve that vision, two functional area pilot conformance assessments were conducted to augment the Phase 2 milestone assessment and generate the FY 1997 process testing results. The results of these assessments provided feedback directly related to the assessment program for consideration and the actual performance results of the assessments performed. The assessment results are included in Attachment 3 .

Starting in FY 1997 the integrated management assessment schedule wi11 incorporate all Tank Farm S/RID requirements into an reoccurring 3 year cycle for each organizational unit. By utilizing this approach, the objectives of the S/RID compliance program will be met.

4.0 Discrepancies

Items originally found non-compliant are in process of being corrected or have already been corrected as noted in the detailed tables provided in Attachment 3.

Rpt. - 2 
WHC-SD-TWR-SRID-003

September 30, 1996

Rev. 0

\subsection{Corrective Action}

Beginning FY 1997, assessment data will be entered and tracked within the Management Assessment Program database with cross-reference to the Hanford Action Tracking System (HATS) for those items needing corrective action. This database will maintain evidence of the standardized objectives and criteria for each requirement assessed. The compilation of data from all assessments will allow meaningful tracking and trending results for all functional areas of all requirements, ranging from a vertical facility-specific level report to a horizontal, functional area slice across all Tank Waste Remediation System (TWRS) operational units.

Rpt. - 3 
WHC-SD-TWR-SRID-003

September 30, 1996

Rev. 0

\section{ATTACHMENT 1 WHC-SD-TWR-SRID-003, Rev. 0 Page i of 56}

Att. $1-j$ 


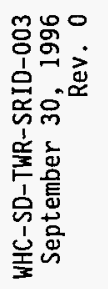

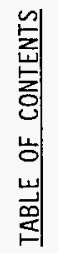
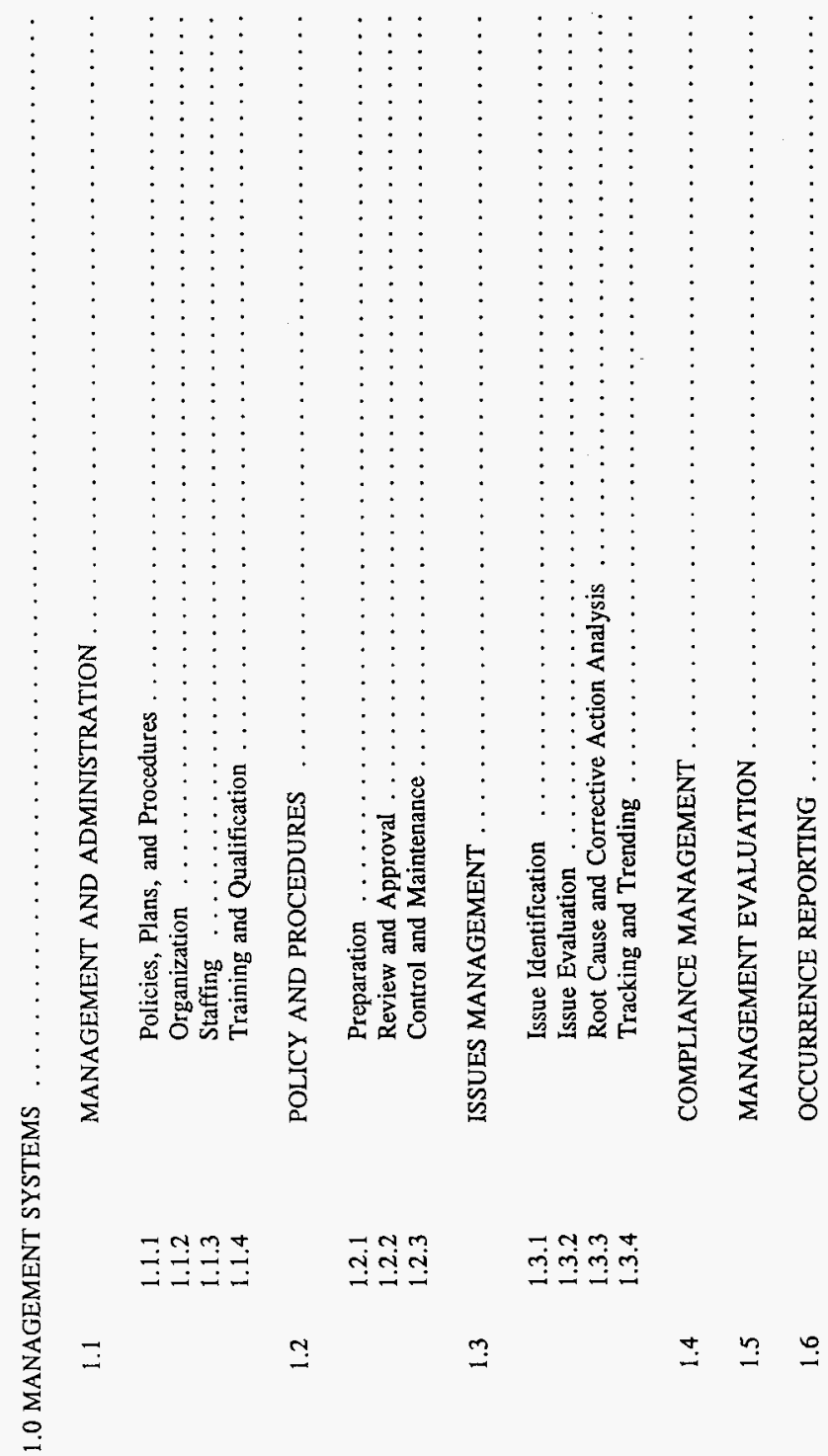

a aㅡ으음 $=\cong$ 


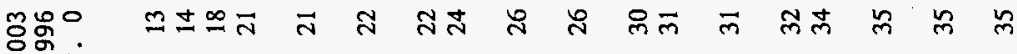
究察

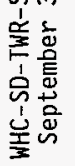

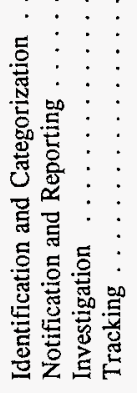

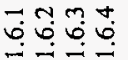

o $\vdots \vdots \vdots$

: $:$

焉

Z

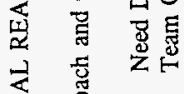

产

赵

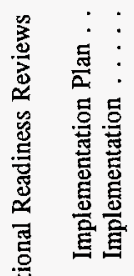

芯

돔

꼼

岂

苍

客

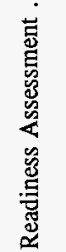

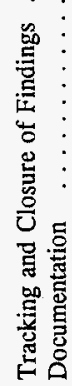

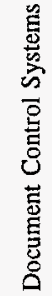

옴

㭊

它

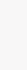

. 


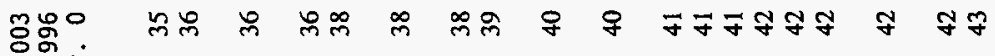

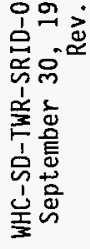



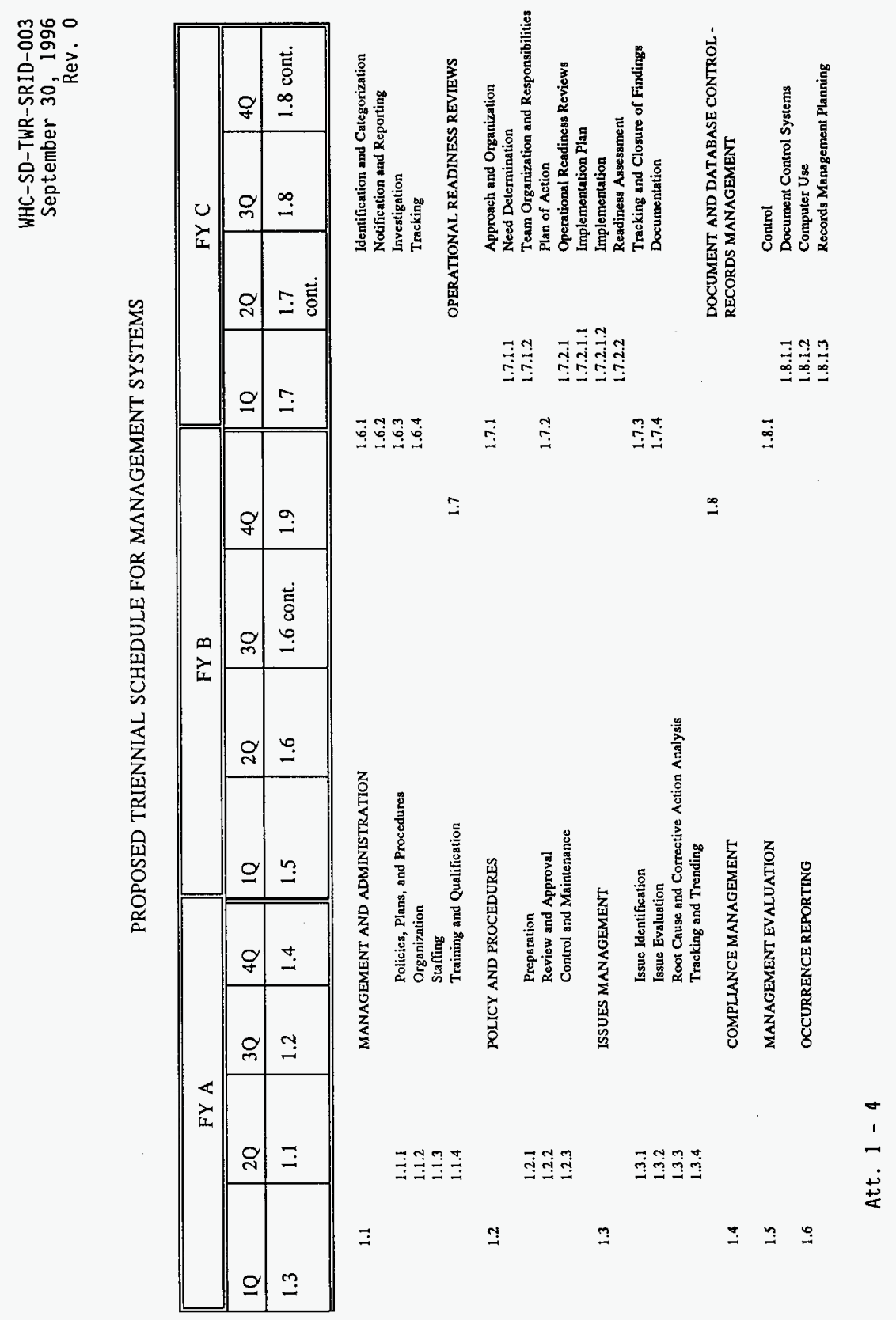

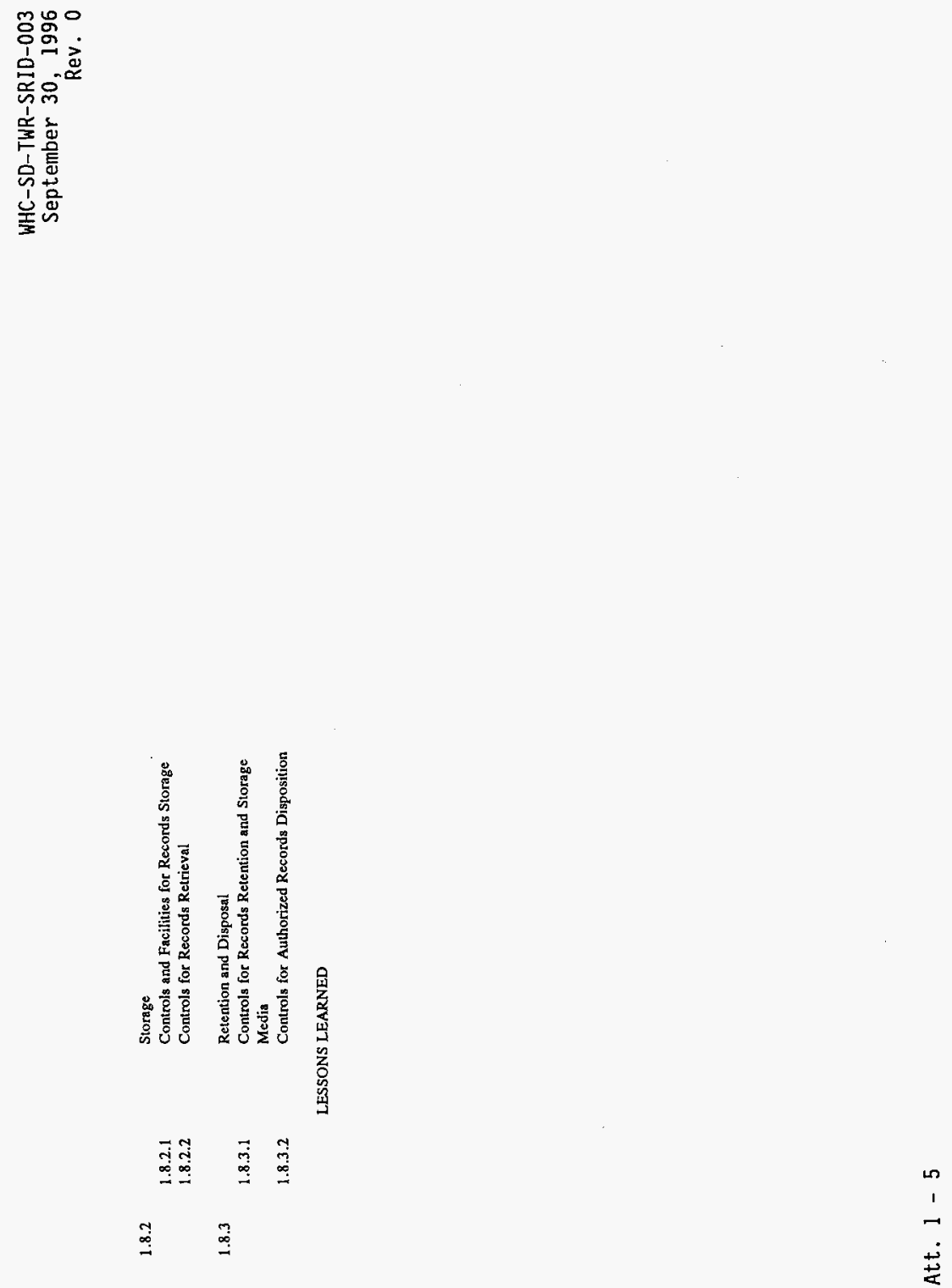
WHC-SD-TWR-SRID-003

September 30, 1996

Rev. 0

\section{TABLE OF CONTENTS}

2.0 QUALITY ASSURANCE

2.1

2.3

2.4

2.5

2.6

2.7

2.8

2.9

2.10

2.11

\section{MANAGEMENT AND}

ADMINISTRATION ........... 3

QUALITY ASSURANCE PROGRAM . . . . . 3

TRAINING AND QUALIFICATION OF PERSONNEL ............. 3

QUALITY IMPROVEMENT . . . . . . . . . 3

DOCUMENTS AND RECORDS $\ldots \ldots \ldots 3$

WORK PROCESSES . . . . . . . . . . 4

DESIGN . . . . . . . . . . . 4

PROCUREMENT ............. 5

INSPECTION AND ACCEPTANCE

TESTING ............... 5

MANAGEMENT ASSESSMENT . . . . . 5

INDEPENDENT ASSESSMENT $\ldots \ldots \ldots \ldots$

\section{KEY INTERFACES}

Training and Qualification Management Systems

Construction

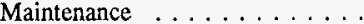

Engineering Program . . . . . .

Environmental Protection

\section{REFERENCES}

Requirement Source

Documents

Reviewed Documents Not Used

as Requirement Sources

Att. $1-6$ 
WHC-SD-TWR-SRD-003

September 30, 1996

Rev. 0

PROPOSED TRIENNIAL SCHEDULE FOR QUALITY ASSURANCE

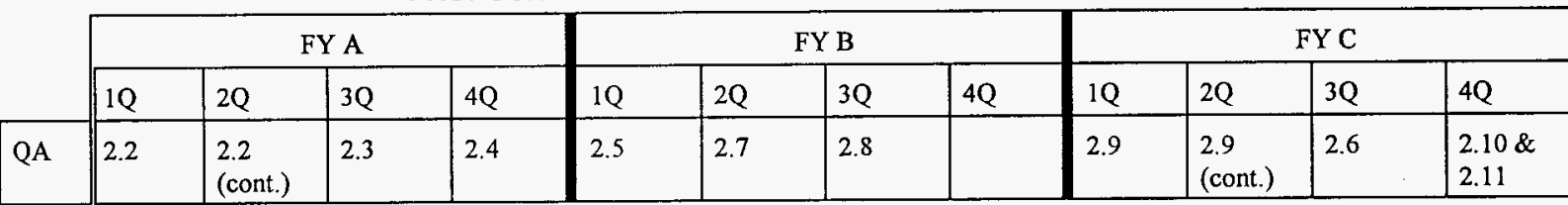

FYA

2.2 QUALITY ASSURANCE PROGRAM

2.2.1 Management and Administration

2.2.2 Program

$\dagger \quad 2.3$ TRAINING AND QUALIFICATION OF

PERSONNEL-Related to TN

2.3.1 Personnel Training and Qualification

2.4 QUALITY IMPROVEMENT

2.4.1 Quality detection

2.4.2 Control and Correction of Nonconformance
2.7 DESIGN - Related to EN

2.7.1 Design Control

2.7.2 Design Bases

2.7.3 Design Interfaces

2.7.4 Design Verification

2.8 PROCUREMENT

2.8.1 Control of Purchased Material, Equipment, and Services

2.8.2 Supplier Evaluations

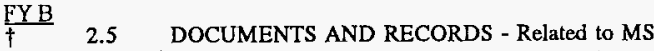

2.5.1 Instructions, Procedures, and Drawings

2.5.2 QA Records

Notes: 1. † Indicates a relationship to other Functional Areas

2. Corrective Actions are assessed integral to each Functional Area Element

Att. $1-7$ 
WHC-SD-TWR-SRID-003

September 30, 1996

Rev. 0

$\underline{\text { FY C }}$

2.6 WORK PROCESSES

2.6.1 Work Controls

2.6.2 Control and Use of Items

2.6.3 Prevention of Loss or Damage

2.6.4 Equipment Calibration

2.9 INSPECTION AND ACCEPTANCE TESTING

2.9.1 Inspections and Testing

2.9.2 Control of Measuring and Test Equipment

2.10 MANAGEMENT ASSESSMENT

2.10.1 Assessment Practices

2.10.2 Corrective Action Management

2.11 Independent Assessment

2.11.1 Planning and Scheduling

2.11.2 Responsibilities

Notes: 1. † Indicates a relationship to other Functional Areas

2. Corrective Actions are assessed integral to each Functional Area Element

Att. 1 - 8 
WHC-SD-TWR-SRID-003

September 30, 1996

Rev. 0

TABLE OF CONTENTS

MANAGEMENT AND

2

3.1.1

3.1 .2

3.1 .3

3.1.4

3.1 .5

3.2

Program Boundary Definition . . . . . . 3

Program Assessment . . . . . . . . 3

Document and Database Control .... . 5

Training .............. 7

Graded Approach $\ldots \ldots \ldots \ldots \ldots 7$

TECHNICAL BASELINE . . . . . . . . 7

3.2 .1

3.2 .2

3.3

3.4

Establishing The Technical Baseline . . 8

Reconstitution of the Technical

Baseline ............. 8

CHANGE CONTROL $\ldots \ldots \ldots \ldots \ldots$

KEY INTERFACES $\ldots \ldots \ldots \ldots \ldots \ldots \ldots$

3.4.1

3.4 .2

3.4 .3

3.4 .4

3.4 .5

3.4 .6

Management Systems . . . . . . . . . 11

Engineering Program ........ 12

Operations . . . . . . . . . . 12

Maintenance ............. 12

Nuclear Safety ............ 12

Training and Qualification ....... 13

\section{REFERENCES}

\section{Requirement Source}

Documents

Reviewed Documents Not Used as Requirement Sources

Att. $1-9$ 
WHC-SD-TWR-SRID-003

September 30, 1996

Rev. 0

PROPOSED TRIENNIAL SCHEDULE FOR CONFIGURATION MANAGEMENT

\begin{tabular}{|c|c|c|c|c|c|c|c|c|c|c|c|}
\hline \multicolumn{4}{|c|}{ FY A } & \multicolumn{4}{|c|}{ FY B } & \multicolumn{4}{|c|}{ FY C } \\
\hline $1 \mathrm{Q}$ & $2 Q$ & $3 Q$ & $4 Q$ & $1 Q$ & $2 Q$ & $3 Q$ & $4 \mathrm{Q}$ & $1 \mathrm{Q}$ & $2 \mathrm{Q}$ & $3 Q$ & $4 Q$ \\
\hline 3.1 & $3.1 \mathrm{cont}$ & $\begin{array}{l}3.1 \\
\text { cont }\end{array}$ & $\begin{array}{l}3.1 \\
\text { cont }\end{array}$ & 3.2 & 3.2 cont & 3.2 cont & 3.2 cont & 3.3 & $3.3 \mathrm{cont}$ & 3.3 cont & 3.3 cont \\
\hline
\end{tabular}

3.0 CONFIGURATION MANAGEMENT

3.1

\begin{tabular}{|l|}
\hline 3.1 .1 \\
3.1 .2 \\
3.1 .3 \\
3.1 .4 \\
\hline 3.1 .5
\end{tabular}

3.2

3.2 .1

3.2 .2

3.3

MANAGEMENT AND ADMINISTRATION

Program Boundary Definition

Program Assessment

Document and Database Control

Training

Graded Approach

TECHNICAL BASELINE

Establishing The Technical Baseline

Reconstitution of the Technical Baseline

CHANGE CONTROL

Att. $1-10$ 
WHC-SD-TWR-SRID-003

September 30, 1996

Rev. 0

TABLE OF CONTENTS

4.0 TRAINING AND QUALIFICATION $\ldots \ldots \ldots \ldots \ldots$

4.1

MANAGEMENT AND

ADMINISTRATION .......... 3

4.1.1

4.1 .2

Program Policy ........... 3

Training Organization Staffing and

Training ............... 4

4.2

ADMINISTRATION OF TRAINING . . . . 5

4.2 .1

4.2 .2

4.2 .3

4.2 .4

4.2 .5

4.2 .6

4.2 .7

4.2 .8

4.2 .8 .1

4.2.8.2

4.2 .9

4.2 .10

Selection and Qualification $\ldots \ldots \ldots 7$

Training Needs Assessment . . . . . 7

Design and Development . . . . . . . . 9

Implementation . . . . . . . . . . 9

Evaluation . . . . . . . . . . . . 10

Facilities and Equipment ....... 11

Training Schedules ... . . . . . . . 11

Testing, Qualification, Certification . . 11

Qualification and

11

Requalification

Revision and Update of Training . . . 14

Extension, Exceptions and

Alterations

14
TRAINING CATEGORIES AND SUBJECIS . . 1/

4.3.1

General Employee Training ... 1/

4.3.1.1

4.3.1.2

4.3.2

4.3.3

4.3.4

4.3.5

4.3.6

4.6

4.6 .2
Lockout and Tagout

Training . . . . . . . . Hazard Communication

Training ........

Maintenance Training Program , . 18 Management and Supervisory

Training . . . . . . . . . . . 19

Operator Training $\ldots \ldots \ldots, 21$

Continuing Training .

Technical Support Personnel

Training

TRAINING RECORDS AND

DOCUMENTATION

ACCREDITATION

KEY INTERFACES

Management Systems

Quality Assurance 
4.6 .3

4.6 .4

4.6 .5

4.6 .6

4.6 .7

4.6 .8

4.6 .9

4.6 .10

4.6 .11

4.6 .12

4.6 .13

4.6 .14

4.6 .15

4.6.16

4.6.17

4.6 .18

4.6 .19

4.7

4.7.1

4.7.2

Att. $1-12$
Configuration Management . . . . . . 29

Emergency Management . . . . . . . 30

Safeguards and Security ....... 30

Engineering Program ........ 30

Construction Program . . . . . . . . . 30

Operations .............. 30

Maintenance ........... 31

Radiation Protection . . . . . . . . . . 31

Fire Protection . . . . . . . . . 31

Packaging and Transportation ..... 32

Environmental Restoration . . . . . . . 32

Decontamination and

Decommissioning .......... 32

Waste Management . . . . . . . . 32

Research and Development and

Experimental Activities . . . . . . . . 32

Nuclear Safety . . . . . . . . . 32

Occupational Safety and Health .... 32

Environmental Protection . . . . . . 33

REFERENCES . . . . . . . . . . . . 33

Requirement Source Documents . . . 33

Reviewed Documents Not Used as

Requirement Sources . . . . . . . . 34 
WHC-SD-TWR-SRID-003

September 30, 1996 Rev. 0

PROPOSED TRIENNIAL SCHEDULE FOR TRAINING AND QUALIFICATION

\begin{tabular}{|l|l|l|l||l|l|l|l||l|l|l|l|}
\hline \hline \multicolumn{9}{|c|}{ FY A } & \multicolumn{9}{c|}{} & \multicolumn{4}{c|}{ FY B } \\
\hline $1 \mathrm{Q}$ & $2 \mathrm{Q}$ & $3 \mathrm{Q}$ & $4 \mathrm{Q}$ & $1 \mathrm{Q}$ & $2 \mathrm{Q}$ & $3 \mathrm{Q}$ & $4 \mathrm{Q}$ & $1 \mathrm{Q}$ & $2 \mathrm{Q}$ & $3 \mathrm{Q}$ \\
\hline 4.1 & 4.2 & $\begin{array}{l}4.2 \\
\text { cont }\end{array}$ & $\begin{array}{l}4.2 \\
\text { cont }\end{array}$ & 4.3 & 4.3 cont & 4.3 cont & 4.3 cont & 4.4 & 4.4 cont & 4.4 cont & 4.5 \\
\hline \hline
\end{tabular}

4.0 TRAINING AND QUALIFICATION

\subsection{MANAGEMENT AND ADMINISTRATION}
4.1.1 Program Policy
4.1.2 Training Organization Staffing and Training

4.2 ADMINISTRATION OF TRAINING

$\begin{array}{ll}\text { 4.2.1 } & \text { Selection and Qualification } \\ \text { 4.2.2 } & \text { Training Needs Assessment } \\ \text { 4.2.3 } & \text { Design and Development } \\ \text { 4.2.4 } & \text { Implementation } \\ \text { 4.2.5 } & \text { Evaluation } \\ \text { 4.2.6 } & \text { Facilities and Equipment } \\ 4.2 .7 & \text { Training Schedules } \\ 4.2 .8 & \text { Testing, Qualification, Certification } \\ & 4.2 .8 .1 \quad \text { Testing } \\ & \text { 4.2.8.2 Qualification and Requalification } \\ \text { 4.2.9 } & \text { Revision and Update of Training } \\ 4.2 .10 & \text { Extension, Exceptions and Alterations }\end{array}$

Att. $1-13$
4.3

\section{TRAINING CATEGORIES AND SUBJECTS}

4.3.1 General Employec Training

4.3.1.1 Lockout and Tagout Training

4.3.1.2 Hazard Communication Training

4.3.2 Maintenance Training Program

4.3.3 Management and Supervisory Training

4.3.4 Operator Training

4.3.5 Continuing Training

4.3.6 Technical Support Personnel Training

4.4 TRAINING RECORDS AND DOCUMENTATION

4.5 ACCREDTATION 
TABLE OF CONTENTS

5.0 EMERGENCY MANAGEMENT

5.1

5.1 .2

5.1 .3

5.2

5.3

5.3 .1

5.3 .2

5.3 .3

5.4
MANAGEMENT AND

ADMINISTRATION . . . . . . . . 3

EMERGENCY RESPONSE TRAINING . . . . 5

PLANNING DOCUMENTS $\ldots \ldots \ldots \ldots 7$

\section{FACILITIES, EQUIPMENT AND}

RESOURCES $\ldots \ldots \ldots \ldots \ldots \ldots \ldots \ldots$

5.4 .1

5.4 .2

5.4 .3

Att. $1-14$
Program Policy .......... 3

Duties, Responsibilities, and

Authorities for Program

Management ........... 3

Duties, Responsibilities and

Authorities for ERO . . . . . . . . 3

Hazards Assessment . . . . . . . . 7

Emergency Plan ........... 7

Emergency Implementing

Procedures

14

Emergency Response Facilities . . . . 17

Emergency Equipment and Supplies . . 17

Communications Equipment ...... 18
WHC-SD-TWR-SRID-003

September 30, 1996

Rev. 0
5.5 .1

CLASSIFICATION, NOTIFICATION AND REPORTING

Event Classification and

Emergency Action Levels

(EALs)

Notifications and Staff Angmentatinno?

Reporting and Event

Investigations $\ldots \ldots \ldots \ldots \ldots$

\section{EVENT CONTAINMENT AND}

PERSONNEL PROTECTION

Event Containment and

Consequence Assessment . . . . . 2

Protective Actions

Personnel Accountability and

Evacuation $\ldots \ldots \ldots \ldots \ldots$ 2l

Medical Response ........ 27

\section{RECOVERY AND REENTKY . . . . 21}

PUBLIC INFORMATION

Public and Media Education . . . .

Emergency Public Information

Response . . . . . . . . . 
WHC-SD-TWR-SRID-003 September 30,1996 Rev. 0

Management Coordination . . . . . . 29

Response Coordination ... . . . . . 29

5.11 .14

DEMONSTRATING, MONITORING AND IMPROVING PERFORMANCE $\ldots \ldots \ldots, 29$

Drill and Exercise Program ...... 29

Reviews, Audits and Evaluations . . . . 30

Emergency Readiness Assurance

Program . . . . . . . . . . . . . . . 30

5.10 .2

5.10 .3

5.10 .4

5.11 .1

5.11 .2

5.11 .3

5.11 .4

5.11 .5

5.11 .6

5.11 .7

5.11 .8

5.11 .9

5.11 .10

Att. $1-15$
Deficiency Identification and Correction 31

KEY INTERFACES $\ldots \ldots \ldots \ldots \ldots \ldots .31$

Safeguards and Security ........ 31

Operations . . . . . . . . . . . . 31

Training and Qualification ....... 31

Radiation Protection ............ 31

Waste Management . . . . . . . . . . 32

Occupational, Health and Safety .... 32

Fire Protection . . . . . . . . . . 32

Medical .............. 32

Management Systems . . . . . . . . 32

Nuclear Safety . . . . . . . . . . . 32
Packaging and Transportation

Quality Assurance

Environmental Protection

Emergency Management

\section{REFERENCES}

Requirement Source

Documents

Reviewed Documents Not Used as

Requirement Sources 3.

3

$3:$ $3 \cdot$ 
PROPOSED TRIENNIAL SCHEDULE FOR EMERGENCY MANAGEMENT

\begin{tabular}{|c|c|c|c|c|c|c|c|c|c|c|c|}
\hline \multicolumn{4}{|c|}{ FY A } & \multicolumn{4}{|c|}{ FY B } & \multicolumn{4}{|c|}{ FY C } \\
\hline $1 Q$ & $2 Q$ & $3 Q$ & $4 Q$ & $1 \mathrm{Q}$ & $2 Q$ & $3 Q$ & $4 Q$ & $1 Q$ & $2 Q$ & $3 Q$ & $4 Q$ \\
\hline 5.1 & 5.2 & 5.3 & 5.4 & 5.5 & 5.6 & $5.6 \mathrm{cont}$ & 5.7 & 5.8 & 5.9 & 5.10 & $5.10 \mathrm{cont}$ \\
\hline
\end{tabular}

\section{MANAGEMENT AND ADMINISTRATION}

5.1.1 Program Policy

5.1.2 Duties, Responsibilities, and Authorities for Program Management

5.1.3 Duties, Responsibilities and Authorities for ERO

\subsection{EMERGENCY RESPONSE TRAINING}

\subsection{PLANNING DOCUMENTS}

\subsubsection{Hazards Assessment \\ 5.3.2 Emergency Plan \\ 5.3.3 Emergency Implementing Procedures}

5.4 FACILITIES, EQUIPMENT AND RESOURCES

$$
\begin{array}{ll}
\text { 5.4.1 Emergency Response Facilities } \\
\text { 5.4.2 Emergency Equipment and Supplies } \\
\text { 5.4.3 Communications Equipment }
\end{array}
$$

\subsection{CLASSIFICATION, NOTIFICATION AND REPORTING}

$$
\begin{array}{ll}
\text { 5.5.1 Event Classification and Emergency Action Levels (EALs) } \\
5.5 .2 \text { Notifications and Staff Augmentations } \\
5.5 .3 \quad \text { Reporting and Event Investigations }
\end{array}
$$

Att. $1-16$

5.6

EVENT CONI

5.6.1 Event Containment and Consequence Assessment

5.6.2 Protective Actions

5.6.3 Personnel Accountability and Evacuation

5.6.4 Medical Response

5.7 RECOVERY AND REENTRY

5.8 PUBLIC INFORMATION

5.8.1 Public and Media Education

5.8.2 Emergency Public Information Response

5.9 COORDINATION WITH OFFSITE AGENCIES

5.9.1 Management Coondination

5.9.2 Response Coordination

5.10 DEMONSTRATING, MONITORING AND MMPROVING PERFORMANCE

5.10 .1

5.10 .2 Reviews, Audits and Evaluations

5.10.3 Emergency Readiness Assurance Program

5.10.4 Deficiency Identification and Correction 
WHC-SD-TWR-SRID-003

September 30, 1996

Rev. 0

\section{TABLE OF CONTENTS}

6.1

6.3 .1

6.3 .2

6.3 .3

6.3 .4

6.3 .5

6.3 .6

6.4
MANAGEMENT AND

ADMINISTRATION .......... 3

PERSONNEL SECURITY . . . . . . 3

PROTECTION PROGRAM OPERATIONS . . . 3

Physical Security . . . . . . . . . . . 4

Security Systems . . . . . . . . . . 5

Protective Forces .......... 5

Security Identification Badges and

Passes ... . . . . . . . . . . . 5

Incident Response and Management ... 5

Transportation Security ........ 5

MATERIAL CONTROL AND ACCOUNTABILITY FOR SPECIAL

NUCLEAR MATERIAL $\ldots \ldots \ldots \ldots$

Material Control and Accountability

Plan ................... 6

Special Nuclear Material

Accountability System . . . . . . . 6

Material Control System . . . . . . . 6
FACILITY APPROVALS, SECURITY AND NUCLEAR MATERIAL

SURVEYS

\section{INFORMATION SECURITY}

PROGRAM
6.6 .1

6.6 .2

6.6 .3

6.6 .4

6.6 .5

6.8
Classified Matter Protection and Control (CMPC) Technical Surveillance Countermeasures (TSCM) Automated Information Systems Security Program (Classified Computer Security) . . Unclassified Computer and Sensitive Automated Data Processing Systems . . . . . . . Communications Security ....

OPERATIONS SECURITY (OPSEC)

FOREIGN OWNERSHIP, CONTROL OR INFLUENCE (FOCI) . . . . . . .

EVALUATION OF RADIOLOGICAL AND TOXICOLOGICAL AND SABOTAGE CONSEQUENCES . . . . . . 

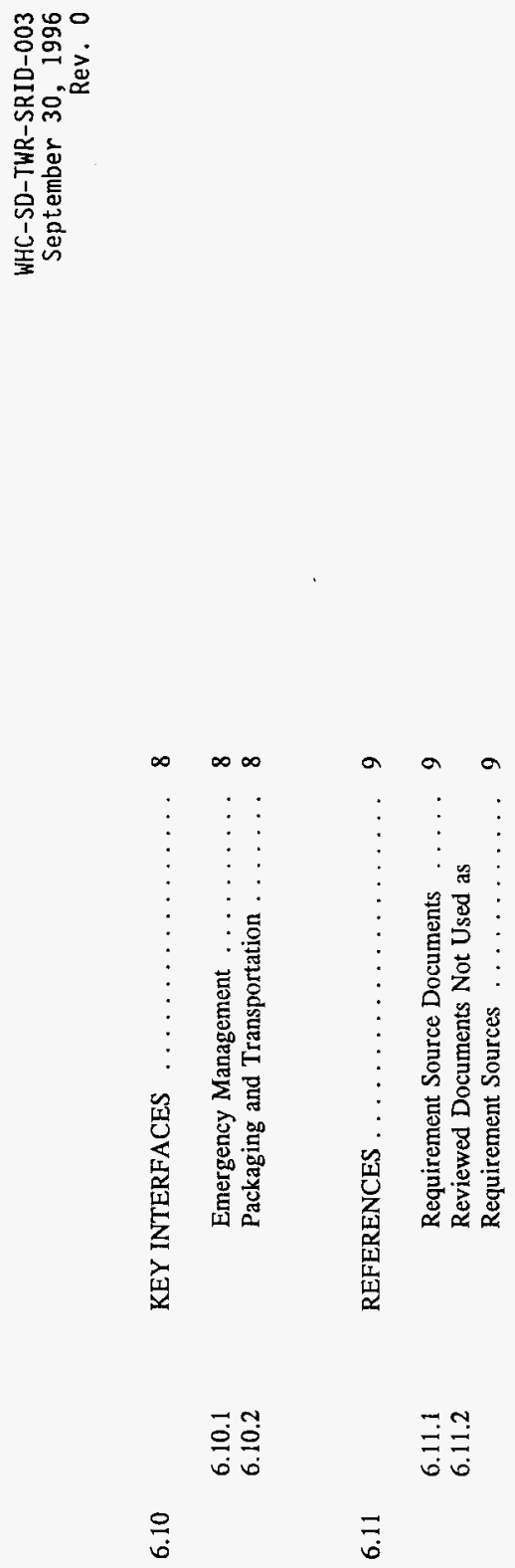

$\infty$
1
-1
$+\infty$
$+\infty$ 
WHC-SD-TWR-SRID-003

PROPOSED TRIENNIAL SCHEDULE FOR SAFEGUARDS AND SECURITY

\begin{tabular}{|c|c|c|c|c|c|c|c|c|c|c|c|}
\hline \multicolumn{4}{|c|}{ FY A } & \multicolumn{4}{|c|}{ FY B } & \multicolumn{4}{|c|}{ FY C } \\
\hline IQ & $2 \mathrm{Q}$ & $3 Q$ & $4 Q$ & $1 \mathrm{Q}$ & $2 Q$ & $3 Q$ & $4 Q$ & 1Q & $2 Q$ & $3 Q$ & $4 Q$ \\
\hline 6.1 & 6.2 & 6.3 & $\begin{array}{l}6.3 \\
\text { cont }\end{array}$ & 6.4 & $6.4 \mathrm{cont}$ & 6.5 & 6.7 & 6.6 & $6.6 \mathrm{cont}$ & 6.8 & 6.9 \\
\hline
\end{tabular}

6.0 SAFEGUARDS AND SECURITY

6.1 MANAGEMENT AND ADMINISTRATION

6.2 PERSONNEL SECURTY

6.3 PROTECTION PROGRAM OPERATIONS

$\begin{array}{ll}\text { 6.3.1 } & \text { Physical Security } \\ \text { 6.3.2 } & \text { Security Systems } \\ 6.3 .3 & \text { Protective Forces } \\ \text { 6.3.4 } & \text { Security Identification Badges and Passes } \\ 6.3 .5 & \text { Incident Response and Management } \\ 6.3 .6 & \text { Transportation Security }\end{array}$

6.7

6.9

Transportation Security

6.4 MATERIAL CONTROL AND ACCOUNTABILITY FOR SPECIAI

$$
\text { NUCLEAR MATERIAL }
$$

6.4.1 Material Control and Accountability Plan

6.4.2 Special Nuclear Material Accountability System

6.4.3 Material Control System

6.5 FACILITY APPROVALS, SECURTYY AND NUCLEAR MATERIAL

$$
\text { SURVEYS }
$$

6.6 INFORMATION SECURTTY PROGRAM
6.6.1 Classified Matter Prolection and Control (CMPC)

6.6.2 Technical Surveillance Countermeasures (TSCM)

6.6.3 Automated Information Systems Security Program (Classified

Computer Security)

6.6.4 Unclassified Computer and Sensitive Automated Data Processing

Systems

6.6.5 Communications Security

OPERATIONS SECURITY (OPSEC)

OREIGN OWNERSHIP, CONTROL OR INFLUENCE (FOCI)

EVALUATION OF RADIOLOGICAL AND TOXICOLOGICAL AND SABOTAGE CONSEOUENCES

Att. $1-19$ 
WHC-SD-TWR-SRID-003
September 30, 1996
Rev. 0

TABLE OF CONTENTS

7.0 ENGINEERING PROGRAM

Design Life . . . . . . . .

\section{KEY INTERFACES}

Scheduling $\ldots \ldots \ldots \ldots \ldots \ldots \ldots \ldots \ldots 6$

Cost Estimating . . . . . . . . . 6

Standards and Guides .......... 6

Engineering Assistance Request

Process . . . . . . . . . . . 7

Testing Program .......... 7

7.1 .9

7.1 .10

7.1 .11

7.1 .12

Engineering Documentation .

Organizational and Programmatic

Interfaces $\ldots \ldots \ldots \ldots \ldots . \ldots 9$

Design Process . . . . . . . . . . 10

Design Criteria . . . . . . . . . . 10

Design Products ............. 10

Design Review and Verification .... 10

Design Change Controls . . . . . . . 11
7.3 .1

7.3 .2

7.3 .3

7.3 .4

7.3 .5

7.3 .6

7.3 .7

7.3.8

Management Systerns

Quality Assurance

Operations .

Maintenance

Construction Program

Fire Protection

Nuclear Safety

Research and Development and

Experimental Activities

7.3 .9

7.3 .10

7.3 .11

7.3 .12

7.3 .13

7.3 .14

7.3 .15

7.4

Waste Management

Environmental Protection

Configuration Management

Emergency Preparedness and

Management

Radiation Protection

Training and Qualification

\section{REFERENCES}

Occupational Safety and Health.

Requirement Source

Documents . . . . . . . . .
Reviewed Documents Not Used

as Requirement Sources ......
11

11

$1 ?$

12

12.

Att. $1-20$ 
WHC-SD-TWR-SRID-003

September 30, 1996

Rev. 0

PROPOSED TRIENNIAL SCHEDULE FOR ENGINEERING PROGRAM

\begin{tabular}{|c|c|c|c|c|c|c|c|c|c|c|c|}
\hline \multicolumn{4}{|c|}{ FY A } & \multicolumn{4}{|c|}{ FY B } & \multicolumn{4}{|c|}{ FY C } \\
\hline $1 Q$ & $2 Q$ & $3 Q$ & $4 Q$ & $1 Q$ & $2 Q$ & $3 Q$ & $4 Q$ & $1 Q$ & $2 Q$ & $3 Q$ & $4 Q$ \\
\hline 7.1 & $7.1 \mathrm{cont}$ & $\begin{array}{l}7.1 \\
\text { cont }\end{array}$ & $\begin{array}{l}7.1 \\
\text { cont }\end{array}$ & 7.2 & $7.2 \mathrm{cont}$ & 7.2 cont & & & & & \\
\hline
\end{tabular}

7.0 ENGINEERING PROGRAM

7.1 MANAGEMENT AND ADMINISTRATION

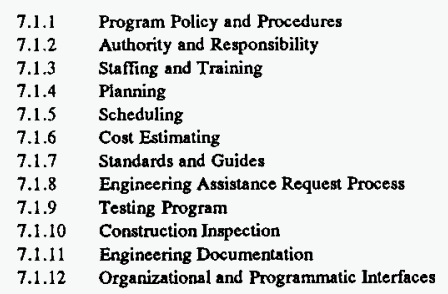

7.2 DESIGN
7.2.1 Design Process
7.2.2 Design Criteria
7.2.3 Design Products
7.2.4 Design Review and Verification
7.2.5 Design Change Controls
7.2.6 Design Life

Att. $1-21$ 
WHC-SD-TWR-SRID-003

September 30, 1996

Rev. 0

\section{TABLE OF CONTENTS}

8.0 CONSTRUCTION PROGRAM $\ldots \ldots \ldots \ldots \ldots \ldots \ldots$

8.1 .1

8.1 .2

8.1 .3

8.2

8.2 .2

8.2 .3

8.2 .4

8.2 .5

8.2 .6

8.2 .7

8.2 .8

8.3

8.3 .1

8.3 .2

8.3 .3

8.3.4

Att. $1-22$

\section{MANAGEMENT AND}

ADMINISTRATION ........... 2

Policies and Procedures ........ 2

Authority and Responsibility ...... 2

Staffing and Training . . . . . . . . 2

PROGRAM ACTIVITIES . . . . . . . . 2

Planning . . . . . . . . . . 3

Scheduling $\ldots \ldots \ldots \ldots \ldots \ldots$

Cost Estimating ........... 3

Constructibility/Maintainability/Valu

e Engineering . . . . . . . . . . . 4

Material and Equipment Storage . . . . 4

Contract Selection ............ 4

Construction Program Controls . . . . . . 4

Walkthroughs of Construction Sites . . 6

KEY INTERFACES $\ldots \ldots \ldots \ldots \ldots \ldots$

Management Systems . . . . . . . . 7

Quality Assurance . . . . . . . . . . 7

Configuration Management ....... 7

Training and Qualification ....... 7
8.3 .5

8.3 .6

8.3 .7

8.3.8

8.3 .9

8.3 .10

Safeguards and Security ......

Engineering Program . . . . . . .

Operations . . . . . . . . .

Maintenance . . . . . . .

Radiation Protection . . . . . . . .

Fire Protection . . . . . . . . .

Research and Development and

Experimental Activities .......

Occupational Safety and Health . .

Environmental Protection .....

\section{REFERENCES}

Requirement Source

Documents

Reviewed Documents Not Used

as Requirement Sources
8 8

8

9


PROPOSED TRIENNIAL SCHEDULE FOR CONSTRUCTION PROGRAM

\begin{tabular}{|c|c|c|c|c|c|c|c|c|c|c|c|}
\hline \multicolumn{4}{|c|}{ FY A } & \multicolumn{4}{|c|}{ FY B } & \multicolumn{4}{|c|}{ FY C } \\
\hline $1 \mathrm{Q}$ & $2 Q$ & $3 Q$ & $4 Q$ & $1 Q$ & $2 Q$ & $3 Q$ & $4 \mathrm{Q}$ & $1 \mathrm{Q}$ & $2 Q$ & $3 Q$ & $4 Q$ \\
\hline 8.1 & 8.1 cont & & & 8.2 & 8.2 cont & $8.2 \mathrm{cont}$ & & & & & \\
\hline
\end{tabular}

\subsection{CONSTRUCTION PROGRAM}

8.I MANAGEMENT AND ADMINISTRATION
8.1.
Policies and Procedures
8.1.2 Authority and Responsibility

8.1.3 Staffing and Training

8.2

PROGRAM ACTIVITIES

$\begin{array}{ll}\text { 8.2.1 } & \text { Planning } \\ \text { 8.2.2 } & \text { Scheduling } \\ \text { 8.2.3 } & \text { Cost Estimating } \\ \text { 8.2.4 } & \text { Constructibility/Maintainability/Value Engineering } \\ \text { 8.2.5 } & \text { Material and Equipment Storage } \\ \text { 8.2.6 } & \text { Contract Selection } \\ \text { 8.2.7 } & \text { Construction Program Controls } \\ \text { 8.2.8 } & \text { Walkthroughs of Construction Sites }\end{array}$

Att. $1-23$ 
WHC-SD-TWR-SRID-003

September 30, 1996

Rev. 0

\section{TABLE OF CONTENTS}

\subsection{OPERATIONS}

9.1

9.1 .1

9.1 .2

9.1 .3

9.1 .4

9.2

9.2 .2

9.3

9.3.1

9.3.2

9.3.3

9.3 .4

9.3 .5

9.4

9.5
9.5 .1

9.5 .2

9.5 .3

9.5 .4

9.5 .5

9.5 .7

9.5 .8

9.5 .11

9.5 .16

9.6

Emergency Procedures . . . . . . . . . 3

Operational Readiness ......... 3

Safety Practices ............ 4

Sensitive System Identification $\ldots . .4$

OPERATIONAL RECORDS ........ 4

KEY INTERFACES $\ldots \ldots \ldots \ldots \ldots \ldots \ldots$
9.5 .6

9.5 .9

9.5 .10

9.5 .12

9.5 .13

9.5 .14

9.5 .15

Management Systems .......

Quality Assurance ..........

Configuration Management

Training and Qualification ..... .

Emergency Management

Engineering Program

Radiation Protection . . . . . . . . .

Research and Development and

Experimental Activities . . . . . . .

Nuclear Safety . . . . . . . . . .

Occupational Safety and Health . .

Environmental Protection .....

Fire Protection . . . . . . . . .

Safeguards and Security ......

Construction ..........

Packaging and Transportation ...

REFERENCES
Requirement Source

Documents

Reviewed Documents Not Used

as Requirement Sources
4

5

5 5

5

6

6

7
7

7

7

8
8

8

8 8

Att. $1-24$ 
WHC-SD-TWR-SRID-003

September 30, 1996

Rev. 0

PROPOSED TRIENNIAL SCHEDULE FOR OPERATIONS

\begin{tabular}{|c|c|c|c|c|c|c|c|c|c|c|c|c|}
\hline & \multicolumn{4}{|c|}{ FY A } & \multicolumn{4}{|c|}{ FY B } & \multicolumn{4}{|c|}{ FY C } \\
\hline & $1 Q$ & $2 Q$ & $3 Q$ & $4 Q$ & $1 Q$ & $2 Q$ & $3 Q$ & $4 Q$ & $1 Q$ & $2 Q$ & $3 Q$ & $4 Q$ \\
\hline $\mathrm{OP}$ & $\begin{array}{l}1 \\
9 a\end{array}$ & $\begin{array}{l}5,6 \\
9 b\end{array}$ & $\begin{array}{l}4,18 \\
9 \mathrm{c}\end{array}$ & $\begin{array}{l}2 \\
9 d\end{array}$ & $\begin{array}{l}7 \\
9 a\end{array}$ & $\begin{array}{l}8 \\
9 b\end{array}$ & $\begin{array}{l}10 \\
9 c\end{array}$ & $\begin{array}{l}11,12 \\
9 \mathrm{~d}\end{array}$ & $\begin{array}{l}13 \\
9 a\end{array}$ & $\begin{array}{l}14,15 \\
9 b\end{array}$ & $\begin{array}{l}16 \\
9 c\end{array}$ & $\begin{array}{l}17,3 \\
9 d\end{array}$ \\
\hline
\end{tabular}

\section{FYA}

Operations Organizations and Administration (A-1)

Control of On-Shift Training (A-2)

Investigation of Abnormal Events (A-2)

Communications (A-3)

Equipment and Piping Labeling (A-3)

Shift Routines and Operating Practices (A-4)

Lockouts and Tagouts (A-1, A-2, A-3, A-4)

\section{FY B}

Notifications (B-1)
Control of Equipment and System Status (B-2)

Independent Verification (B-3)

Logkeeping (B-4)

Operations Turnover (B-4)

Lockouts and Tagouts (B-1, B-2, B-3, B-4)

$\underline{F Y C}$

Operations Aspects of Facility Chemistry and Unique Processes (C-1)

Required Reading (C-2)

Timely Orders to Operators (C-2)

Operations Procedures (C-3)

Operator Aid Postings (C-4)

\footnotetext{
Notes: 1. † Indicates a relationship to other Functional Areas

2. Corrective Actions are assessed integral to each Functional Area Element
} 

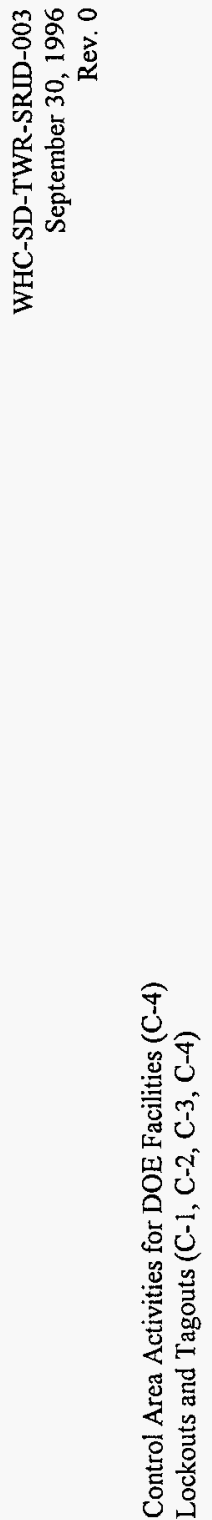

$\stackrel{+}{~}$
$\vdots$
$\dot{K}$ 

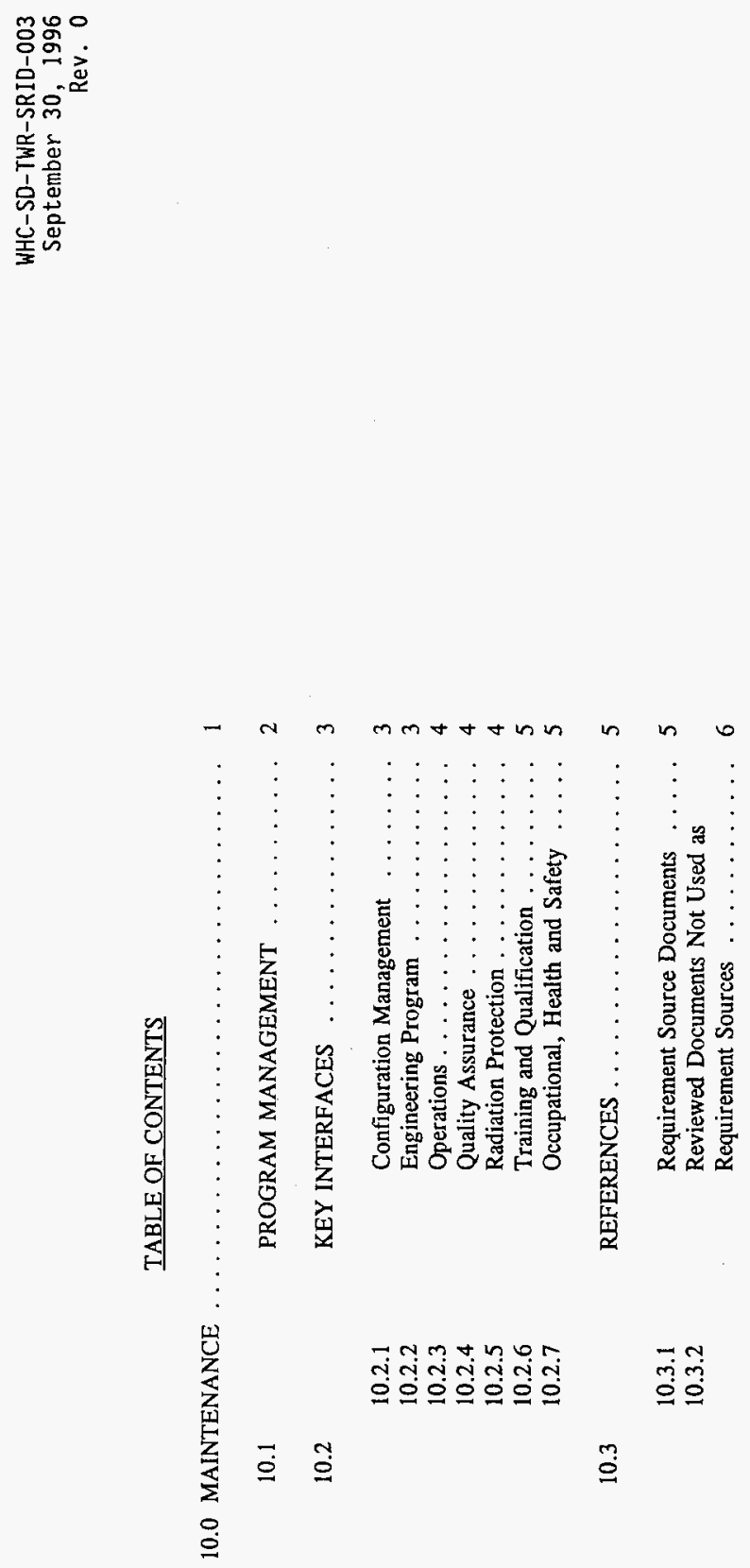

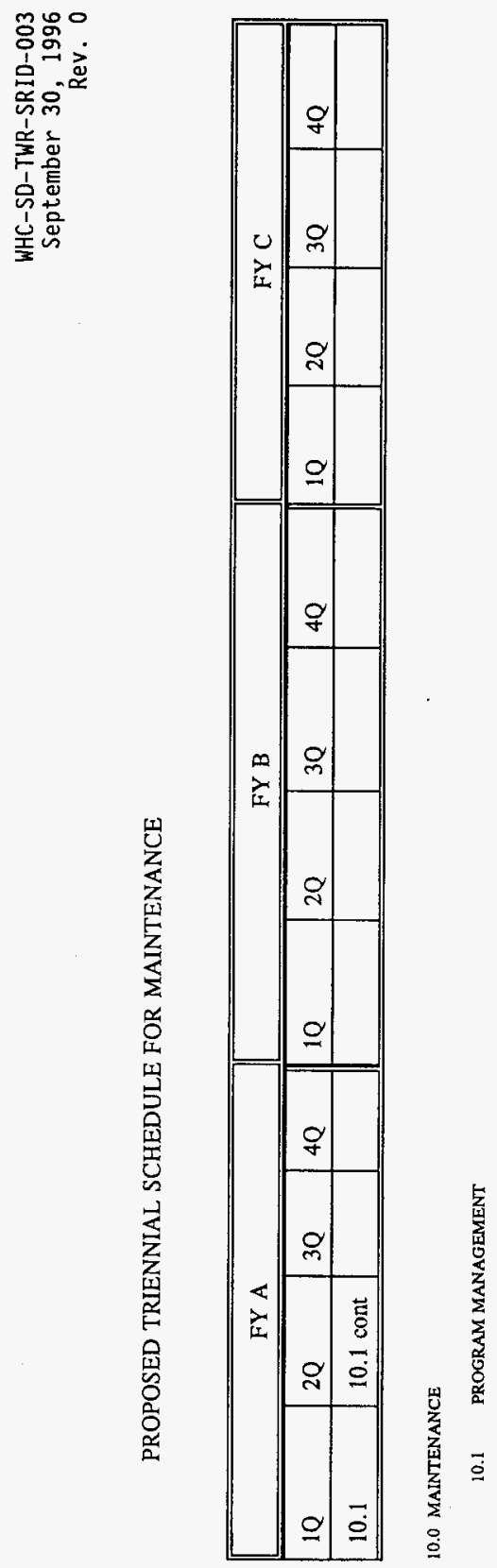
WHC-SD-TWR-SRID-003

September 30, 1996

Rev. 0

\section{TABLE OF CONTENTS}

11.0 RADIATION PROTECTION $\ldots \ldots \ldots \ldots \ldots \ldots \ldots$

11.1

PROGRAM MANAGEMENT ....... 3

11.1.7.2

11.1.7.3

11.1 .1

Exposure Reduction and ALARA

3

11.1.1.1

11.1.1.2

11.1.1.3

11.1.1.4

11.1.1.5

11.1.1.6

11.1 .2

11.1.3

11.1.4

11.1.5

11.1.6

11.1.7

11.1.7.1

Exposure Controls ....... . 4

Radiological Work Planning ... 5

ALARA Reviews ........ 7

ALARA Performance and

Training Requirements . . . . . 8

ALARA Committee and

Staffing ......... 8

Dose Tracking and Trending . . 9

Radiation Protection Training ...... 9

RP Selection and Qualification ...... 9

Radiological Program Performance

Goals ................. 9

Program Policy and Procedures . . . 10

Policy for Response to Abnormal

Situations .............. 10

Records Management .......... 11

Survey

Records/Radiological Work

Control Records
ALARA Review/Program Records Miscellaneous Radiation

Protection Records

\section{MONITORING AND SURVEYS}

\section{Radiation Monitors, Alarms}

and Surveys ............

Airborne Radioactivity Monitors,

Alarms and Surveys

Contamination Monitoring and

Surveys

Dose Rate Surveys

\section{PERSONNEL EXPOSURE}

MONITORING

Personnel Exposure Monitoring .

Exposure Limits . . . . . . . . .

Dosimetry Program . . . . . . . . 20

Calculation Methods/Models ... 21

RADIATION AREA ACCESS

CONTROL

Access Restrictions and Posting . 21 


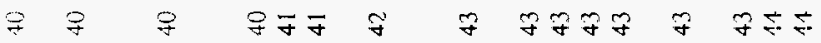
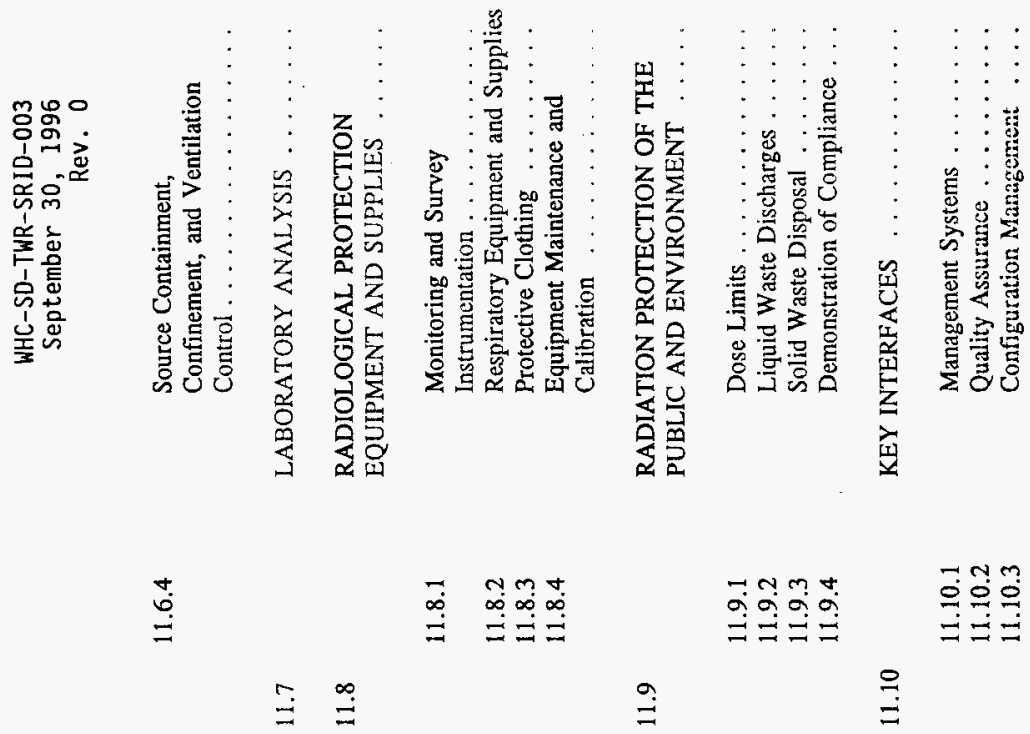

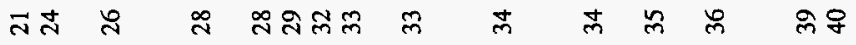

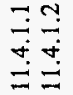
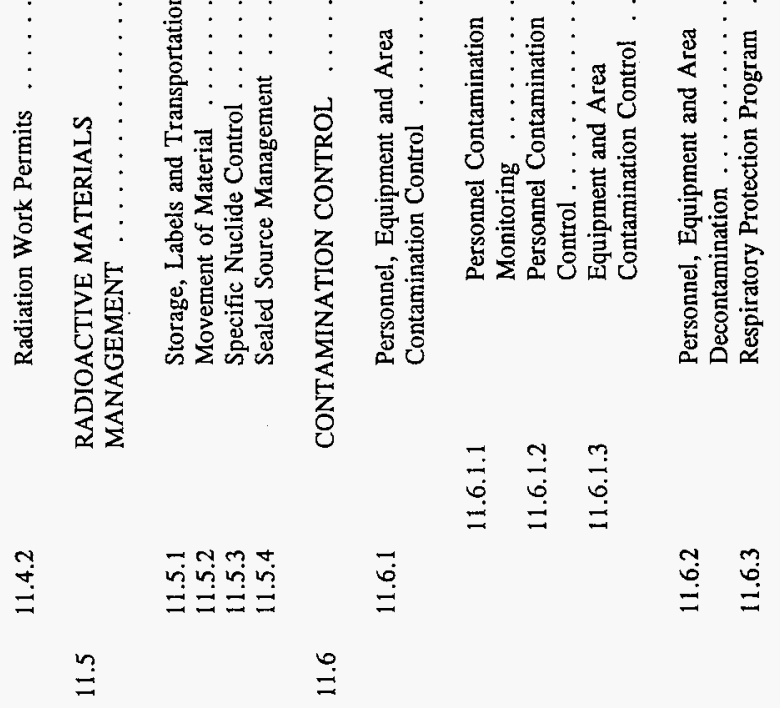

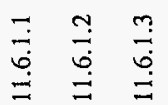

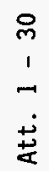


11.10 .4

11.10 .5

11.10 .6

11.10 .7

11.10 .8

11.10 .9

11.10.10

11.10 .11

11.10 .12

11.10 .13

11.11

11.11 .1

11.11.2

Att. $1-31$
Training and Qualifications ...... 44

Emergency Planning . . . . . . . . . 44

Engineering Program . . . . . . . . 44

Operations . . . . . . . . . . . . . 44

Maintenance $\ldots . . . . . . . . .45$

Packaging and Transportation ..... 45

Research and Development and

Experimental Activities . . . . . . . . 45

Nuclear Safety ... . . . . . . 45

Environmental Protection ....... 45

Occupational Safety and Health . . . 45

REFERENCES . . . . . . . . . . . 45

Requirement Source Documents . . . 45

Reviewed Documents Not Used as

Requirement Sources ......... 46 


\section{PROPOSED TRIENNIAL SCHEDULE FOR RADIATION PROTECTION}

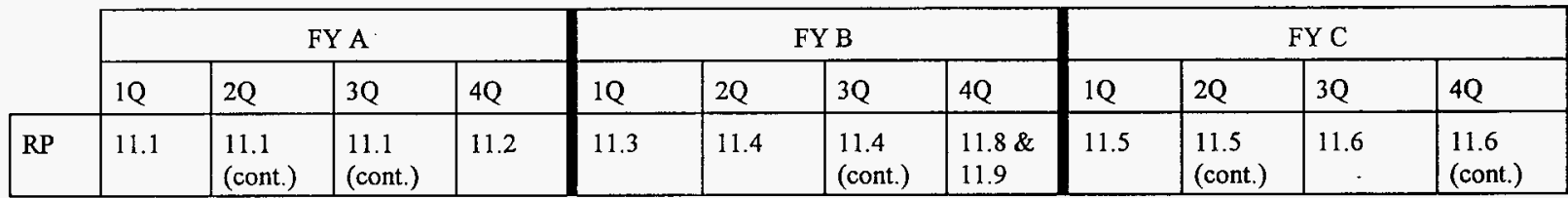

\section{FYA ALARA, PLANNING TRAINING \& SURVEYS}

11.1 PROGRAM MANAGEMENT (A-1,A-2, A-3)

$$
11.1 .1
$$

Exposure Reduction and ALARA

11.1.1.1 Exposure Controls

11.1.1.2 Radiological Work Planning

11.1.1.3 ALARA Reviews

11.1.1.4 ALARA Performance and Training Requirements

11.1.1.5 ALARA Committee and Staffing

11.1.1.6 Dose Tracking and Trending

11.1.2 Radiation Protection Training - related to TN

11.1.3 RP Selection and Qualification

11.1.4 Att. 1 - 3232 Radiological Program Performance Goals

11.1.5 Program Policy and Procedures

11.1.6 Policy for Response to Abnormal Situations

11.1.7 Records Management

11.1.7.1 Survey Records/Radiological Work Control Records

11.1.7.2 ALARA Review/Program Records

11.1.7.3 Miscellaneous Radiation Protection Records

11.2 MONITORING AND SURVEYS (A-4)

11.2.1 Radiation Monitors, Alarms and Surveys

11.2 .2

11.2 .3

11.2 .4

Airborne Radioactivity Monitors, Alarms and Surveys

Contamination Monitoring and Surveys

Dose Rate Surveys

\author{
FY B ACCESS, EXPOSURE \& EQUIPMENT \\ 11.3 \\ PERSONNEL EXPOSURE MONTORING (B-1) \\ 11.3.1 Personnel Exposure Monitoring \\ 11.3.2 Exposure Limits \\ 11.3.3 Dosimetry Program \\ 11.3.4 Calculation Methods/Models \\ 11.4 RADIATION AREA ACCESS CONTROL (B-2, B-3) \\ 11.4.1 Access Restrictions and Posting \\ 11.4.1.1 Access Restrictions \\ 11.4.1.2 Posting \\ 11.4.2 Radiation Work Permits \\ 11.8 RADIOLOGICAL PROTECTION EQUTPMENT AND SUPPLIES (B-4)

$\begin{array}{ll}\text { 11.8.1 } & \text { Monitoring and Survey Instrumentation } \\ 11.8 .2 & \text { Respiratory Equipment and Supplies } \\ \text { 11.8.3 } & \text { Protective Clothing }\end{array}$ \\ 11.8.4 Equipment Maintenance and Calibration
}

11.9 RADIATION PROTECTION OF THE PUBLIC AND ENVIRONMENT (B-4) $\begin{array}{ll}11.9 .1 & \text { Dose Limits } \\ 11.9 .2 & \text { Liquid Waste Discharges } \\ 11.9 .3 & \text { Solid Waste Disposal }\end{array}$

FYC CONTAMINATION CONTROL \& MATERIAL MANAGEMENT

11.5 RADIOACTIVE MATERIALS MANAGEMENT (C-1, C-2)

\footnotetext{
Notes: 1. † Indicates a relationship to other Functional Areas

2. Corrective Actions are assessed integral to each Functional Area Element

3. 11.7, Laboratory Analysis is not applicable to TWRS per the S/RDD.
} 
11.5.1 Storage, Labels and Transportation

11.5.2 Movement of Material

11.5.3 Specific Nuclide Control

11.5.4 Sealed Source Management

11.6 CONTAMINATION CONTROL $(\mathrm{C}-3, \mathrm{C}-4)$

11.6.1 Personnel, Equipment and Area Contamination Control

11.6.1.1 Personnel Contamination Monitoring

11.6.1.2 Personnel Contamination Control

11.6.1.3 Equipment and Area Contamination Control

11.6.2 Personnel, Equipment and Area Decontamination

11.6.3 Respiratory Protection Program

11.6.4 Source Containment, Confinement, and Ventilation control

Notes: 1. † Indicates a relationship to other Functional Areas

2. Corrective Actions are assessed integral to each Functional Area Element

3. 11.7, Laboratory Analysis is not applicable to TWRS per the S/RID.

Att. 1 - 33 
WHC-SD-TWR-SRID-003

September 30, 1996

Rev. 0

\section{TABLE OF CONTENTS}

12.0 FIRE PROTECTION

MANAGEMENT AND ADMINISTRATION . . 3

12.1.1

12.1.2

12.1.2.1

12.1.2.2

Management $\ldots \ldots \ldots \ldots \ldots \ldots$

Administrative ........... 4

12.1.2.3

12.1.2.4

12.1.2.5

12.1.2.6

12.1.2.7

12.2

FIRE PROTECTION PROGRAM . . . . . 5

12.2.1

Fire Protection Suppression Systems . . 5

12.2.1.1

Automatic Fire Suppression

Provisions .......... 6

12.2.1.1.1

Automatic Sprinkler

12.2.1.1.2

12.2 .1 .1 .3

Systems ........7 7

Wet Pipe Systems . . . 8

Dry Pipe Systems . . . 8

Tracking Program $\ldots \ldots \ldots . .4$

Operability Specifications . . . . 5

$\ldots 5$
12.2.1.1.4

12.2.1.1.5

12.2.1.1.6

12.2.1.1.7

12.2.1.2

12.2.1.3

\section{2 .2 .1}

12.2.2.1.1

12.2.2.1.4

12.2 .2 .1 .5
Preaction . . . . . .

Deluge . . . . . . .

Pressure-Relief Valves'

Pressure-Reduci

ng Valves

Special Fire

Suppression System

Control of Liquid

Runoff

Water Supply and Distribution

Systems

Water Supply Systems

Mains, Water

Storage, and

Fire Pumps

Fire Hydrant

Capacity . .

Fire Hydrant

Spacing and

I ncation

Air Release and

Vacuum Valves

Distribution

Systems Mains

Depth

8

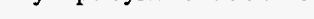


WHC-SD-TWR-SRID-003

September 30, 1996

Rev. 0

12.2.2.1.6

12.2.2.1.7

12.2.2.1.8

12.2.2.1.9

12.2.2.1.10

12.2 .2 .1 .12

12.2 .2 .1 .13
12.2.2.1.11

Water Distribution

Loop Systems . . . . . 12

Sprinkler Supply Lead-Ins 13

Combined Fire and

Domestic Process

Water Systems .... 13

Sprinkler Risers . . . 13

Outside Control

Valves ......... 13

Key Operated

Buried Valves . . . . . 13

Sprinkler Systems Lead-Ins

and Fire Hydrants . . 14

Piping Protection

Against Differential

Settlements
12.2.3.1

12.2.3.2

12.2.4

12.2.4.1
Fire Barrier Design

Requirements ......... 14

Fire Doors and Windows ... 15

Life Safety . . . . . . . . . 15

Facility Buildings . . . . . 15
12.2.4.1.1

12.2.4.1.2

12.2.4.1.3

12.2.4.1.4

12.2 .4 .1 .5

12.2 .4 .1 .6

12.2.4.1.7
Improved Risk Facilities

Decommissioning Planning

Construction

Fire Alarm Systems

Life Safety for

Laboratories .

Egress

Corridor

Widths

Door

Encroachment

Security Areas

Zoning for

Automatic

Control . . . . . . 1\%

Life Safety in

Hazardous

Areas ....... 17

12.2 .8 .1

12.2.8.2

12.2 .8 .3
Fire Detection and Alarm Systems Design, Installation, Inspection, and Testing

Fire Alarm System

Features ....... .

Compatibility of Alarm

Systems ........ 
WHC-SD-TWR-SRID-003

September 30, 1996

Rev. 0

12.2.8.4

12.2 .8 .5

12.2 .9

12.3

12.4

12.4 .2

12.4.4

12.4.4.1

12.4.4.2

12.4 .4 .3

12.4.4.4

12.4.4.5
Fire Watch and Alarm

Systems .......... 21

Underground Cables for

Alarm Systems . . . . . . . 22

Fire Detection Systems . . . . . . . 22

FIRE HAZARD ANALYSIS $\ldots \ldots \ldots \ldots 22$

FIRE PREVENTION (BUILDING

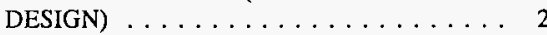

Performance Objectives in the

Design of DOE Facilities . . . . . 25

Exterior Fire Protection Systems

and Features ........... 26

Fire Resistance for Materials and

Construction ........... 26

Control of Combustibles . . . . . . 27

Interior Finish Materials . . . 27

Interior Floor Coverings . . . 27

Control of Combustible

Materials by Building

Design ........... 27

Quantities of Stored

Materials ........... 27

Fire and Explosion Potential of the

Materials ......... 28
12.4 .4 .6

12.4 .5

12.4.5.1

12.4.5.2

12.4.5.3

12.4.5.4

12.4.5.5

12.4.6

12.4.6.1

12.4.6.2

12.4.6.3

12.4.6.4
Storage and Use of

Compressed Gases

Electrical Systems

Ignition Source by

Electrical Equipment

Listing Requirements for Electrical Materials and Equipment

Conduits . . . . . . . . 30

Redundant Electric

Circuits ......

Primary, Auxiliary,

Emergency, and

Standby Power Systems

Exhaust and Ventilation

Systems

Ductwork and Air

Ventilation Systems ....

Smoke Pressurization and

Evacuation Systems

Confinement Systems

Function During the

DBF

Confinement Systems

and Fire Protectionn
30

30

29)

29

29)

31

32

32

32

Att. $1-36$ 
WHC-SD-TWR-SRID-003

September 30, 1996

Rev. 0
12.4.6.5

12.4.6.6
Design Features for Lower

Flammability Limit . . . . . 32

HEPA Filters . . . . . . . 32

Lighting Protection $\ldots \ldots \ldots \ldots . \ldots 33$

Seismic Requirements . . . . . . . . . 33

Safety Class Equipment . . . . . . 33
12.8 .8

12.8 .9
12.4 .7

12.4 .8

12.4 .9

12.5

12.6

12.6.1

12.6.3

12.7

12.7 .8

12.7 .9

12.7.10

12.7.11

12.7.12

12.7.13

12.8
FIRE, HAZMAT AND MEDICAL

SUPPORT

NT

34

ASSESSMENT . . . . . . . . . . 34

Fire Protection Investigation and

Reporting $\ldots \ldots \ldots \ldots \ldots \ldots, 34$

Control of Fire Protection

Impairments $\ldots \ldots \ldots \ldots \ldots \ldots, 38$

KEY INTERFACES $\ldots \ldots \ldots \ldots \ldots, 38$

Configuration Management $\ldots \ldots . \quad 38$

Engineering Program ......... 38

Emergency Management . . . . . . . 39

Nuclear Safety . . . . . . . . . . . 39

Occupational Safety and Health ... . 39

Management Systems . . . . . . . . . 39

REFERENCES . . . . . . . . . . 40
Requirement Source

Documents ...........

Reviewed Documents Not Used

as Requirement Sources
40

40

Att. $1-37$ 
$8 \varepsilon-\mathrm{I} \cdot 77 \forall$

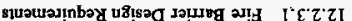

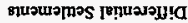

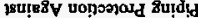

$$
\text { squesp } K_{H}
$$

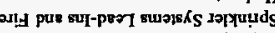
sanje $\Lambda$ payng pojerado kอY

son[в

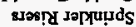

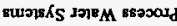

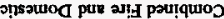

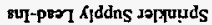
wrens

$$
\text { प1ded }
$$

survW מurosks uonnqüsid

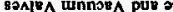

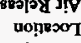

pue sutords jueup $\hat{K}_{\mathbf{H}}$ 2r!y

Ki!̣odeว Juejp $K_{H}$ aț

sdund

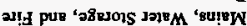

suris

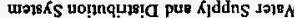

Jouny pinbic Jo jolluo

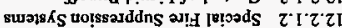
wo!nomord a!t อn!ssed

$\varepsilon \cdot 2 \cdot$

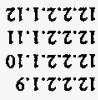

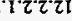

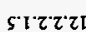

๑ัI'Z'ZI

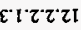

$2 \cdot 2 \cdot 2$

I' ไ'z'z!

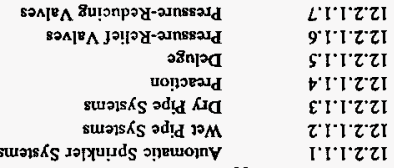

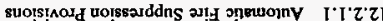

strejs

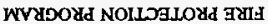

sopsopunumuos $L Z^{*} I^{\prime} z$

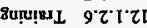

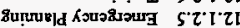

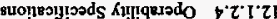

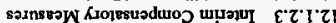

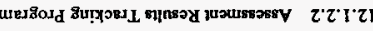

somposard Uo!̣uonard ant $\tau^{\prime} \cdot Z^{\prime} \cdot \gamma^{\prime} \cdot \tau$

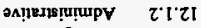

\begin{tabular}{|c|c|c|c|c|c|c|c|c|c|c|c|}
\hline juos $\nabla^{\circ} Z I$ & $\begin{array}{l}\text { juos } \\
\downarrow^{*} Z I\end{array}$ & $\begin{array}{l}\text { Juos } \\
\nabla^{\circ} Z I\end{array}$ & $t^{\prime} Z I$ & $9^{\circ} \mathrm{ZI}$ & S'ZI & $\varepsilon^{\circ} Z I$ & I'ZI & $\begin{array}{l}\text { 1uos } \\
Z^{\prime} Z I\end{array}$ & $\begin{array}{l}\text { IUOO } \\
Z^{\circ} Z I\end{array}$ & łuos z’zl & Z’ZI \\
\hline$\overline{O t}$ & $\partial \mathcal{E}$ & $\mathrm{Or}$ & $\mathrm{OI}$ & $\mathrm{Ot}$ & $\partial \varepsilon$ & $\partial z$ & $\mathrm{OI}$ & $\mathrm{Ot}$ & $\partial \mathcal{E}$ & $\partial z$ & OI \\
\hline \multicolumn{4}{|c|}{ D XA } & \multicolumn{4}{|c|}{$\mathrm{g} X \mathrm{~A}$} & \multicolumn{4}{|c|}{$V X H$} \\
\hline
\end{tabular}

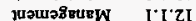

NOILVYISINIWOV बNV INGWEOVNVW I'Zl

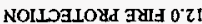

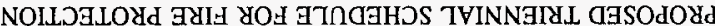

0 '

966I 'OE daquazdas

عO0-0IVS-УML-OS-כHM 
12.2.4 Life Safety

Life

12.2.4.1 Facility Buildings

12.2.4.1.1 Life Safety for Laboratories

12.2.4.1.2 Egress

12.2.4.1.3 Corridor Widths

12.2.4.1.4 Door Encroachment

12.2.4.1.5 Security Areas

12.2.4.1.6 Zoning for Automatic Control

12.2.4.1.7 Life Safety in Hazardous Areas

12.2.5 Improved Risk Facilities

12.2.6 Decommissioning Planning

12.2.7 Construction

12.2.8 Fire Alarm Systems

12.2.8.1 Fire Detection and Alarm Systems Design, Installation, Inspection, and Testing

12.2.8.2 Fire Alarm System Features

12.2.8.3 Compatibility of Alarm Systems

12.2.8.4 Fire Watch and Alarm Systems

12.2.8.5 Underground Cables for Alarm Systems

12.2.9 Fire Detection Systems

\subsection{FIRE HAZARD ANALYSIS}

\subsection{FIRE PREVENTION (BUILDING DESIGN)}

12.4.1 Performance Objectives in the Design of DOE Facilities

12.4.2 Exterior Fire Protection Systems and Features

12.4.4 Control of Combustibles

12.4.4.1 Interior Finish Materials

12.4.4.2 Interior Floor Covering

12.4.4.3 Control of Combustible Materials by Building Design

12.4.4.4 Quantities of Stored Materials

12.4.4.5 Fire and Explosion Potential of the Materials

12.4.4.6 Storage and Usc of Compressed Gases

12.4.5 Electrical Systems
12.4.5.1 Ignition Source by Electrics1 Equipment

12.4.5.2 Listing Requirements for Electrical Materials and Equipment

12.4.5.3 Conduits

12.4.5.4 Redundant Electric Circuits

12.4.5.5 Primary, Auxiliary, Emergency, and Siandby Power Systems

12.4.6 Exhaust and Ventilation Systems

12.4.6.1 Ductwork and Air Ventilation Systems

12.4.6.2 Smoke Pressurization and Evacuation Systems

12.4.6.3 Confinement Systems Function During the DBF

12.4.6.4 Confinement Systems and Fire Protection

12.4.6.5 Design Features for Lower Flammability Limit

12.4.6.6 HEPA Filters

12.4.7 Lighting Protection

12.4.8 Seismic Requirements

12.4.9 Safety Class Equipment

12.5 FIRE, HAZMAT AND MEDICAL SUPFORT

12.6 ASSESSMENT

12.6.1 Fire Protection Investigation and Reporting

12.6.3 Control of Fire Protection Impairments

12.7

12.7.8

12.7 .9

12.7 .10

12.7 .11

12.7 .12

12.7 .13

12.8

12.8 .8

12.8 .9

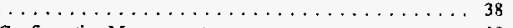
Configuration Management $\ldots \ldots \ldots \ldots \ldots \ldots \ldots \ldots .38$ Engineering Program $\ldots \ldots \ldots \ldots \ldots \ldots \ldots \ldots \ldots \ldots, 38$

Emergency Management $\ldots \ldots \ldots \ldots \ldots \ldots . \ldots \ldots$

Nuclear Safety . . . . . . . . . . . . . . . . . . . . . . . 39

Occupational Safety and Health $\ldots \ldots \ldots \ldots \ldots \ldots \ldots \ldots, 39$ Management Systems $\ldots \ldots \ldots \ldots \ldots \ldots \ldots \ldots \ldots \ldots \ldots \ldots$

REFERENCES . . . . . . . . . . . . . . . .

Requirement Source Documents . . . . . . . 40

Reviewed Documents Not Used as

Requirement Sources . . . . . . . . . . . . . . 40

Att: $1-39$ 
TABLE OF CONTENTS

13.0 PACKAGING AND TRANSPORTATION

13.1

13.2
MANAGEMENT AND

ADMINISTRATION

\section{PACKAGING AND TRANSPORTATION}

OPERATIONS

Packaging $\ldots \ldots \ldots \ldots \ldots \ldots . \ldots 4$

13.2 .1

13.2 .2

13.2 .3

13.2.4

13.2 .5

13.2 .6

13.2.6.1

13.2.6.2

13.2.6.3

13.2.7

13.2.7.1

13.2.7.2

13.2 .8

Coordination and Planning of Base

Technology .............. 11

Vehicle and Equipment Control and

Maintenance ............ 11

Onsite Material Tracking . . . . . . . 11

Offsite Transportation Management . . 11

Marking, Labeling and Placarding . . . 11

Marking Requirements . . . . 11

Labeling Requirements . . . . 17

Placarding Requirements ... . 22

Shipping Papers, Bills of Lading

and Manifests ............ . 26

Waste Manifests ....... 26

Shipping Papers ....... 27

Shipment Plans ... . . . . . . 33
13.2 .9

13.2.10

13.2.11

13.2.12

13.2 .13

13.3

13.3.2

13.3.3

13.3.4

13.3.5

13.4.3
Notification of State Authorities of

Shipments of High-Hazard Materials 34 Emergency Response

Information . . . . . . . 34

Receipt Inspection . . . . . . . 36

Loading Operations . . . . . . . 36

Transportation Operations .... 38

OFFSITE SAFETY . . . . . . . 39

Package Standards and

Certifications .......... 39

Safety Analysis . . . . . . . . 39

Design, Fabrication, Assembly

and Testing QA for OffSite

Shipping Containers ....... 39

Physical Protection for Security . 39

Nuclear Explosives,

Components, and Assemblies . . . 39

\section{ONSITE SAFETY}

Coordination of Material

Transfers

Requirements for Potentially

Explosive and Hazardous

Materials

(1) 
Training and Qualification ....... 41

13.5 .2

13.5 .3

13.5.4

13.5 .5

13.5 .6

13.6

Safeguards and Security . . . . . . 42

Nuclear Safety . . . . . . . . . . . . 42

Emergency Management . . . . . . 42

Radiation Protection . . . . . . . . . . . 42

Waste Management ........ . 42 


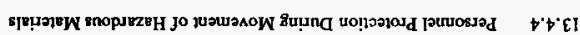

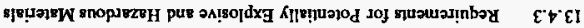

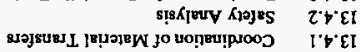

\section{XIGHVS ZIISNO}

$\bullet \boldsymbol{\varepsilon I}$

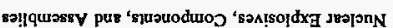

sivi!nuog gu!dd! पs

भ! SW०

SIBRituY KiगJ

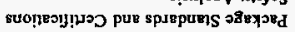

$S \cdot \varepsilon \cdot \varepsilon \mathrm{I}$

$\rightarrow \cdot \varepsilon \boldsymbol{L I}$

$\varepsilon \cdot \varepsilon \cdot \varepsilon$

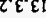

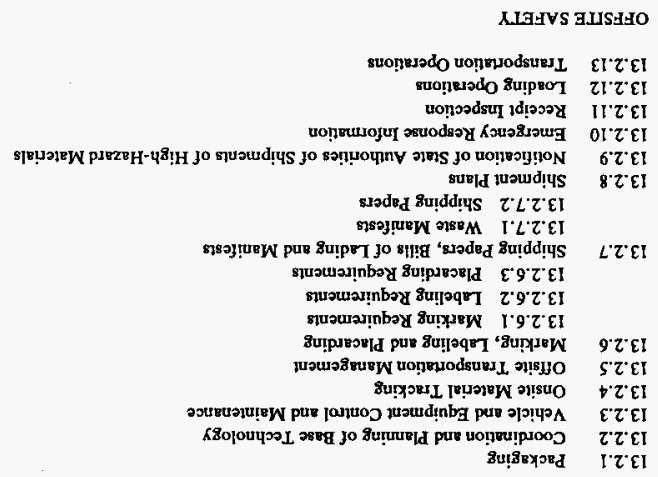

SNOILYZJオO NOILVLUOJSNVAI GNV ONIDVXOVd

$\tau$ นเ

NOIIVZISINIWGY GNV INEWGOVNVW

NOILVLب̣OdSNYXXY GNV JNIOVYOVd $0^{\circ} \varepsilon I$

\begin{tabular}{|c|c|c|c|c|c|c|c|c|c|c|c|}
\hline & & $\begin{array}{l}\text { IUos } \\
\nabla^{\prime} E I\end{array}$ & $\nabla^{\circ} E I$ & & & 7 Uoग $\mathcal{E} \mathcal{E} \mathrm{I}$ & $\mathcal{E} \mathcal{E} I$ & $\begin{array}{l}\text { JUOS } \\
\tau \cdot \mathcal{E} \text { I }\end{array}$ & $\begin{array}{l}\text { quos } \\
\tau \cdot \mathcal{E} I\end{array}$ & $Z^{*} \mathcal{E} I$ & {$[\mathcal{E} I$} \\
\hline Ot & $\partial \mathcal{E}$ & $\mathrm{Or}$ & OI & Ot & $O \mathcal{E}$ & $\partial z$ & $\mathrm{OI}$ & $O t$ & $\overline{O E}$ & $\mathrm{Oz}$ & OI \\
\hline \multicolumn{4}{|c|}{$\rho \boldsymbol{X} \boldsymbol{I}$} & \multicolumn{4}{|c|}{$\boldsymbol{B} \boldsymbol{X} \mathbf{H}$} & \multicolumn{4}{|c|}{$V X_{H}$} \\
\hline
\end{tabular}

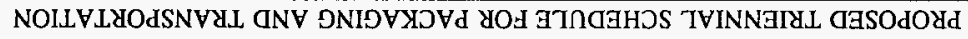

$0 \cdot \wedge$ วу

966 [ 'Oع גәqша7das

عO0-0IVS-YMI-OS-JHM 
mo

8.

古文

동

\%

춘

它

농

紊心

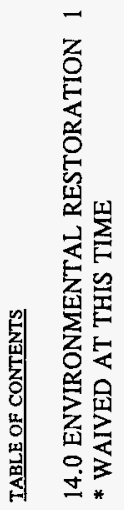



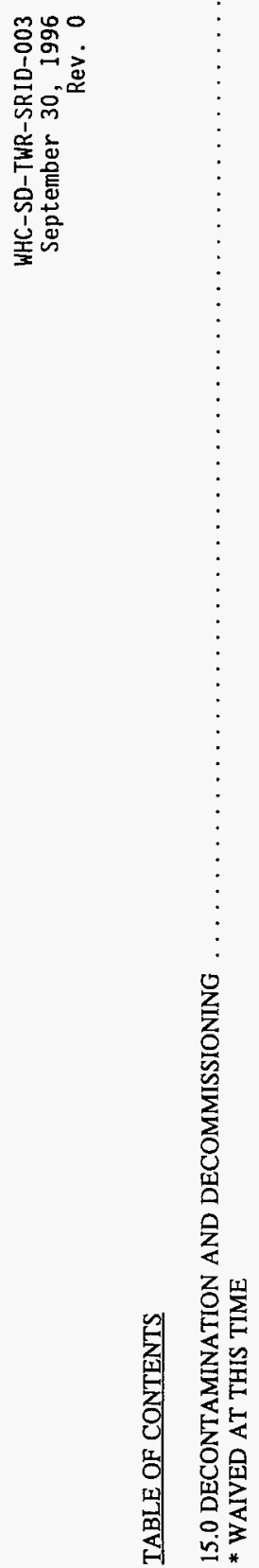


\section{TABLE OF CONTENTS}

16.5

16.0 WASTE MANAGEMENT

WASTE CHARACTERIZATION AND

CERTIFICATION . . . . . . . . . . 3

16.1 .1

16.1 .2

16.1.3

16.2

TRU Waste . . . . . . . . . . . 3

Low-Level Radioactive Waste . . . . . 4

Mixed/Dangerous Waste . . . . . . . 4

\section{PACKAGING AND LABELING}

COMPLIANCE . . . . . . . . . . 28

Low-Level Radioactive Waste

Packaging . . . . . . . . . . . 28

Dangerous/Mixed Waste Packaging and

Labeling . . . . . . . . . . . . . 29

PCB Waste Labeling . . . . . . . 30

16.2 .3

16.3

TRANSPORTATION

36

16.4

PLANS, RECORDS AND REPORTING . . 37

16.4 .1

16.4 .2

16.4 .3

16.4 .4
TRU Waste . . . . . . . . . . . . 37

Low-Level Radioactive Waste . . . . 37

Mixed/Dangerous Waste . . . . . . 37

PCB Waste ............. . . 38

PERMITTING

WASTE ACCEPTANCE CRITERIA . .

16.6.1

16.6 .2

16.6 .3

16.6 .4

16.8

16.8 .1

16.8 .2

16.8.2.1

16.8 .2 .2

16.8 .3

16.8 .4

16.8 .5

16.8.6
TRU Waste ...............

Low-Level Radioactive Waste . .

Mixed/Dangerous Waste ......

PCB Waste . . . . . . . . . .

WASTE MINIMIZATION

WASTE TREATMENT AND

DISPOSAL TECHNOLOGY

Low-Level Radioactive Waste

Mixed/Dangerous Waste

Management of

Containers

Waste Treatment

Asbestos Waste

Tank Systems

Closure

Used Oi
49

4)

50

51

$$
52
$$

52

53

$$
58
$$

is

72

85

91

Att. $1-45$ 


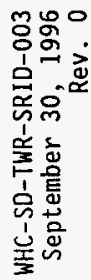

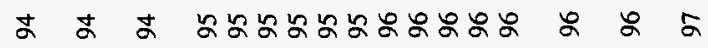
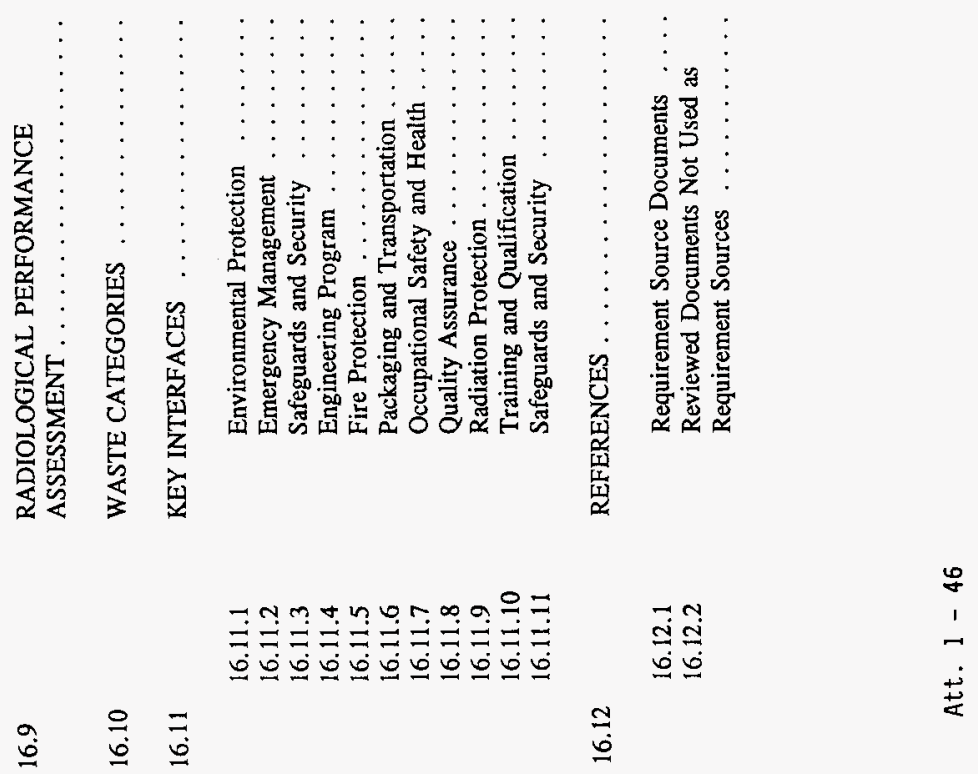
PROPOSED TRIENNIAL SCHEDULE FOR WASTE MANAGEMENT

\begin{tabular}{|l|l|l|l||l|l|l|l||l|l|l|l|}
\hline \multicolumn{3}{|c||}{ FY A } & \multicolumn{4}{c||}{ FY B } & \multicolumn{4}{c|}{ FY C } \\
\hline $1 \mathrm{Q}$ & $2 \mathrm{Q}$ & $3 \mathrm{Q}$ & $4 \mathrm{Q}$ & $1 \mathrm{Q}$ & $2 \mathrm{Q}$ & $3 \mathrm{Q}$ & $4 \mathrm{Q}$ & $1 \mathrm{Q}$ & $2 \mathrm{Q}$ & $3 \mathrm{Q}$ & $4 \mathrm{Q}$ \\
\hline 16.1 & 16.2 & 16.3 & 16.4 & 16.5 & 16.6 & 16.7 & 16.9 & 16.8 & $\begin{array}{l}16.8 \\
\text { cont }\end{array}$ & 16.10 & \\
\hline
\end{tabular}

16.0 WASTE MANAGEMENT

16.1 WASTE CHARACTERIZATION AND CERTIFICATION

$$
\begin{array}{ll}
\text { 16.1.1 } & \text { TRU Waste } \\
\text { 16.1.2 } & \text { Low-Level Radioactive Waste } \\
\text { 16.1.3 } & \text { Mixed/Dangerous Waste }
\end{array}
$$

16.2 PACKAGING AND LABELING COMPLIANCE

$$
\begin{aligned}
& \text { 16.2.1 Low-Level Radioactive Waste Packaging } \\
& \text { 16.2.2 Dangerous/Mixed Waste Packaging and Labeling } \\
& \text { 16.2.3 PCB Waste Labeling }
\end{aligned}
$$

16.3 TRANSPORTATION

16.4 PLANS, RECORDS AND REPORTING

$$
\begin{array}{ll}
\text { 16.4.1 } & \text { TRU Waste } \\
\text { 16.4.2 } & \text { Low-Level Radioactive Waste } \\
\text { 16.4.3 } & \text { Mixed/Dangerous Waste }
\end{array}
$$

16.4.4 PCB Waste

16.5 PERMITTING

Att. I -47
16.6 WASTE ACCEPTANCE CRITERIA

16.6.1 TRU Waste

16.6.2 Low-Level Radioactive Waste

16.6.3 Mixed/Dangerous Waste

16.6.4 PCB Waste

16.7 WASTE MINIMIZATION

16.8 WASTE TREATMENT AND DISPOSAL TECHNOLOGY

16.8.1 Low-Level Radioactive Waste

16.8.2 Mixed/Dangerous Waste

16.8.2.1 Management of Containers

16.8.2.2 Waste Treatment

16.8.3 Asbestos Waste

16.8.4 Tank Systems

16.8.5 Closure

16.8.6 Used Oil

\subsection{RADIOLOGICAL PERFORMANCE ASSESSMENT}

16.10 WASTE CATEGORIES 
WHC-SD-TWR-SRID-003

September 30,1996 Rev. 0

TABLE OF CONTENTS

17.0 RESEARCH AND DEVELOPMENT AND EXPERIMENTAL

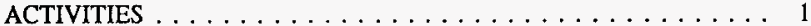

* WAIVED AT THIS TIME

Att. $1-48$ 

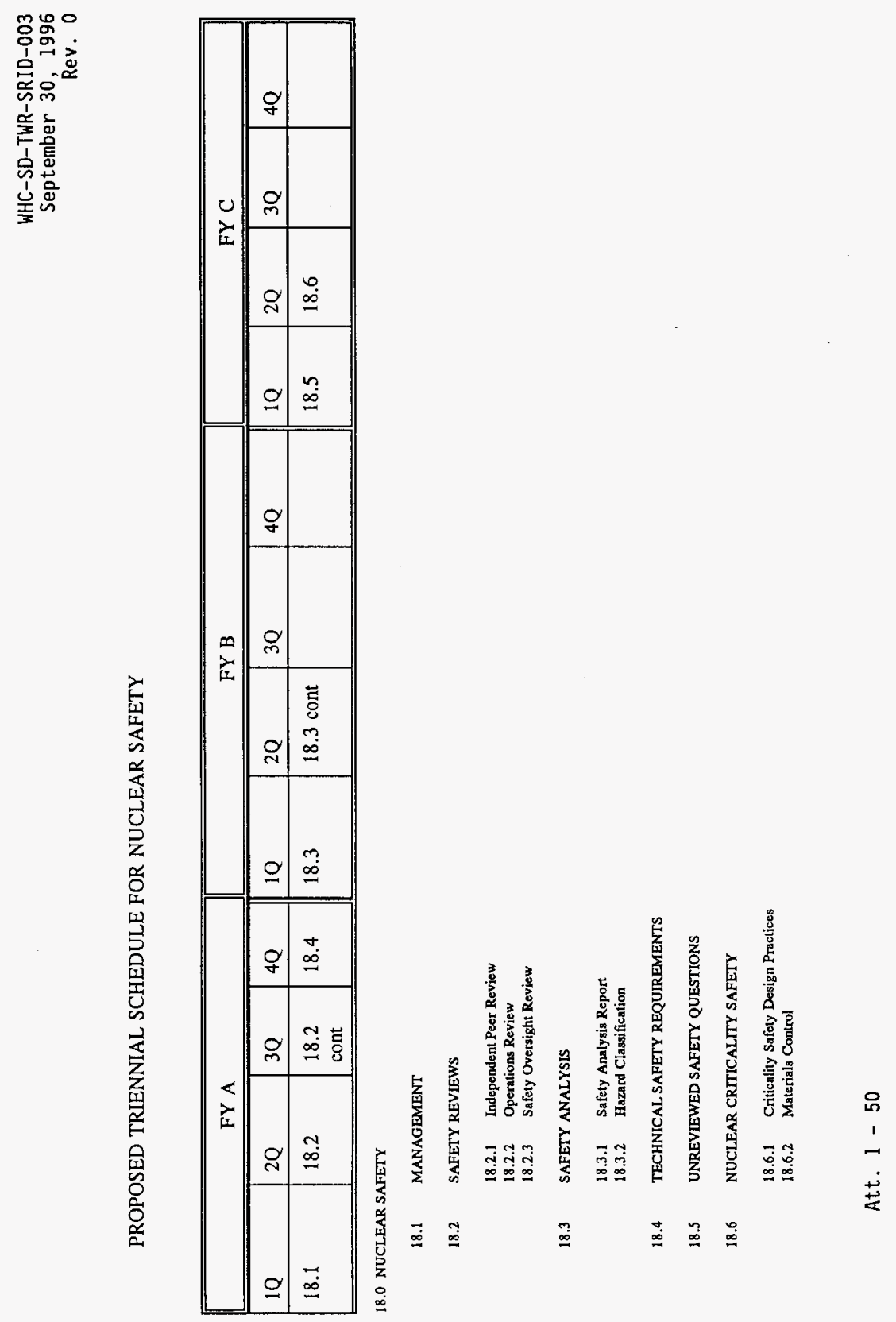
WHC-SD-TWR-SRID-003

September 30, 1996

Rev. 0

19.0 OCCUPATIONAL SAFETY AND HEALTH $\ldots \ldots \ldots \ldots \ldots$

19.1

\section{MANAGEMENT AND}

ADMINISTRATION ........... 3

19.1.1

19.1.2

19.1.3

19.2

19.2.1

19.2.2

19.2.3

19.2.4

19.2 .5

19.3

19.3.2

Att. $1-51$

Program Policy ........... 3

Occupational Safety and Health

Goals and Objectives .......... 3

Requests for Exemptions/Variances ... 3

HAZARD ANTICIPATION, IDENTIFICATION AND EVALUATION . . . 5

Hazard Assessment Program . . . . . 5

Hazards Reporting System . . . . . . . 6

Investigation of Occurrences,

Accidents, and Near Misses . . . . . . 8

Injury and Illness Trend Analysis $\ldots .8$

Occupational Safety and Health

Hazard Inventory System $\ldots \ldots \ldots .8$

\section{OSH HAZARD PREVENTION AND}

CONTROL $\ldots \ldots \ldots \ldots \ldots \ldots \ldots$

Hazard Monitoring, Sampling, and

Surveillance .............. . 8

Hazard Controls ............ 8
TABLE OF CONTENTS

19.3.2.1
19.4

19.4.1

19.4 .2

19.4.3

19.4 .4

19.4 .5

19.4.6

19.4.7

19.4 .8

19.6

\section{Administrative Controls \\ Personal Protective \\ Equipment . \\ Construction Safety and \\ Health}

Safety Inspection and Maintenance

21

\section{OCCUPATIONAL HEALTH}

PROGRAM

Health Examinations

Health Maintenance

Diagnosis and Treatment.

Fitness for Duty

Medical Facilities and

Equipment . . .

Professional Development of

Occupational Staff

Health Records and Reporting

Medical Staffing

OCCUPATIONAL SAFETY AND

HEALTH TRAINING

RECORDKEEPING AND

REPORTING

21

$2 \cdot$

24

25
25
25
25 
WHC-SD-TWR-SRID-003

September 30, 1996

Rev. 0

19.6 .1

Occupational Injury and Illness

Reporting ............ 26

19.6.2 Occurrence Reporting . . . . . . 27

19.7

KEY INTERFACES $\ldots \ldots \ldots \ldots \ldots 27$

19.7.1

19.7.2

19.7.3

19.7.4

19.7.5

19.8

REFERENCES . . . . . . . . . . . 28

19.8.1

19.8 .2

Requirement Source Documents . . . 28

Reviewed Documents Not Used as

Requirement Sources . . . . . . . . 28

Att. $1-52$ 
PROPOSED TRIENNIAL SCHEDULE FOR OCCUPATIONAL SAFETY AND

HEALTH

\begin{tabular}{|l|l|l|l||l|l|l|l||l|l|l|l|}
\hline \multicolumn{9}{|c|}{ FY A } & \multicolumn{9}{c||}{ FY B } & \multicolumn{3}{c|}{ FY C } \\
\hline $1 Q$ & $2 \mathrm{Q}$ & $3 \mathrm{Q}$ & $4 \mathrm{Q}$ & $1 \mathrm{Q}$ & $2 \mathrm{Q}$ & $3 \mathrm{Q}$ & $4 \mathrm{Q}$ & $1 \mathrm{Q}$ & $2 \mathrm{Q}$ & $3 \mathrm{Q}$ & $4 \mathrm{Q}$ \\
\hline 19.1 & 19.2 & $\begin{array}{l}19.2 \\
\text { cont }\end{array}$ & 19.5 & 19.3 & 19.3 cont & 19.3 cont & 19.6 & 19.4 & $\begin{array}{l}19.4 \\
\text { cont }\end{array}$ & $\begin{array}{l}19.4 \\
\text { cont }\end{array}$ & \\
\hline
\end{tabular}

19.0 OCCUPATIONAL SAFETY AND HEALTH

19.1 MANAGEMENT AND ADMINISTRATION

$$
\begin{array}{ll}
\text { 19.1.1 } & \text { Program Policy } \\
\text { 19.1.2 } & \text { Occupational Safety and Health Goals and Objectives } \\
\text { 19.1.3 } & \text { Requests for Exemptions/Variances }
\end{array}
$$

19.2 HAZARD ANTICIPATION, IDENTIFICATION AND EVALUATION

$\begin{array}{ll}\text { 19.2.1 } & \text { Hazard Assessment Program } \\ \text { 19.2.2 } & \text { Hazards Reporting System } \\ \text { 19.2.3 } & \text { Investigation of Occurrences, Accidents, and Near Misses } \\ \text { 19.2.4 Injury and Illness Trend Analysis }\end{array}$

19.2.5 Occupational Safety and Health Hazard Inventory System

19.3 OSH HAZARD PREVENTION AND CONTROL

19.3.1 Hazard Monitoring, Sampling, and Surveillance

19.3.2 Hazard Controls

19.3.2.1 Administrative Controls

19.3.2.2 Personal Protective Equipment

19.3.2.3 Construction Safety and Health
19.3.3 Safety Inspection and Maintenance

19.4 OCCUPATIONAL HEALTH PROGRAM

\author{
19.4.I Health Examinations \\ 19.4.2 Health Maintenance \\ 19.4.3 Diagnosis and Treatment \\ 19.4.4 Fitness for Duty \\ 19.4.5 Medical Facilities and Equipment \\ 19.4.6 Professional Development of Occupational Staff \\ 19.4.7 Health Reconds and Reporting \\ 19.4.8 Medical Staffing
}

\subsection{OCCUPATIONAL SAFETY AND HEALTH TRAINING}

19.6 RECORDKEEPING AND REPORTING
19.6.1
19.6 .2
Occupational lnjury and Illncsa Reporting

Att. $1-53$ 
WHC-SD-TWR-SRID-003

September 30,1996

Rev. 0

\section{TABLE OF CONTENTS}

20.0 ENVIRONMENTAL PROTECTION $\ldots \ldots \ldots \ldots \ldots \ldots$

20.3

20.1

\section{ENVIRONMENTAL POLICY}

MANAGEMENT ............ 3

20.1 .1

20.1 .2

National Environmental Policy Act ... 3

State Environmental Policy Act ..... 9 9

PERMITS ............... 11

20.2

Clean Water Permits

11

20.2 .1 .1

20.2.1.2

20.2 .2

20.2.2.1

20.2.2.2

20.2.2.3

20.2 .3

20.2 .4
Underground Injection Control (UIC) Registration . . 16 Domestic Sewage ...... 17

Clean Air Permits . . . . . . . . 25

Notice of Construction . . . . 26

Toxic Air Pollutants . . . . . . 29

Radionuclide Emissions . . . . 31

RCRA TSD Facility Permits $\ldots \ldots \quad 35$

Underground Storage Tanks . . . . . . 36

ENVIRONMENTAL MONITORING, SURVEILLANCE AND

INSPECTIONS

41

20.3.1

20.3 .2

20.3 .3

20.4

20.4 .1

20.4 .2

20.4 .3

20.5

20.6

20.6 .1

20.6 .2

20.6 .3

20.6 .4
Monitoring, Surveillance and

Inspection Plans and

Procedures $\ldots \ldots \ldots \ldots \ldots, 41$

Tank Systems . . . . . . . . . . 4)

Quality Assurance

ENVIRONMENTAL CONTROL

STANDARDS

Water Quality

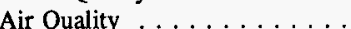

Radiological Eftluents

POLLUTION PREVENTION

\section{RECORDKEEPING, REPORTS AND} NOTIFICATIONS

Incident Investigation and

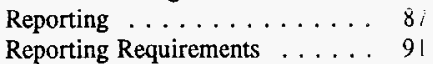

Underground Storage Tanks . . . . 91

Records Management . . . . . $10 t$ 

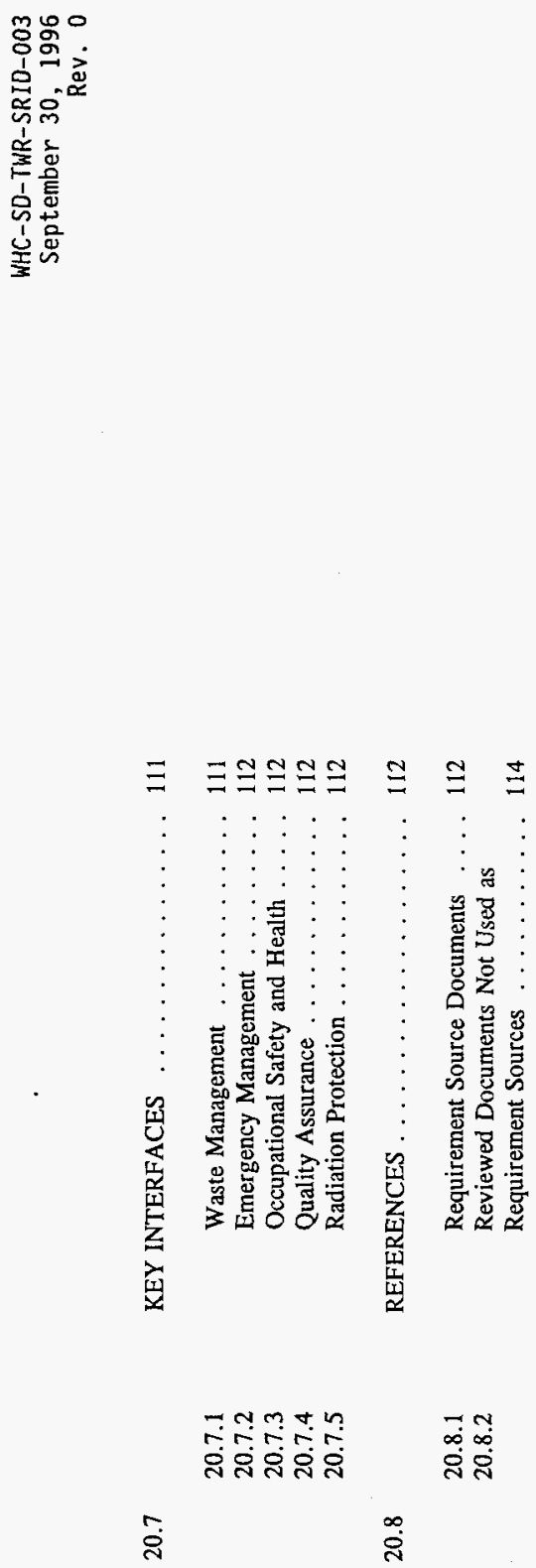
PROPOSED TRIENNIAL SCHEDULE FOR ENVIRONMENTAL PROTECTION

\begin{tabular}{|l|l|l|l||l|l|l|l|l||l|l|l|l|}
\hline \multicolumn{9}{|c|}{ FY A } & \multicolumn{9}{c|}{ FY B } & \multicolumn{3}{c|}{ FY C } \\
\hline $1 \mathrm{Q}$ & $2 \mathrm{Q}$ & $3 \mathrm{Q}$ & $4 \mathrm{Q}$ & $1 \mathrm{Q}$ & $2 \mathrm{Q}$ & $3 \mathrm{Q}$ & $4 \mathrm{Q}$ & $1 \mathrm{Q}$ & $2 \mathrm{Q}$ & $3 \mathrm{Q}$ & $4 \mathrm{Q}$ \\
\hline 20.1 & 20.2 & $\begin{array}{l}20.2 \\
\text { cont }\end{array}$ & 20.5 & 20.3 & 20.3 cont & 20.4 & 20.4 cont & 20.6 & $\begin{array}{l}20.6 \\
\text { cont }\end{array}$ & & & \\
\hline
\end{tabular}

20.0 ENVIRONMENTAL PROTECTION

20.1 ENVIRONMENTAL POLICY MANAGEMENT
20.1.1 National Environmental Policy Act

20.1.2 State Environmental Policy Act

20.2 PERMITS
20.2.1 Clean Water Permits
20.2.1.1 Underground Injection Control (UIC) Registration
20.2.1.2 Domestic Sewage
20.2.2 Clean Air Permits
20.2.2.1 Notice of Construction
20.2.2.2 Toxic Air Pollutants
20.2.2.3 Radionuclide Emissions
20.2.3 RCRA TSD Facility Permits
20.2.4 Underground Storage Tanks

20.3 ENVIRONMENTAL MONITORING, SURVEILLANCE AND INSPECTIONS

20.3.1 Monitoring, Surveiliance and Inspection Plans and Procedures
20.3.2 Tank Systems

20.3.3 Quality Assurance

Att. $1-56$

\section{ENVIRONMENTAL CONTROL STANDARDS}

20.4.1 Water Quality

20.4.2 Air Quality

20.4.3 Radiological Emluents

20.5 POLLUTION PREVENTION

20.6 RECORDKEEPING, REPORTS AND NOTIFICATIONS

20.6.1 Incident Investigation and Reporting

20.6.2 Reporting Requirements

20.6.3 Underground Storage Tanks

20.6.4 Records Management 
WHC-SD-TWR-SRID-003

September 30, 1996 Rev. 0

\section{ATTACHMENT 2 WHC-SD-TWR-SRID-003, Rev. 0 Page $i$ of 188}

Att. $2-i$ 


\section{MANAGEMENT SYSTEM}

\section{$1.0 \quad$ PURPOSE}

This section provides management systems functional area elements, performance objectives, and criteria intended for use by Tank Farm operational activities to ensure compliance with applicable State and Federal Regulations and Department of Energy (DOE) Orders as defined in the Tank Waste Remediation System (TWRS) Standards and Requirements Identification Document (S/RID) for Management Systems.

\subsection{SCOPE}

The performance objectives and criteria (PO\&C) apply to all Tank Farm facilities and organizations subject to evaluation under the TWRS Management Assessment Program.

\subsection{FUNCTIONAL AREA ELEMENTS}

The following are the management systems functional area elements. Each functional area element has performance objectives and subsequent criteria. The criteria are used to assess the objectives.

\subsection{MANAGEMENT AND ADMINISTRATION}

\subsubsection{Performance Objective}

Policies and plans are developed and established defining the organization, staffing, responsibilities, and work processes.

\section{Criteria}

3.1.1.1 A written Quality Assurance Plan (QAP) has been developed, implemented, and maintained. The QAP describes the organizational structure, functional responsibilities, levels of authority, and interfaces for those managing, performing, and assessing the work. The QAP describes management processes including planning, scheduling, and resource considerations. [10 CFR 830, Part 120(c)(1)(I)] 
3.1.1.2 General and detailed requirements applicable to personnel selection, staffing and training are identified and established. [Training and Qualification (T\&Q) Functional Area; DOE 5480.20A]

3.1.1.3 Work is performed to established technical standards and administrative controls using approved instructions, procedures, or other appropriate means. [10 CFR 830, Part 120(c)(2)(I)]

3.1.1.4 Items are identified and controlled to ensure their proper use. Items are maintained to prevent their damage, loss, or deterioration.

[10 CFR 830, Part 120(c)(2)(I)]

3.1.1.5 Equipment used for process monitoring or data collection is calibrated and maintained. [10 CFR 830, Part 120(c)(2)(I)]

3.1.1.6 Workers and their supervisors are held accountable for operating performance. Personnel involved in significant or frequent violations of operating practices are counseled, retrained, and/or disciplined, as appropriate. Supervisor performance appraisals and promotions include an assessment of operating performance.

[DOE 5480.19 Chapter I, Section C.4]

\subsubsection{Performance Objective}

Procedures have been prepared, reviewed, approved, issued, used, and revised to prescribe processes, specify requirements, or establish design.

[10 CFR 830, Part 120(c)(1)(iv)]

\section{Criteria}

3.1.2.1 Procedures have been developed for all anticipated operations, evolutions, tests, and abnormal or emergency situations.

[DOE 5480.19, Chapter XVI, Section C.1, Paragraph 1, and Paragraph 2, Sentence 1 thru 3]

3.1.2.2 Procedures incorporate appropriate information from applicable source documents, such as the facility design documents, safety analysis documents, and vendor technical manuals.

[DOE 5480.19 Chapter XVI, Section C.2.b] 
3.1.2.3 To ensure consistency among operations procedures, the methods for developing new procedures, including procedure formats, are clearly defined.

[DOE 5480.19 Chapter XVI, Section C.1, Paragraph 1, and Paragraph 2, Sentences 1 thru 3]

3.1.2.4 New or revised procedures are verified to ensure technical accuracy and proper format.

[DOE 4330.4B Chapter II, Section 6.3.2, Paragraph 1, Sentences 1 through 3]

3.1.2.5 Procedures are controlled in accordance with facility administrative requirements. [DOE 4330.4B Chapter I, Section 6.3.6, Paragraph 1]

3.1.2.6 Facility operation is conducted in accordance with applicable procedures that reflect the facility design basis. Procedural requirements are clearly defined and understood by all operators. If procedures are deficient, procedure changes are initiated.

[DOE 5480.19 Chapter XVI, Section C.7]

3.1.2.7 Operating procedures are approved by the operations supervisor. In addition, procedures that affect safety-related equipment and emergency procedures are reviewed by the facility safety review committee or by another appropriate review mechanism.

[DOE 5480.19 Chapter XVI, Section C.4, Paragraph 1, and Paragraph 2, Sentence 1]

3.1.2.8 New and revised operations procedures are reviewed prior to issuance and at periodic intervals to ensure that the information and instructions are technically accurate and that appropriate human-factor considerations have been included. Applicable procedures are reviewed after an unusual incident. [DOE 5480.19 Chapter XVI, Section C.5]

3.1.2.9 Procedure revisions receive the same depth of review and level of approval as the initial versions. New and revised procedures are approved prior to use.

[DOE 5480.19 Chapter XVI, Section C.4, Paragraph 1 and Paragraph 2, Sentence 11

3.1.2.10 Operators have procedures with them and follow them in a step-by-step manner when the procedures contain sign-offs for the various activities. [DOE 5480.19 Chapter XVI, Section C.7] 


\subsection{ISSUES MANAGEMENT}

\subsubsection{Performance Objective}

Processes to detect and prevent quality problems have been established and implemented. Items, services, and processes that do not meet established requirements are identified, controlled, and corrected according to the importance of the problem and the work affected in an Issues Management Program. Correction includes identifying the causes of problems and working to prevent recurrence. [10 CFR 830, Part 120(c)(1)(iii)]

\section{Criteria}

3.2.1.1 Criteria have been developed and are used to assess the significance of issues. [DOE 5480.29 Preamble, Section 9.d]

3.2.1.2 A problem/issue is evaluated using appropriate techniques to establish a final root cause.

[DOE 4330.4B Chapter II, Section 17.3.3, Paragraph 1, Sentences 1 and 2]

3.2.1.3 Appropriate corrective actions are established for each event investigation, and specific personnel are assigned responsibilities for the corrective actions. [DOE 5480.19 Chapter VI, Section C.5.d, Sentence 1]

3.2.1.4 A tracking and trending system is established for issues contained in the Issues Management System. [10 CFR 20, Appendix A]

\subsection{MANAGEMENT EVALUATION}

\subsubsection{Performance Objective}

A systematic process has been established for management's evaluation of facility.

\section{Criteria}

3.3.1.1 Facility managers assess facility performance indicators and other operations information, such as reportable occurrences, for trends in improving or deteriorating conditions.

[DOE 5480.26, Section 6.f Introduction, and 6.f.(1)] 
3.3.1.2 Facility managers assess their facility operating information for trends and indications of deteriorating/improving conditions. Identified lessons-learned and good practices are used in their facility to prevent occurrences or to improve safety and/or operations.

[DOE 5480.26, Section 7.b.(1), Sentence 2]

3.3.1.3 Patterns of deficiencies such as operator errors or inadequate procedures are trended. A periodic summary report of events, causes, and trends is submitted to department heads, the facility manager, and appropriate managers. Department heads ensure that training programs include appropriate material from the summary report.

[DOE 5480.19 Chapter VI, Section C.8]

3.3.1.4 Internal appraisals are conducted at the operating level by persons not directly responsible for performance of the activities being appraised. [DOE 5482.1B, Section 9.d(1)]

3.3.1.5 Investigations of Type $\mathrm{A}, \mathrm{B}$, and $\mathrm{C}$ incidents are properly conducted when required. [RLIP 5484.1A, Section 4.1]

\subsection{OCCURRENCE REPORTING}

\subsubsection{Performance Objective}

Procedures for the Occurrence Reporting Program have been developed, have been approved, and are in use. [DOE-O-232.1, Part 4]

\section{Criteria}

3.4.1.1 Facility personnel ensure appropriate categorization, notification, reporting, and investigating of events and/or conditions.

[DOE-O-232.1, Part 4.c, and 4.c(1)]

3.4.1.2 A facility manager or facility manager designee is available at all times to categorize the event and to make the proper notification pursuant to the event's categorization. [DOE O 232.1, Part 4.b, and 4.b(1)]

\subsubsection{Performance Objective}

Occurrence reports to DOE regarding emergencies and/or accidents are prepared and submitted in accordance with departmental requirements. [10 CFR 835, Part 1301(e)] 


\section{Criteria}

3.4.2.1 Procedures are developed that address appropriate notifications. [DOE 5480.19 Chapter VII, Section C. 1]

3.4.2.2 Adequate communication equipment is maintained in the main control area to support occurrence/event reporting and notification. [DOE 5480.19 Chapter VII, Section C. 5]

3.4.2.3 Investigative reports are prepared. Each report includes a description of the event, a discussion of the impact of the event, root cause, the lessons learned, and the proposed corrective action(s). Investigative reports are approved by the facility manager and reviewed by appropriate supervisors, managers, and the safety review committee.

[DOE 5480.19 Chapter VI, Section C.6, Paragraph 1]

3.4.2.4 Appropriate corrective action is established for each event investigation, and specific personnel are assigned responsibilities for the corrective action. [DOE 5480.19 Chapter VI, Section C.5.d, Sentence 1]

3.4.2.5 The final approval for corrective action is made by the facility manager. [DOE 5480.19 Chapter VI, Section C.5.d, Sentence 3]

\subsubsection{Performance Objective}

Events that occur in the facility and adversely affect operations, personnel safety, or DOE requirements (DOE 5000.3A) receive a thorough investigation. The criteria for when to perform an event investigation is clearly established. Specific events requiring investigation should be listed for supervisory use, along with criteria for use in deciding what "near miss" situations are to receive review. [DOE 5480.19 Chapter VI, Section C.1, Sentences 1 thru 3]

\section{Criteria}

3.4.3.1 Investigators are trained in facility systems and operations and in other major disciplines appropriate for the event under investigation. Additionally, investigators are trained in techniques for conducting an investigation.

\section{[DOE 5480.19 Chapter VI, Section C.3, Sentences 4 and 5]}

3.4.3.2 Sufficient data is collected to allow the event investigators to perform a reconstruction and analysis of an event. Necessary information is collected as soon as possible after the event. 
[DOE 5480.19 Chapter VI, Section C.4, Paragraph 1, Sentences 1 through 3]

3.4.3.3 The root causes of events are determined. [DOE 5480.19 Chapter VI, Section C.5.c, Sentence 1]

3.4.3.4 Appropriate corrective action is established for each event investigation, and specific personnel are assigned responsibilities for the corrective action. The final approval for corrective action is made by the facility manager.

[DOE 5480.19 Chapter VI, Section C.5.d, Sentences 1 and 3]

\subsection{OPERATIONAL READINESS REVIEWS}

\subsubsection{Performance Objective}

Operational Readiness Reviews (ORRs) provide a structured methodology for determining that a facility, project, process, or activity is ready to be occupied and/or operated in a safe and controlled manner.

\section{Criteria}

3.5.1.1 The actions to be taken in the restart process are established and responsibility for authorizing the restart of a nuclear facility is assigned.

\section{[DOE 5480.31 and RLID 5480.31]}

3.5.1.2 An ORR or Readiness Assessment (RA) is performed based on the hazard category. [RLID 5480.31, Section 8.1.c and 8.2.e]

3.5.1.3 All facility new start and restart activities planned for the next 2 years are identified to Richland Operations (RL) quarterly. When an unplanned shutdown occurs and an ORR or RA is required for restart, RL line management is notified verbally and in writing, as soon as practical. [RLID 5480.31, Section 8.0 and Section 8.2.c, Paragraph 1]

3.5.1.4 Personnel who are responsible for ORR and RA performance prepare an implementing procedure for use in performing startup and restart activities. [RLID 5480.31, Section 6.e(1)]

3.5.1.5 Startups and restarts of facilities or activities not requiring an ORR are evaluated to determine if the startup will be evaluated using an RA.

[RLID 5480.31, Section 8.1.d] 


\subsubsection{Performance Objective}

Line management develops the breadth of the ORR and documents it in the Plan of Action (POA). The minimum set of core requirements is addressed.

[RLID 5480.31, Section 8.1.g]

\section{Criteria}

3.5.2.1 A POA is prepared for all ORRs and submitted to the cognizant RL line management for review and approval prior to conducting the ORRs.

\section{[RLID 5480.31, Section 6.e(2)]}

3.5.2.2 A formal POA, implementing procedure (IP), and final report that includes closure of prestart findings is prepared. The resolution of all findings from the ORR is documented and maintained with the POA, IP, and the final report. [RLID 5480.31, Section 8.1.f]

3.5.2.3 A prerequisite for starting the ORR or RA is verification and certification by line management that readiness to startup or restart of the facility has been achieved. [RLID 5480.31, Section 8.1.f and Section 8.2.1]

3.5.2.4 Prestart findings of a DOE ORR or RA are satisfied prior to startup or restart of the facility. [RLID 5480.31, Section 8.1.p and 8.2.n]

3.5.2.5 Requirements applicable to startups or restarts of facilities/activities involving RAs are met. [RLID 5480.31, Section 8.2.g]

\subsubsection{Performance Objective}

The requirements by which tracking and closure of review findings, including independent verification of closure, are conducted are specified.

\section{Criteria}

3.5.3.1 Corrective action plans are prepared for the correction of all findings. [RLID 5480.31, Attachment 10.7, Section 3] 
3.5.3.2 Monitoring and verification of satisfactory closure of prestart findings is defined in the ORR report as either the responsibility of the ORR team or line management

[RLID 5480.31, Attachment 10.7, Section 4]

3.5.3.3 The mechanism for closure of RA prestart findings is defined.

[RLID 5480.31, Section 8.2.p]

\subsection{DOCUMENT AND DATABASE CONTROL - RECORDS MANAGEMENT}

\subsubsection{Performance Objective}

Requirements and processes are established to manage records policies, procedures, engineering drawings, databases, and other documents or information requiring control and retention.

\section{Criteria}

3.6.1.1 A plan has been established for the preservation of records documenting the organization, functions, policies, decisions, procedures, and essential transactions. The plan includes records containing evidence or information necessary for the protection of the rights of the Government and individuals. [DOE 1324.2A Preamble, Section 9.b]

3.6.1.2 The proper disposition authority for each filing series is identified and obtained. The complete inventory is reviewed to determine the proper disposition authority. [DOE 1324.2A Chapter I, Section 3]

3.6.1.3 All supporting information pertaining to each Occurrence Report (such as, graphs and analyses) is retained.

[DOE 1324.5B and DOE O 232.1 Part 4.c.(2)]

3.6.1.4 The document control organization provides notice of pending changes to the persons on the controlled distribution list for the document involved. A notice of the pending change is also attached to, or appropriately referenced on, the affected master document to alert anyone requesting a copy of the document.

[DOE-STD-1073-93 Chapter 2, Section 2.3.2.3, Paragraph 6]

3.6.1.5 Procedures are established to discourage the abuse or misuse of the software operated at the site or abuse or misuse of any of the data associated with that software. Custom-developed software has safeguards 
against abuse or misuse identified and incorporated into the software as early in the development process as possible.

[DOE 1330.1D, Section 8.g]

\subsubsection{Performance Objective}

Records are stored at the site so as to ensure ease of access, retrieval, and control. [DOE 5500.7B, Section 11.b]

\section{Criteria}

3.6.2.1 The practice of centralized files is limited to those instances where there is a realistic need to be centralized. [DOE 1324.3 Chapter I, Section 5.b]

3.6.2.2 Duplicate file stations consisting of extra copies or other nonrecord material are established only when official stations are not readily accessible to another group that needs frequent reference to the records. [DOE

\subsection{Chapter I, Section 5.a]}

3.6.2.3 Classified and Unclassified Controlled Nuclear Information (UCNI) records are handled in accordance with security requirements. [DOE $\mathbf{5 6 3 2 . 5}$, DOE 5635.1A, and DOE 5635.4]

3.6.2.4 Special precautions are taken to ensure the safekeeping of electronically stored data. Before establishing safeguards, the sensitivity of the data is determined, vulnerabilities are identified, and the degree of risk is considered. [DOE 1324.6, Section 15]

3.6.2.5 Personnel are able to easily retrieve electronically stored records until time of authorized disposition. [DOE 1324.6, Section 11.a]

3.6.2.6 Unclassified, sensitive electronic records are not processed without the express written approval of the Computer Protection Program Manager. [DOE 1360.2, Page 5, Paragraph 6c(1)]

\subsubsection{Performance Objective}

A planned approach has been developed to control, store, and retire or transfer records. [DOE 1324.2A Preamble, Section 9.c] 


\section{Criteria}

3.6.3.1 The approved Records Inventory Disposition Schedule (RIDS) is the basic document in the management plan. RIDS are reviewed, analyzed, and compiled at records officer level. The contractor records officer has a plan for records management activities, which is based on the RIDS.

[DOE 1324.2A Chapter II, Section 2.d]

3.6.3.2 Separate RIDS are prepared for each file station.

[DOE 1324.2A Chapter II, Section 2.a(2)]

3.6.3.3 Responsibility for files maintenance and disposition actions is assigned to an appropriate staff member. [DOE 1324.2A Chapter II, Section 2.a(2)]

3.6.3.4 Records no longer required for current activities are transferred to lower cost storage with a preference for use of Federal Records Centers over local records holding areas. [DOE 1324.2A Preamble, Section 9.c]

\subsection{LESSONS LEARNED}

\subsubsection{Performance Objective}

Lessons learned from the facility's respective occurrences and the operations information obtained from other similar DOE facilities are collected and disseminated to facility personnel. [DOE 232.1, Part 4.c.(3)]

\section{Criteria}

3.7.1.1 Patterns of deficiencies such as operator errors or inadequate procedures are trended. [DOE 5480.19 Chapter VI, Section C.8]

3.7.1.2 A periodic summary report of events, causes, and trends is submitted to department heads, the facility manager, and appropriate managers.

[DOE 5480.19 Chapter VI, Section C.8]

3.7.1.3 Department heads ensure that training programs include appropriate material from the summary report.

[DOE 5480.19 Chapter VI, Section C.8] 


\subsection{PREREQUISITES}

None.

\subsection{SPECIAL APPROVALS}

None. 


\subsection{REFERENCES}

The following documents were used to create this MS section:

10 CFR 20, Standard for Protection Against Radiation, 1 January 1996.

10 CFR 830, Nuclear Safety Management, Part 120, Quality Assurance Requirements, 5 May 1994.

10 CFR 835, Occupational Radiation Protection, 13 December 1993.

DOE O 232.1, Occurrence Reporting and Processing of Operations Information, 30 October 1995 .

DOE 1324.2A, Records Disposition, 13 September 1988; Change 1, 9 April 1992.

DOE 1324.3, Files Management, 2 March 1981; Change 1, 9 April 1992.

DOE 1324.5B, Records Management Program, 6 January 1987

DOE 1324.6, Automated Office Electronic Record keeping, 8 July 1987; Change 1, 12 June 1992.

DOE 1330.1D, Computer Software Management, 18 May 1992.

DOE 1360.2, Unclassified Computer Security Program, 18 May 1992.

DOE 4330.4B, Maintenance Management Program, 10 February 1994.

DOE 5480.19, Conduct of Operations Requirements for DOE Facilities, 9 July 1990; Change 1, 18 May 1992

DOE 5480.20, Personnel Selection, Qualification, Training, and Staffing Requirements at DOE Reactor and Non-Reactor Facilities, 20 February 1991.

DOE 5480.26, Trending and Analysis of Operations Information Using Performance Indicators, 15 January 1993.

DOE 5480.29, Employee Concerns Management System, 15 January 1993.

DOE 5480.31, Startup and Restart of Nuclear Facilities, 15 September 1993.

DOE 5482.1B, Environmental, Safety, and Health Appraisal Program, 23 September 1986; Change 1, 18 November 1991. 
DOE 5500.7B, Emergency Operating Records Protection Program, 23 October 1991. DOE 5632.5, Physical Protection of Classified Matter, 3 February 1988.

DOE 5635.1A, Control of Classified Documents and Information, 12 February 1988.

DOE 5635.4, Protection of Unclassified Controlled Nuclear Information, 3 February 1988.

DOE-STD-1073-93, Guide for Operational Configuration Management Program, November 1993.

RLID 5480.31, Startup and Restart of Facilities Operational Readiness Review and Readiness Assessments, 26 September 1994.

RLIP 5484.]A, Environmental Protection, Safety, and Health Protection Information Reporting Requirements, 26 February 1993.

WHC-SD-MP-SRID-001, Tank Waste Remediation System Standards and Requirements Identification Document, 30 January 1996. 


\section{QUALITY ASSURANCE}

\subsection{PURPOSE}

This section provides quality assurance (QA) functional area elements, performance objectives, and criteria intended for use by Tank Farm operational activities to ensure compliance with applicable State and Federal Regulations and Department of Energy (DOE) Orders as defined in the Tank Waste Remediation System (TWRS) Standards and Requirements Identification Document (S/RID), and Quality Assurance Program.

\section{$2.0 \quad$ SCOPE}

The performance objectives and criteria $(\mathrm{PO} \& \mathrm{C})$ apply to all Tank Farm facilities and organizations subject to evaluation under the TWRS Management Assessment Program.

\subsection{FUNCTIONAL AREA ELEMENTS}

The following are the QA functional area elements. Each functional area element has performance objectives and subsequent criteria. The criteria are used to assess the objectives.

\subsection{MANAGEMENT AND ADMINISTRATION}

\subsubsection{Performance Objective}

A QA Program has been developed and implemented and is being maintained.

[10 CFR 830, Part 120 (c)(Ixi); WHC-SP-1131]

\section{Criteria}

3.1.1.1 Line management has taken responsibility for implementation of the QA Program and the achievement of quality. Each individual is responsible for the quality of his/her work. [10 CFR 830, Part 120 (c)(1)(i); WHC-SP-1131] 


\subsection{QUALITY ASSURANCE PROGRAM}

\subsubsection{Performance Objective}

A written Quality Assurance Plan (QAP) has been developed, implemented, and maintained. [10 CFR 830, Part 120(c)(1)(i)]

\section{Criteria}

3.2.1.1 A QAP has been prepared for the TWRS activities.

[10 CFR 830, Part 120(c)(1)(i); WHC-SP-1131]

3.2.1.2 The QAP describes:

Organizational structure;

Functional responsibilities;

Levels of authority;

Interfaces for those managing, performing, and assessing the work; and

Management processes, including planning, scheduling, and resource considerations.

[10 CFR 830, Part 120(c)(1)(i); WHC-SP-1131]

3.2.1.3 By using a graded approach, the quality of items and/or processes is achieved to an extent consistent with their risk.

[10 CFR 830, Part 120(c)(1)(i); WHC-SP-1131]

3.2.1.4 Work assigned outside the organization is identified; administrative controls are established; responsibilities are assigned; and lines of communication are identified.

[10 CFR 830, Part 120(c)(1)(i); WHC-SP-1131]

\subsection{TRAINING AND QUALIFICATION OF PERSONNEL}

\subsubsection{Performance Objective}

Personnel are initially trained and qualified to ensure that they can perform their assigned work. Personnel are provided continuing training in order to maintain job proficiency. [10 CFR 830, Part 120(c)(1)(i); WHC-SP-1131] 


\section{Criteria}

3.3.1.1 Job qualifications requirements are established for specific job categories within an organization. [WHC-SP-1131]

3.3.1.2 On the job, personnel can perform their assigned tasks.

[10 CFR 830, Part 120(c)(1)(ii); WHC-SP-1131]

3.3.1.3 Training plans provide for proficiency and are not limited to attainment of initial qualification. [WHC-SP-1131]

3.3.1.4 Training plans for management personnel include professional, managerial, communication, and interpersonal skills. [WHC-SP-1131]

3.3.1.5 Personnel performing work that required special skills or abilities are qualified prior to performing the work. [WHC-SP-1131]

\subsection{QUALITY IMPROVEMENT}

\subsubsection{Performance Objective}

Processes to detect and prevent quality problems are established and implemented. [10 CFR 830, Part 120(c)(1)(iii)]

\section{Criteria}

3.4.1.1 Work processes to detect and prevent quality problems are established and implemented [WHC-SP-1131]

3.4.1.2 Performance data, internal and external failure costs, prevention costs, and other qualityrelated information is analyzed to identify trends that adversely impact quality and to identify opportunities to improve items and/or processes. [WHC-SP-1131]

3.4.1.3 Work processes to promote continuous improvement are established and implemented. This includes the identification and improvement of expected performance standards and associated perfonnance measures. [WHC-SP-1131]

\subsubsection{Performance Objective}

Correction items, services, and processes that do not meet established requirements are identified, controlled, and corrected according to the importance of the problem and the work affected. Item characteristics, process implementation, and other quality-related information are revicwed and the data analyzed to identify itens, scrvices, and processes needing improvement. [10 CFR 830, Part 120(c)(1)(iii); WHC-SP-1131] 


\section{Criteria}

3.4.2.1 Management encourages personnel to identify nonconforming items and/or processes and to recommend improvements. [WHC-SP-1131]

3.4.2.2 Items and/or processes that do not meet established requirements or do not result in the anticipated quality are promptly identified, documented, analyzed, and resolved. As a result, appropriate action is taken. The extent of cause analyses for nonconforming items is commensurate with the importance or significance of the problem. [WHC-SP-1131]

3.4.2.3 Management, at all levels, fosters a no-fault attitude to encourage the identification of nonconforming items and/or processes and is involved in the quality improvement process. [WHC-SP-1131]

3.4.2.4 Nonconforming items and/or processes are properly controlled to prevent their inadvertent test, installation, or use. [WHC-SP-1131]

3.4.2.5 Personnel responsible for analyzing and dispositioning nonconformances have adequate technical understanding of the area in which they are working and have access to pertinent background relative to the nonconformance. The justification for disposition is appropriately documented. [WHC-SP-1131]

3.4.2.6 Rework, repair, and replacement items and/or processes are inspected and tested in accordance with original requirements or specified alternatives. [WHC-SP-1131]

\subsection{DOCUMENTS AND RECORDS}

\subsubsection{Performance Objective}

Documents are prepared, reviewed, approved, issued, used, and revised to prescribe processes, specify requirements, or establish design.

\section{[10 CFR 830, Part 120(c)(1)(iv), WHC-SP-1131]}

\section{Criteria}

3.5.1.1 A work process to manage preparation, review, approval, issuance, use, and revision of documents that establish policies, prescript work, specify requirements, or establish design is cstablished and implemented.

[WHC-SP-1131]

3.5.1.2 The scope of the document control system work process is defined. [WHC-SP-1131]

3.5.1.3 Controlled documents are used by persomel performing the work. [WHC-SP-1131]

3.5.1.4 Superseded and canceled documents are managed so as to ensure that only correct documents are in use. [WHC-SP-1131] 


\subsubsection{Performance Objective}

Records are specified, prepared, reviewed, approved, and maintained.

[10 CFR 830, Part 120(c)(1)(iv), WHC-SP-1 131]

\section{Criteria}

3.5.2.1 A process is established and implemented to ensure that sufficient records are specified, prepared, reviewed, approved, and maintained to accurately reflect the work. Record maintenance includes provisions for retention, protection, preservation, traceability, accountability, and retrieval.

[WHC-SP-1131]

3.5.2.2 Records that require special processing and control (such as, computer codes or information on high density media or optical disks), hardware, and/or software required to maintain and access records are controlled to ensure records are useable. [WHC-SP$1131]$

3.5.2.3 While in storage, records are protected from damage, loss, and deterioration. Quality assurance records are identified on Records Inventory and Disposition Schedules (RIDS).

[WHC-SP-1131]

\subsection{WORK PROCESSES}

\subsubsection{Performance Objective}

Work is performed to established technical standards and administrative controls using approved instructions, procedures, or other appropriate means.

[10 CFR 830, Part 120(c)(2)(i); WHC-SP-1131]

\section{Criteria}

3.6.1.1 Personnel performing work are responsible for the quality of their work. Personnel are knowledgeable of requirements for work they perform and the capability of the tools and processes they use. [WHC-SP-1131]

3.6.1.2 Work is planned, authorized, and accomplished under controlled conditions using technical standards, instructions, procedures, or other appropriate means of a detail commensurate with the complexity and risk of the work. [WHC-SP-1131]

\subsubsection{Performance Objective}

Items are identified and controlled to ensure their proper use.

[10 CFR 830, Part 120(c)(2)(i)] 


\section{Criteria}

3.6.2.1 Work processes to identify, control, and maintain items are established and implemented. [WHC-SP-1131]

3.6.2.2 Identification of items is maintained to ensure appropriate traceability. [WHC-SP-1131]

3.6.2.3 Work processes to control consumables and items with limited shelf life, prevent the use of incorrect or defective items, and control samples are established and implemented. [WHCSP-1131]

\subsubsection{Performance Objective}

Items are maintained to prevent their damage, loss, or deterioration.

[10 CFR 830, Part 120(c)(2)(i)]

\section{Criteria}

3.6.3.1 Work processes to control the handling, storage, transportation, cleaning, and preservation of items to prevent damage, deterioration, or loss are established and implemented. [WHCSP-1131]

3.6.3.2 Special protective measures are specified and provided when required to maintain an acceptable quality. [WHC-SP-1131]

\subsubsection{Performance Objective}

Equipment used for process monitoring or data collection is calibrated and maintained. [10 CFR 830, Part 120(c)(2)(i)l

\section{Criteria}

3.6.4.1 Work processes to control the selection, calibration, and maintenance of process instrumentation used for monitoring and data collection are established and implemented.

[WHC-SP-1131]

3.6.4.2 The process(es) incorporates provisions that enables traceability of calibration certifications to national standards, where possible

[WHC-SP-1131] 


\subsection{DESIGN}

\subsubsection{Performance Objective}

Items and processes are designed using sound engineering/scientific principles and appropriate standards. [10 CFR 830, Part 120(c)(2)(ii); WHC-SP-1131]

\section{Criteria}

3.7.1.1 System design requirements and operating parameters are documented and controlled, and compliance requirements of applicable DOE Orders are determined. [WHC-SP-1131]

3.7.1.2 Facility safety documentation is in place that describes the "safety envelope" of the facility. [10 CFR 830, Section 6.1]

3.7.1.3 Design analyses with approval designators are performed and documented in a planned, timely, and controlled manner.

[WHC-SP-1131]

3.7.1.4 Applicable design inputs are appropriately specified and correctly translated into design documents. [WHC-SP-1131]

3.7.1.5 Applicable infonmation derived from experience, as set forth in reports or other documentation, are made available to cognizant design personnel. [WHC-SP-1131]

\subsubsection{Performance Objective}

Design work, including changes, incorporates applicable requirements and design bases. [10 CFR 830, Part 120(c)(2)(ii); WHC-SP-1131]

\section{Criteria}

3.7.2.1 The design organization has prescribed and documented the design activities on a timely basis and to the level of detail necessary to permit the design process to be completed correctly and to permit verification that the design meets requirements. [WHC-SP-1131]

3.7.2.2 Design documents are adequate to support facility design, construction and operation, and environmental activities.

[WHC-SP-1131]

3.7.2.3 Design changes from approved design inputs, including the reason for the change, are identified, documented, approved, and controlled.

[WHC-SP-1131] 


\subsubsection{Performance Objective}

Design interfaces are identified and controlled.

[10 CFR 830, Part 120(c)(2)(ii); WHC-SP-1131]

Criteria

3.7.3.1 Physical/functional design interfaces are identified and controlled, and design efforts are coordinated among the participating organizations. [WHC-SP-1131]

3.7.3.2 Design information transmitted across organizational interfaces are documented and controlled. [WHC-SP-1131]

\subsubsection{Performance Objective}

The adequacy of design products is verified or validated by individuals or groups other than those who performed the work.

[10 CFR 830, Part 120(c)(2)(ii); WHC-SP-1131]

Criteria

3.7.4.1 Design verification is performed by qualified, competent individual(s) or groups other than those who performed the original design.

[WHC-SP-1131]

3.7.4.2 Verification is performed in a timely manner. [WHC-SP-1131]

3.7.4.3 The design method in use is identified and documented by the responsible design organization. The verification results are documented and identification of the verifier is clearly indicated. [WHC-SP-1131]

3.7.4.4 Design methods, materials, parts, equipments, and processes that are essential are verified for suitability of application. [WHC-SP-1131]

3.7.4.5 Design verification occurs for new application of a design or when design inputs to the original design have been changed for the same application. [WHC-SP-1131]

\subsubsection{Performance Objective}

Verification and validation work is completed before approval and implementation of the design. [10 CFR 830, Part 120(c)(2)(ii); WHC-SP-1131] 


\section{Criteria}

3.7.5.1 Design verification for the level of design activity is performed prior to release for procurement, manufacture, construction, or release to another organization for its use in another design activity.

[WHC-SP-1131]

3.7.5.2 Verification of the design has been documented to provide evidence that verification has occurred. [WHC-SP-1131]

\subsection{PROCUREMENT}

\subsubsection{Performance Objective}

Procured items and services meet established requirements and perform as specified. [10 CFR 830, Part 120(c)(2)(iii); WHC-SP-1131]

\section{Criteria}

3.8.1.1 Processes to ensure that purchased items and services meet cstablished requirements and perform as expected are established. [WHC-SP-1131]

\subsubsection{Performance Objective}

Prospective suppliers are evaluated and selected on the basis of specified criteria. [10 CFR 830, Part 120(c)(2)(iii); WHC-SP-1131]

\section{Criteria}

3.8.2.1 Processes to ensure that purchased items and services meet established requirements and perform as expected are implemented. Applicable technical and administrative requirements (such as specifications, codes, standards, tests, and inspections) are invoked for procurement of items and services. Procurement documents include acceptance criteria. [WHC-SP-1131]

3.8.2.2 Selection of procurement sources is based on the evaluation of the suppliers. [WHC-SP1131]

\subsubsection{Performance Objective}

Processes to ensure that approved suppliers continue to provide acceptable items and services are established and implemented. [10 CFR 830, Part 120(c)(2)(iii); WHC-SP-1131] 


\section{Criteria}

3.8.3.1 Supplier performance is measured and monitored to ensure that acceptable items and services continue to be supplied.

[WHC-SP-1 131]

3.8.3.2 Reliability of supplier performance is verified through audits, inspections, or surveillance of supplier facilities, processes, methods, or records relevant to the part, material, or service provided.

[WHC-SP-1131]

\subsection{INSPECTION AND ACCEPTANCE TESTING}

\subsubsection{Performance Criteria}

Inspection and testing of specified items, services, and processes are conducted using established acceptance and performance criteria.

[10 CFR 830, Part 120(c)(2)(iv); WHC-SP-1131]

\section{Criteria}

3.9.1.1 Work processes that specify when and what type of inspection are performed have been established and implemented by using a graded approach. Administrative controls and/or status indicators, used to prevent inadvertent bypassing of required inspections and to prevent inadvertent operation of the item or process, are established and implemented. [WHC-SP-1131]

3.9.1.2 Inspections are implemented by or for the organization performing the work to be inspected. The level of inspection and degree of independence of inspection persomel are based upon risk and complexity. [WHC-SP-1131]

3.9.1.3 Provisions to ensure inspection planning is properly accomplished are established. Work planning documents identify item characteristics and processes to be inspected, inspection techniques, acceptance criteria, hold points, and the organization responsible for performing the inspection. [WHC-SP-1131]

3.9.1.4 Testing processes to demonstrate that items and/or processes perform as intended are established and implemented.

[WHC-SP-1131]

3.9.1.5 Item and process test requirements and acceptance criteria are provided by or approved by the organization responsible for design, unless otherwise designated. Administrative controls and/or status indicators are used to preclude inadvertent bypassing of required tests or operation of the item or process. [WHC-SP-1131] 
3.9.1.6 Test procedures are developed, approved, and controlled. As a minimum, the procedure includes instructions and prerequisites to perform the test, completeness and accuracy of data, use of test equipment, acceptance criteria, required inspection hold points, and test article configuration. [WHC-SP-1131]

3.9.1.7 When acceptance testing is performed by the organization performing the work, personnel within the organization do not test their own work. [WHC-SP-1131]

3.9.1.8 When inspection or test acceptance criteria are not met, deficiencies are resolved. [WHCSP-1131]

3.9.1.9 Inspection personnel independence is established and maintained per established procedures. [WHC-SP-1131]

\subsubsection{Performance Objective}

Equipment used for inspections and tests is calibrated and maintained.

[10 CFR 830, Part 120(c)(2)(iv); WHC-SP-1131]

\section{Criteria}

3.9.2.1 Work processes to control calibration, maintenance, accountability, and use of equipment to control any process parameter that influences the quality of an iten's characteristics or that is used for in-process or final acceptance of an itcm are established and implenented.

[WHC-SP-1131]

3.9.2.2 The types of equipment to be used are defined. [WHC-SP-1131]

3.9.2.3 Measuring and test equipment is calibrated at specified intervals, immediately before and after use or on the basis of the item's required accuracy, intended use, stability characteristics, or other condition affecting its performance. [WHC-SP-1131]

3.9.2.4 Measuring and test equipment is controlled to indicate its calibration status and to ensure traceability to calibration test data.

[WHC-SP-1131]

3.9.2.5 Measuring and test equipment is calibrated against standards having an accuracy to ensure that equipment being calibrated is within required tolerances. If nationally recognized standards exist, calibration standards are traceable to such standards.

\section{[WHC-SP-1131]}

3.9.2.6 Measuring and test equipment that is out-of-calibration or out-of-tolerance is tagged or segregated and not used until it is successfully recalibrated. The acceptability of items or processes measured, inspected, or tested with an out-of-tolerance device is determined. [WHC-SP-1131] 


\subsection{MANAGEMENT ASSESSMENT}

\subsubsection{Performance Objective}

Managers assess their management processes.

[10 CFR 830, Part 120(c)(3)(i); WHC-SP-1131]

\section{Criteria}

3.10.1.1 Assessment practices have been established to identify program weakness, including response to employee concerns.

[WHC-SP-1131]

3.10.1.2 Management is presence in the field and is involved in assessing facility activities, with subsequent follow-up action. [WHC-SP-1131]

3.10.1.3 Goals and performance indicators are used to measure and improve performance.

[WHC-SP-1131]

\subsubsection{Performance Objective}

Problems that hinder the organization from achieving its objectives are identified and corrected. [10 CFR 830, Part 120(c)(3)(i)]

\section{Criteria}

3.10.2.1 QA and other oversight organization findings are being used as a management tool.

3.10.2.2 All open items resulting from program audits/assessments are being tracked, and closure plans are in place.

3.10.2.3 A program of management assessment is established to measure operational performance and to determine root causes of Unusual Occurrences (UOs).

3.10.2.4 Evidence of effective communication is established at all organizational interfaces, including matrixed.

\subsection{INDEPENDENT ASSESSMENT}

\subsubsection{Performance Objective}

Planned and periodic independent assessments are conducted to measure item quality and process effectiveness and to promote improvement.

[10 CFR 830, Part 120 (c)(3)(ii); WHC-SP-1131] 


\section{Criteria}

3.11.1.1 Independent oversight assessments have been planned and are completed as scheduled.

\subsubsection{Performance Objective}

The organization performing independent assessments has authority and freedom from the line organization to carry out its responsibilities.

[10 CFR 830, Part 120 (c)(3)(ii); WHC-SP-1131]

\section{Criteria}

3.11.2.1 Understandings have been established with internal/external independent organizations covering interface coordination and responsibilities.

3.1 1.2.2 Persons with authority to carry out QA functions are identified and a description of how these actions are carried out are provided in QA manuals or other appropriate documentation.

\subsection{PREREQUISITES}

None.

\subsection{SPECIAL APPROVALS}

None.

\subsection{REFERENCES}

The following documents were used to create this QA section:

10 CFR 830, Part 120, Nuclear Safety Management, April 1994.

WHC-CM-6-1, Standard Engineering Practices, 11 January 1988.

WHC-SD-MP-SRID-001, Tank Waste Remediation System Standards and Requirements Identification Document, 30 January 1996.

WHC-SP-1131, "Rule Implementation Plan for 10CFR 830, Part 120," 1 March 1995. 


\section{CONFIGURATION MANAGEMENT}

\subsection{PURPOSE}

This section provides configuration management (CM) functional area elements, performance objectives, and criteria intended for use by Tank Waste Remediation Systems (TWRS) operational activities to ensure compliance with applicable Federal Regulations and Department of Energy (DOE) Orders as defined in the Tank Waste Remediation Systems (TWRS) Standards and Requirements Identification Document (S/RID) and the Configuration Management Program.

\subsection{SCOPE}

The performance objectives and criteria apply to all TWRS facilities and organizations subject to evaluation under the TWRS Management Assessment Program.

\subsection{FUNCTIONAL AREA ELEMENTS}

The following are the $\mathrm{CM}$ functional area elements. Each functional area element has performance objectives and criteria. The criteria are used to assess the objectives.

\subsection{MANAGEMENT AND ADMINISTRATION}

\subsubsection{Performance Objective}

Work is performed to established CM technical standards and administrative controls using approved instructions, procedures, or other appropriate means.

[10 CFR 830, Part 120(c)(2)(I)]

\section{Criteria}

3.1.1.1 Items are identified and controlled to ensure their proper use.

[10 CFR 830, Part 120(c)(2)(I)]

3.1.1.2 Items are maintained to prevent their damage, loss, or deterioration.

[10 CFR 830, Part 120(c)(2)(I)] 
3.1.1.3 Equipment used for process monitoring or data collection is calibrated and maintained. [10 CFR 830, Part 120(c)(2)(I)]

3.1.1.4 The CM program provides for the review and approval of vendor procedures prior to the commencement of work or imposes the use of facility procedures in all work performed at the facility. [DOE-STD-1073-93 Chapter 2, Section 2.1.2, Paragraph 6, Sentences 2 through 4]

3.1.1.5 Action plans identify how $\mathrm{CM}$ development activities and results are communicated throughout the organization.

[DOE-STD-1073- 93 Chapter 2, Section 2.1.4.1, Paragraph 3, Sentences 1 thru 3]

3.1.1.6 Configuration management governing procedures support the action plan. The CM program plan identifies the CM governing procedures. [DOE-STD-1073-93 Chapter 2, Section 2.1.4.2, Paragraph 1, Sentences 1 and 3 ]

3.1.1.7 Appropriate implementing procedures are prepared for each $\mathrm{CM}$ program function. Implementing procedures are developed for individual program elements as needed.

[DOE-STD-1073-93 Chapter 2, Section 2.1.4.3, Paragraph 1]

3.1.1.8 The CM equipment database has been established to cross-reference the CM program structures, systems, and components (SSCs) with their design requirements, design basis, and associated documents.

[DOE-STD-1073-93 Chapter 2, Section 2.2.1.5, Paragraph 1]

3.1.1.9

The graded approach is used in the assignment of grades and the subsequent application of those grades in determining the degree of implementation.

[DOE-STD-1073-93 Chapter 1, Section 1.4.2.5, Paragraph 1]

\subsubsection{Performance Objective}

A system of assessing compliance with the requirements of the Configuration Management Program has been established and is being implemented.

\section{Criteria}

3.1.2.1 Initial CM assessments have been conducted on safety systems associated with the facility's principal hazard and on change control 


\section{[DOE-STD-1073-93 Chapter 1, Section 1.3.5.1, Paragraph a, Sentences 1 through 5]}

3.1.2.2 After the CM program upgrades are implemented, an assessment is performed for each CM program element to determine if the element identifies weaknesses and is effective in accomplishing the CM functions. [DOE-STD-1073-93 Chapter 1, Section 1.3.5.1, Paragraph b]

3.1.2.3 A combination of vertical and horizontal slice assessments are performed periodically to measure the overall $\mathrm{CM}$ program effectiveness and to determine if $\mathrm{CM}$ controls are adequate and appropriate. The results of these assessments are used to establish the basis for revisions to the $\mathrm{CM}$ program plan (either increasing or decreasing controls).

\section{[DOE-STD-1073-93 Chapter 1, Section 1.3.5.1, Paragraph c]}

3.1.2.4 Physical configuration assessments, or walkdowns, are performed for representative sample SSCs to determine the degree of agreement between the physical configuration and the configuration depicted in the facility documentation. Physical walkdowns are included as part of the programmatic assessments conducted during the initial assessments, post-implementation assessments, and periodic effectiveness assessments. [DOE-STD-1073-93 Chapter 1, Section 1.3.5.2]

3.1.2.5 Performance monitoring program has been implemented to routinely monitor, trend, and analyze performance data for SSCs within the CM Program. The Monitoring Program responsibility includes the establishment of performance goals and acceptance criteria consistent with the associated SSC design requirements. [DOE-STD-1073-93 Chapter 2, Section 2.5.3.3, Paragraph 3, Sentences 1 and 4]

3.1.2.6 SSCs within the CM program are tested after modification (and before being turned over for service) to determine if they are capable of meeting design requirements (that is, the post-implementation acceptance criteria). [DOE-STD-1073-93 Chapter 1, Section 1.3.5.4]

3.1.2.7 For each document type in the CM Program, the adequacy of the existing document control process has been evaluated against each of the basic document control functions. A survey of existing document control processes has been conducted to identify the process that either identifies, stores, controls, tracks, or retrieves the included document types. [DOE-STD-1073-93 Chapter 2, Section 2.3.1.2, Paragraph 1, Sentences 1 and 2] 


\subsubsection{Performance Objective}

Documents have been prepared, reviewed, approved, issued, used, and revised to prescribe processes, specify requirements, or establish design. Records have been specified, prepared, reviewed, approved, and maintained. [10 CFR 830, Part $120($ c)(1)(iv)]

\section{Criteria}

3.1.3.1 Databases used to identify, store, control, and retrieve information that is important to configuration management have been established. The policy and criteria for their use are defined. [DOE-STD-1073-93 Chapter 1, Section 1.3.1.5]

3.1.3.2 Special controls have been instituted to ensure that any database used for $\mathrm{CM}$ purposes is protected to prevent inadvertent or unauthorized changes of the data. [DOE-STD-1073-93 Chapter 2, Section 2.1.3, Paragraph 7, Sentence 21

3.1.3.3 The document database has the capability to identify documents within the CM Program on the basis of their relationship to particular SSCs (such as, a particular pump), types of SSCs (such as, motor-operated valves), technical topics (such as, fire protection), and other relational data (such as, the specific vendor) necessary for the identification of documents. This information is integrated with other appropriate information (such as, information regarding pending changes) for document control and tracking. [DOE-STD-1073-93 Chapter 2, Section 2.3.2.4, Paragraph 3]

3.1.3.4 Availability and retrieval times are based on the needs of document owners and users. Periodic monitoring is done to ensure that document retrieval requirements continue to be adequate. [DOE-STD-1073-93 Chapter 2, Section 2.3.2.4, Paragraph 4, Sentences 1 and 6]

\subsection{TECHNICAL BASELINE}

\subsubsection{Performance Objective}

Design requirements are incorporated into an equipment database that correlates each SSC with the SSC grade, the design requirements, technical topics involved, and associated documentation. [DOE-STD-1073-93 Chapter 1, Section 1.3.2.1, Paragraph c] 


\section{Criteria}

3.2.1.1 Equipment databases specify equipment classifications, contain or reference equipment design requirements, and cross-reference supporting $\mathrm{CM}$ information. These databases provide current information on facility SSCs and associated documents within the CM Program, with emphasis on design. [DOE-STD-1073-93 Chapter 2, Section 2.1.3, Paragraph 8]

3.1.3.2 The design requirements for new facilities and modifications to existing facilities have been established, categorized, and documented in a form amenable to review and for inclusion in the equipment database. [DOE-STD-1073-93 Chapter 1, Section 1.3.2.1, Paragraph d]

3.2.1.3 The boundaries for each system and process have been established to contain the components necessary to satisfy the design requirements for that system or process. [DOE-STD-1073-93 Chapter 1, Section 1.3.2.2]

3.2.1.4 Each SSC has been assigned a grade based on the most important type of design requirements applicable to it. The SSC grade is used as the basis for the degree of control on all activities associated with the SSC.

[DOE-STD-1073-93 Chapter 1, Section 1.3.2.3]

3.2.1.5 On the basis of the equipment scope, criteria, and the assignment of SSC grades, the specific SSCs included in the CM Program have been identified. [DOE-STD-1073-93 Chapter 1, Section 1.3.2.4]

\subsubsection{Performance Objective}

The design basis for new or modified design requirements is established and documented. [DOE-STD-1073-93 Chapter 1, Section 1.3.2.5, Paragraph b]

\section{Criteria}

3.2.2.1 Procedures are in place that adequately establish the associated design requirements and their design basis, and documents them in a form suitable for use in the CM Program. [DOE-STD-1073-93 Chapter 2, Section 2.2.1, Paragraph 2]

3.2.2.2 The design requirements are categorized (such as, safety, environmental, mission, or other) and accurate as-built drawings are provided.

[DOE-STD-1073-93 Chapter 2, Section 2.2.1.2, Paragraph 2] 
3.2.2.3 Processes and procedures are established to maintain the design requirements and the design basis so that they are complete and accurate.

[DOE-STD-1073-93 Chapter 2, Section 2.2.1, Paragraph 2]

\subsubsection{Performance Objective}

A program plan, an action plan, and implementing procedures have been developed for the Design Reconstitution (DR) adjunct program. [DOE-STD-1073-93 Chapter 1, Section 1.3.6.1]

\section{Criteria}

3.2.3.1 The DR program plan is based on the initial assessments and the graded approach. The DR adjunct program is implemented in stages to provide a timely initial set of design information and more information as it becomes available. [DOE-STD-1073-93 Chapter 1, Section 1.3.6.1]

3.2.3.2 Technical review and identification of design information from each source document includes both design requirements and design basis information. Extracted design information is identified as to the applicable facility SSC, type of SSC, technical topic area, and whether it is a design requirement or design basis. [DOE-STD-1073-93 Chapter 1, Section 1.3.6.2, Paragraph b]

3.2.3.3 Extracted design information is verified by a second party to ensure that the design information was extracted completely and accurately from the source documents. [DOE-STD-1073-93 Chapter 1, Section 1.3.6.3]

3.2.3.4 Extracted design requirements are entered into the $\mathrm{CM}$ equipment database promptly after verification and technical validation. [DOE-STD-1073-93 Chapter 1, Section 1.3.6.6, Paragraph 1]

3.2.3.5 Design information summaries are field validated to ensure that design requirements are properly reflected in the physical configuration and in the associated facility documentation. [DOE-STD-1073-93 Chapter 1, Section 1.3.6.3]

3.2.3.6 DR Program open items are dispositioned by a formal resolution process and are tracked to completion and closeout, which includes documentation of their resolution. [DOE-STD-1073-93 Chapter 1, Section 1.3.6.4, Sentence 2] 
3.2.3.7 Safety-significant open items (that is, discrepancies) are promptly addressed by existing programs for determining operability and reportability and are resolved by those programs. [DOE-STD-1073-93 Chapter 1, Section 1.3.6.4, Sentence 3]

3.2.3.8 Missing design information is evaluated to determine which part needs to be regenerated. Missing design information that is critical, including that necessary to support the facility accident analysis and Technical Safety Requirements (TSRs), is regenerated in order of priority. [DOE-STD-1073-93 Chapter 1, Section 1.3.6.5]

\subsection{CHANGE CONTROL}

\subsubsection{Performance Objective}

Design changes, including field changes and nonconforming items dispositioned use-as-is or repair, are controlled by measures commensurate with those applied to the original design. Temporary modifications receive the same levels of control as the designs of permanent modifications. [DOE-GUIDE-10 CFR 830 Section 6.6]

\section{Criteria}

3.3.1.1 Formal control measures are provided for any change process that affects either (1) the physical configuration, as defined by the SSCs included in the CM Program or (2) the facility documents included in the CM Program. [DOE-STD-1073-93 Chapter 2, Section 2.4.1.2, Paragraph 1]

3.3.1.2 All mechanisms that can lead to temporary or permanent changes in the design requirements, facility configuration, or facility documentation within the CM Program are identified. Change mechanisms are evaluated to determine which are adequate as is, and which need to be improved, consolidated, or terminated. The resulting change mechanisms are integrated with the CM Program. [DOE-STD-1073-93 Chapter 1,

\section{Section 1.3.4.1]}

3.3.1.3 Each specific proposed change is reviewed to determine if it is within the bounds of the design requirements. Changes to the design requirements are evaluated and approved by design authority prior to implementation. [DOE-STD-1073-93 Chapter 1, Section 1.3.4.2]

3.3.1.4 Before implementation, management reviews proposed changes (including those that do not involve a change to design requirements) to verify that 
the technical reviews have been performed adequately, that the change package is complete and ready for implementation, and that any external approvals that are necessary prior to implementation have been obtained. Management takes approval action on the basis of these reviews.

[DOE-STD-1073-93 Chapter 1, Section 1.3.4.3]

3.3.1.5 Each change is implemented in accordance with its approved change package. The change process includes mechanisms for field change requests, and technical reviews and approvals of field changes are commensurate with those of the original change package. The change process generates accurate as-built information. After the physical implementation of changes, post-modification testing is conducted. [DOE-STD-1073-93 Chapter 1, Section 1.3.4.4]

3.3.1.6 Each change is documented and that documentation includes a description of the change, as well as an account of the technical reviews, management approvals, as-built information, and post-modification test results. Documents included in the CM Program that are affected by a change (either directly or indirectly) are revised. [DOE-STD-1073-93 Chapter 1, Section 1.3.4.5]

3.3.1.7 Mechanisms for temporary physical changes and temporary document changes are identified for formal change control. [DOE-STD-1073-93 Chapter 2, Section 2.4.1.1, Paragraph 2, Sentence 4]

\subsection{PREREQUISITES}

None.

\subsection{SPECIAL APPROVALS}

None.

\subsection{REFERENCES}

The following documents were used to create this $\mathrm{CM}$ section:

10 CFR 830, Nuclear Safety Management, 5 April 1994.

DOE-STD-1073-93, Guide for Operational Configuration Management Program, Parts I and II, November 1993. 
DOE Implementation Guide for 10CFR 830.120, August 1994.

WHC-SD-MP-SRID-001, Tank Waste Remediation System Standards and Requirements Identification Document, 30 January 1996. 


\section{TRAINING AND QUALIFICATION}

\subsection{PURPOSE}

This section provides training and qualification functional area elements, performance objectives, and criteria intended for use by Tank Waste Remediation System (TWRS) operational activities to ensure compliance with applicable Federal Regulations and Department of Energy (DOE) Orders as defined in the Tank Waste Remediation System (TWRS) Standards and Requirements Identification Document (S/RID) and the Training and Qualification Program.

\subsection{SCOPE}

The performance objectives and criteria (PO\&C) apply to all TWRS facilities and organizations subject to evaluation under the TWRS Management Assessment Program.

\subsection{FUNCTIONAL AREA ELEMENTS}

The following are the training and qualification functional area elements. Each functional area element has performance objectives and subsequent criteria. The criteria are used to assess the objectives.

\subsection{MANAGEMENT AND ADMINISTRATION}

\subsubsection{Performance Objective}

The facility provides a program of classroom instruction and/or on-the-job training (OJT) for facility personnel. This program teaches personnel to perform their duties in order to ensure the facility's compliance with dangerous waste management procedures (including contingency plan implementation) relevant to the positions in which they are employed. Additionally, the program ensures that facility personnel are able to respond effectively to emergencies; it includes those elements set forth in a training plan.

\section{Criteria}

3.1 .1 .1

The training program is directed by a person knowledgeable in dangerous waste management procedures and includes training 
relevant to the positions in which the facility personnel are employed. [WAC-173-303, Section 330(1)]

3.1.1.2

3.1.1.3

3.1.1.4

3.1.1.5

A written training plan has been developed. [WAC-173-303, Section 330(2)]

The training program is required to be completed by the facility personnel. Employees are supervised until they complete the training program. [WAC-173-303, Section 330(1)]

The training program familiarizes facility personnel with emergency equipment and systems, and emergency procedures.

[WAC-173-303, Section 330(1)]

Facility personnel participate in an annual review of the training provided in the training program. [WAC-173-303, Section 330(1)]

\subsubsection{Performance Objective}

An organization responsible for the training of operating organization personnel has been established. This organization is accountable for providing facility line management with the support necessary to ensure that personnel in the operating organization are qualified to safely and effectively meet job requirements.

\section{Criteria}

\subsubsection{1}

3.1.2.2

3.1.2.3

3.1.2.4
The responsibilities, qualifications, and authority of training organization personnel are documented. Managerial responsibilities and authority are clearly defined. [DOE 5480.20A Chapter I, Section 2]

Training personnel meet the specified education and experience requirements, as well as any special requirements. [DOE $5480.20 \mathrm{~A}$ Chapter IV, Sections 2.g.(1) and (2)]

A process has been established for selection and assignment of operating organization personnel. [DOE 5480.20A Chapter I, Section 4.a]

Subcontractor personnel meet the qualification requirements for the job functions that they perform. [DOE 5480.20A Chapter I, Section 3] 
3.1.2.5

The operating organization ensures that subcontractor and temporary personnel who perform specialized activities (such as, radiation protection, maintenance, in-service inspection, radiography, and welding) are qualified to perform their assigned tasks. [DOE 5480.20A Chapter I, Section 3]

\subsection{ADMINISTRATION OF TRAINING}

\subsubsection{Performance Objective}

Personnel are trained and qualified to ensure that they can perform their assigned work. Personnel are provided continuing training to ensure that job proficiency is maintained. [10 CFR 830, Part 120(c)(1)(ii)]

\section{Criteria}

3.2.1.1

3.2.1.2

3.2.1.3

3.2 .1 .4

3.2.1.5
The training and qualification program for nuclear facilities has been developed on the basis of the hazards involved and risk associated with the operation of the facility or activity. [DOE 5480.20A Chapter I, Section 7.a.(2)]

A Training Implementation Matrix that defines and describes selection, qualification, certification, and training requirements for facility personnel has been prepared and approved. [DOE 5480.20A Chapter I, Section 7.a.(1) Introduction]

Training to support qualification and certification programs is based on a systematic approach to training. A graded approach is used to establish the systematic approach to training for operations personnel, maintenance personnel, technicians, and the technical staff. [DOE 5480.20A Chapter I, Section 7 Introduction, Sentences 1 and 2]

Each operable nuclear facility has established an initial training program for operating organization personnel to develop or enhance their knowledge and skills to perform job assignments. [DOE 5480.20A Chapter I, Section 7.c, Sentences 1-3]

Personnel who are in-training do not independently make decisions or take actions that could affect facility safety, nor are they placed in such positions. They may independently perform specific tasks 
or job assignments for which they are qualified. [DOE 5480.20A Chapter I, Section 7.c, Sentences 4 and 5]

3.2.1.6

Instructors-in-training are monitored by a qualified instructor. [DOE/EH0256T Chapter 6, Part 1, Article 616.3]

3.2.1.7

Subject matter experts (SMEs) without instructor qualification may provide training in their areas of expertise. Routinely, these SMEs are trained as instructors when this occurs routinely.

[DOE/EH0256T Chapter 6, Part 1, Article 616.4]

3.2.1.8

Periodic systematic evaluations of training and qualification programs are performed. [DOE 5480.20A Preamble, Attachment 1]

\subsubsection{Performance Objective}

Training design, development, and implementation are based upon learning objectives. [DOE 5480.20A Chapter I, Section 7.b.(3)]

\section{Criteria}

3.2 .2 .1

Initial and continuing training programs have been established to ensure that operating organization personnel are qualified to perform job requirements. This is achieved by using a systematic approach to training. [DOE 5480.20A Chapter I, Section 7.b Introduction, Sentences 1 and 2]

3.2 .2 .2

A systematic analysis of the jobs has been performed. The analysis includes both normal and emergency duties. Program goals are established and the scope of training program content is defined. A graded approach is used when analyzing jobs. [DOE 5480.20A Chapter I, Section 7.b.(1)]

3.2.2.3 Learning objectives define the content of the training program. [DOE 5480.20A Chapter I, Section 7.b.(2)]

3.2.2.4

Training programs consist of a combination of classroom-type and OJT, and include simulator and laboratory training as it applies to the position. [DOE $5480.20 \mathrm{~A}$ Chapter I, Section 7.a Introduction] 
3.2.2.5

Personnel have been trained as a team, stressing team communications and interaction, where job functions require team solutions and activities. [DOE 5480.20A Chapter I, Section 7.a.(3), Sentences 2 and 3]

\subsubsection{Performance Objective}

The conduct and effectiveness of training is routinely evaluated.

\section{Criteria}

3.2.3.1 Evaluations of training and qualification programs are conducted using DOE-STD-1070-94. [DOE 5480.20A Preamble, Section 6.b]

3.2.3.2 Trainee mastery of the learning objectives is evaluated during training. [DOE 5480.20A Chapter I, Section 7.b.(4)]

3.2.3.3 Qualification and certification programs are reviewed by facility management. These programs are kept current to reflect changes to the facility, Safety Analysis Reports (SARs), Technical Safety Requirements (TSRs), procedures, regulations, and applicable industry operating experience. [DOE 5480.20A Chapter I, Section 7.a.(3), Sentence 1]

3.2.3.4 Evaluation and revision of the training is based on the performance evaluation of trained personnel in the job setting. [DOE 5480.20A Chapter I, Section 7.b.(5)]

3.2.3.5 Training and retraining schedules are maintained to keep all personnel adequately qualified and/or certified. [DOE/EH0135 TC.1.15]

\subsubsection{Performance Objective}

Procedures and processes that provide for the testing, qualification, and certification of personnel are in use.

\section{Criteria}

\section{2 .4 .1}

Written procedures that establish requirements for examinations are implemented. At a minimum, these procedures address examination/ evaluation development, approval, security, administration, remediation, and maintenance of examination question banks. [DOE 5480.20A Chapter I, Section 8.a] 
3.2.4.2

Qualification requirements for personnel in operating organizations are defined in each functional level. The relative importance of managerial and technical competence has been considered by management in establishing these requirements. [DOE 5480.20A

\section{Chapter I, Section 5.a]}

3.2.4.3 Comprehensive written and oral examinations and operational evaluations are administered to demonstrate that certified operator and certified supervisor candidates possess the required knowledge and skills. Comprehensive written examinations and individual performance demonstrations are administered to ascertain the qualification of other operator and supervisor candidates. The examinations include duties that are important to engineered safety features as identified in the SAR. [DOE 5480.20A Chapter I, Section 8 Introduction]

3.2.4.4 Qualification is granted only after ensuring that all requirements (including training and examinations as required) and other specified requirements (such as, medical examination) have been satisfactorily completed

\section{[DOE 5480.20A Chapter I, Section 5.e]}

3.2.4.5 Continuing training and professional development programs are established to meet the needs of the individual and the position. [DOE $5480.20 \mathrm{~A}$

\section{Chapter I, paragraph 7.d.(1)]}

3.2.4.6 Participation in the continuing training program is required following initial qualification to the extent that it applies to the position. [DOE 5480.20A Chapter I, Section 5.d, Sentences 5 and 7]

3.2.4.7 Operators and their immediate supervisors are not allowed to continue in qualified or certified positions if they have not completed all of the requalification or recertification program elements within the 2 year continuing training cycle. [DOE $5480.20 \mathrm{~A}$ Chapter I, Section 10 Introduction]

\subsubsection{Performance Objective}

Provisions for extension of the time requirements for and exceptions and alterations to training and qualification requirements have been established.

\section{Criteria}

3.2.5.1 Administrative procedures that describe the methods used to administer and document exceptions to initial training program requirements are 
established. The procedures for granting exceptions have been approved by the Operations Office Manager. [DOE 5480.20A Chapter I, Section 11.a]

3.2.5.2 Exception from training is based on a review of previous training records (that is, transcripts), personal interviews, and examinations that are based on the objectives stated for the training program. [DOE 5480.20A

\section{Chapter I, Section 11.b]}

Any exceptions from qualification or certification requirements are approved by management after approval of the exception procedure by the Operations Office Manager. [DOE 5480.20A Chapter I, Section 11.c]

3.2.5.4 When challenge examinations are administered, they adequately test the learning objective(s) that are stated in the training program.

[DOE 5480.20A Chapter I, Section 11.d]

An administrative procedure for granting extensions to qualification or certification has been established. [DOE 5480.20A Chapter I, Section 12 Introduction and Section 12.a]

Extensions of certification of operators and supervisors are approved only by the Operations Office Manager. Extensions of qualification of operators and supervisors may be approved by facility management. [DOE 5480.20A Chapter I, Section 12.b]

3.2.5.7 Persons who do not possess the formal educational requirements specified may be evaluated on a case-by-case basis and, where other factors ensure their abilities to fulfill the duties of a specific position, they are approved and documented. [DOE 5480.20A Chapter I, Section 13.a]

\subsection{TRAINING CATEGORIES AND SUBJECTS}

\subsubsection{Performance Objective}

Training programs for certain categories of personnel and for certain subjects have been developed and are established as required. 


\section{Criteria}

3.3.1.1 A formal training program is established for the instruction and qualification of all personnel (i.e., primary and alternate) comprising the facility emergency response organization to include initial training and annual retraining for both on-site and off-site incidents, including transportation incidents. [DOE 5500.3A Section 11.c.(11)(b)]

3.3.1.2 All persons employed either full- or part-time in DOE nuclear facilities receive General Employee Training (GET) commensurate with their job duties. [DOE 5480.20A Chapter I, Section 7.e Introduction]

3.3.1.3 Employees are provided information and training on hazardous chemicals in their work area at the time of their initial assignment and whenever a new hazard is introduced into their work area. [29 CFR 1910, Part 1200(h)]

3.3.1.4 Visitors, contracted personnel, and temporary personnel are under continuous escort while at the facility unless they have been trained in appropriate areas to the extent necessary to ensure safe execution of their duties. [DOE 5480.20A Chapter I, Section 7.e.(2)]

3.3.1.5 Qualified persons permitted to work on or near exposed energized electrical parts have been trained in and are familiar with the required electrical safety requirements. [29 CFR 1910, Part 332(b)(3) and 29 CFR 1910, Part 333(c)(2)]

\subsubsection{Performance Objective}

All technicians and maintenance personnel are qualified to perform the tasks associated with their specialty or work under the direct supervision of personnel qualified to perform the activity or task. [DOE 5480.20A Chapter I, Section 7.g.(1)]

\section{Criteria}

3.3.2.1 Maintenance personnel are trained in maintenance and repair of mechanical and electrical equipment for which they have maintenance and repair responsibilities. [DOE $5480.20 \mathrm{~A}$ Chapter IV, Section 2.e]

3.3.2.2 Technician and maintenance personnel qualifications include demonstrated performance capabilities (performance demonstrations) to ascertain their ability to adequately perform assigned tasks. Written examinations are also 
administered to personnel in these positions. [DOE 5480.20A Chapter I, Section 5.c]

3.3.2.3 In addition to training in technical maintenance functions, a select group or team has been schooled in principles and methods of root-cause analysis. [DOE 4330.4B Chapter II, Section 3.3.6, Sentence 1]

3.3.2.4 Training on engineered safety features as identified in the facility SAR has been conducted for personnel who perform work on those systems/ components. [DOE 5480.20A Chapter I, Section 7.g.(2)]

3.3.2.5 Technicians, such as those principally involved in calibration, inspection, troubleshooting, testing, maintenance, and radiation protection activities at the facility, have been satisfactorily trained for their responsibilities. [DOE 5480.20A Chapter IV, Section 2.d]

\subsubsection{Performance Objective}

Additional training required for managers and supervisors is defined.

\section{Criteria}

3.3.3.1 Training material applicable to a management or supervisory position is included in the training programs for these personnel, as appropriate to their job responsibilities. [DOE 5480.20A Chapter I, Section 7.I Introduction]

3.3.3.2 Prior to assuming the duties of the assigned position, persons at the manager or supervisor level meet the specified education and experience requirements, as well as any special requirements. [DOE 5480.20A Chapter IV, Section 2.a and 2.b]

3.3.3.3 Managers and supervisors receive the required supervisory skills and management training. [DOE 5480.20A Chapter I, Section 7.I.(1) and 7.I.(2)]

3.3.3.4 The supervisor training program includes the categories and OJT specified for operators to the extent to which they are applicable. [DOE 5480.20A Chapter IV, Section 4.c]

3.3.3.5 Line managers who manage, supervise, or provide oversight of radiological control programs are trained in radiological control principles. Incumbents 
participate in continuing training. [DOE/EH0256T Chapter 6, Part 5, Article 651]

\subsubsection{Performance Objective}

Additional specific training requirements pertain to operators is defined.

\section{Criteria}

3.3.4.1 The depth and scope of training and qualification programs for operating organization personnel at nonreactor nuclear facilities is commensurate with the hazard level and complexity of the operations. [DOE 5480.20A Chapter IV, Section 4 Introduction]

3.3.4.2 Operator training sufficiently covesr areas that are fundamental to the candidate's assigned tasks to ensure that personnel are capable of safely performing their job duties. [DOE 5480.20A Chapter IV, Section 4.a]

3.3.4.3 Operators have the minimum educational and/or experience required. [DOE 5480.20A Chapter IV, Section 2.c]

3.3.4.5 Operators are trained in the appropriate techniques for verifying the positions of all facility components. [DOE $\mathbf{5 4 8 0 . 1 9}$ Chapter X, Section C.3, Sentence 1 and 2]

\subsubsection{Performance Objective}

Continuing training programs improve the knowledge and skills of operating organization personnel.

\section{Criteria}

3.3.5.1 Continuing training programs are established to maintain and enhance the knowledge and skills of operating organization personnel who perform functions associated with engineered safety features as identified in the facility SAR. [DOE 5480.20A Chapter I, Section 7.d Introduction]

3.3.5.2 Continuing training programs are structured commensurate with specific position needs, and are administered on a cycle not to exceed 2 years. [DOE 5480.20A Chapter I, Section 7.d.(1)] 
3.3.5.3 Periodic examinations (written, oral, operational evaluations, performance demonstrations, as applicable to the position) are administered and documented throughout the cycle on material included in the operator (operators and their immediate supervisors) training programs. Periodic examinations (written and/or performance demonstrations) of other members of the operating organization (that is, maintenance personnel, technicians, technical staff) are also appropriate in some areas during the continuing training program. [DOE 5480.20A Chapter I, Section 7.d.(2)]

\subsubsection{Performance Objective}

Additional training requirements for Technical Support Personnel are being met.

Criteria

3.3.6.1 Training organization personnel work with the line organization to identify and meet personnel and organization needs. Training organization personnel assist line organizations in determining training program content, developing training materials, scheduling training, and delivering training programs for the operating organization. [DOE 5480.20A Chapter IV, Section 2.g Introduction]

3.3.6.2 A list of specific technical staff positions that have a direct impact on employee, facility, or public safety has been developed. [DOE 5480.20A Chapter I, Section 7.h.(1)]

3.3.6.3 Training is provided to entry level technical staff personnel who provide technical support to the operating organization. This training includes facility specific training that includes facility organization and facility fundamentals. [DOE 5480.20A Chapter I, Section 7.h.(2)]

3.3.6.4 Personnel involved in surveillance, testing, analyzing facility data, planning modifications, program review, and technical problem resolution in their area of expertise have expertise in mechanical, electrical, instrumentation and control, chemistry, radiation protection, safety, or assessment. Additionally, these personnel meet the establish QA/independent ed education and experience requirements. [DOE 5480.20A Chapter IV, Section 2.f]

3.3.6.5 The Configuration Management (CM) Program includes training on CM concepts, terminology, definitions, and procedures. [DOE-STD-1073-93 Chapter 1, Section 1.1.1.6, Paragraph 1, Sentence 3] 
3.3.6.6 Radiological support personnel training includes applicable training on standardized core courses and job-specific topics and training to provide continued knowledge and improvement in skills. [DOE/EH0256 T Chapter 6, Part 5, Article 654.3]

3.3.6.7 Training program content for radiological control technicians (RCT) is in accordance with the requirements contained in 10 CFR 835, Occupational Radiation Protection and DOE/EH0256T, DOE Radiological Control Manual. [DOE 5480.20A Chapter I, Section 7.g.(3)]

3.3.6.8 A written practice for the control and administration of Nondestructive Testing (NDT) personnel training, examination, and certification has been established. [SNT-TC-1A, Sections 5.1 and 5.2]

\subsection{TRANNING RECORDS AND DOCUMENTATION}

\subsubsection{Performance Objective}

Training records are be maintained, as necessary, to demonstrate compliance with requirements. [10 CFR 835, Part 704(a)]

\section{Criteria}

3.4.1.1 Administrative procedures specify requirements for the maintenance of training, qualification, and certification records for operating organization personnel. [DOE 5480.20A Chapter I, Section 15 Introduction and TG-17]

3.4.1.2 The required instructional materials are maintained. [DOE/EH0256 T Chapter 7, Part 2, Article 725.5]

3.4.1.3 Training records of plant employees, radiation workers, and radiation safety personnel are retained to document the level of understanding and proficiency of personnel who work with radioactive materials. Certification of successful completion of training programs and performance records are also retained. [DOE 5480.11, Section 9.m(5)]

3.4.1.4 Qualification and certification of personnel are documented in an easily auditable format. The contents of individual record documentation meets the minimum requirements. [DOE 5480.20A Chapter I, Section 15.a] 
3.4.1.5 Historical record documents initial qualification or certification and other required applicable information that verifies the most recent qualification or certification is retained in individual records. Superseded information is handled in accordance with DOE records disposition requirements.

[DOE 5480.20A Chapter 1, Section 15.b and DOE 1324.2A]

\subsection{PREREQUISITES}

None.

\subsection{SPECLAL APPROVALS}

None.

\subsection{REFERENCES}

The following documents were used to create this $\mathrm{T} \& \mathrm{Q}$ section:

10 CFR 830, Nuclear Safety Management, 5 May 1994.

10 CFR 835, Occupational Radiation Protection, 13 December 1993.

29 CFR 1910, Occupational Safety and Health Standards, May 1994.

DOE 1324.2A, Records Disposition, 13 September 1988

DOE 4330.4B, Maintenance Management Program, 10 February 1994.

DOE 5480.11, Radiation Protection for Occupational Workers, Change 3, 17 June 1992.

DOE 5480.19, Conduct of Operations Requirements For DOE Facilities, Change 1, 18 May 1992.

DOE 5480.20A, Personnel Selection, Qualification, Training, and Staffing Requirements at DOE Reactor and Non-Reactor Nuclear Facilities, 15 November 1994.

DOE 5500.3A, Planning and Preparedness for Operational Emergencies, Change 1, 27 February 1992

DOE/EH0135, Performance Objectives and Criteria for Technical Safety Appraisals at Department of Energy Facilities and Sites, 28 June 1990. 
DOE/EH0256T, DOE Radiological Control Manual, April 1994.

DOE-STD-1070-94, DOE Standard For Evaluation of Nuclear Facility Training Programs, 1 June 1994.

DOE-STD-1073-93, DOE Standard Guide for Operational Configuration Management Program, Rev. 0, 17 January 1994.

SNT-TC-1A, American Society for Nondestructive Testing, August 1984.

WAC-173-303, Dangerous Waste Regulations, 1993.

WHC-SD-MP-SRID-001, Tank Waste Remediation System Standards and Requirements Identification Document, 30 January 1996. 


\section{EMERGENCY MANAGEMENT}

\subsection{PURPOSE}

This section provides emergency management functional area elements, performance objectives, and criteria intended for use by Tank Farm operational activities to ensure compliance with applicable State and Federal Regulations and Department of Energy (DOE) Orders as defined in the Tank Waste Remediation System (TWRS) Standards and Requirements Identification Document (S/RID) and the Emergency Management Program.

\subsection{SCOPE}

The performance objectives and criteria (PO\&C) apply to all Tank Farm facilities and organizations subject to evaluation under the TWRS Management Assessment Program

\subsection{FUNCTIONAL AREA ELEMENTS}

The following are the emergency management functional area elements. Each functional area element has performance objectives and subsequent criteria. The criteria are used to assess the objectives.

\subsection{MANAGEMENT AND ADMINISTRATION}

\subsubsection{Performance Objective}

Emergency Management (EM) programs have been established that consist of plans and procedures for response to Operational Emergencies involving or affecting TWRS facilities, including transportation. [DOE 5500.3A, Section 11.a]

\section{Criteria}

3.1.1.1 Provisions are in place for the continued administration of the Emergency Management Program. [DOE 5500.3A, Section 11.c.(13)(a)] 
3.1.1.2 An individual has been designated to administer the Emergency

Management Program for their facility. [DOE 5500.3A, Section 11.c.(13)(a)]

3.1.1.3 The Emergency Response Organization (ERO) has clearly specified authorities and responsibilities for emergency response and mitigation of an emergency, including the initial and ongoing response. [DOE 5500.3A, Section 11.c.(1)]

3.1.1.4 A current list of names, addresses, and phone numbers (office and home) of all persons qualified to act as the emergency coordinator is maintained.

[WAC-173-303, Section 350(3)(d)]

3.1.1.5 Copies of the complete building emergency response organization listing are issued, at a minimum, to appropriate facility locations and to Westinghouse Hanford Company (WHC) Emergency Preparedness.

[WHC-CM-4-43]

\subsection{EMERGENCY RESPONSE TRAINING}

\subsubsection{Performance Objective}

A training program, which is part of the safety and heatth program, has been developed and implemented for employees who are exposed to health hazards or hazardous substances at treatment, storage, and disposal (TSD) operations. The program is designed to enable the employees to perform their assigned duties and functions in a safe and healthful manner so as not to endanger themselves or other employees. [29 CFR 1910, Part $120(p)(7)(i)]$

\section{Criteria}

3.2.1.1 A formal training program is in place for the instruction and qualification of all personnel (i.e., primary and alternate) comprising the facility ERO to include initial training and annual retraining for both onsite and offsite incidents, including transportation incidents. [DOE 5500.3A, Section 11.c.(11)(b), Introduction]

3.2.1.2 Training for emergency response employees is completed before they are considered qualified to perform in real emergencies. [29 CFR 1910, Part 120(p)(8)(iii)(A)] 
3.2.1.3 The employer certifies that each covered employee has attended and successfully completed the required training, or certifies the employee's competency at least yearly. The method used to demonstrate competency for certification of training is recorded and maintained by the employer. [29 CFR 1910, Part 120(p)(8)(iii)(C)]

3.2.1.4 All training is systematic and performance based (i.e., based on an analysis of tasks to be pefformed during an emergency) and developed with performance objectives, emphasis on team training, and facility-specific emergency response scenarios. [DOE 5500.3A, Section 11.c.(11)(b)(1)]

3.2.1.5 Annual retraining includes training on weaknesses detected during drills and exercises and changes to plans, procedures, and lessons learned from emergencies at DOE and other industrial facilities. [DOE 5500.3A, Section 11.c.(11)(b)(2)]

\subsection{PLANNING DOCUMENTS}

\subsubsection{Performance Objective}

The Emergency Plan is in writing and covers those designated actions that TWRS management and employees must take to ensure employee safety from fire and other emergencies. [29 CFR 1910, Part 38(a)(1)]

\section{Criteria}

3.3.1.1 A hazards assessment has been prepared and maintained for each facility and is used for emergency planning purposes. [DOE 5500.3A, Section 11.b.(1)]

3.3.1.2 Each facility has developed and maintained an emergency plan and associated procedures to document their emergency management program. [DOE 5500.3A, Section 11.d.(1)]

3.3.1.3 The emergency plan and implementing procedures are controlled by distribution documents and are annually reviewed and updated. [DOE 5500.3A, Section 11.c.(13)(b)]

3.3.1.4 A copy of the contingency plan and all revisions to the plan are maintained at the facility. [WAC-173-303, Section 350(4)] 
3.3.1.5 The contingency plan is reviewed and immediately amended when necessary. [WAC-173-303, Section 350(5)]

\subsubsection{Performance Objective}

Procedures exist that describe how the emergency plan is implemented. [DOE 5500.3A, Section 11.d.(2)]

\section{Criteria}

3.3.2.1 Procedures are consistent and compatible with the emergency plan. [DOE 5500.3A, Section 11.d(2)]

3.3.2.2 Provisions are established to adequately assess the actual or potential onsite and offsite consequences of an emergency. [DOE 5500.3A, Section 11.c.(5)]

Provisions are established for specific predetermined actions to be taken in response to emergency conditions to protect onsite personnel and the public including provisions for determination of the area surrounding the specific facility actually affected by an operation emergency. [DOE 5500.3A, Section 11.c.(6)(e)]

3.3.2.4

The procedures identify, to the extent possible, all hazardous substances or conditions present and address, as appropriate, site analysis, use of engineering controls, maximum exposure limits, hazardous substance handling, and use of any new technologies. [29 CFR1910, Part 120(q) (3)(ii)]

\subsection{FACILITIES, EQUIPMENT, AND RESOURCES}

\subsubsection{Performance Objective}

Emergency facilities, equipment, and resources are available and maintained in a state of readiness to support emergency operations.

\section{Criteria}

\subsubsection{1}

Adequate equipment and supplies are available and operable for emergency response personnel to carry out their respective duties and responsibilities. [DOE 5500.3A, Section 11.c.(10)(d)] 
3.4.1.2

3.4.1.3

3.4.1.4
An employee alarm system provides warning for necessary emergency action (as called for in the emergency action plan), or for reaction time for safe escape of employees from the workplace or the immediate work area, or both. [29 CFR 1910, Part 165(b)(1)]

An up-to-date list of all required emergency equipment at the facility (such as fire extinguishing systems, spill control equipment, communications and alarm systems, and decontamination equipment) is maintained. The plan includes the location and a physical description of each item on the list and a brief outline of its capabilities. [WAC-173-303, Section 350(3)(e)]

All facility communications or alarm systems, fire protection equipment, spill control equipment, and decontamination equipment, where required, is tested and maintained as necessary to ensure its proper operation in time of emergency. [WAC-173-303, Section 340(1)]

\subsection{CLASSIFICATION, NOTIFICATION AND REPORTING}

\subsubsection{Performance Objective}

The proper identification, categorization, and notification of emergencies or other reportable occurrences to line management and the Occurrence Notifications Center (ONC) occurs. The ONC makes the required reports to HQ EOC. [DOE 5500.1B, Section 10.w(26)(a)1]

Criteria

3.5.1.1 Operational Emergencies are characterized as one of the Operational Emergency classes (e.g., Alert, Site Area Emergency, or General Emergency). Emergency Action Levels (EAL), the specific criteria used to recognize and categorize events, have been developed for the spectrum of potential Operational Emergencies identified by the hazards assessment. EALs form the basis for notification and participation of offsite organizations and for determining what and when protective measures will be implemented. [DOE 5500.3A, Section 11.c.(3)]

3.5.1.2 Occurrence reports to DOE regarding emergencies and/or accidents are prepared and submitted in accordance with Departmental requirements for occurrence reporting and processing. [10 CFR 835, Part 1301(e)] 
3.5.1.3

DOE and appropriate local authorities are notified that the facility is in compliance with the requirements associated with waste generated during the emergency before operations are resumed in the affected area(s) of the facility. [WAC-173-303, Section $360(2)(j)]$

\subsection{PERSONNEL PROTECTION}

\subsubsection{Performance Objective}

Personnel protection procedures control and minimize personnel exposure to any hazardous materials during abnormalities, ensure that exposures are accurately determined and recorded, and ensure proper medical support.

\section{Criteria}

3.6.1.1 Provisons and procedures are in place for facility evacuation. [WAC 173303, Section 350(3)(f)]

3.6.1.2 After determination of an emergency, all facility personnel are accounted for within a 30-minute timeframe (not to exceed 45 minutes), workers are sheltered within the timeframe and/or are evacuated. The ER program includes predetermined criteria, procedures, assembly areas, transportation methods, and routes.

3.6.1.3 Primary and alternate staging areas have been identified for the facility. [WHC-CM-4-43]

3.6.1.4 The risk of injury to those individuals involved in rescue and recovery operations are minimized. [10 CFR 835, Part 1302(a)]

3.6.1.5 Records of onsite personnel exposures to hazardous materials are controlled, monitored, and maintained. [DOE 5500.3A, Section 11.c.(6)(b)] 


\subsection{DEMONSTRATION, MONITORING, AND MMPROVING PERFORMANCE}

\subsubsection{Performance Objective}

A continuing program of training, drills, and exercises for facility personnel is in place. [DOE 5500.1B, Section 10.w(26)(a)3]

\section{Criteria}

3.7.1.1 Drills are used to develop and maintain personnel skills, expertise, and response capability. Drills are of sufficient scope and frequency to ensure adequate response capability in all applicable areas. [DOE 5500.3A, Section 11.c.(12)(a)]

3.7.1.2 A coordinated program of drills and exercises is an integral part of the Emergency Management Program. [DOE 5500.3A, Section 11.c.(12)(c, d, and e)]

3.7.1.3 Drills and exercises are conducted to emphasize facility-specific emergency events and response activities and to minimize the use of generic, nonspecific simulations. [DOE 5500.3A, Section 11.c.(12)(c)]

3.7.1.4 Each member of the ERO participates in a drill or exercise at least annually to demonstrate proficiency in assigned response duties and responsibilities. [DOE 5500.3A, Section 11.c.(12)(d)]

3.7.1.5 Emergency management improvements and corrective actions identified during actual emergencies or during drills and exercises are incorporated into the Emergency Management Program. [DOE 5500.3A, Section 11.c.(12)(e)]

3.7.1.6 Root cause(s) are determined and corrective actions to prevent recurrence are developed. [DOE 5500.1B, Section 10.w(26)(a)5]

\subsection{PREREQUISITES}

None.

\subsection{SPECIAL APPROVALS}

None. 


\subsection{REFERENCES}

The following documents were used to create this EM section:

10 CFR 835, Occupational Radiation Protection, 13 December 1993.

29 CFR 1910, Occupational Safety and Health Standards; OSHA/Labor, I July 1993.

40 CFR 265, Interim Status Standards for Owners and Operators of Hazardous Waste Treatment, Storage, and Disposal Facilities; EPA/Solid Wastes, 1 July 1992.

40 CFR 355, Emergency Planning and Notification; EPA/Superfund, Emergency Planning, and Community Right-to-Know Programs, 1 July 1993.

DOE 5480.10, Contractor Industrial Hygiene Program, 26 June 1985.

DOE 5480.11, Radiation Protection for Occupational Workers, Change 3, 21 December 1988.

DOE 5482.1B, Environment, Safety, and Health Appraisal Program, 09/23/86, Change 1, 18 November 1991.

DOE 5500.1B, Emergency Management System, 04/30/91, Page Change 1, 27 February 1992.

DOE 5500.2B, Emergency Categories, Classes, and Notification and Reporting Requirements, 04/30/91, Page Change 1, 27 February 1992.

DOE 5500.3A, Planning and Preparedness for Operational Emergencies, 04/30/91, Page Change 1, 27 February 1992.

WAC-173-303, Dangerous Waste Regulations; Washington State Department of Ecology, 1992.

WAC-296-62, Occupational Health Standards - Safety Standards for Carcinogens; Washington Department of Labor and Industries, 1990.

WHC-CM-4-43, Engineering Management Procedures, 21 March 1988.

WHC-SD-MP-SRID-001, Tank Waste Remediation System Standards and Requirements Identification Document, 30 January 1996. 


\section{SAFEGUARDS and SECURITY}

\subsection{PURPOSE}

This section provides safeguards and security functional area elements, performance objectives, and criteria intended for use by Tank Farm operational activities to ensure compliance with applicable State and Federal Regulations and Department of Energy (DOE) Orders as defined in the Tank Waste Remediation System (TWRS) Standards and Requirements Identification Document (S/RID) and Safeguards and Security Program.

\subsection{SCOPE}

The performance objectives and criteria (PO\&C) apply to all Tank Farm facilities and organizations subject to evaluation under the TWRS Management Assessment Program.

\subsection{FUNCTIONAL AREA ELEMENTS}

The following are the safeguards and security functional area elements. Each functional area element has performance objectives and subsequent criteria. The criteria are used to assess the objectives.

\subsection{MANAGEMENT AND ADMINISTRATION}

\subsubsection{Performance Objective}

A protection program has been tailored to the facility's operational needs, recognizing ongoing programs, current threat guidance, current policy and technology, and unique site-specific requirements. [DOE 5630.11B, Section 9.d]

\section{Criteria}

3.1.1.1 A security focal point(s) has been appointed who is responsible for coordinating with the Security Organization all security concerns that are relative to the facility. [RLID 5632.1B, Section 6.c] 


\subsection{PROTECTION PROGRAM OPERATIONS}

\subsubsection{Performance Objective}

An Asset Protection Review has been performed. Threat(s) to the asset, asset value, strategic business impact(s), and/or any unacceptable risks involved with the protection strategy have been identified. The appropriate Security Organization concurrence and signature from the Asset owner have been obtained. [RLID 5632.1B, Section 7.1.c]

\section{Criteria}

3.2.1.1 An Asset Protection Agreement has been completed and approved. [RLID 5632.1B, Section 7.1.g]

3.2.1.2 The levels of protection appropriate to particular security interests are provided in a graded manner in accordance with the potential risks.

[DOE 5630.11B, Section 9.d]

\subsubsection{Performance Objective}

Administrative controls are adequate for access control. [RLID 5632.1B Section 7.1.d]

\section{Criteria}

3.2.2.1 Specific facility check procedures have been established. [RLID 5632.1B Section 7.1.d]

3.2.2.2 A sign has been installed at the facility's main entrance; the sign indicates entry/access requirements and/or instructions. [RLID 5632.1B

Section 7.1.d]

3.2.2.3 Certain types of low-level assets (such as, Category IV D SNM, precious metals, explosives, drugs) are secured as required in applicable directives. [RLID 5632.1B Section 7.1.d]

\subsubsection{Performance Objective}

Access control is provided according to the asset protection template. [RLID 5632.1B, Section 7.3.b] 


\section{Criteria}

3.2.3.1 Minimum physical security requirements have been established and are met for each facility. [RLID 5632.1B, Section 7.4.a]

3.2.3.2 The number of frequently used entrances to a facility are limited. Visitors requiring entry into the facility are assisted. [RLID 5632.1B, Section 7.3.b]

3.2.3.3 Signs are posted around the perimeter and main entrances to facilities. The signs prohibit trespassing, list prohibited articles, and advise personnel that vehicles and hand carried items are subject to search. [RLTD 5632.1B, Section 7.4.a]

3.2.3.4 Unoccupied/abandoned facilities are locked. [RLID 5632.1B,
[R Section 7.4.a]

3.2.3.5 If interior locks are installed, issuance and records management of keys/combinations is conducted by facility management. [RLID 5632.1B, Section 7.4.a]

\subsection{MATERIAL CONTROL AND ACCOUNTABILITY FOR SPECIAL NUCLEAR MATERLAL}

\subsubsection{Performance Objective}

Line management has established and implemented policies and procedures that control and account for nuclear materials. [WHC-CM-4-33]

\section{Criteria}

3.3.1.1 Facility materials control and accountability procedures are reviewed and approved (prior to implementation) by facility operations management at a level of authority sufficient to ensure compliance by operations personnel. Procedures are consistent with the approved facility Materials Control and Accountability Plan. Procedures are distributed to all applicable organizations and individuals in the facility who have materials control and accountability responsibilities. [DOE 5633.3B Chapter I, Section 6.a] 


\subsection{FACLITY APPROVALS, SECURITY AND NUCLEAR MATERIAL SURVEYS}

\subsubsection{Performance Objective}

Surveys of facilities include a performance evaluation to assess the capability of the Safeguards and Security System to meet performance objectives. The performance evaluation determines system performance against scenarios for applicable threats/targets. [DOE 5634.1B, Chapter IV, Section 7]

\section{Criteria}

3.4.1.1 Performance evaluations relative to any TWRS security interests are performed. [DOE 5634.1B, Chapter IV, Section 7]

\subsection{NFORMATION SECURITY PROGRAM}

\subsubsection{Performance Objective}

A comprehensive resource control program is established to prevent access to, or compromise of, classified matter. [DOE-M-5632.1C-1]

Criteria

3.5.1.1 Classified matter access is limited to persons who possess appropriate access authorization and who require such access (need-to-know) in the performance of official duties. Controls have been established to detect and deter unauthorized access to classified matter. [DOE-M-5632.1C-1, Chapter III, Section 1.b]

3.5.1.2 Custodians and authorized users of classified matter are responsible for the protection and control of such matter. [DOE-M-5632.1C-1, Chapter III, Section 1.c]

3.5.1.3 Classified matter in use is constantly attended by or under the control of a person or persons having the proper access authorization and a need-to-know. [DOE-M-5632.1C-1, Chapter III, Section 2, Sentence 1]

3.5.1.4 Classified matter is stored in a manner to prevent unauthorized persons from gaining access. [DOE-M-5632.1C-1, Chapter III, Section 3.a] 


\subsection{OPERATION SECURITY (OPSEC)}

\subsubsection{Performance Objective}

OPSEC working groups have been established to perform the necessary management and support functions required for an effective OPSEC Program, which includes education and awareness. [DOE 5639.7 Preamble, Section 8.h Introduction and 8.h (1-13)]

\section{Criteria}

3.6.1.1 Facilities included in the OPSEC Program develop and maintain OPSEC plans, procedures, and program files. [DOE 5639.7 Preamble, Section 8.h Introduction and 8.h (1-13)]

3.6.1.2 A critical and sensitive information list (CSIL) and supporting essential elements of friendly information (EEFI) have been developed.

[DOE 5639.7 Preamble, Section 8.h Introduction and 8.h (1-13)]

3.6.1.3 Management briefings and security awareness updates are used to remind personnel of their role in protecting government assets. [WHC-CM-4-33]

\subsection{EVALUATION OF RADIOLOGICAL AND TOXICOLOGICAL AND SABOTAGE CONSEQUENCES}

\subsubsection{Performance Objective}

An evaluation of radiological and toxicological sabotage consequences has been performed with facility participation. The identified protection strategies have been implemented. [DOE 5632.1C Preamble; RLID 5630.3A Section 7.0, Paragraph 1]

Criteria

3.7.1.1 The range of potential adversary threats to programs and facilities has been identified and characterized. Field elements have been reviewed and a supplementary local threat policy has been developed, as appropriate, to take into account site-specific and regional-specific threat considerations. [DOE 5632.1C Preamble, Section 7.b]

3.7.1.2 A graded assessment of the risk, due to radiological/toxicological sabotage, has been performed consistent with the levels of hazards present within the facility. [RLID 5630.3A Section 7.0, Paragraph 1] 
3.7.1.3 Protection and control are provided in a graded, cost-effective fashion, in accordance with the potential risks to national security and/or the health and safety of the employees, the public, and the environment.

[DOE 5632.1C Preamble, Section 5.b]

\subsection{PREREQUISITES}

None

\subsection{SPECIAL APPROVALS}

None.

\subsection{REFERENCES}

The following documents were used to create this S\&S section:

DOE 5632.1C, Protection and Control of Safeguards and Security Interests, July 1994.

DOE 5633.3B, Control and Accountability of Nuclear Materials, September 94.

DOE 5634.1B, Facility Approvals, Security Surveys, and Nuclear Materials Surveys, September 1992.

DOE-M-5632.1C-1, Manual for Protection and Control of Safeguards and Security Interests, July 1994.

RLID 5632.1B, Asset Protection Requirements, August 1994.

WHC-CM-1-1, Management Policies, 1 December 1987.

WHC-CM-1-3, Management Requirement Practices, 19 February 1988.

WHC-SD-MP-SRID-001, Tank Waste Remediation System Standards and Requirements Identification Document, 30 January 1996. 


\section{ENGINEERING PROGRAM}

\subsection{PURPOSE}

This section provides engineering program functional area elements, performance objectives, and criteria intended for use by Tank Farm operational activities to ensure compliance with applicable State and Federal Regulations and Department of Energy (DOE) Orders as defined in the Tank Waste Remediation System (TWRS) Standards and Requirements Identification Document (S/RID) and Engineering Program.

\section{$2.0 \quad$ SCOPE}

The performance objectives and criteria (PO\&C) apply to all Tank Farm facilities and organizations subject to evaluation under the TWRS Management Assessment Program.

\subsection{FUNCTIONAL AREA ELEMENTS}

The following are the engineering program functional area elements. Each functional area element has performance objectives and subsequent criteria. The criteria are used to assess the objectives.

\subsection{MANAGEMENT AND ADMINISTRATION}

\subsubsection{Performance Objective}

Work is performed to prescribed-standards, procedures, or instructions of a detail commensurate with the complexity and importance of the work. When possible, administrative controls are simplified to minimize the impact of controls on the worker. Personnel performing a process are included in process improvement activities. The work process is designed to produce the desired quantity and quality of output. [10 CFR 830, Section 5.2, Paragraph 2]

\section{Criteria}

3.1.1.1 A formal design process is established that provides control of design inputs, outputs, verification, configuration and design changes, documentation, records, and technical and administrative interfaces. [10 CFR 830, Section 6.1]

3.1.1.2 Design work is based on sound engineering and scientific principles. [10 CFR 830, Section 6.1] 
3.1.1.3 Applicable work process documents are readily accessible to the worker. Work process documents are based on the skills of the workers using them and on the complexity and importance of the work. Work process documents include any requirements for special processes that are highly dependent on the control of the process or the skill of the operator, and for which the quality of the product cannot be readily determined by inspection or test. [10 CFR 830, Section 5.4, Paragraph 2]

3.1.1.4 Interface requirements related to major system elements, facilities, utilities, hardware, software, and procedures are established, coordinated, and maintained. [DOE 4700.1, Chapter III.B.2.c.(2)(b)(2)]

3.1.1.5 Clear lines of communications and timely dissemination of changes to these interface documents is maintained. [DOE 4700.1, Chapter III.B.2.c.(2)(b)(3)]

\subsection{DESIGN INPUT}

\subsubsection{Performance Objective}

Design inputs are technically correct and complete. [10 CFR 830, Section 6.2, Paragraph 1]

Criteria

3.2.1.1 The design is completed from a total system viewpoint to include facilities, utilities, hardware, software, personnel, and procedures. [DOE 4700.1, Chapter

III.B.2.c.(2)(a)]

3.2.1.2 Requirements regarding design compatibility of engineering interfaces are defined in appropriate specifications. [DOE 4700.1, Chapter III.B.2.c.(2)(b)(1)]

3.2.1.3 Technical objectives for each project are established so that relationships among project needs, urgency, risks, and value can be established. [DOE 4700.1, Chapter III.B.2.c.(1)(a)]

3.2.1.4 Technical design interfaces are identified in the input documents and methods have been established for their control. [10 CFR 830, Section 6.2, Paragraph 1] 


\subsection{DESIGN OUTPUT}

\subsubsection{Performance Objective}

The design process translates design input into design output documents that are technically correct and meet the end-users' requirements. Aspects critical to the safety or reliability of the designed system, structure, or component are identified during the design phase. Design output documents are useable by other project processes such as: manufacturing, assembly, construction, testing, inspection, maintenance, and decommissioning. [10 CFR 830, Section 6.3]

\section{Criteria}

3.3.1.1 The agency accomplishing the design verifies that design output documents meet design input requirements and that any deviations have been approved and documented. [10 CFR 830, Section 6.3, Paragraph 3]

3.3.1.2 Computer software used to originate or verify design solutions during the design process is validated or the status of code validation is identified and documented prior to use. [10 CFR 830, Section 6.3]

3.3.1.3 The completed design is recorded in design output documents such as drawings, specifications, test/inspection plans, maintenance requirements, and reports. As-built drawings and shop drawings are maintained after production or construction to show actual configuration. The administrative interface process clearly indicates responsibilities for design output document activities including as-built markup and updating during project construction/production phases, media use and transmission, document control, and records management. [10 CFR 830, Section 6.4]

3.3.1.4 To the extent practicable, and particularly in the case of innovative design, the design is independently reviewed by competent consultants in construction or manufacturing techniques to confirm the practicability of construction or manufacture. [DOE 6430.1A, Section 0140(10)]

\subsection{DESIGN CHANGE CONTROL}

\subsubsection{Performance Objective}

Changes that impact the design portion of the technical baseline are controlled. 
Criteria

3.4.1.1 A document control process establishes requirements to release documents for distribution, identify recipients, specify actions to be taken with existing documents (such as, when revisions are released for distribution or documents are canceled), and identify unique revisions and copies. [10 CFR 830, Section 4.2]

3.4.1.2 Deviations from specified standards are identified and procedures have been established to ensure their control. [DOE 6430.1A, Section 0140(09)]

3.4.1.3 Design changes, including fjeld changes and nonconforming items dispositioned "use-as-is" or "repair," are controlled by measures commensurate with those applied to the original design. Temporary modifications receive the same levels of control as the designs of permanent modifications. [10 CFR 830, Section 6.6]

\subsection{DESIGN VERIFICATIONS}

\subsubsection{Performance Objective}

Design calculations and/or critical design parameters are verified by technically knowledgeable persons separate from personnel performing the design. [10 CFR 830, Section 6.5, Paragraph 2]

\section{Criteria}

3.5.1.1

Design verification is performed by technically knowledgeable persons separate from those who performed the design. The extent and number of design verifications is based on a graded approach and depends on the designed product's complexity and importance to project success. [10 CFR 830, Section 6.5 , Paragraph 2]

3.5.1.2 Design verification is completed before design output is used by other organizations or to support other work such as procurement, manufacture, construction, or experiment. When this timing cannot be achieved, the unverified portion of the design is identified and controlled. In all cases, design verifications are completed before relying on the system, structure, or component to perform its function and before installation becomes irreversible. [10 CFR 830, Section 6.5, Paragraph 3]

3.5.1.3 Systems, structures, and components important to safety are subjected to more stringent operational criteria and verification requirements than those not important to safety. Safety Analysis Reports (SARs) exist for each DOE nuclear facility and define the facility's systems, structures, and components that are important to safety. [10 CFR 830, Section 6.1] 


\subsection{TEST/ACCEPTANCE PROGRAM}

\subsubsection{Performance Objective}

The final designed and installed system, process, or facility meets its functional requirements.

\section{Criteria}

3.6.1.1 Inspections/tests are accomplished to verify that physical characteristics and functions of systems, structures, and components are acceptable to the organization that will use the systems, structures, and components. Systems, structures, and components requiring inspection/test are identified early in the design phase. [10 CFR 830, Section 8.1]

3.6.1.2 Inspections and tests are conducted according to a graded approach. Acceptance parameters and other requirements such as inspection/test equipment or qualified inspection/test personnel are specified in design documentation. [10 CFR 830, Section 8.1]

3.6.1.3 Systems, structures, and components are ready for service at the conclusion of the inspection or test process. The types of systems, structures, and components and the length of time that they are to remain in storage is considered when generating the inspection/test plan. [10 CFR 830, Section 8.1]

3.6.1.4 Inspections/tests are performed to written directives. Appropriate sections of approved codes or standards are used for acceptance requirements and inspection/test methods in lieu of specially written test procedures. Inspection/test results are evaluated and verified by authorized personnel to document that all requirements have been satisfied. [10 CFR 830, Section 8.2]

3.6.1.5 Inspection/test methods are established to define the requirements for activities that verify conformance of systems, structures, or components with specified requirements. Results of these activities are documented and retained as project records. [DOE 6430.1A, Section 0140(10)]

3.6.1.6 The inspection and acceptance testing methods establish requirements for a calibration system to ensure that measuring and test equipment (M\&TE) used to verify conformance to design requirements are of the proper type, range, accuracy, and are uniquely identified and traceable to their calibration data. [10 CFR 830, Section 8.3]

3.6.1.7 Adequate procedures for testing, retesting, adjusting, and re-calibration of M\&TE are maintained and documented by organizations performing inspection and testing functions. When applicable, M\&TE are calibrated to standards traceable to the National Institute of Standards and Technology. [10 CFR 830, Section 8.3] 
3.6.1.8 The inspection/test process identifies the status of systems, structures, and components requiring examination to ensure that failed or untested systems, structures, and components are not used. A method is developed to control reinspection and retesting for previously failed systems, structures, or components. The method provides for review and documentation of changed inspection/test parameters. [10 CFR 830, Section 8.1]

3.6.1.9 Inspections/tests are performed by technically qualified personnel that have the freedom of access and communication to report inspection/test results. Final acceptance of systems, structures, or components are verified and documented by the organization having the final responsibility for the system, structure, or component. [10 CFR 830, Section 8.1]

\subsection{PREREQUISITES}

None.

\subsection{SPECIAL APPROVALS}

None.

\subsection{REFERENCES}

The following documents were used to create this ENG section:

10 CFR 830, Nuclear Safety Management, 15 April 1994.

DOE 4700.1, Project Management System, 2 June 1992.

DOE 6430.1A, General Design Criteria, 16 April 1989.

DOE Implementation Guide for 10 CFR 830.120, August 1994.

DOE-STD-1073-93, Guide for Operational Configuration Management Program, November 1993.

WHC-SD-MP-SRID-001, Tank Waste Remediation System Standards and Requirements Identification Document, 30 January 1996. 


\section{CONSTRUCTION PROGRAM}

\subsection{PURPOSE}

This section provides construction program functional area elements, performance objectives, and criteria intended for use by Tank Farm operational activities to ensure compliance with applicable State and Federal Regulations and Department of Energy (DOE) Orders as defined in the Tank Waste Remediation System (TWRS) Standards and Requirements Identification Document (S/RID), and Construction Program.

\subsection{SCOPE}

The performance objectives and criteria (PO\&C) apply to all Tank Farm facilities and organizations subject to evaluation under the TWRS Management Assessment Program.

\subsection{FUNCTIONAL AREA ELEMENTS}

The following are the quality assurance functional area elements. Each functional area element has performance objectives and subsequent criteria. The criteria are used to assess the objectives.

\subsection{MANAGEMENT AND ADMINISTRATION}

\subsubsection{Performance Objective}

A Construction Work Control Program to control and document construction activities is approved and implemented prior to the performance of construction work activities.

\section{Criteria}

3.1.1.1 The management control systems includes policies, procedures, and methods that are designed to ensure that all authorized work and related resources are defined to meet the requirements of the contract, using the framework of the contract work breakdown structure (WBS). [DOE 4700.1, Attachment III-7.2.a.(1)]

3.1.1.2 Work is performed to established technical standards and administrative controls using approved instructions, procedures, or other appropriate means. [10 CFR 830, Part 120(c)(2)(I)]

3.1.1.3 Itens are identified and controlled to ensure their proper use. [10 CFR 830, Part $120(\mathrm{c})(2)(\mathrm{I})]$

3.1.1.4 Items are maintained to prevent their damage, loss, or deterioration. [10 CFR 830, Part 120(c)(2)(I)] 
3.1.1.5 Equipment used for process monitoring or data collection is calibrated and maintained. [10 CFR 830, Part 120(c)(2)(I)]

\subsection{PROGRAM ACTIVITIES}

\subsubsection{Performance Objective}

A process has been established and is in operation throughout the project life to identify programmatic, operational, legislative, institutional, and other requirements or constraints (which may affect technical, cost, or schedule baselines) and to ensure that such baselines properly reflect such potential impacts. [DOE N4700.5, Attachment 2, Section 2.a.(4)(b)1]

\section{Criteria}

3.2.1.1 Specific project management plans are prepared for each major system acquisition and major project. [DOE 4700.1, Chapter V.A.2.c.(1) (1)]

3.2.1.2 General project management plans are prepared for categories or types of projects that will be similarly managed. [DOE 4700.1, Chapter V.A.2.c.(2)]

3.2.1.3 Projects managed by general management plans have a specific document containing the scope, estimate, schedule, and designated individual-assigned authorities and responsibilities. [DOE 4700.1, Chapter V.A.2.c.(3) (1)]

3.2.1.4 Standard change control procedures are established for projects that do not have specific project management plans. [DOE 4700.1, Chapter V.C.2.h.(2)(d)1 (5)]

3.2.1.5 The change control procedures include authorities and responsibilities for changes during both design and construction. [DOE 4700.1, Chapter V.C.2.h.(2)(d)1 (6)]

\subsubsection{Performance Objective}

Schedules are integrated with the WBS and cost estimate and represent the scope of all work regardless of the funding source. Activity logic is used to depict the total scope of the work, constraints, and decision points. Activities representing work accomplishment have been assigned durations. [DOE N4700.5, Attachment 2, Section 2.a.(4)(b)2]

\section{Criteria}

3.2.2.1 An approved schedule baseline has been established. This schedule baseline clearly depicts critical path activities and milestones from which actual performance for all activities and milestones can be compared and from which forecast data can be generated. [DOE N4700.5, Attachment 2, Section 2.a.(4)(b)3] 
3.2.2.2 Resource-load activities have been identified, as required, and are at the appropriate level, to develop time-phased budgets that are integrated with the schedule. [DOE N4700.5, Attachment 2, Section 2.a.(4)(b)3]

3.2.2.3 Only authorized changes to the schedule baseline are pernitted. [DOE N4700.5, Attachment 2, Section 2.a.(4)(b)3]

\subsubsection{Performance Objective}

Cost estimates are prepared using appropriate estimating methodologies that are integrated with the WBS, and the DOE cost structure (as specified by the DOE) for all contract work. [DOE N4700.5, Attachment 2, Section 2.a.(3)(b)1]

\section{Criteria}

3.2.3.1 Estimates are consistent with DOE 5700.2D and in accordance with FAR 15.804, "Cost and Price Data Analysis," as applicable. [DOE N4700.5, Attachment 2, Section 2.a.(3)(b)1]

3.2.3.2 Each estimate documentation file includes the basis for the estimate, shows how the estimate was performed, and contains a contingency analysis. All estimates are performed in constant-year dollars and then escalated into year-of-expenditure (gencrally fiscal year) dollars. Both the estimates and the escalation rates used are kept on file until the project is completed. [DOE 5700.2D, Preamble: Section 8.c]

3.2.3.3 Check estimates are used for validating project estimates. The check estimate should be made by someone other than the person(s) who performed the original estimate. [DOE 5700.2D, Preamble: Section 8.d]

3.2.3.4 All sequential cost estimates are reconciled and kept on file with previous estimates until the project is completed. [DOE 5700.2D, Preamble: Section 8.c]

\subsection{CONSTRUCTION RECORDS}

\subsubsection{Performance Objective}

Working drawings and construction specifications, as-built drawings, shop drawings, standard drawings, repair and alterations, equipment specifications, operating and maintenance manuals, equipment warranty data, final inspection and acceptance reports, construction cost and schedule data, space assignment plans, and other essential information are developed and retained to document the construction process. [DOE 1324.2A, Chapter V, Attachment V-14, Item 2.a]

\section{Criteria}

3.3.1.1 Construction project files and other essential information to document the construction process are retained until dismantlement or disposal of facility, equipment, system or 
process or when superseded or obsolete, whichever occurs first. Documents are prepared, reviewed, approved, issued, used, and revised to prescribe processes, specify requirements, or establish design. [DOE 1324.2A, Chapter V, Attachment V-14, Item 2.a]

3.3.1.2 Records are retained for 5 years for projects terminated prior to construction completion. [DOE 1324.2A, Chapter V, Attachment V-14, Item 2.a]

3.3.1.3 Construction Completion Reports are retained for 20 years for unique or special-interest projects. For other projects, completion reports are retained until dismantlement or disposal of the facility, equipment, or process or when superseded or obsolete, whichever occurs first. [DOE 1324.2A, Chapter V, Attachment V-14, Item 2.b]

3.3.1.4 Information correspondence, and other records developed during the construction process, essential to performance of the process but not essential for project record purposes following project completion are retained until project completion. [DOE 1324.2A, Chapter V, Attachment V-14, Item 2.c]

3.3.1.5 Records selected for architectural, historical, and technological significance are offer to NARA when the file is inactive. [DOE 1324.2A, Chapter V, Attachment V-14, Item 2.d]

\subsection{CONSTRUCTION SITE WALKTHROUGHS}

\subsubsection{Performance Objective}

Inspection methods of activities affecting quality are established and executed by or for the organization performing the activity. [DOE 4700.1, Chapter III, Section D.2.j]

\section{Criteria}

3.4.1.1 The inspection validates conformance with the prescribed documented instructions, procedures, and drawings. [DOE 4700.1, Chapter III, Section D.2.j]

3.4.1.2 Examinations, measurements, or tests of material or products processed are performed for each work operation, where necessary, to assure quality. If inspection of processed material or products is impossible or not advantageous, indirect control by monitoring processing methods, equipment, and personnel are provided. Both inspection and process monitoring are provided when control is inadequate without both. [DOE 4700.1, Chapter III, Section D.2.j]

3.4.1.3 If mandatory inspection points that require witnessing or inspection by the contractor's designated representative, and if work cannot proceed beyond these points without the consent of its designated representative, the specific points are indicated in appropriate documents. [DOE 4700.1, Chapter III, Section D.2.j]

3.4.1.4 A comprehensive health and safety program has been established and utilized for all DOE construction projects. [DOE 4700.1 , Chapter V, Section A.2.1] 
Rev. 0

\subsection{PREREQUISITES}

None.

\subsection{SPECIAL APPROVALS}

None.

\subsection{REFERENCES}

The following documents were used to create this construction program section:

10 CFR Part 830, Nuclear Safety Management, 5 April 1994.

DOE 1324.2A, Records Disposition, Change 1, 9 April 1992.

DOE 4700.1, Project Management System, Change 1, 2 June 1992.

DOE N4700.5, Project Control System Guidelines, 21 August 1992.

DOE 5700.2D, Cost Estimating, Analysis, and Standardization, 6 April 1989.

WHC-SD-MP-SRID-001, Tank Waste Remediation Svstem Standards and Requirements Identification Document, 30 January 1996. 


\section{OPERATIONS}

\subsection{PURPOSE}

This section provides operations functional area elements, performance objectives, and criteria intended for use by Tank Farm operational activities to ensure compliance with applicable State and Federal Regulations and Department of Energy (DOE) Orders as defined in the Tank Waste Remediation System (TWRS) Standards and Requirements Identification Document (S/RID).

The operations functional area defines the key elements for policies and programs that govern the activities of operating facilities.

\section{$2.0 \quad$ SCOPE}

The performance objectives and criteria (PO\&C) apply to all Tank Farm facilities and organizations subject to evaluation under the TWRS Management Assessment Program.

\subsection{FUNCTIONAL AREA ELEMENTS}

The following are the operations functional area elements. Each functional area element has performance objectives and subsequent criteria. The criteria are used to assess the objectives.

\subsection{OPERATIONS ORGANIZATION AND ADMINISTRATION}

\subsubsection{Performance Objective}

The organization and administration ensures that a high level of operational performance is achieved through effective implementation and control of operations activities. Policies and written standards that describe the philosophy of standards of excellence under which operations are conducted and that establish clear lines of responsibility for normal and emergency conditions have been developed and promulgated. [DOE 5480.19, Chapter I, Section A]

\section{Criteria}

3.1.1.1 Procedures or other definitive documentation specify policies that will be applied for operations; provide performance goals and the means to achieve these goals; and provide for the types of controls necessary to implement the policies. [DOE 5480.19, Chapter I, Section C.1]

3.1.1.2 Responsibilities for implementing these policies, which includes the responsibilities of shift personnel, are clearly defined. [DOE 5480.19, Chapter I, Section C.1] 

responsibility, accountability, and interface with other groups. [DOE 5480.19, Chapter I, Section C.1]

Operations managers are provided with sufficient resources in materials and personnel, including technical support, to accomplish assigned tasks without requiring excessive overtime by the Operations staff. [DOE 5480.19, Chapter I, Section C.2]

3.1.1.5

3.1.1.6

3.1.1.7

3.1.1.8

3.1.1.9

3.1.1.10

3.1.1.11

3.1.1.12
A long-range staffing plan that anticipates personnel losses is developed and implemented. [DOE 5480.19, Chapter I, Section C.2]

Line managers and other supervisors perform frequent direct observations of Operations personnel and activitics. Any deficiencies noted are documented, trended, and corrected. [DOE 5480.19, Chapter I, Section C.3]

Operating problems are documented and evaluated. Based on assessments of these problems, corrective actions are taken to improve organization performance. [DOE 5480.19 , Chapter I, Section C.3]

Safety, environment, and operating goals are established. The goals are auditable, measurable, realistic, and challenging. Progress toward achieving the goals is periodically monitored, and management action is taken to address significant variance from the desired results. [DOE 5480.19, Chapter I, Section C.3]

Periodically, an audit of performance relative to operating goals is provided to senior management and DOE, which includes an explanation of performance and actions planned to improve future performance. [DOE 5480.19, Chapter I, Section C.3]

Workers and their supervisors are held accountable for operating performance. Personnel involved in significant or frequent violations of operating practices are counseled, retrained, and disciplined, as appropriate. Supervisor performance appraisals and promotions include an assessment of operating performance. [DOE 5480.19, Chapter I, Section C.4]

Formalized supervisory and management training, which includes training for firstline supervisors on-shift, is incorporated into training programs. [DOE 5480.19, Chapter I, Section C.5]

Guidance that describes safety preplanning requirements for all operational activities has been developed and promulgated and all Operations personnel understand the safety planning requirements. [DOE 5480.19, Chapter I, Section C.6] 


\subsection{SHIFT ROUTINE AND OPERATING PRACTICES}

\subsubsection{Performance Objective}

Shift routines and operating practices are defined and implemented to ensure professional conduct of operations, clear understanding of responsibilities and authorities, clarity of understanding by oncoming shift personnel on processing and equipment status, completion of accurate shift records, and quality communications between all organizations on shift. [DOE 5480.19, Chapter II]

\section{Criteria}

3.2.1.1 Responsibilities and authority for work areas, processing and support equipment, and surveillance are clearly defined and communicated to employees. [DOE 5480.19, Chapter II, Section C.91

3.2.1.2 Procedures clearly state responsibilities of the on-coming shift crew to understand the processing and equipment status in each individual's assigned work area. Special emphasis is placed on safety and environmental protection equipment. [DOE 5480.19, Chapter II, Section C.3]

3.2.1.3 Operator tours (surveillances) and supporting Round Sheets (data sheets) for assigned work areas and processing support equipment are defined to ensure that processes and equipment are operating in the desired envelope, and actions are taken to reverse any observed trends toward violating the envelope. [DOE 5480.19, Chapter II, Sections C.3 and C.4]

3.2.1.4 Shift personnel are aware of process and equipment status at all times. Specific action is taken and documented for restoring inoperable or malfunctioning equipment to desired operating conditions with special emphasis on safety and environmental protection equipment. [DOE 5480.19, Chapter II, Section C.3]

3.2.1.5 Alarms and indications that are normally in an alarmed condition during operation is mininized. Operators are able to differentiate between annunciator lights that provide status information and annunciator lights that indicate an alarm condition. [DOE 5480.19, Chapter II, Section C.6; DOE 5480.19, Chapter III, Section C.8]

3.2.1.6 Operators take appropriate action to correct or report deficiencies noted during tours. [DOE 5480.19, Chapter II, Section C.3] 


\subsection{CONTROL AREA ACTIVITIES}

\subsubsection{Performance Objective}

Control area activities are conducted in a professional and business-like manner to ensure timely and accurate monitoring of process and supporting instrumentation to maximize safe and reliable facility operation. [DOE 5480.19, Chapter III, Sections A and B]

\section{Criteria}

3.3.1.1 Control areas and "At-the-Controls" areas are defined and communicated to on-shift personnel assigned to the control areas and to personnel needing access to the control areas. [DOE 5480.19, Chapter III, Sections C.1 and C.2]

3.3.1.2 Specific duties of on-shift personnel in the control areas are defined and clearly communicated to assigned shift personnel (supervisors and operators). [DOE 5480.19, Chapter III, Sections C.3, C.4, and C.5]

3.3.1.3 Owmership of the control area and control area equipment is clearly defined, and only persons authorized by adnimistrative procedures operate control area equipment. [DOE 5480.19, Chapter III, Section C.5]

\subsection{COMMUNICATIONS}

\subsubsection{Performance Objective}

Procedures, equipment, and personnel training are established to ensure that timely and accurate conmunications are maintained throughout the facility. [DOE 5480.19, Chapter IV]

\section{Criteria}

3.4.1.1 Equipment required for effective communications is defined, in place, and routinely checked for operability (radios, telephones, pagers, PA system, etc.). [DOE 5480.19, Chapter IV, Section C. 1]

3.4.1.2 Attributes (written and oral) of clear communications are defined, communicated, and implemented. [DOE 5480.19, Chapter IV, Section C.6] 


\subsection{CONTROL OF ON-SHIFT TRAINING}

\subsubsection{Performance Objective}

Equipment operation by personnel under instruction is carefully supervised and controlled to avoid mistakes in operations by unqualified personnel and to use trainees' time effectively. On-shift training is conducted so that the trainee satisfactorily completes all of the required training objectives and receives maximum learning benefit from this experience. [DOE 5480.19, Chapter V, Section A]

\section{Criteria}

3.5.1.1 On-shift training is conducted in accordance with training programs that specifically identify items that the trainee must accomplish on shift. [DOE 5480.19, Chapter V, Section C.1]

3.5.1.2 On-shift training is conducted by qualified operators who have been specifically selected and trained as on-shift instructors. [DOE 5480.19, Chapter V, Section C.2]

3.5.1.3 Whenever a trainee operates equipment or records data on official data sheets, a qualified operator serving as an on-shift instructor will monitor the trainee closely and remain in a position to intervene or assume control, if necessary, in order to ensure that the trainee does not make an error that could adversely impact operations. [DOE 5480.19, Chapter V, Section C.3]

3.5.1.4 The operator qualification program is approved by the Operations Manager and changes to the program are coordinated with the training department. [DOE 5480.19 , Chapter V, Section C.4]

3.5.1.5 Completion of the operator qualification program is formally documented, including the completion of on-shift requirements. [DOE 5480.19, Chapter V, Section C.5]

3.5.1.6 Trainee operation of equipment is immediately suspended during abnomal cvents, accident conditions or whenever operations personnel or the on-shift instructor believes suspension is necessary to ensure safe and reliable operation [DOE 5480.19, Chapter V, Section C.6]

3.5.1.7 A maximum limit for the trainee-to-instructor ratio is specified. [DOE 5480.19, Chapter V, Section C.7] 


\subsection{INVESTIGATION OF ABNORMAL EVENTS}

\subsubsection{Performance Objective}

A program is established for the investigation of abnormal events that ensures that TWRS events are thoroughly investigated to assess the impact of the event, to determine the root cause of the event, to ascertain whether the event is reportable to DOE in accordance with DOE $0232.1 / \mathrm{DOE} 5000.3 \mathrm{~B}$ and to identify corrective actions to prevent recurrence of the event. The program includes the investigation of near miss situations, which reduces the probability of a similar situation recurring as an actual TWRS event. [DOE 5480.19, Chapter VI, Section A]

\section{Criteria}

3.6.1.1 Events that occur at TWRS and adversely affect operations, personnel safety, or DOE requirements (DOE $O 232.1 /$ DOE $5000.3 \mathrm{~B}$ ) receive a thorough investigation. The criteria for when to perform an event investigation are clearly established. These criteria include a listing for supervisory use of specific events that requires investigation along with criteria for use in deciding what "ncar miss" situations should receive review. [DOE 5480.19, Chapter VI, Section C.1]

3.6.1.2 The operations supervisor or another manager is responsible for event investigations. The responsible manager may delegate specific investigations or portions of investigations to other personnel; however, the overall responsibility for the consistency and thoroughness of event investigations remains with the designated manager. [DOE 5480.19, Chapter VI, Section C.2]

3.6.1.3 Event investigators are technically knowledgeable and respected by the organization staff and have no bias or vested interest in the results of the investigation. [DOE 5480.19, Chapter VI, Section C.3]

3.6.1.4 Event investigators are trained in TWRS systems, operations, and otber major disciplines that are appropriate for the event under investigation. Additionally, they are trained in techniques for conducting an investigation such as root-cause determination, interviewing techniques, and factors affecting human performance. [DOE 5480.19, Chapter VI, Section C.3]

3.6.1.5 Guidance is promulgated concerning the collection of data to allow event investigators to perform reconstruction and analysis of events. [DOE 5480.19, Chapter VI, Section C.4I

3.6.1.6 Event investigation procedures, which include reconstruction, event analysis and evaluation, root-cause determination, corrective action determination, and report preparation and approval, are promulgated. [DOE 5480.19, Chapter VI, Sections C.5 and C.6] 
3.6.1.7 In-house events are evaluated by the Operations manager to determine if the event should be included in the training program for Operations personnel. A mechanism is established so that immediate training can be conducted (if appropriate) due to the severity or the possible safety consequences of some events. [DOE 5480.19, Chapter VI, Section C.7]

3.6.1.8 Patterns of deficiencies such as operator errors or inadequate procedures are trended and a periodic summary report of events, causes, and trends is submitted to department heads, other appropriate managers, and the TWRS manager. [DOE 5480.19, Chapter VI, Section C.8]

3.6.1.9 Procedures are established in order to conduct event investigations for acts of known or suspected sabotage. [DOE 5480.19, Chapter VI, Section C.9]

\subsection{NOTIFICATIONS}

\subsubsection{Performance Objective}

Guidance is established for the timely notification of appropriate DOE personnel and other agencies, when required, to ensure that TWRS is responsive to public health and safety concerns. These guidelines ensure uniformity, efficiency, and thoroughness of these notifications to support fulfillment of DOE requirements that are consistent with DOE O 232.1/DOE 5000.3B. [DOE 5480.19, Chapter VII, Section A]

\section{Criteria}

3.7.1.1 Procedures are developed that address appropriate notifications, including notification responsibility and readily available listing of the names of the primary and alternate points of contact. Adequate communication equipment is maintained in the main control area to carry out required notifications. [DOE 5480.19, Chapter VII, Sections C.1, C.2, C.3, and C.5]

3.7.1.2 Notifications are documented, and a formal record of notifications is maintained. [DOE 5480.19, Chapter VII, Section C.4]

\subsection{CONTROL OF EQUIPMENT AND SYSTEM STATUS}

\subsubsection{Performance Objective}

A program is established to confirm and periodically reconfirm the condition, configuration, and status (operability) of safety systems, including safety-related process systems and safety-related utility systems. [DOE 5480.19, Chapter VIII] 


\section{Criteria}

3.8.1.1 Procedures are implemented for monitoring and controlling configuration, status, and testing of processing systems by operations and support personnel who are responsible to maintain compliance with the facility safety envelope. [DOE 5480.19, Chapter VIII, Section C.4]

3.8.1.2 Changes in configuration and status of processing systems and equipment are communicated to shift personnel and documented. [DOE 5480.19, Chapter VIII, Section C.1]

3.8.1.3 Procedures are established and implemented for control of temporary modifications. [DOE 5480.19, Chapter VIII, Section C.9]

3.8.1.4 Test and calibration safety systems results and instruments that monitor Limiting Conditions of Operation (LCOs) are known and acceptable prior to placing in operation. Deficient equipment is identified, documented, repaired, and tested prior to placing it in service. [DOE 5480.19 Chapter VIII, Sections C.5, C.6, and C.7]

\section{$3.9 \quad$ LOCKOUTS AND TAGOUTS}

\subsubsection{Performance Objective}

An effective Lockout/Tagout Program is implemented to control lockout/tagout preparation, approval, placement, removal, and documentation. The program also includes detailed administrative procedures, training of personucl, and the use of uniquely identifiable tags. [DOE 5480.19, Chapter IX]

Criteria

3.9.1.1 Detailed administrative and operating procedures are established for executing the Lockout/Tagout Program. [DOE 5480.19, Chapter IX, Sections B and C.4]

3.9.1.2 Protective materials and hardware are available to effectively implement the program. [DOE 5480.19, Chapter IX, Section C.3]

3.9.1.3 Training is provided and documented to ensure that the purpose and function of the Lockout/Tagout Progran is understood by all personnel and that they have the knowledge and skills required for safe application, use, and removal of lockouts and tagouts. [DOE 5480.19, Chapter IX, Section C.10] 


\subsection{INDEPENDENT VERIFICATION}

\subsubsection{Performance Objective}

A program/procedure is established and effectively implemented by trained personnel to ensure that specified operations or component positioning are independently verified to meet stated conditions or criteria. [DOE 5480.19, Chapter X]

Criteria

3.10.1.1 A program is established that defines when and how to perform independent verifications. [DOE 5480.19, Chapter X, Sections A and B]

3.10.1.2 Specific procedures and related documentation are available to identify those operations or component positions that require independent verification before operating. [DOE 5480.19, Chapter X, Sections C.1 and C.2]

3.10.1.3 Personnel are trained in independent verification techniques through detailed classroom instruction and on-shift training (OST). [DOE 5480.19, Chapter X, Section C.3]

\subsection{LOGKEEPING}

\subsubsection{Performance Objective}

An accurate history of facility operations, including abnormal events, is available from operating logs for all defined key operations positions. [DOE 5480.19, Chapter XI]

\section{Criteria}

3.11.1.1 Administrative procedures that define logkeeping requirements and responsibilities are implemented. [DOE 5480.19, Chapter XI, Section A]

3.11.1.2 All key operations positions that require the establishment and maintenance of operating logs are maintaining logs. [DOE 5480.19, Chapter XI, Section C.1]

3.11.1.3 Specific procedures for review of log books, interim storage of log books in the facility, and permanent storage of log books are implemented. [DOE 5480.19, Chapter XI, Sections C.6 and C.7]

3.11.1.4 Round sheets, $\log$ books, and all other formal plant records are legible, accurate, specific, and maintained using practices acceptable for documenting plant events and performance. [DOE 5480.19, Chapter II, Section C.4] 


\subsection{OPERATIONS TURNOVER}

\subsubsection{Performance Objective}

Information transfer at shift turnover is accurate and provides the on-coming shift with information on plant status and needed near-term actions to maintain the facility in a safe condition and to continue operations within an acceptable operating envelope. [DOE 5480.19, Chapter XII]

\section{Criteria}

3.12.1.1 Formal documents (that is, checklists) ensure that effective shift turnover are defined and understood. [DOE 5480.19, Chapter XII, Section C.1]

3.12.1.2 Provisions are established for the on-coming and departing shift to communicate key items that affect plant status, safety, and environmental protection. The oncoming shift communicates among themselves (early in the shift) on major actions anticipated during the shift. [DOE 5480.19, Chapter XII, Section C.4]

3.12.1.3 As early as possible in a given shift, communications among all organizations (Operations, Technical, Maintenance, Analytical Lab, Radiological Control Organization, Industrial Hygiene, etc.) on specific problems/tasks to be addressed on the shift are ensured in a meeting of organization supervisors and/or other key personnel. [DOE 5480.19, Chapter II, Section C.5]

\subsection{OPERATIONS ASPECTS OF FACILITY CHEMISTRY AND UNIQUE PROCESSES}

\subsubsection{Performance Objective}

Chemical and unique processing safety and the operating envelope are defined and operations and technical support personnel are trained and in place to monitor key process parametcrs and to execute defensible actions to maintain process safety. [DOE 5480.19, Chapter XIII]

\section{Criteria}

3.13.1.1 Responsibilitics are defined and understood for personnel to monitor and control process parameters. [DOE 5480.19, Chapter XIII, Section C.1]

3.13.1.2 Technical support personnel are identifted and available to provide both technical guidance and authority during interfaces with operations. [DOE 5480.19, Chapter XIII, Section C.4]

3.13.1.4 Technical knowledge requirements are defined and implemented to analyze offnormal situations and to take appropriate actions. [DOE 5480.19, Chapter XIII, Section C.2] 


\subsection{REQUIRED READING}

\subsubsection{Performance Objective}

A formal process is established to ensure that all personnel are aware of information required to safely and efficiently execute their job assignment. [DOE 5480.19, Chapter XIV]

\section{Criteria}

3.14.1.1 The responsibilities and processes for required reading are defined and implemented. [DOE 5480.19, Chapter XIV, Section C.2]

3.14.1.2 The types of documents to be included in Required Reading are identified. [DOE 5480.19, Chapter V, Section C.1]

3.14.1.3 A review process is established to ensure required reading is completed on time. [DOE 5480.19, Chapter XIV, Section C.5]

\subsection{TIMELY ORDERS TO OPERATORS}

\subsubsection{Performance Objective}

Operations management disseminates short-term information and administrative instructions to shift personnel on a timely basis. [DOE 5480.19, Chapter XV]

\section{Criteria}

3.15.1.1 Procedures and responsibilities are defined and implemented to ensure the issuance of needed information in a timely manner. [DOE 5480.19, Chapter XV, Section C.1]

3.15.1.2 Timely orders are routinely reviewed and outdated material removed. [DOE 5480.19, Chapter XV, Section C.3]

\subsection{TECHNICAL PROCEDURES}

\subsubsection{Performance Objective}

Procedures are developed for all expected situations and evolutions, with a consistent format, and in a clear and lucid style. [DOE 5480.19, Chapter XVI] 


\section{Criteria}

3.16.1.1 Programs are established and implemented for procedure development, approval, revision, review, issuance, and cancellation. [DOE 5480.19, Chapter XVI, Section C.1; DOE 4330.4B, Chapter II, Section 6.3.1; WHC-CM-3-5, Section $12.5,5.0]$

3.16.1.2 Procedure writers are selected on the basis of training and/or experience. Procedures are written by knowledgeable individuals. Facility management designates a staff to support procedure writing, approval, and modification. [DOE 4330.4B, Chapter II, Section 6.3.1; WHC-CM-3-5, Section 12.5, 5.0]

\subsubsection{Performance Objective}

Facility procedures ensure that the authorization basis and safety envelope are maintained. [DOE 5480.19, Chapter XVI]

Criteria

3.16.2.1 Following the procedure as written does not result in the operation straying outside of the Authorization Basis, for example, Technical Safety Requirements/Operational Safety Requirements (TSRs/OSRs), safety envelope, or environmental release permit limits. [DOE 5480.19, Chapter XVI, C.2.b]

3.16.2.2 Facility technical procedures are verified to ensure that safety limit controls and TSR/OSR are incorporated. [DOE 5480.19, Chapter XVI, Section C.5; DOE 4330.4B, Chapter II, Section 6.3.1; WHC-CM-3-5, Section 12.5, 5.3]

3.16.2.3 Initial conditions and prerequisites are detailed. [DOE 5480.19, Chapter XVI, Section C.2.b; DOE 4330.4B, Chapter II, Section 6.3.1; WHC-CM-3-5, Section $12.5,5.3]$

3.16.2.4 Each step in the procedure contains only one action, which is described with the appropriate level of detail. Steps are arranged logically in sequential order. [DOE 5480.19, Chapter XVI, Sections C.2.f and C.2.g; DOE 4330.4B, Chapter II, Section 6.3.1; DOE-STD-1029-92; WHC-CM-3-5, Section 12.5, 5.3]

3.16.2.5 Warnings, cautions, and notes precede the steps to which they apply, and contain no action steps. [DOE 5480.19, Chapter XVI, Sections C.2.h and C.2.i; DOE 4330.4B, Chapter II, Section 6.3.1; DOE-STD-1029-92; WHC-CM-3-5, Section 12.5, 5.3]

3.16.2.6 Human factors are considered during procedure development. [DOE-STD-1029-92; WHC-CM-3-5, Section 12.5, 5.3] 


\subsubsection{Performance Objective}

Procedure changes (on-the-spot modifications to a procedure, which do not require re-typing or reissue) and revisions (new re-typed, re-approved versions of the procedure) are documented and approved. [DOE 5480.19, Chapter XVI]

\section{Criteria}

3.16.3.1 Changes and revisions (that is, modifications) are documented, accessible, and reflected in all procedure copies used by procedure users. [DOE 5480.19, Chapter XVI, Sections C.3.d and C.3.e; DOE 4330.4B, Chapter II, Section 6.3.6; WHCCM-3-5, Section 12.5, 5.4]

3.16.3.2 When in error, procedures are revised. [DOE 5480.19, Chapter XVI, Section C.3.b; DOE 4330.4B, Chapter II, Section 6.3.5; WHC-CM-3-5, Section 12.5, 5.4]

3.16.3.3 Procedures are modified to reflect changes in the facility. [DOE 5480.19, Chapter XVI, Section C.3.d; DOE 4330.4B, Chapter II, Section 6.3.6; WHC-CM-3-5, Section 12.5, 5.4]

3.16.3.4 Procedure modifications are communicated to procedure users. [DOE 5480.19, Chapter XVI, Section C.3.e; DOE 4330.4B, Chapter II, Section 6.3.6; WHCCM-3-5, Section 12.5, 5.5]

\subsubsection{Performance Objective}

Procedures are reviewed and approved prior to issue for use. [DOE 5480.19, Chapter XVI] Criteria

3.16.4.1 Procedures have reviews for specific technical, operational, administrative, and quality assurance (QA) details. [DOE 5480.19, Chapter XVI, Section C.5; DOE 4330.4B, Chapter II, Section 6.3.2; WHC-CM-3-5, Section 12.5, 5.4]

3.16.4.2 Reviews (verification and validation) are conducted and documented by members of organizations affected by the procedure, such as those specifically identified to accomplish steps in the procedure. [DOE 5480.19, Chapter XVI, Section C.5; DOE 4330.4B, Chapter II, Section 6.3.2; WHC-CM-3-5, Section 12.5, 5.4]

3.16.4.3 Procedure reviewers (verifiers and validators) are trained in revicw techniques. [WHC-CM-3-5, Section 12.5, 5.1]

3.16.4.4 Procedures are validated (for useability and correctness) by defined methods in the facility (for operating and maintenance procedures) or by desk review (administrative procedures) to ensure workability. [DOE 5480.19, Chapter XVI, Section C.5; DOE 4330.4B, Ch. II, Section 6.3.3; WHC-CM-3-5, Section 12.5, 5.4] 
3.16.4.5 Procedure review comment resolutions are documented. [WHC-CM-3-5, Section $12.5,5.4]$

3.16.4.6 Emergency operating procedures are approved by the line manager (or designee) and others as determined by the procedure's Approval Designator. [DOE 5480.19, Chapter XVI, Section C.4; DOE 4330.4B, Chapter II, Section 6.3.4; WHCCM-3-5, Section 12.7]

3.16.4.7 Administrative procedures are approved by cognizant personnel, as determined by the organization initiating the procedure.

3.16.4.8 Approvals are documented. [WHC-CM-3-5, Section 12.5, 5.4]

\subsubsection{Performance Objective}

Procedures are reviewed at periodic intervals.

\section{Criteria}

3.16.5.1 The frequency of periodic reviews is based on a schedule. [DOE 5480.19, Chapter XVI, Section C.5; DOE 4330.4B, Ch. II, Section 6.3.6; WHC-CM-3-5, Section $12.5,5.4]$

3.16.5.2 Review includes criteria from section 3.16.4.

\subsubsection{Performance Objective}

Controlled and working (performance or disposable) procedure copies are available.

\section{Criteria}

3.16.6.1 Controlled copies of all procedures are current and are accessible to the procedure user. [DOE 5480.19, Chapter XVI, Section C.6; DOE 4330.4B, Chapter II, Section 6.3.5; WHC-CM-3-5, Section 12.5, 5.5]

3.16.6.2 Working copies of controlled documents are available during procedure execution. [DOE 5480.19, Chapter XVI, Section C.6; DOE 4330.4B, Chapter II, Section 6.3.5; WHC-CM-3-5, Section 12.5, 5.5]

3.16.6.3 Controlled annunciator (alarm) response procedures are easily available to those procedure users who respond to alarms. [DOE 5480.19, Chapter XVI, Section C.6; WHC-CM-3-5, Section 12.5, 5.5] 


\subsubsection{Performance Objective}

Operations are conducted in accordance with written procedures that reflect the facility design basis.

\section{Criteria}

3.16.7.1 Procedure users are trained in procedure use. [DOE 5480.19, Chapter XVI, Section C.7; WHC-CM-3-5, Section 12.5, 5.1]

3.16.7.2 Procedure exist that govern procedure receipt, control, use, and modification. [DOE 5480.19, Chapter XVI, Section C.7; DOE 4330.4B, Chapter II, Section 6.3.6; WHC-CM-3-5, Section 12.5, 5.0]

3.16.7.3 Procedure users are aware that they are authorized to take whatever action is necessary during emergency conditions to place the facility in a safe condition and to protect equipment, personnel, and public safety without first initiating a procedure change. [DOE 5480.19, Chapter XVI, Section C.7; DOE 4330.4B, Chapter II, Section 6.3.5; WHC-CM-3-5, Section 12.5, 5.5]

\subsection{OPERATOR AID POSTINGS}

\subsubsection{Performance Objective}

Essential operator aids are made available to operators and are controlled to improve execution of existing procedures. [DOE 5480.19, Chapter XVII]

\section{Criteria}

3.17.1.1 The preparation, approval, control, and use of operator aids are defined and communicated to responsible personnel. [DOE 5480.19, Chapter XVII, Sections C.1, C.2, C.3, and C.4]

3.17.1.2 Operator aids are routinely reviewed to maintain operator aids accurate and up-todate and to ensure timely incorporation into procedures where appropriate. [DOE 5480.19, Chapter XVII, Section C.6]

3.17.1.3 All approved operator aids are controlled with a reference copy being maintained. [DOE 5480.19, Chapter XVII, Section C.5] 


\subsection{EQUIPMENT AND PIPING LABELING}

\subsubsection{Performance Objective}

Equipment and piping are accurately labeled to assist operations and maintenance personnel in positively identifying equipment that they operate or repair. [DOE 5480.19, Chapter XVIII]

\section{Criteria}

3.18.1.1 Procedures and responsibilities are defined and communicated with respect to maintaining plant labeling. [DOE 5480.19, Chapter XVIII, Section B]

3.18.1.2 Missing or damaged labels are identified and replaced during routine surveillances and special operations to ensure labeling accuracy. [DOE 5480.19, Chapter XIII, Section C.4]

3.18.1.3 A process is defined and implemented for ensuring that required labels are placed in the facility in a timely manner. [DOE 5480.19, Chapter XVIII, Section C.4.6]

3.18.1.4 Labeling of controls and displays is consistent in format and legibility. Information on component labels is consistent with information found in facility procedures. Abbreviations and nomenclature are standardized and understood by personnel.

[DOE 5480.19, Chapter XVIII, Section C.2]

\subsection{PREREQUISITES}

None.

\subsection{SPECIAL APPROVALS}

None.

\subsection{REFERENCES}

The following documents were used to create this OP section:

DOE O 232.I (5000.3B), "Preamble: Occurrence Reporting and Processing of Operations," 2 July 1993.

DOE 5480.19, Conduct of Operations Requirements for DOE Facilities, 18 May 1992.

DOE 4330.4B, Maintenance Management Program, 10 February 1994.

DOE-STD-1029-92, Writer's Guide for Technical Procedures. 
WHC-CM-3-5, Technical Procedures Standard, 5 July 1988.

WHC-SD-MP-SRID-001, Tank Waste Remediation System Standards and Requirements Identification Document, 30 January 1996. 


\section{MAINTENANCE}

\subsection{PURPOSE}

This section provides maintenance functional area elements, performance objectives, and criteria for use by Tank Waste Remediation System (TWRS) operational activities to ensure compliance with applicable Federal Regulations and Department of Energy (DOE) Orders as defined in the Tank Farm Remediation System (TWRS) Standards and Requirements Identification Document (S/RID) and the Maintenance Program.

\section{$2.0 \quad$ SCOPE}

The performance objectives and criteria (PO\&C) apply to all TWRS facilities and organizations subject to evaluation under the TWRS Management Assessment Program.

\subsection{FUNCTIONAL AREA ELEMENTS}

\subsection{MAINTENANCE IMPLEMENTATION PLAN}

\subsubsection{Performance Objective}

Maintenance program elements are implemented through approved plans.

Criteria

3.1.1.1 Nuclear facilities have a Maintenance Implementation Plan (MIP). [DOE 4330.4B, Paragraph 10.a. and Chapter 1, Section 3.3]

3.1.1.2 Maintenance Programs are developed, documented, and implemented using a graded approach that relates resource expenditure to facility specific requirements such as safety, operational reliability, environmental compliance, safeguards and security, programmatic mission, and preservation. [DOE 4330.3B, Paragraphs 10b, 10d, $10 \mathrm{e}]$

\subsection{ORGANIZATION AND ADMINISTRATION}

\subsubsection{Performance Objective}

Maintenance organization and administration cnsure effective implementation and control of maintenance activities. 


\section{Criteria}

3.2.1.1 The assignment of responsibilities and authority for all levels of the maintenance organization is clearly defined and understood by maintenance personnel, including interfaces with supporting groups. [DOE 4330.4B, Chapter I, Section 3.1 and Chapter II, Section 2.3.1, 10a(3)]

3.2.1.2 Sufficient numbers of qualified maintenance personnel are available to allow maintenance organizations to adequately support operations while maintaining training of maintenance personnel. [DOE 4330.4B, Chapter II, Section 2.3.3]

3.2.1.3 The Maintenance Program is developed, documented, and implemented using a graded approach. [DOE 4330.4B, Chapter I, Section 3.1 and Chapter II, Section 1]

3.2.1.4 Implementation and control of maintenance activities are achieved primarily by establishing written policies, procedures, and standards for maintenance. [DOE 4330.4B, Chapter II, Section 2.1]

3.2.1.5 A performance feedback program, such as performance appraisals, is used to evaluate facility maintenance personnel performance. [DOE 4330.4B, Chapter II, Section 2.3.5]

3.2.1.6 Maintenance management presence and oversight are apparent by maintenance managers' participation in facility inspections including monitoring facility equipment conditions and review and observation of the maintenance programs. [DOE 4330.4B, Chapter I, Section 3.1.1 and Chapter II, Sections 14 and 15]

3.2.1.7 Maintenance management effectively control maintenance staffing and assignment to best use available manpower, training, qualifications, and special skills and area knowledge. [DOE 4330.4B, Chapter I, Section 3.1.1 and Chapter II, Section 2]

\subsection{TRAINING AND QUALIFICATION OF MAINTENANCE PERSONNEL}

\subsubsection{Performance Objective}

The maintenance training and qualification program is implemented to develop and maintain the knowledge and skills of maintenance personnel.

\section{Criteria}

3.3.1.1 Maintenance management supports all training schedules and provides feedback to training departments in order to adjust course content and emphasis as required. [DOE 4330.4B, Chapter I, Section 3.1.4 and Chapter II, Section 3.1] 
3.3.1.2 Maintenance management provides guidance for maintenance training tasks. [DOE 4330.4B, Chapter I, Section 3.1.4 and Chapter II, Section 3.1]

3.3.1.3 On-the-job-training (OJT) is conducted by maintenance personnel qualified as trainers/evaluators. [DOE 4330.4B, Chapter I, Section 3.1.4 and Chapter II, Section 3.3.4]

3.3.1.4 Maintenance management ensures that maintenance trainees complete needed training requirements prior to assignment to independently perform a task on equipment. [DOE 4330.4B, Chapter II, Section 3.3.4]

3.3.1.5 Maintenance management ensures enginecring personnel are trained in the principles and methods of root cause analysis. [DOE 4330.4B, Chapter II, Section 3.3.6]

3.3.1.6 Maintenance personnel knowledge, which is attained by adequate training and/or formal qualification, is evidenced by an appropriate understanding of required areas [DOE 4330.4B, Chapter I, Section 3.1.4 and Chapter II, Section 3; DOE 5480.11, Section 9.0; and DOE5480.20A, Chapter I, Section 7.g]

3.3.1.7 Adequate maintenance training facilities and equipment for training of maintenance personnel are provided to ensure safe, efficient, and high-quality maintenance. [DOE 4330.4B, Chapter I, Section 3.5.1 and Chapter II, Section 3.2]

\subsection{CONDUCT OF MAINTENANCE}

\subsubsection{Performance Objective}

Maintenance is conducted in a safe and effective manner to support each facility condition and operation on the site.

Criteria

3.4.1.1 Maintenance supervisors routinely monitor work in progress to ensure maintenance activities are conducted in accordance with DOE and facility policies and procedures. [DOE 4330.4B, Chapter II, Section 8.3.3]

3.4.1.2 Maintenance personnel are kept knowledgeable of procedural changes; site/facility policies that affect their activities; and lessons learned from past and current facility. site, and industry experience. [DOE 4330.4B, Chapter I, Section. 3.7.7 and Chapter II, Section 15, 16, 17]

3.4.1.3 Maintenance supervisors recognize and encourage good work practices; poor work practices are corrected on the spot. [DOE 4330.4B, Chapter II, Section 8.3.3] 
3.4.1.4 Appropriate maintenance personnel are aware of post-maintenance test requirements and results and take corrective action, as necessary. [DOE 4330.4B, Chapter I, Section 3.4.7, Chapter II, Section 9.3.4 and DOE 5480.19, Chapter 8, Section C.7]

3.4.1.5 Maintenance supervisors review completed work control documents to ensure that they are complete (including documentation of suspected failure to mechanisms, post-maintenance testing results, maintenance and test equipment utilized) and that all required reviews and approval signatures are present. [DOE 4330.4B, Chapter II, Section 8.3.4]

3.4.1.6 Maintenance is performed by, or under the direct supervision of, personnel who have completed adequate training or formal qualification associated with the tasks to be performed; such qualification is documented and understood. [DOE 4330.4B, Chapter I, Section 3.1.4 and Chapter II, Section 3]

3.4.1.7 Maintenance personnel conduct work activities in a quality manner, which includes utilization of approved procedures, pre-job briefings, performing work as specified in approved work packages, post-job evaluations, and maintaining quality documentation. Additionally, exposure to hazardous and radioactive materials is minimized. [DOE 4330.4B, Chapter II, Section 8.2]

3.4.1.8 Maintenance personnel understand and comply with programs to identify and correct deficiencies. [DOE 4330.4B, Chapter I, Section 3.6.3 and Chapter II, Section 8.3.1]

3.4.1.9 Subcontract personnel perform maintenance under the same controls and procedures, and to the same standards, as in-house maintenance personnel. [DOE 4330.4B, Chapter I, Section 3.1.1 and Chapter II, Section 8.3.6]

3.4.1.10 Maintenance persomel are cognizant of the effects of modifications prior to maintaining modified structures, systems, and equipment. [DOE 4330.4B, Chapter II, Section. 18.3.1]

3.4.1.11 Maintenance standards are established with input from the maintenance staff and craft personnel. [DOE 4330.4B, Chapter II, Section 2.2]

3.5 MAINTENANCE FACILITIES, EQUIPMENT, AND MATERIAL

\subsubsection{Performance Objective}

Facilities, equipment, and material effectively support the performance of maintenance activities. 
Criteria

3.5.1.1 Maintenance shop fabrication areas provide for segregation of materials by type to prevent cross-contamination or use of wrong materials (such as, stainless steel segregated from carbon steel). [DOE 4330.4B, Chapter I, Section. 3.5.3 and Chapter II, Section 11.3.3]

3.5.1.2 Maintenance programs for evaluating the adequacy of maintenance facilities, equipment, and tools are established to ensure that maintenance activities can be safely and effectively accomplished. [DOE 4330.4B, Chapter II, Section 4.2]

3.5.1.3 Portable measurement and test equipment (M\&TE) is calibrated and controlled to ensure accuracy and traceability. The calibration status is readily apparent. [DOE 4330.4B, Chapter I, Section 3.5.4 and Chapter II, Section 12]

3.5.1.4 M\&TE are identified, categorized (that is, calibrated or not calibrated), and current in calibration requirements. [DOE 4330.4B, Chapter II, Section 12.3.1]

3.5.1.5 Appropriate safety devices and personnel safety equipment are provided, periodically inspected where necessary, and used. [DOE 4330.4B, Chapter II, Sections 13.3.1 and 13.3.2]

3.5.1.6 Calibration standards that are traceable to the National Institute of Standards and Technology or other nationally recognized standards are used in calibration of M\&TE. These standards are kept in designated storage locations. [DOE 4330.4B, Chapter I, Section 3.5.4 and Chapter II, Section 12.3.2]

3.5.1.7 Instrument standards have an uncertainty rating of no more than one-fourth of the specified uncertainty for the M\&TE under calibration, or an exception is justified per WHC procedures. [DOE 4330.4B, Chapter II, Section 12.3.2(b)]

3.5.1.8 A documented system is established to provide for periodic safety inspection of lifting, hoisting, and rigging equipment. [DOE 4330.4B, Chapter I, Section 3.5.5 and Chapter II, Section 13.3.3]

3.5.1.9 Lay down and staging areas are identified and controlled. [DOE 4330.4B, Chapter I, Section 3.5.1 and Chapter II, Section 4.3.1]

3.6 PLANNING, SCHEDULING, AND WORK CONTROL

\subsubsection{Performance Objective}

The planning, scheduling, and control of work ensures that identified maintenance actions are properly completed in a safe, timely, and effective manner. 


\section{Criteria}

3.6.1.1 Maintenance management ensures high quality maintenance performance by establishing an organization that provides time for long-range planning. [DOE 4330.4B, Chapter I, Sections 3.1.1 and 3.1.2 and Chapter II, Sections 2.2 and 2.3.2]

3,6.1.2 The work control system provides management with a means for determining the status of outstanding work orders and maintenance planning. [DOE 4330.4B, Chapter I, Section 3.4.8 and Chapter II, Sections 2, 3, and 7]

3.6.1.3 Identified problems and deficiencies in equipment or systems are reported, evaluated, prioritized based on functional classification (that is, Nuclear Safety (NS), Critical Processes (CP), Primary System (PS), General Services (GS)), and corrected. [DOE 4330.4B, Chapter I, Section 3.4.8 and Chapter II, Sections 7.3.2, 8.3.1, and 8.3.2]

3.6.1.4 The backlog of maintenance work is monitored and effectively managed to ensure that work is not delayed unnecessarily. [DOE 4330.4B, Chapter I, Section 3.4.8 and Chapter II, Section 2.3.4]

3.6.1.5 Work planning and scheduling includes conditions such as material, tool, and manpower requirements; prerequisites; interdepartmental coordination; safety considerations; quality control requirements; and actions needed to minimize exposures to radiation and hazardous materials. [DOE $4330.4 \mathrm{~B}$, Chapter I, Section 3.4.2 and Chapter II, Sections 7.3.1 and 7.3.2]

3.6.1.6 The concept of as low as is reasonably achievable (ALARA), including cost-benefit, is emphasized in planning all work involving exposures to radioactive and hazardous materials. [DOE 4330.4B, Chapter I, Section 3.1.4 and Chapter II, Section 7.3.1]

3.6.1.7 Maintenance scheduling is integrated into and coordinated with the overall facility schedule, which considers prerequisites, job-site preparation, and other support groups. [DOE 4330.4B, Chapter I, Section 3.4.6 and Chapter II, Section 7.3.2]

3.6.1.8 Work packages include detailed instructions, as required by the complexity of the work involved, to safely and properly control each part of the job. [DOE 4330.4B, Chapter I, Section 3.4.1 and Chapter II, Sections 6.3.1, 7.2, 7.3, and 8.3.2]

3.6.1.9 Work clearance permits and other special safety-related permits, such as those for welding and burning and for enclosed space entry, are required; copies are available at the job site for use by the workers. [DOE 4330.4B, Chapter I, Section 3.4.5 and Chapter II, Section 8.3.1]

3.6.1.10 Post-maintenance testing requirements are clearly defined and include the required elements. [DOE 4330.4B, Chapter I, Sections 3.4.1 and 3.4.7 and Chapter II, Section 9] 
3.6.1.11 Management control of work is accomplished by using an effective priority assignment system. [DOE 4330.4B, Chapter I, Section 3.4.6 and Chapter II, Section 7.3.2]

3.6.1.12 Advance planning is established for scheduled and unscheduled outages, including considerations such as work priority, system conditions, length of outage required, pre-staging of documents and materials, and coordination of support activities. [DOE 4330.4B, Chapter I, Section 3.4.2 and Chapter II, Section 7.3.4]

3.6.1.13 Work order packages identify or include: applicable guidelines, procedures, special precautions to be followed when the work is on hazardous systems, requirements associated with Technical Specifications/Operational Safety Requirements or other technical operational requirements, and any requirements for special surveillance to be performed. [DOE 4330.4B, Chapter I, Section 3.4.1 and Chapter II, Section. 8.3.2]

3.6.1.14 Completed work control documents are reviewed to verify proper completion of administrative requirements and to identify preventive maintenance program adjustments that are needed. [DOE 4330.4B, Chapter I, Section 3.7.2 and Chapter II, Section 7.3.1]

3.6.1.15 Temporary repairs receive adequate technical review and are appropriately documented and tracked until permanent repairs and corrective actions have been completed in accordance with an approved Temporary Modification Program.

[DOE 4330.4B, Chapter I, Section 3.6.4 and Chapter II, Sections 8.2 and 14.3]

3.6.1.16 Maintenance history records and operating experience are appropriately considered in planning for corrective maintenance, modifications, preventive maintenance, and predictive maintenance. [DOE 4330.4B, Chapter I, Section 3.4.9 and Chapter II, Section 16.3.3]

3.6.1.17 Work is properly authorized and controlled. [DOE 4330.4B, Chapter I, Section 3.4.1 and Chapter II, Section 7 and 8]

3.6.1.18 A master equipment list (MEL) and database for structures, systems, and components (SSCs) designcd to support work control processes, preventive and corrective maintenance programs, equipment assignments, and tracking in the facility has been established. [DOE 4330.4B, Chapter II, Sections 5.3.1 and 16.3.1]

\subsection{CORRECTIVE MAINTENANCE}

\subsubsection{Performance Objective}

The material condition of components and equipment is maintained to support safe and effective operation of all facilities on the site 
Criteria

3.7.1.1 Mechanical systems and equipment are in good working order. [DOE 4330.4B, Chapter I, Section 3.2 and Chapter II, Section 14.3]

3.7.1.2 Fluid system leaks are minimized, monitored, appropriately corrected or controlled, and assessed for impact on safe operations. [DOE 4330.4B, Chapter I, Section 3.2 and Chapter II, Section 14.3]

3.7.1.3 Electrical and electronic equipment is operable and appropriately protected from adverse environmental conditions. [DOE 4330.4B, Chapter I, Section 3.2 and Chapter II, Section 14.3]

3.7.1.4 Mechanical operators, fasteners, and supports are in place and operable. [DOE 4330.4B, Chapter I, Section 3.2 and Chapter II, Section 14.3]

3.7.1.5 Equipment, structures, and systems are properly preserved and insulated. [DOE 4330.4B, Chapter I, Section 3.2; and Chapter II, Section 14.3]

3.7.1.6 An inspection program is established where members of management, including maintenance management, identify and ensure that deficiencies have been corrected. This ensures that these practices conform to management's standards and expectations. [DOE 4330.4B, Chapter I, Sections 3.2 and 3.7.4 and Chapter II, Section 14]

3.7.1.7 An overview of equipment failures, out-of-service equipment, alarms, and indicators that show failed equipment and instrumentation and overall operating versus shutdown times ensures that the maintenance program is effective in the overall sense. [DOE 4330.4B, Chapter I, Section 3.7.3 and Chapter II, Section. 15.3.4]

3.7.1.8 Industrial safety and radiological hazards are minimized. [DOE 4330.4B, Chapter I, Section 3.2.1 and Chapter II, Section 14.3.1]

3.7.1.9 Coatings or coverings used to seal walls and floors in potentially contaminated areas are in good condition and assist in controlling contamination. [DOE 4330.4B, Chapter I, Section 3.2.1 and Chapter II, Section 14.3.1]

3.7.1.10 Protective cabinet doors and electrical enclosure covers are installed to maintain design integrity. [DOE 4330.4B, Chapter I, Section 3.2.1 and Chapter II, Section 14.3.1] 


\subsection{PREVENTIVE MAINTENANCE}

\subsubsection{Performance Objective}

Preventive maintenance (PM) contributes to maximum performance and reliability of systems and equipment important to operations.

\section{Criteria}

3.8.1.1 Good lubrication practices are evident and a lubrication schedule is implemented. [DOE 4330.4B, Chapter I, Section 3.6.1 and Chapter II, Section 14.3]

3.8.1.2 Instrumentation, controls, and associated indicators are operable, and are calibrated as required. [DOE 4330.4B, Chapter I, Section 3.6.1 and Chapter II, Section 14.3]

3.8.1.3 A PM Program exists that includes systems and equipment that affect safe and reliable operations. [DOE 4330.4B, Chapter I, Section 3.6.1 and Chapter II, Section 5.3.2(b)]

3.8.1.5 The backlog of PM is minimized. PM activities are not changed, revised, or waived beyond the grace period without justification, documentation, and management approval. [DOE 4330.4B, Chapter I, Section 3.6.1 and Chapter II, Sections 5.3.4 and 7.3.2]

3.8.1.6 Predictive Maintenance techniques, such as vibration analysis and oil analysis, are used to assess equipment performance. [DOE 4330.4B, Chapter I, Section 3.6.1 and Chapter II, Section 5.3.2]

3.8.1.7 Documentation of PM provides a record of work performed, associated data and, where appropriate, the condition of the equipment. [DOE 4330.4B, Chapter I, Section 3.6.1 and Chapter II, Section 16.3]

3.8.1.8 The effectiveness of the PM Program is periodically evaluated at an appropriate management level and the results are used to make program improvements. [DOE 4330.4B, Chapter I, Section 3.6.1 and Chapter II, Section 16.3.3]

3.8.1.9 The PM Program includes provisions for determining and mitigating the effects of age-related degradation of components and systems, including in-service inspection. [DOE 4330.4B, Chapter I, Section 3.6.1 and Chapter II, Section 5.2]

3.8.1.10 The scope of Preventive and Predictive Maintenance programs is established by considering essential source data such as operations maintenance surveillances, inspections, and in-service inspections. [DOE 4330.4B, Chapter II, Section 5.1] 
3.8.1.11 A Freeze Protection Plan is prepared, approved, and implemented to ensure protection of the equipment/facility from the effects of cold weather and/or freezing. [DOE 4330.4B, Chapter I, Section 4.2 and Chapter II, Section 19.1.3]

3.8.1.12 $\quad$ PM justification and frequencies changes are approved by the maintenance manager [DOE 4330.4B, Chapter II, Section 5.3.3]

\subsection{MAINTENANCE HISTORY}

\subsubsection{Performance Objective}

Maintenance history evaluation and systematic root cause analyses is used to support maintenance activities and to maximize equipment performance.

\section{Criteria}

3.9.1.1 Maintenance history is effectively documented in the Maintenance History Program, and history records are maintained for systems, equipment, and components that affect safe and reliable operations. [DOE 4330.4B, Chapter I, Section 3.4.9 and Chapter II, Section 16]

3.9.1.2 Maintenance history records are readily accessible. [DOE 4330.4B, Chapter I, Section 3.4.9 and Chapter II, Section 16.3.3]

3.9.1.3 Maintenance history is utilized to identify and evaluate trends and persistent maintenance problems. Provisions are established to initiate appropriate corrective action where indicated. A systematic analysis methodology is employed to identify root causes. [DOE 4330.4B, Chapter I, Sections 3.4.9 and 3.6.2 and Chapter II, Section 17]

3.9.1.4 Information related to the hazardous aspects of maintenance (such as high pressures, temperatures, or radiological, chemical, or other toxic hazards) is recorded for analysis and use in recurring work. [DOE 4330.4B, Chapter I, Section 3.4.1 and Chapter II, Section 8.3.4]

3.9.1.5 The responsibility for collection of maintenance history data and analysis of equipment problems is clearly defined. [DOE 4330.4B, Chapter I, Section 3.4.9 and Chapter II, Section 16.3.2] 


\subsection{PROCEDURES AND DOCUMENTATION}

\subsubsection{Performance Objective}

Maintenance procedures and related documents provide appropriate directions and guidance for work and are used to ensure that maintenance is performed safely and effectively.

\section{Criteria}

3.10.1.1 Procedures are established for administrative control of the Maintenance Program elements. [DOE 4330.4B, Chapter I, Section 3.1.2 and Chapter II, Section 2.3.1]

3.10.1.2 Maintenance policy and administrative procedures receive proper approval and periodic review and are administered as part of a document control system. [DOE 4330.4B, Chapter I, Section 3.1.2 and Chapter 11, Section 6.3.6]

3.10.1.3 Mechanisms for establishing and approving standards and procedures for maintenance activities are in place. In addition, a process for periodically updating these procedures and standards exists. [DOE 4330.4B, Chapter I, Section 3.1.2 and Chapter II, Sections 6.3.4 and 6.3.6]

3.10.1.4 Maintenance procedures are prepared by well-qualified personnel, who are knowledgeable of proper maintenance standards and administrative procedures and familiar with the systems, equipment, and facilities involved. [DOE 4330.4B, Chapter I, Section 3.4.5 and Chapter II, Section. 6.3.1]

3.10.1.5 Records of previous maintenance on a particular system, component, or equipment are used to prepare for new work, especially with regard to safety or when dealing with potential exposure to radioactive or hazardous materials. [DOE 4330.4B, Chapter I, Section 3.4.9 and Chapter II, Section 16.3.3]

3.10.1.6 The preparation, review, approval, and revision of procedures and documents are properly controlled. [DOE 4330.4B, Chapter I, Section 3.4.5 and Chapter II, Section 6.3.6]

3.10.1.7 Procedures are verified or validated in the review cycle prior to first time use. [DOE 4330.4B, Chapter I, Section 3.4.5 and Chapter II, Sections 6.3.2 and 6.3.3]

3.10.1.8 Work procedures, drawings, vendor manuals, and reference materials, including posted job performance aids (used in support of maintenance) are technically accurate and current. [DOE 4330.4B, Chapter I, Section 3.4.5 and Chapter II, Section. 6.3.6]

3.10.1.9 Procedures are readily available, clearly identified, and appropriately used. [DOE 4330.4B, Chapter I, Section 3.4.5 and Chapter II, Section 6.3.5] 
3.10.1.10 Procedures are clear, concise, and contain adequate information for users to understand and perform their activities safely and effectively and are related to Technical Specifications/Operational Safety Requirements or other technical operational requirements. [DOE 4330.4B, Chapter I, Section 3.4.5 and Chapter II, Section 6.3.1]

3.10.1.11 Portions or steps of other documents used or referred to when performing a procedure are specifically identified in the procedure. [DOE 4330.4B, Chapter I, Section 3.4.5 and Chapter II, Section 6.3.1]

3.10.1.12 A policy governing the use of procedures is implemented. [DOE 4330.4B, Chapter I, Section 3.4.5 and Chapter II, Section 6]

3.10.1.13 Temporary changes to procedures, if used, are controlled. [DOE 4330.4B, Chapter I, Section 3.4.5 k. and Chapter II, Section 6.3.6]

3.10.1.14 Special maintenance procedures are provided for equipment that is unusual, especially sensitive, or requires special maintenance skills or qualification. [DOE 4330.4B, Chapter I, Section 3.4.5 and Chapter II, Section 6]

3.10.1.15 Maintenance management ensures that responsibilities for procedure program administration are clearly defined. [DOE 4330.4B, Chapter II, Section 6.3.6]

3.10.1.16 Maintenance management ensures vendor manuals or the portions of a vendor manual and reference materials used are technically accurate and controlled. [DOE 4330.4B, Chapter II, Section 6.3.6]

\subsection{MATERIAL CONTROL}

\subsubsection{Performance Objective}

All phases of receiving, inspecting, handling, storing, retrieving, and issuing of equipment, parts, and materials for conducting maintenance activities are covered by effectively implemented policies and procedures from the time an item is received until it is installed at the facility.

\section{Criteria}

3.11.1.1 Programs are implemented to order, receive, and issue proper parts and material for normal maintenance, outages, and modifications. Methods exist to ensure that stock levels are adjusted, as necessary, to meet maintenance needs. [DOE 4330.4B, Chapter I, Section 3.5.2 and Chapter II, Sections 10 and 11]

3.11.1.2 Material is inspected prior to acceptance and storage to ensure conformance to design requirements. Acceptance is documented and nonconforming items are clearly identified to prevent their use. [DOE 4330.4B, Chapter I, Section. 3.5.3 and Chapter II, Section 11.3.1] 
3.11.1.3 The quality of stored equipment, parts, and material is maintained by PM and environmental and shelf-life controls. [DOE 4330.4B, Chapter I, Sections 3.5.1 and 3.5.2 and Chapter II, Sections 10.3.2 and 11.3.3]

3.11.1.4 Provisions are established for proper storage, segregation, and control of hazardous materials such as chemicals, reagents, explosives, and flammables items. [DOE 4330.4B, Chapter I, Section 3.5.3 and Chapter II, Section 11.3.3]

3.11.1.5 Storage for parts and materials issued for installation is properly controlled. [DOE 4330.4B, Chapter I, Section 3.5.3 and Chapter II, Section 11.3.3]

3.11.1.6 Materials are stored and identified in a manner that results in timely retrieval of requested items. [DOE 4330.4B, Chapter I, Section 3.5.3 and Chapter II, Sections 11.3.3 and 11.3.4]

3.11.1.7 A shelf-life control program is provided for stored items that are important to safe and reliable facility operations. [DOE 4330.4B, Chapter II, Section 11.3.3]

3.11.1.8 Proper engineering control and approval are obtained on any deviation from the design specifications for parts or material. [DOE 4330.4B, Chapter I, Section 3.5.2 and Chapter II, Section 11.3.1]

3.11.1.9 Stock records are maintained, purchase orders are tracked, and safety-related parts are readily traceable from purchase order to installation. [DOE 4330.4B, Chapter I, Sections 3.5.2 and 3.5.3, and Chapter II, Sections 11.3.1 and 11.3.4]

3.11.1.10 Parts and material are properly controlled, segregated, and identified during the interval between storeroom checkout and installation. [DOE 4330.4B, Chapter I, Section 3.5.3 and Ch. II, Section 11.3.4]

3.11.1.11 Mechanisms are established to provide for the expeditious procurement of parts and material on a high priority basis, when needed. [DOE 4330.4B, Chapter I, Section 3.5.2 and Chapter II, Section 10.3.3]

3.11.1.12 A program is established for acquisition of replacement parts that are not available from the original supplier. [DOE 4330.4B, Chapter I, Section 3.5.2 and Chapter II, Section 10.3.3]

3.11.1.13 Receipt inspection and testing programs are established for procurement of new parts to increase the probability that products perform as expected. The engineering staff is involved in the selection of procured parts, in determining the critical characteristics of the product that are verified at acceptance, in determining the specific testing requirements applicable to the related products, and in evaluating the test results. [DOE 4330.4B, Chapter I, Section 3.5.2 and Chapter II, Section 11.3.1] 
3.11.1.14 An adequate equipment spare parts list is identified and adequate spares are onhand or on-site. [DOE 4330.4B, Chapter I, Section 3.4.5 and Chapter II, Section 10.1]

\subsection{PREREQUISITES}

None.

\subsection{SPECIAL APPROVALS}

None

\subsection{REFERENCES}

The following documents were used to create this $\mathrm{MN}$ section:

DOE Order 4330.4B, Maintenance Management Program, 10 February 1994.

DOE 5480.11, Radiation Protection for Operational Workers, 21 December 1988.

DOE Order 5480.19, Conduct of Operation Requirements for DOE Facilities, Change 1, 18 May 1992.

DOE Order 5480.20A, Personnel Selection, Qualification, Training, and Staffing Requirements at DOE Reactor and non-Reactor Nuclear Facilities, 15 November 1994.

WHC-SD-MP-SRID-001, Tank Waste Remediation System Standards and Requirements Identification Document, 30 January 1996. 


\section{RADIATION PROTECTION}

\subsection{PURPOSE}

This section provides radiation protection functional area elements, performance objectives, and criteria intended for use by Tank Farms operational activities to ensure compliance with the applicable Federal Regulations, Department of Energy (DOE) Orders, and the DOE Radiological Control Manual as defined in the Tank Wastes Remediation System (TWRS) Standards and Requirements Identification Document (S/RID) and the Radiation Protection Program.

\subsection{SCOPE}

The performance objectives and criteria (PO\&C) apply to all Tank Farm facilities and organizations subject to evaluation under TWRS Management Assessment Program.

\subsection{FUNCTIONAL AREA ELEMENTS}

The following are the radiation protection functional areas elements. Each functional area element has performance objectives and subsequent criteria. The criteria are used to assess the objectives.

\subsection{EXPOSURE REDUCTION AND ALARA}

\subsubsection{Performance Objective}

Measures are taken to maintain radiation exposure in controlled areas as low as is reasonably achievable (ALARA) through facility and equipment design and administrative control. The primary methods used are physical design features (such as, confinement, ventilation, remote handling, and shielding). Administrative controls and procedural requirements are employed only as supplemental methods to control radiation exposure. [10 CFR 835, Part 1001(a)]

\section{Criteria}

3.1.1.1. For specific activities where use of physical design features are demonstrated to be impractical, administrative controls and procedural requirements are used to maintain radiation exposures ALARA.

[10 CFR 835, Part 1001(b)] 
3.1.1.2 During routine operations, the combination of design features and administrative control procedures provide: [10 CFR 835, Part 1003(a)]

(1) The anticipated magnitude of the total effective dose equivalent shall not exceed 5 rems $(0.05$ sievert) in a year;

(2) The anticipated magnitude of the committed dose equivalent to any organ or tissue, plus any deep dose equivalent from external exposure, shall not exceed 50 rems ( 0.5 sievert) in a year; and

(3) Exposure levels are ALARA.

3.1.1.3 Technical requirements for the conduct of work, including construction, modifications, operations, maintenance and decommissioning, incorporate radiological criteria to ensure safety and maintain radiation exposures ALARA. The primary methods used to maintain exposures ALARA are facility and equipment design features. These features may be augmented by administrative and procedural requirements. To accomplish this, the design and planning processes incorporate radiological considerations in the early planning stages. [DOE/EH0256T Chapter 3, Part 1, Article 311]

\subsubsection{Performance Objective}

Sufficient controls are established to limit and control the exposure to ionizing radiation of TWRS personnel.

\section{Criteria}

3.1.2.1 The installation, use, and removal of temporary shielding is controlled by procedure. [DOE/EH0256T Chapter 3, Part 1, Article 314.1]

3.1.2.2 The effects of the additional weight of temporary shielding on systems and components are evaluated and established to be within the design basis prior to installation. [DOE/EH0256T Chapter 3, Part 1, Article 314.2]

3.1.2.3 Installed temporary shielding is periodically inspected and surveyed to verify effectiveness and integrity. [DOE/EH0256T Chapter 3, Part 1, Article 314.3]

3.1.2.4 Radiation surveys are performed during the alteration or removal of installed temporary shielding. [DOE/EH0256T Chapter 3, Part 1, Article 314.4] 
3.1.2.5 Installed temporary shielding is visibly marked or labeled with the following or equivalent wording: "Temporary Shielding - Do Not Remove Without Permission from Radiological Control." [DOE/EH0256T Chapter 3, Part 1, Article 314.5]

3.1.2.6 Periodically, installed temporary shielding is evaluated to assess the need for its removal or replacement with permanent shielding. [DOE/EH0256T Chapter 3, Part 1, Article 314.6]

3.1.2.7 Where practicable, parts and components are removed to areas with low dose rates to perform work. [DOE/EH0256T Chapter 3, Part 4, Article 342.8]

3.1.2.8 Radiological Control personnel maintain logs to document radiological occurrences, status of work activities, and other relevant information. [DOE/EH0256T Chapter 3, Part 4, Article 343.1]

3.1.2.9 Communication systems required by the Radiological Work Permit (RWP) or technical work document are periodically checked for operability before being placed in the work area and during work. [DOE/EH0526T Chapter 3, Part 4, Article 343.3]

3.1.2.10 Workers keep Radiological Control personnel informed of the status of work activities that affect radiological conditions. [DOE/EH0256T Chapter 3, Part 4, Article 343.4]

\subsubsection{PERFORMANCE OBJECTIVE}

Maintenance and modification plans and procedures are reviewed to identify and incorporate radiological requirements, such as engineering controls and dose and contamination reduction considerations. [DOE/EH0256T Chapter 3, Part 1, Article 312.1]

\section{Criteria}

3.1.3.1 Technical work documents (such as, procedures, work packages, or job or research plans) are used to control hands-on work with radioactive materials. [DOE/EH0256T Chapter 3, Part 1, Article 315.1]

3.1.3.2 Technical work documents used to control radiological work activities are reviewed and approved by the Radiological Control Organization.

[DOE/EH0256T Chapter 3, Part 1, Article 315.2]

3.1.3.3 Radiological Control Hold Points are incorporated into technical work 
documents for steps that require action by the Radiological Control Organization to prevent radiation exposures in excess of administrative control levels, high airborne radioactivity concentrations, or the release of radioactivity to the environment. [DOE/EH0256T Chapter 3, Part 1, Article 315.3]

3.1.3.4 Pre-job briefings are held prior to the conduct of work anticipated to exceed the trigger levels identified. [DOE/EH0256T Chapter 3, Part 1, Article 312.3 and Part 2, Article 324.1]

3.1.3.5 Pre-job briefings are conducted by the cognizant work supervisor. [DOE/EH0256T Chapter 3, Part 2, Article 324.3]

3.1.3.6 Workers and supervisors directly participating in the job, cognizant Radiological Control personnel, and representatives from involved support organizations attend the briefings. [DOE/EH0256T Chapter 3, Part 2, Article 324.4]

3.1.3.7 A summary of topics discussed and attendance at the pre-job briefing are documented. This documentation is maintained with the technical work document. [DOE/EH0256T Chapter 3, Part 2, Article 324.5]

3.1.3.8 Radiological work activities are conducted as specified by the controlling technical work document and RWP. [DOE/EH0256T Chapter 3, Part 4, Article 341.1]

3.1.3.9 The identity of components and systems are verified prior to work. [DOE/EH0256T Chapter 3, Part 4, Article 342.6]

3.1.3.10 Work activities and shift changes are scheduled to prevent idle time in radiation areas. [DOE/EH0256T Chapter 3, Part 4, Article 342.7]

3.13.1 During the performance of jobs for which a pre-job dose estimate was made, the Radiological Control Organization, in cooperation with line management, periodically monitors collective dose accumulation and compares it with the pre-job dose estimate. Differences are reviewed to identify causes and assess the need for corrective actions.

[DOE/EH0256T Chapter 3, Part 4, Article 344.3]

\subsubsection{Performance Objective}

Tasks with the potential to exceed the trigger levels undergo a formal, documented radiological or ALARA review. [DOE/EH0256T Chapter 3, Part 1, Article 312.4] 


\section{Criteria}

3.14.1 Radiological requirements identified as part of the radiological review are documented in the job plans, procedures, or work packages.

[DOE/EH0256T Chapter 3, Part 1, Article 312.5]

\subsubsection{Performance Objective}

An ALARA Committee is established. [DOE/EH0256T Chapter 1, Part 3, Articles 132 and 138]

\section{Criteria}

3.1.5.1 The membership includes managers and workers from the line, the technical support organization and the Radiological Control Organization [DOE/EH0256T Chapter 1, Part 3, Articles 132 and 138]

3.1.5.2 The ALARA Committee makes recommendations to management to improve progress toward minimizing radiation exposure and radiological releases. [DOE/EH0256 T Chapter 1, Part 3, Article 138]

3.1.5.3 Radiological work anticipated to exceed individual or collective dose criteria established in the Hanford Site Radiological Control Manual (HSRCM) is reviewed and approved by the ALARA Committee. [DOE/EH0256T Chapter 3, Part 1, Article 312.6]

\subsubsection{Performance Objective}

Training and qualification of radiological control technicians and their immediate supervisors address routine operations and also focus on recognizing and handling situations in both normal and changing radiological conditions. [DOE/EH0256T Chapter 6, Part 4, Article 641]

\section{Criteria}

3.1.6.1 Radiological Control Technician qualification consists of the standardized core course training material, on-the-job training per the qualification standards, and passing both a final comprehensive written examination and final oral examination board. [DOE/EH0256T Chapter 6, Part 4, Article 642.11

3.1.6.2 Radiological control technician supervisors have supervisory and leadership capabilities to direct the work of technicians; effectively interact with 
crafts, line supervisors, professional staff, and other managers; and be able to respond and direct others in emergency and abnormal situations.

\section{[DOE/EH0256T Chapter 6, Part 4, Article 644.2]}

3.1.6.3 Newly qualified technicians and those still in training are given the opportunity to work with qualified, experienced technicians to foster development. [DOE/EH0256T Chapter 6, Part 4, Article 641]

\subsubsection{Performance Objective}

A performance indicator program for measuring and trending the effectiveness of the Radiological Control Program against predetermined goals is established and maintained. [DOE/EH0256T Chapter 1, Part 2, Article 121.9]

\section{Criteria}

3.1.7.1 Radiological performance goals are reviewed at least annually and revised as appropriate. [DOE/EH0256T Chapter 1, Part 3, Article 132.4]

3.1.7.2 The radiological control manager provides radiation exposure information, such as supplemental dosimeter-readings or volume of waste generated, to supervisors and managers frequently to permit priority management of exposure control. The frequency is consistent with the nature of the workload and the radiation exposure potential. [DOE/EH0256T Chapter 1, Part 3, Article 133.2]

\subsubsection{Performance Objective}

Administrative procedures are written to demonstrate compliance with the provisions of 10 CFR 835.

\section{Criteria}

3.1.8.1 Managers, supervisors, and workers are involved in the development of accurate, clear, written procedures for performing radiological work.

[DOE/EH0256T Chapter 1, Part 2, Article 125.5]

3.1.8.2 The administrative procedures include actions essential to ensure the effectiveness and operability of barricades, devices, alarms, and locks. [10 CFR 835, Part 501(d)]

3.1.8.3 Authorizations are required to perform specific work within the area and include specific radiation protection measures. [10 CFR 835, Part 501(d)] 
3.1.8.4 If during the use of procedures a written requirement cannot be responsibly followed, the work is stopped and guidance is obtained. [DOE/EH0256T Chapter 1, Part 2, Article 125.5]

\subsubsection{Performance Objective}

Personnel associated with work involving radiological controls demonstrate the ability to respond to abnormal situations.

\section{Criteria}

3.1.9.1 Radiological control technicians and their supervisors, line supervisor, and any worker through their supervisor have the authority and responsibility to stop radiological work activities. [DOE/EH0256T Chapter 3, Part 4, Article 345.1]

3.1.9.2 Once radiological work has been stopped, it does not resume until proper radiological control has been reestablished. [DOE/EH0256T Chapter 3, Part 4, Article 345.3]

3.1.9.3 Resumption of radiological work requires the approval of the line manager responsible for the work and the radiological control manager.

[DOE/EH0256T Chapter 3, Part 4, Article 345.4]

\subsubsection{Performance Objective}

Records are maintained to document compliance with radiation protection programs. [10 CFR 835, Part 101 and 701(a)]

\section{Criteria}

3.1.10.1 Radiological control records are complete, accurate, and legible. [DOE/EH0526T Chapter 7, Part 1, Article 713.1]

3.1.10.2 Surveys results for radiation and radioactive material in the workplace is documented and maintained. [10 CFR 835, Parts 401, 403, and 404]

3.1.10.3 Changes in equipment, techniques, and procedures used for monitoring in the workplace are documented. [10 CFR 835, Part 704(e)]

3.1.10.4 Maps with sufficient detail that permit identification of original survey and sampling locations are maintained. [DOE/EH0256T Chapter 7, Part 5, Article 751.1] 
3.1.10.5 Records contain sufficient detail to be meaningful even after the originator is no longer available. [DOE/EH0256T Chapter 7, Part 5, Article 751.1]

3.1.10.6 Radiological surveys are recorded on appropriate standard forms and include the required information. [DOE/EH0256T Chapter 7, Part 5, Article 751.1, 753 and 754]

3.1.10.7 Actions taken to maintain occupational exposures ALARA, as well as facility design and control actions are documented. [10 CFR 835, Part 704(b)]

3.1.10.8 Records of ALARA plans and goals are maintained to demonstrate the adequacy of the ALARA Program. These records include the minutes of ALARA committees and other committees where radiological safety issues are formally discussed. [DOE/EH0256T Chapter 7, Part 4, Article 742]

3.1.10.9 Records are maintained to document the results of internal audits and other reviews of program content and implementation. [10 CFR 835, Part 704(c)]

3.1.10.10 Written declarations of pregnancy are maintained. [10 CFR 835, Part 704(d)]

\subsection{MONITORING AND SURVEYS}

\subsubsection{Performance Objective}

Monitoring of individuals and areas is performed. [10 CFR 835, Part 401(a)] Criteria

3.2.1.1 Area monitoring in the workplace is routinely performed to identify and control potential sources of personnel exposure to radiation and/or radioactive material. [10 CFR 835, Part 401(b)]

3.2.1.2 Instruments and techniques used for radioactive contamination monitoring and control are adequate to measure the intended radiation types, levels, and energies, are appropriate for the environmental conditions, and capable of measuring ambient dose rates. [10 CFR 835, Part 401(c)]

3.2.1.3 Instruments used for monitoring and contamination control are maintained and calibrated on an established frequency of at least once per year, routinely tested for operability, and used by trained/qualified personnel. [10 CFR 835, Part 401(c)] 
3.2.1.4 Monitoring of radiation in the workplace is performed using stationary (area) or portable radiation instruments, or a combination thereof. The instruments are readily available and are capable of measuring ambient radiation dose rates to control radiation exposures. [10 CFR 835, Part 403(b)]

3.2.1.5 Measurements of radioactivity concentrations in the ambient air of the workplace are performed where, under normal conditions, a person is likely to receive an annual intake of 2 percent or more of the specified Annual Limitation Intake (ALI) values. [10 CFR 835, Part 403(a)]

3.2.1.6 Continuous air monitoring equipment has alarm capability and sufficient sensitivity to alert potentially exposed individuals that immediate action is necessary in order to minimize or terminate inhalation exposures. [10 CFR 835, Part 403(a)l

3.2.1.7 Routine radiation surveys are performed in accordance with the DOE specified minimum frequencies. [DOE/EH0256T Chapter 5, Part 5, Articles 551 and 552.1]

3.2.1.8 Routine contamination surveys are conducted in Radiological Buffer Areas established for the control of contamination and other areas with the potential for spread of contamination. [DOE/EH0256T Chapter 5, Part 5, Articles 551 and 554.1]

3.2.1.9 Contamination surveys incorporate techniques to detect both removable and fixed contamination. [DOE/EH0256T Chapter 5, Part 5, Article 554.3]

3.2.1.10 Surveys are conducted whenever operations are being performed that might result in personnel being exposed to small intense beams of radiation, such as those generated by shielded $x$-ray devices or due to removal or alteration of shielding. [DOE/EH0256T Chapter 5, Part 5, Article 552.3]

\subsection{PERSONNEL EXPOSURE MONITORING}

\subsubsection{Performance Objective}

The TWRS monitors the personnel exposure to ionizing radiation.

\section{Criteria}

3.3.1.1 Personnel dosimetry is provided to and used to monitor exposures to 
external radiation. [10 CFR 835, Part 402(a)]

3.3.1.2 Internal dose evaluation programs (including routine bioassay programs) are conducted for the purpose of monitoring individual exposures to internal radiation. [10 CFR 835, Part 402(c)]

3.3.1.3 The occupational exposure to general employees resulting from $\mathrm{DOE}$ activities, other than planned special exposures and emergency exposure situations, is controlled so that annual limits are not exceeded.

[10 CFR 835, Part 202(a)]

3.3.1.4 Any member of the public exposed to radiation and/or radioactive material during direct on-site access at a DOE site or facility has not exceed 0.1 rem (0.001 sievert) total effective dose equivalent in a year. [10 CFR 835, Part 208]

3.3.1.5 The occupational exposure of a declared pregnant worker is controlled so that limits from the period of conception to birth are not exceeded.

[10 CFR 835, Part 206(a)]

3.3.1.6 The derived air concentration (DAC) values are used in the control of occupational exposures to airborne radioactive material. [10 CFR 835, Part 209(a) with Appendices A and C]

3.3.1.7 General employees who have not received Radiological Worker I or II training are not normally expected to exceed $100 \mathrm{mrem}$ in a year.

[DOE/EH0256T Chapter 2, Part 1, Article 213.5]

\subsubsection{Performance Objective}

Personnel dosimetry is being performed in compliance with the requirements of 10 CFR 835 by the implementation of the DOE-approved Hanford Site Radiological Control Manual (HSRCM) and the Radiation Protection Program.

\section{Criteria}

3.3.2.1 Non-uniform exposures of the skin from X-rays, beta radiation, and/or radioactive material on the skin are assessed. [10 CFR 835, Part 205(a)] 


\subsection{RADIATION AREA}

\subsubsection{Performance Objective}

Personnel entry control is maintained for each radiological area. [10 CFR 835, Part 501(a)]

\section{Criteria}

3.4.1.1 The degree of control is commensurate with existing and potential radiological hazards within the area. [10 CFR 835, Part 501(b)]

3.4.1.2 A combination of postings, barricades, control devices on entryways, visual and audible alarms, locked entryways, and access control systems is used to ensure control. [10 CFR 835, Part 501(c)]

3.4.1.3 No controls are installed at any radiological area exit that would prevent rapid evacuation of personnel under emergency conditions. [10 CFR 835, Part 501(e)]

3.4.1.4 One or more of the access control devices are used for each entrance or access point to a high radiation area. [10 CFR 835, Part 502(a)]

3.4.1.5 Additional measures are implemented to ensure that individuals will not be able to gain access to very high radiation areas when dose rates are in excess of the posting requirements of 10 CFR 835 Part 603 (c).

[10 CFR 835, Part 502(b)]

3.4.1.6 No controls have been established in a high or very high radiation area that would prevent rapid evacuation of personnel. [10 CFR 835, Part 502(c)]

3.4.1.7 A Radiological Buffer Area is not required for High Contamination Areas or Airborne Radioactivity Areas that are completely within Contamination Areas. [DOE/EH0256T Chapter 2, Part 3, Article 233.2]

3.4.1.8 Physical controls to prevent inadvertent or unauthorized access to High and Very High Radiation Areas are maintained. [DOE/EH0256T Chapter 3, Part 3, Article 334.2]

3.4.1.9 Minimum requirements for unescorted entry into High Radiation Areas are established. [DOE/EH0256T Chapter 3, Part 3, Article 334.3]

3.4.1.10 Facility operations personnel are notified prior to personnel entry to areas where operational or system changes made by operations personnel could 
result in significantly increased area dose rates. [DOE/EH0256T Chapter 3, Part 3, Article 334.6]

3.4.1.11 The number, issue, and use of keys are strictly controlled where locked entry ways are used to control access to High and Very High Radiation Areas. [DOE/EH0256T Chapter 3, Part 3, Article 334.7]

3.4.1.12 The Radiological Control Organization maintains an inventory of High and Very High Radiation Areas. [DOE/EH0256T Chapter 3, Part 3, Article 334.8]

3.4.1.13 Weekly inspections of the physical access controls to High and Very High Radiation Areas are made to verify controls are adequate to prevent unauthorized entry. [DOE/EH0256T Chapter 3, Part 3, Article 334.9]

\subsubsection{Performance Objective}

Working areas require posting because of the presence, or potential presence, of radiation and/or radioactive material. Radioactive items or containers of radioactive materials, require individual labeling if adequate warning is not provided by control measures and required posting. [10 CFR 835, Part 601(a)]

\section{Criteria}

3.4.2.1 DOE approved signs, labels, and radiation symbols are used to identify areas. [10 CFR 835, Part 601(b)]

3.4.2.2 Required signs and labels have a yellow background. The radiation symbol is black or magenta. [10 CFR 835, Part 601(c)]

3.4.2.3 Required signs are clear and conspicuously posted and may include radiological protection instructions. [10 CFR 835, Part 601(d)]

3.4.2.4 Each access point to a controlled area is posted, which identifies it as a controlled area, whenever radioactive material and/or radiation fields that require posting are or may be present in the area. [10 CFR 835, Part 602(a)]

3.4.2.5 Each access point to a radiological area is posted appropriately. [10 CFR 835, Part 603]

3.4.2.6 Radiological Buffer Areas are established within the Controlled Areas to provide secondary boundaries to minimize the spread of contamination and to limit doses to general employees who have not been trained as 
radiological workers. The need for Radiological Buffer Areas in conjunction with Radioactive Material Areas has been evaluated. [DOE/EH0256T Chapter 2, Part 3, Article 233]

3.4.2.7 Underground Radioactive Material Areas are established and posted to indicate the presence of underground items that contain radioactive materials such as pipelines, radioactive cribs, covered ponds, covered ditches, catch tanks, inactive burial grounds, and sites of known, covered, unplanned releases (spills). [D.OE/EH0256T Chapter 2, Part 3, Article 237.1, 237.2, and 237.3]

\subsubsection{Performance Objective}

Radiation Work Permits (RWPs) are used to control entry into Radiation Areas and Contamination Areas and the handling of materials with removable contamination above the specified limits. [DOE/EH0256T Chapter 3, Part 2, Article 322.2]

\section{Criteria}

3.4.3.1 Job-specific RWPs are used to control nonroutine operations or work in areas with changing radiological conditions. Job-specific RWPs remain in effect only for the duration of the job. [DOE/EH0256T Chapter 3, Part 2, Article 322.3]

3.4.3.2 General RWPs are used to control routine or repetitive activities, such as tours and inspections or minor work activities, in areas with well-characterized and stable radiological conditions. General RWPs are not approved for periods longer than 1 year. [DOE/EH0256T Chapter 3, Part 2, Article 322.4]

3.4.3.3 Radiological surveys are routinely reviewed to evaluate adequacy of RWP requirements. RWPs are updated if radiological conditions change to the extent that protective requirements need modification. [DOE/EH0256T Chapter 3, Part 2, Article 322.5]

3.4.3.4 RWPs are posted at the access point to the applicable radiological work area. [DOE/EH0256T Chapter 3, Part 2, Article 322.6]

3.4.3.5 Workers acknowledge by signature or through electronic means where automated access systems are established that they have read, understand, and will comply with the RWP prior to initial entry to the area and after any revisions to the RWP. [DOE/EH0256T Chapter 3, Part 2, Article 322.7] 
3.4.3.6 Worker pocket or electronic dosimeter readings are recorded in a format that identifies and provides linkage to the applicable RWP.

[DOE/EH0256T Chapter 3, Part 2, Article 322.8]

3.4.3.7 RWPs are reviewed and approved by the Radiological Control

Organization. [DOE/EH0256T Chapter 3, Part 2, Article 323.2]

3.4.3.8 RWPs are based on current radiological surveys and anticipated radiological conditions. [DOE/EH0256T Chapter 3, Part 2, Article 323.3]

3.4.3.9 RWPs are approved by the supervisor responsible for the work or area and the appropriate Radiological Control supervisor. Revisions or extensions to RWPs are subject to the same approval process. [DOE/EH0256T

Chapter 3, Part 2, Article 323.4]

\subsection{RADIOACTIVE MATERIALS MANAGEMENT}

\subsubsection{Performance Objective}

Radioactive material is stored in a designated Radioactive Material Area.

[DOE/EH0256T Chapter 4, Part 1, Article 414.1]

Criteria

3.5.1.1 Long-term (more than 60 days) storage of radioactive material is in a specially designated Radioactive Material Area. [DOE/EH0256T Chapter 4, Part 1, Article 414.2]

3.5.1.2 Each Radioactive Material Area is approved by the radiological control manager. [DOE/EH0256T Chapter 4, Part 1, Article 414.4]

3.5.1.3 The custodian conducts walkthroughs of Radioactive Material Areas to check container integrity. [DOE/EH0256T Chapter 4, Part 1, Article 414.6]

3.5.1.4 The custodian conducts annual or more frequent reviews of each Radioactive Material Area, with emphasis on decontamination, movement of material to long-term storage locations and disposal of unneeded material. [DOE/EH0256 T Chapter 4, Part 1, Article 414.7]

3.5.1.5 Outdoor storage of radioactive material is discouraged. In cases where outdoor storage is necessary, the integrity of containers used prevent 
degradation from weathering and subsequent release of radioactive material. The custodian checks container integrity monthly at outdoor Radioactive Material Areas. [DOE/EH0256T Chapter 4, Part 1, Article 414.9]

\subsubsection{Performance Objective}

Radioactive materials are moved in strict compliance with the requirements to prevent unnecessary exposure, to preclude the loss of control of such materials, and to prevent the spread of contamination.

\section{Criteria}

3.5.2.1 Material and equipment in radiological areas established to control surface or airborne radioactive material is treated as radiological material and is not released if measurements of accessible surfaces show that either total or removable contamination levels exceed the values specified in appendix D of 10 CFR 835 or prior use suggests that the contamination levels on inaccessible surfaces are likely to exceed the values specified in appendix D. [10 CFR 835, Part 1101]

3.5.2.2 Surveys for the release of radioactive materials are conducted. [DOE/EH0256T Chapter 4, Part 2, Articles 421 and 422 and Chapter 5, Part 5, Article 554.2]

3.5.2.3 Material not immediately released after survey is controlled to prevent contamination while awaiting release. [DOE/EH0256T Chapter 4, Part 2, Article 422.4]

3.5.2.4 Radiological labeling has been removed from or defaced on material prior to release for unrestricted use. [DOE/EH0256T Chapter 4, Part 2, Article 422.5]

3.5.2.5 The requirements for assessing representative samples of bulk material (such as sand, sweeping compounds, or plate steel), which are not suitable for normal loose and fixed contamination-level assessinent techniques, are observed. [DOE 5400.5 and DOE/EH0256T Chapter 5, Part 5, Article 554.5]

3.5.2.6 Release program and monitoring methods are adequate to demonstrate compliance with applicable regulations and requirements. Appropriate release limits are applied based on isotopic characterization. [DOE5400.5 Chapter II, Section 5.c, Items (1)-(4)] 


\subsubsection{Performance Objective}

Measures for controlling hot particles are required upon identification of hot particles, during new or nonroutine operations with a high potential for hot particles, based on previous history, and upon direction of the Radiological Control Organization.

[DOE/EH0256T Chapter 3, Part 4, Article 348.2]

\section{Criteria}

3.5.3.1 Areas or operations with the potential for hot particle contamination are surveyed. [DOE/EH0256 T Chapter 3, Part 4, Article 348.3 and Chapter 5, Part 5, Article 554.7]

3.5.3.2 Contamination Area postings are annotated to specifically identify the presence of hot particles. [DOE/EH0256T Chapter 3, Part 4, Article 348.4]

3.5.3.3 Access to hot particle areas are controlled by a job-specific RWP. [DOE/EH0256T Chapter 3, Part 4, Article 348.5]

3.5.3.4 Personal protective equipment (PPE) and clothing used in hot particle areas are segregated from other radiological protective equipment and clothing during laundering and is surveyed prior to reuse. [DOE/EH0256T Chapter 3, Part 4, Article 348.6]

\subsubsection{Performance Objective}

Sealed and unsealed radioactive sources are controlled by receipt, inventory, during storage, transfer and disposal. Sealed sources are also tested for integrity. [DOE N 5400.9 (extended by DOE N 5400.10) and DOE/EH0256T Chapter 4, Part 3, Article 431.1]

Criteria

3.5.4.1

Procurement of radioactive sources is coordinated with the Radiological Control Organization. [DOE/EH0256T Chapter 4, Part 3, Article 431.2]

3.5.4.2

Receipt surveys of radiological material shipments are performed by the Radiological Control Organization. [DOE/EH0256T Chapter 4, Part 3, Article 431.3]

3.5.4.3

Radioactive sources, including radiography sources, are not brought on site by external organizations without the prior written approval of the Radiological Control Organization. 


\subsection{CONTAMINATION CONTROL}

\subsubsection{Performance Objective}

Personnel monitoring and contamination are controlled in accordance with the requirements of 10 CFR 835 by implementation of the DOE-approved Hanford Site Radiological Control Manual and the Radiation Protection Program.

\section{Criteria}

3.6.1.1 Appropriate monitoring, used to detect and prevent the spread of contamination, is performed by individuals exiting radiological areas that are established to control removable contamination and/or airborne radioactivity. [10 CFR 835, Part 404(f)]

3.6.1.2 Personal items, such as notebooks, papers, and flashlights, are subject to the same frisking requirements as the person carrying them.

[DOE/EH0256T Chapter 3, Part 3, Article 338.7]

3.6.1.3 Instructions for personnel frisking are posted adjacent to personnel frisking instruments or monitors. [DOE/EH0256T Chapter 3, Part 3, Article 338.8]

3.6.1.4 When personnel detect skin contamination, they notify the Radiological Control Organization. [DOE/EH0256T Chapter 5, Part 4, Article 541.2]

3.6.1.5 Smoking, eating, or chewing are not be permitted in Contamination, High Contamination or Airborne Radioactivity Areas. When a potential exists for personnel heat stress, drinking may be permitted within a Contamination Area under specific conditions and controls. [DOE/EH0256T Chapter 3, Part 4, Article 342.11]

\subsubsection{Performance Objective}

Equipment and areas that are contamined are controlled and monitored to prevent the spread of contamination. Levels are maintained at ALARA. 


\section{Criteria}

3.6.2.1 Any area in which contamination levels exceed the values specified in appendix D of 10 CFR 835 is posted and controlled in a manner commensurate with the physical and chemical characteristics of the contaminant, the radionuclides present, and the fixed and removable contamination levels. [10 CFR 835, Part 404(c)and 603]

3.6.2.2 Conditions that could cause or promote the spread of contamination (such as a leaking roof or piping) are identified and corrected on a priority basis. [DOE/EH0256T Chapter 1, Part 2, Article 125.10]

3.6.2.3 A Soil Contamination Area is established for contaminated soil that is not releasable. [DOE 5400.1 and DOE/EH0256T Chapter 2, Part 2, Article 222.6]

3.6.2.4 Solid barriers to enclose areas are used wherever practicable. [DOE/EH0256T Chapter 3, Part 3, Article 337.1]

3.6.2.5 Items such as hoses and cords that cross the boundary are marked and secured. [DOE/EH0256T Chapter 3, Part 3, Article 337.2]

3.6.2.6 Tools and equipment are inspected to verify operability before being brought into Contamination, High Contamination or Airborne

Radioactivity Area. [DOE/EH0256T Chapter 3, Part 4, Article 342.2]

3.6.2.7 The use of radiologically clean tools or equipment is minimized by the implementation of a contaminated tool crib. When such use is necessary, tools or equipment with complex or inaccessible areas are wrapped or sleeved to minimize contamination. [DOE/EH0256T Chapter 3, Part 4, Article 342. 3 and Chapter 4, Article 492.5]

\subsubsection{Performance Objective}

Work that may involve high hazards, or potentially adverse environmental conditions, is appropriately evaluated to ensure adequate radiological conditions.

\section{Criteria}

3.6.3.1 Engineering controls, such as containment devices (that is, glove bags, glove boxes and tents), portable or auxiliary ventilation and temporary shielding, are installed in accordance with the technical work documents and inspected prior to use. [DOE/EH0256T Chapter 3, Part 4, Article 342. 4] 
3.6.3.2 Covers, wind screens, and run-off collection basins are used to preclude the inadvertent spread of radioactive material. [DOE/EH0256T Chapter 3, Part 7, Article 372.1]

3.6.3.3 Provisions are established for work-site personnel to assemble and to be monitored prior to release or reestablishment of work. [DOE/EH0256T Chapter 3, Part 7, Article 372.2]

3.6.3.4 Work areas are evaluated to determine if a need exists for modified work controls or decontamination. [DOE/EH0256T Chapter 3, Part 7, Article 372.3]

\subsubsection{Performance Objective}

Contaminated personnel, equipment, and areas are decontaminated and controlled to maintain levels ALARA.

\section{Criteria}

3.6.4.1 Reasonable efforts are made to decontaminate an area before a coating is applied. A fixative coating is not applied without the approval of the radiological control manager. [DOE/EH0256T Chapter 2, Part 2, Article 222.2]

3.6.4.2 Contamination levels caused by ongoing work are monitored and maintained ALARA. Work is curtailed and decontamination performed at preestablished levels, which considers worker exposure. [DOE/EH0256T Chapter 3, Part 4, Article 342.1]

3.6.4.3 Requirements for area cleanup are included in the technical work documents. Work activities are not considered complete until support material and equipment have been removed and the area has been returned to at least prework status. [DOE/EH0256T Chapter 3, Part 4, Article 342.10]

3.6.4.4 Skin decontamination methods are established for site-specific radionuclides. [DOE/EH0256T Chapter 5, Part 4, Article 541.4]

\subsubsection{Performance Objective}

Airborne radioactive areas are controlled and maintained to keep airborne levels ALARA. 


\section{Criteria}

3.6.5.1 The Radiological Control Organization is notified when engineering controls that prevent worker exposure to airborne radioactivity (such as barriers, glove boxes and glove bags) are compromised. An evaluation is made of continuing operations with compromised engineering controls.

[DOE/EH0256T Chapter 4, Part 5, Article 453.2]

3.6.5.2 Preventive maintenance and surveillance procedures are established to ensure that equipment controls are maintained in an operable condition for containment of airborne radioactivity. [DOE/EH0256T Chapter 4, Part 5, Article 453.3]

\subsection{RADIOLOGICAL PROTECTION EQUIPMENT AND SUPPLIES}

\subsubsection{Performance Objective}

Conduct of radiological operations and contamination control techniques are such that spread of contamination is minimized and worker doses are ALARA.

\section{Criteria}

3.7.1.1 Personnel wear protective clothing as required by the RWP. [DOE/EH0256T Chapter 3, Part 2, Article 325.1]

3.7.1.2 Personal protective equipment and clothing is selected as prescribed by the controlling RWP. [DOE/EH0256T Chapter 3, Part 2, Article 325.4]

3.7.1.3 Protective clothing and shoes designated for radiological control are marked and used for radiological control purposes only. [DOE/EH0256T Chapter 3, Part 2, Article 325.2]

3.7.1.4 Protective clothing dress-out areas are established directly adjacent to the work area. Workers proceed directly to the radiological work area after donning PPE and clothing. [DOE/EH0256T Chapter 3, Part 2, Article 325.3]

3.7.1.5 Instructions for donning and removing protective clothing are posted at the dress-out and step-off pad areas. [DOE/EH0256T Chapter 3, Part 2, Article 325.6]

3.7.1.6 Company-issued clothing, such as work coveralls and shoes, is not used for radiological control purposes. [DOE/EH0256T Chapter 3, Part 2, Article 325.8] 
3.7.1.7 Cleaned personal protective equipment and laundered protective clothing is inspected prior to use. Clothing is free of tears, separated seams, deterioration and damage, or repaired in a manner that provides the original level of protection. [DOE/EH0256T Chapter 4, Part 6, Article 462.6]

\subsection{PREREQUISITES}

None

\subsection{SPECIAL APPROVALS}

None.

\subsection{REFERENCES}

The following documents were used to create this RP section

10 CFR 835, Occupational Radiation Protection, 13 December 1993.

DOE 5400.5, Radiation Protection of the Public and the Environment, 8 February 1990.

DOE-EH0256T, DOE Radiological Control Manual, 30 April 1994.

HSRSCM-1, Hanford Site Radiological Control Manual, 21 December 1994.

WHC-SP-1 145, Radiation Protection Program, 30 March 1995.

WHC-SD-MP-SRID-001, Tank Waste Remediation System (TWRS) Standards and

Requirements Identification Document, 30 January 1996. 


\section{FIRE PROTECTION}

\subsection{PURPOSE}

This section provides fire protection (FP) functional area elements, performance objectives, and criteria intended for use by Tank Farm operational activities to ensure compliance with applicable State and Federal Regulations and Department of Energy (DOE) Orders as defined in the Tank Waste Remediation System (TWRS) Standards and Requirements Identification Document (S/RID), and Fire Protection Program.

\section{$2.0 \quad$ SCOPE}

The performance objectives and criteria (PO\&C) apply to all Tank Farm facilities and organizations subject to evaluation under the TWRS Management Assessment Program.

\subsection{FUNCTIONAL AREA ELEMENTS}

The following are the FP functional area elements. Each functional area element has performance objectives and subsequent criteria. The criteria are used to assess the objectives.

\subsection{FIRE PROTECTION PROGRAM}

\subsubsection{Performance Objective}

A documented Fire Protection Program is implemented.

\section{Criteria}

3.1.1.1 The program outlines management's commitment; incorporates additional requirements stipulated by the Program Senior Officer (PSO); defines responsibility; and institutes policy and mandatory requirements that will be used in implementing a comprehensive program. [DOE 5480.7A, Section 9.a.(1), 9.b.(17)]

3.1.1.2 A system is established to ensure that the requirements of the DOE Fire Protection Program are documented and incorporated in the plans and specifications for all new facilities and for major modifications of existing facilities. This includes review and comment by a qualified fire protection engineer concerning plans, specifications, test procedures, and results for 
3.1.1.3 The facility maintains or has access to an adequate fire protection staff, including a qualified fire protection engineer(s). Continuing education and training is provided to maintain and enhance the level of competency of the fire protection staff. [DOE 5480.7A, Section 8.I]

3.1.1.4 Information from the Fire Protection Program is incorporated in the Facility Emergency Plan. The facility fire protection organization is involved in the development of the Emergency Plan and in all related training and drills. [DOE 5480.7A, Section 9.c.(5)]

\subsubsection{Performance Objective}

Documented facility fire protection evaluations are performed periodically.

\section{Criteria}

3.1.2.1 Annual fire protection assessments are made of facilities valued in excess of $\$ 50$ million; those facilities considered moderate (Category 2 Hazard) or high hazard (Category 1 Hazard), as defined in DOE 5481.1B, for nonnuclear facilities and in DOE 5480.23, for nuclear facilities; or facilities in which vital programs are involved. [RLID 5480.7, Section 6.2.d.(1)]

3.1.2.2 Fire protection assessments are made at least every 2 years of facilities valued at $\$ 10$ million to $\$ 50$ million. [RLID 5480.7, Section 6.2.d.(2)]

3.1.2.3 Fire protection assessments are made at least every 3 years of facilities valued at $\$ 1$ million to $\$ 10$ million. [RLID 5480.7, Section 6.2.d.(3)]

3.1.2.4 Facilities, whose property value is less than $\$ 1$ million, do not require a fire protection facility assessment that contains the required nature and scope elements contained in DOE $5480.7 \mathrm{~A}$, unless significant programmatic impacts, hazardous materials, or radioactive materials are involved. Such facility assessments are made at least every 3 years. [RLID 5480.7, Section 6.2.d.(5)]

3.1.2.5 A fire protection assessment is made at least every 3 years for facilities valued at $\$ 250,000$ to $\$ 1$ million. The documented assessment for these facilities includes findings, observations, and recommendations. Where applicable, these assessments include, as a minimum, findings and observations and supporting documentation that identify fire hazards that could cause facility loss or life safety concerns. [RLID 5480.7, Section 6.2.d.(5)] 
3.1.2.6 The assessment includes an evaluation of the program-related, and facilityrelated fire-protection systems against mandatory fire protection criteria. Copies of the two most recent reports are kept on file by the facility. [DOE 5480.7A, Section 9.a.(2)(c)]

3.1.2.7 At least yearly, the owner or operator inspects those areas of his facility where ignitable or reactive wastes are stored. This inspection is performed in the presence of a professional person who is familiar with the Uniform Fire Code, or in the presence of the local, state, or federal fire marshal. After the inspection, the owner or operator enters the information in his inspection log or operating record. [WAC-173-303 Section 395(1)]

\subsubsection{Performance Objective}

A Fire Hazard Analysis (FHA), Safety Analysis Report (SAR), or other similar document that reflects the risks from potential fires, has been performed.

\section{Criteria}

3.1.3.1 The FHA/SAR has been performed under the direction of a qualified fire protection engineer. The report comprehensively assesses the risk from fire within individual fire areas in a DOE facility in relation to existing or proposed fire protection. [DOE 5480.7A Section 9.a.(3)]

3.1.3.2 The FHA/SAR contains an analysis of all elements that ensure that the fire protection objectives have been met. [DOE 5480.7A, Section 9.a.(3)]

\subsection{PROGRAM PHYSICAL FEATURE}

\subsubsection{Performance Objective}

The facility's egress system ensures that personnel can promptly exit potentially occupied areas so as to minimize the consequences of fire with respect to life safety.

\section{Criteria}

3.2.1.1 Life safety provisions that are in accordance with the Life Safety Code (LSC), NFPA Standard 101 are provided for all facilities. [DOE 5480.7A, Section 9.b.(2)]

3.2.1.2 Exit requirements for toxic and explosive environments are determined by 
the authority having jurisdiction (AHJ). In addition, for explosive environments, exits reflect the criteria contained in the DOE Explosives Safety Manual, (DOE/EV 06194). [DOE 5480.7A, Section 9.b.(2)]

\subsubsection{Performance Objective}

A maximum credible fire will not result in an unacceptable property loss or program interruption.

\section{Criteria}

3.2.2.1 Complete automatic fire suppression systems designed in accordance with applicable National Fire Protection Association (NFPA) standards are provided in all structures having a maximum possible fire loss (MPFL) in excess of $\$ 1$ million, or where the maximum credible fire will result in the loss of use of a vital structure for a period longer than specified as acceptable by the applicable PSO. [DOE 5480.7A, Section 9.b.(3)]

3.2.2.2 When the MPFL exceeds $\$ 50$ million, a redundant fire protection system is provided that, despite the failure of the primary Fire Protection System, will limit the loss to $\$ 50$ million. [DOE 5480.7A, Section 9.b.(4)]

3.2.2.3 When the MPFL exceeds $\$ 150$ million, a redundant fire protection system and a 3-hour fire barrier are required to limit the maximum possible fire loss to $\$ 150$ million. [DOE 5480.7A, Section 9.b.(4)]

\subsubsection{Performance Objectives}

Protection measures are taken to ensure that a fire does not cause an on-site or off-site release of radiological or other hazardous material that will threaten the public health and safety of the environment

\section{Criteria}

3.2.3.1 Off-site release of radioactive, toxic, or other hazardous materials into the atmosphere, as a result of fire, is minimized to that of acceptable levels as required by DOE 5480.23, and other applicable orders. [DOE 5480.7A, Section 5; 9.b.(12)]

3.2.3.2 Natural or artificial means of controlling liquid runoffs from a maximum credible fire are provided so that contaminated or polluting liquids will not escape the site. This includes potentially contaminated water resulting from firefighting operations. [DOE 5480.7A, Section 9.b.(10); 


\section{DOE6430.1A Section 1540-99.0.2(1)]}

3.2.3.3 In areas where a fire could cause damage to safety class equipment and where no redundant safety capability exists, a redundant Fire Protection System is provided for the safety class equipment. [DOE 5480.7A, Section 9.b.(1)]

3.2.3.4 Redundant safety class electric systems are physically protected or separated to prevent a common external event from causing a failure of the redundant systems. [DOE 6430.1A, Section 1660-99.0.1(4)]

3.2.3.5 Hazards unique to DOE and not addressed by mandatory codes and standards are protected by isolation, segregation, or use of special fire control systems. Devices for limiting or controlling the effects of a fire are also provided. [DOE 5480.7A, Section 9.b.(13)]

\subsubsection{Performance Objective}

Fire protection systems are characterized by quality design, installation, and maintenance.

\section{Criteria}

3.2.4.1 New permanent structures in excess of a 5,000 square feet area are noncombustible or fire resistive construction. [DOE 5480.7A, Section 9.b.(6)]

3.2.4.2 Fire protection systems are tested and maintained in accordance with the applicable NFPA standards and as supplemented by criteria in the DOE Fire Protection Resource Manual. [DOE 5480.7A, Section 9.b.(5)]

3.2.4.3 Where fire suppression or fire alarm systems are provided, local alarms in the protected area and alarm transmission to an acceptable remote attended location is provided. [DOE 5480.7A, Section 9.b.(11); DOE 6430.1A, Section 1530-99.8(3)]

3.2.4.4 The design of fire protection systems to withstand seismic events are in accordance with the criteria developed by the NFPA, except as required by other DOE criteria. [DOE $5480.7 \mathrm{~A}$, Section 9.b.(15)]

3.2.4.5 Emergency power systems are capable of maintaining total operation of emergency loads for the full time period specified by the cognizant DOE authority (nominally, a minimum of 24 hours). Switchover to emergency power is automatic when the primary power source fails as indicated on the annunciator panel. The annunciator panel is located in an occupied area 
and indicates any problems with the emergency system. Such power has necessary built-in features to facilitate operation testing periodically to verify system readiness. [DOE 6430.1A, Section 1660-1(4) and Section 1660-2]

3.2.4.6 Future use of Halon is governed under the conditions set forth in the DOE memorandum "Interim Position on the Installation of New Halon 1301 Fixed Fire Suppression Systems and Halon 1211 Portable Fire Extinguishers" and superseding documents. [DOE 5480.7A, Section 9.b.(14)]

\subsection{ADMINISTRATION}

\subsubsection{Performance Objective}

The potential occurrence of a fire is minimized. [DOE 5480.7A, Section 4.a]

\section{Criteria}

3.3.1.1 Facilities have procedures governing the use and storage of combustible, flammable, radioactive, and hazardous materials to minimize the risk from fire. Procedures also exist for activities, such as smoking limitations, isolation of hot work, and other fire prevention measures, which contribute to the decrease in fire risk. [DOE 5480.7A, Section 9.c.(1); WAC-173-303 Section 395(1); 29 CFR 1910 Subpart H]

3.3.1.2 Facilities that require ventilation containment systems are protected from the effects from fire to preclude release of radioactive, toxic, or other hazardous materials. [DOE 5480.7A, Section 9.b.(12)]

3.3.1.3 A program for the inspection and/or testing and maintenance of fire doors, fire dampers, and fire walls or separations has been developed and implemented. [DOE 5480.7A, Section 8.2.b]

3.3.1.4 The Fire Protection Program includes a fire protection system winterization program to ensure that fire protection systems are protected against cold weather effects. [RLID 5480.7, Section 8.9]

3.3.1.5 Electrical materials and equipment are UL or FM tested, and have a label attached (for the purpose intended) whenever such products are available. Where there are no UL or FM listed products of the type, testing and certification by another nationally recognized testing agency may be acceptable. Installation methods are in accordance with the manufacturer's 
instructions, with NFPA 70, and other applicable requirements. [DOE 6430.1A, Section 1605-1(2)]

\subsubsection{Performance Objective}

Access to all available firefighting equipment is maintained at all times. [29 CFR 1926, Part 150(a)(2)]

3.3.2.1 All firefighting equipment, provided by the employer, is conspicuously located. [29 CFR 1926, Part 150(a)(3)]

3.3.2.2 All firefighting equipment is periodically inspected and maintained in operating condition. Defective equipment is immediately replaced. [29 CFR 1926, Part 150(a)(4)]

3.3.2.3 Fire detection systems are integrated with the central alarm location and any associated automatic fire suppression system. [DOE 6430.1A, Section 1161.3]

\subsubsection{Performance Objective}

Proper control systems are incorporated to ensure a successful fire protection program.

\section{Criteria}

3.3.3.1 A program exists to identify, prioritize, and monitor the status of fire protection-related assessment findings/recommendations until resolution is achieved. [DOE 5480.7A, Section 9.c.(2); RLID 5480.7, Section 6.2.d.(5)]

3.3.3.2 Fire protection facility assessments are retained and are available to RL representatives upon request. Copies of the two most recent assessment reports are kept readily accessible on file. [RLID 5480.7, Section 6.2.d.(5)]

3.3.3.3 Minimum requirements to establish operability have been developed for fire protection features such as: fire doors, fire dampers, fire detection and suppression systems, fire protection water supplies, etc. Periodic tests are conducted to confirm that these features are operable. If the Fire Protection System will be inoperable for a significant period of time, interim compensatory measures are implemented until operability is restored. [DOE 5480.7A, Section 9.c.(4)]

3.3.3.4 Emergency communications are outlined in the Emergency Plan. The 
communications capability among potential responders are coordinated to avoid confusion and interference. This capability is tested on an established frequency. [DOE 5480.7A, Section 9.c.(7)]

3.3.3.5 Appropriate training (including emergency fire drills) is periodically provided, for all individuals involved with the Fire Protection Program; as required by applicable NFPA standards and other facility specific requirements. [DOE 5480.7A, Section 9.c.(6 and 7)]

3.3.3.6

Employees are provided annual fire prevention training. [RLID 5480.7, Section 8. 7]

3.3.3.7 A Fire Protection System Impairment Program is provided to control operation and tracking of impairments during periods when fire protection systems are out of service. [DOE 5480.7A, Section 9.b.(16)]

\subsection{PREREQUISITES}

None.

\subsection{SPECIAL APPROVALS}

None.

\subsection{REFERENCES}

The following documents were used to create this FP section:

29 CFR 1910, Occupational Safety and Health Standards, 1 July 1993.

29 CFR 1926, Safety and Health Regulations for Construction, 1 July 1994.

DOE 5480.7A, Fire Protection, 17 February 1993.

DOE 6430.1A, General Design Criteria, 6 April 1989.

RLID 5480.7, Fire Protection, 17 January 1994.

WAC-173-303, Dangerous Waste Regulations, 8 December 1993.

WHC-SD-MP-SRID-001, Tank Waste Remediation System Standards and Requirements Identification Document, 30 January 1996. 


\section{PACKAGING AND TRANSPORTATION}

\subsection{PURPOSE}

This section provides packaging and transportation functional area elements, performance objectives, and criteria intended for use by Tank Farm operational activities to ensure compliance with applicable State and Federal Regulations and Department of Energy (DOE) Orders as defined in the Tank Waste Remediation System (TWRS) Standards and Requirements Identification Document (S/RID) and Packaging and Transportation Program.

\subsection{SCOPE}

The performance objectives and criteria (PO\&C) apply to all Tank Farm facilities and organizations subject to evaluation under the TWRS Management Assessment Program.

\subsection{FUNCTIONAL AREA ELEMENTS}

The following are the packaging and transportation functional area elements. Each functional area element has performance objectives and subsequent criteria. The criteria are used to assess the objectives.

\subsection{PACKAGING AND TRANSPORTATION OPERATIONS}

\subsubsection{Performance Objective}

A system of hazardous materials packaging and transportation policies and directives provides for effective implementation of DOE Orders, DOE 5480.3, DOE 1540.1A, DOE 1540.2, Federal and State regulations, and good industrial practices.

\section{Criteria}

3.1.1.1 Policies and implementing procedures are documented and systematically reviewed to verify conformance with applicable DOE Orders.

[DOE 1540.1A and 1540.2; DOE 1540.3A, Section 8.c; DOE 5480.3]

3.1.1.2 Facility procedures are reviewed and updated for changes in package safety documentation requirements. [DOE 1540.2, Section 9d; DOE 5480.3, Section 10 a, f] 
3.1.1.3 Packaging and transportation personnel staffing is adequate in number and expertise to perform all functions listed in WHC-2-14.

3.1.1.4 Relationships between all organizations directly involved in packaging development are clearly documented and effective. [DOE 5480.3, Section 9b(1)]

\subsubsection{Performance Objective}

All packaging and transportation operations involving hazardous materials are conducted in compliance with applicable State and Federal regulations, including those of the Department of Transportation (DOT), Nuclear Regulatory Commission (NRC), Occupational Safety and Health Administration (OSHA), and Environmental Protection Agency (EPA).

\section{Criteria}

3.1.2.1 A program exists to ensure and measure compliance with applicable State and Federal regulations, including those of DOT, NRC, OSHA, and EPA. [DOE 1540.3A; DOE 5480.3, Section 10a]

\subsubsection{Compliance documentation that demonstrates the appropriate} procurement, use, and maintenance of certified or specification packages is maintained and is current (such as, DOE Certificates of Compliance; NRC Certificates of Compliance) as required by DOE 1540.2. and DOE 5480.3 . [DOE 1540.2; DOE 5480.3, Section 10f]

3.1.2.3 Use of DOE alternatives, DOT exemptions, the National Security Provision, and other regulatory variances is minimized. Management reviews the use of these variances, reviews their need, and initiates actions to minimize such use. [DOE 1540.2, Chapters 3 and 4; DOE 5480.3, Section $6 c(3),(4)]$

\subsubsection{Performance Objective}

Accidents and incidents involving packaging and transportation of hazardous materials are reported in a timely manner to DOE.

\section{Criteria}

3.1.3.1 Accidents and incidents are documented and reported in accordance with the current reporting requirements of DOE and the Federal regulatory agencies. [DOE 1540.1A, Chapter II, Section 7.d; DOE O 232.1; 


\section{DOE 5480.3; 49 CFR 171.15; 49 CFR 171.16]}

\subsubsection{Performance Objective}

Records of hazardous materials movements, transfers, and shipments are prepared and maintained to ensure compliance with DOE and other regulatory requirements and to provide an audit trail of actions.

\section{Criteria}

3.1.1.1 Records are maintained in a centralized location (to the extent practicable) such that the level of effort required for retrieval for audits or investigations is minimal. [DOE 5480.3, Section 10e]

\subsubsection{Performance Objective}

The DOE Field Office conducts periodic packaging and transportation safety appraisals of contractors, and each contractor conducts independent internal packaging and transportation safety audits.

\section{Criteria}

3.1.5.1 Safety appraisals and internal assessments are independent and include onsite and off-site packaging and transportation operations. The frequency and timely notification of findings, and an effective follow-up system are established. [DOE 1540.1A, Section 7.g; DOE 5480.3, Section 6.c]

\subsection{TRANNING}

\subsubsection{Performance Objective}

Packaging and transportation personnel are trained, qualified, and certified in the identification and proper handling of hazardous materials as required by DOE 5480.3 and 49 CFR.

Criteria

3.2.1.1 Packaging and transportation personnel (including traffic management staff, packaging personnel, truck drivers, fork lift operators, and their supervisors) are given initial and recurrent training (on-the-job, in-house, and/or offsite) as appropriate. [DOE 5480.3; 49 CFR 172.700-704] 
3.2.1.2 Packaging and transportation personnel are tested to establish their qualifications under approved performance criteria and are so certified by management. [DOE 5480.20; 49 CFR 172.702]

3.2.1.3 Training is accomplished by qualified trainers who meet established administrative qualifications as trainers. [DOE 5700.6C, Chapter II]

3.2.1.4 Training records are maintained for all packaging and transportation personnel. [DOE 5480.20; 49 CFR 172, 700-704]

\subsection{QUALITY ASSURANCE}

\subsubsection{Performance Objective}

A system of checks and balances exists that ensures the quality assurance (QA) requirements of applicable DOE orders.

\section{Criteria}

3.3.1.1 A QA program exists for management and operational accountability in packaging and transportation activities of Type $A$ and $B$ packagings. [DOE 1540.2, Chapter 1; DOE 5480.3, Section 9; DOE 5700.6C]

3.3.1.2 QA reviews include the design, procurement (requisitioning and receipt), use, inspection, and maintenance of packaging as required by DOE orders and DOT regulations. [DOE 1540.2, Chapters 1 and 2; DOE 5480.3, Section 9b]

3.3.1.3 A system exists to ensure that new designs and specifications for both onsite and off-site packaging are reviewed by packaging and transportation personnel prior to being procured. [DOE 5700.6C, Section 9b]

3.3.1.4 Records are maintained of quality assurance audits, inspections, responses, and action plans of package design and construction. [DOE 5700.6C]

3.3.1.5 A system exists for positive and timely followup and action on findings and recommendations made during previous audits and appraisals.

[DOE 5700.6C]

\subsubsection{Performance Objective}

Procedures describe hazardous material packaging and storage activities to ensure

Att. $2-139$ 
conformance with regulatory requirements.

\section{Criteria}

3.3.2.1 DOT-Specification 7A packaging for hazardous material transport meets the federal regulatory requirements. [49 CFR 173; DOE 1540.2, Chapter I]

3.3.2.2 New packagings are fabricated in accordance with Federal regulatory requirements. [DOE 1540.2; 49 CFR 173]

\subsection{OPERATIONS}

\subsubsection{Performance Objective}

Operations involving packaging and transportation of hazardous materials are conducted in a safe, consistent, and accountable manner, following approved procedures, in conformance with applicable standards and accepted practices.

\section{Criteria}

3.4.1.1 Storage, inspection, and maintenance of reuseable packagings are performed in an effective and logical manner. [DOE 5480.3, Section 9b]

3.4.1.2 Marking and identification of previously used containers and empty radioactive packaging are clear, durable, and easily understood. The markings give a quick and ready identification of the general nature of the residual hazards of the package contents; markings and labels are consistent with DOT regulations. [DOE 5480.3, Section 7; DOE 1540.1A, Chapter II, Section 2]

3.4.1.3 A system exists for planning unanticipated or emergency operations. Emergency procedures are documented and readily available to all personnel. [DOE 1540.1A, Chapter II, Section 7c]

3.4.1.4 A Safety Analysis Report for Packaging (SARP) is prepared to support all Type $B$ and fissile material packaging designs certified by DOE. The SARP includes a physical and technical description of the package; design, development and test methodologies (and the test results); and technical references that provide a clear treatment of the subject. [DOE 1540.2, Chapter 2; DOE 5480.3, Section 10.f]

3.4.1.5 Health Protection monitoring of radioactive packages occurs before 


\subsection{ON-SITE TRANSFERS}

\subsubsection{Performance Objective}

On-site transfers of hazardous materials are conducted in a safe, consistent, and accountable manner by following approved procedures in conformance with applicable standards and accepted safety practices.

\section{Criteria}

3.5.1.1 Packaging (including package marking and labeling) and en-route transit storage of hazardous materials meet the requirements of DOE 5480.3 and 49 CFR (for public access roads), and the local on-site Transportation Safety Manual. [49 CFR; DOE 5480.3]

3.5.1.2 Vehicle operations for on site transfer comply with the requirements of 49 CFR 392. Vehicles that carry hazardous materials are maintained properly in accordance with 49 CFR 396.

3.5.1.3 Procedures for packaging, vehicle loading, cargo tie-downs, and unloading of hazardous materials are documented, approved, and followed.

\subsection{PREREQUISITES}

None

\subsection{SPECLAL APPROVALS}

None.

\subsection{REFERENCES}

The following documents were used to create this P\&T section:

49 CFR Parts 100-199, Hazardous Material Regulations, 10 October 1994.

49 CFR Parts 380-399, Federal Motor Carrier Regulations, 1 October 1994.

DOE O 232.1, Occurrence Reporting and Processing of Operations Information, 
25 September 1995.

DOE 1540.1A, Materials Transportation and Traffic Management, 8 July 1992.

DOE 1540.2, Hazardous Materials Packaging for Transport - Administrative Procedures, 30 September 1986.

DOE 1540.3A, Base Technology for Radioactive Material Transportation and Packaging System, 8 July 1992.

DOE 5480.20, Personnel Selection, Qualification, Training, and Staffing Requirements at DOE Reactor and Non-Reactor Facilities, 20 February 1991.

DOE 5480.3, Safety Requirements for the Packaging and Transportation of Hazardous Materials, Hazardous Substances, and Hazardous Waste.

DOE 5700.6C, Quality Assurance, 21 August 1991.

WHC-SD-MP-SRID-001, Tank Waste Remediation System Standards and Requirements Identification Document, 30 January 1996.

WHC-2-14, Hazardous Material Packaging and Shipping, August 1988. 


\section{ENVIRONMENTAL RESTORATION}

\subsection{PURPOSE}

This section provides environmental restoration (ER) functional area elements, performance objectives, and criteria intended for use by Tank Farm operational activities to ensure compliance with applicable State and Federal Regulations and Department of Energy (DOE) Orders as defined in the Tank Waste Remediation System (TWRS) Standards and Requirements Identification Document (S/RID) and ER Program.

\subsection{SCOPE}

The performance objectives and criteria (PO\&C) apply to all Tank Farm facilities and organizations subject to evaluation under the TWRS Management Assessment Program. Standards and requirements for a facility are identified based on the current and near-term mission of the facility. ER activities are not presently identified as integral to the TWRS mission.

\subsection{FUNCTIONAL AREA ELEMENTS}

Sections 3.1 through 3.3 list the ER functional area elements. Each functional area element has performance objectives and subsequent criteria. The criteria are used to assess the objectives.

\subsection{SITE IDENTIFICATION AND CHARACTERIZATION}

\subsubsection{Performance Objective}

Requirements used to identify and characterize a site when it has been determined that a release has occurred from an inactive waste site are addressed in this functional area element. Although TWRS is concerned with operational releases, Tank Farms is not a disposal facility subject to these actions. Operational releases (such as, reportable quantity releases, tank releases) are addressed in the environmental protection functional area PO\&C. 


\subsection{COMMUNITY RELATIONS AND PUBLIC INVOLVEMENT}

\subsubsection{Performance Objective}

Provisions for preparing a formal community relations plan under the Comprehensive Environmental Response, Compensation, and Liability Act (CERCLA) are provided in this functional area element. Specific provisions for providing public notification of releases, public notifications during response action development and implementation, public hearings, and maintenance of administrative records are addressed. Under CERCLA, the mission of TWR does not include commumity-relation activities. Public involvement is addressed in the environmental protection functional area PO\&C.

\subsection{SELECTION AND IMPLEMENTATION OF THE ACTION}

\subsubsection{Performance Objective}

This functional area element addresses requirements for the selection of the Remedial Action under CERCLA, Uranium Mill Tailings Remedial Action Amendments Act of 1988 , or cleanup goals/standards and available technologies. These requirements include provisions for issuing Records of Decision and for complying with the National Environmental Policy Act (NEPA) for CERCLA actions, as necessary. NEPA actions for new or modified facilities are addressed in the environmental protection functional area. The environmental restoration contractor administers the requirements for the remedial action selection process.

\subsection{PREREQUISITES}

None.

\subsection{SPECIAL APPROVALS}

None 


\subsection{REFERENCES}

The following documents were used to create this ER section:

Comprehensive Environmental Response, Compensation, and Liability Act (CERCLA) of 1980, Public Law 96-510, 11 December 1980 as amended (42 USC 9601 et seq.).

Uranium Mill Tailings Remedial Action Amendments Act of 1988, Public Law 100-616, 5 November 1988, 102 Stat, 3192 (42 USC 7901 et seq.).

National Environmental Policy Act (NEPA) of 1969, Public Law 91-190, 1 January 1990 as amended (42 USC 4321 et seq.).

WHC-SD-MP-SRID-001, Tank Waste Remediation System Standards and Requirements Identification Document, 30 January 1996. 


\section{DECONTAMINATION AND DECOMMISSIONING}

\subsection{PURPOSE}

This section provides decontamination and decommissioning (D\&D) functional area elements, performance objectives, and criteria intended for use by Tank Farm operational activities to ensure compliance with applicable State and Federal Regulations and Department of Energy (DOE) Orders as defined in the Tank Waste Remediation System (TWRS) Standards and Requirements Identification Document (S/RID), and D\&D Program.

\section{$2.0 \quad$ SCOPE}

The performance objectives and criteria (PO\&C) apply to all Tank Farm facilities and organizations subject to evaluation under the TWRS Management Assessment Program.

\subsection{FUNCTIONAL AREA ELEMENTS}

Sections 3.1 through 3.5 list D\&D functional area elements. Each functional area element has performance objectives and subsequent criteria. The criteria are used to assess the objectives.

\subsection{SITE IDENTIFICATION, SURVEILLANCE, AND MAINTENANCE}

\subsubsection{Performance Objective}

Requirements to identify contaminated facilities, placing facilities in a safe storage condition, and performing long-term surveillance and maintenance are provided in this functional area element. The Tank Farms facility is not subject to these actions.

\subsection{CHARACTERIZATION AND ENVIRONMENTAL REVIEW PROCESS}

\subsubsection{Performance Objective}

Provisions for collecting data to characterize a facility in support of the Resource Conservation and Recovery Act (RCRA) and Comprehensive Environmental Response, Compensation, and Liability Act (CERCLA) corrective action requirements and decommissioning alternatives assessment of the National Environmental Policy Act 
(NEPA) are provided in this functional area element. NEPA actions are addressed in the Environmental Protection Functional Area. D\&D activities are not presently identified as integral to the TWRS mission.

\subsection{DECONTAMINATION OPERATIONS}

\subsubsection{Performance Objective}

Development of a Decommissioning Project Plan, in compliance with applicable regulations, are addressed in this Functional Area Element. Tank Farms decontamination operations are performed as part of routine housekeeping operations and are covered in the Radiation Protection Functional Area PO\&C.

\subsection{POST-DECOMMISSIONING ACTIVITIES}

\subsubsection{Performance Objective}

Final radiological and chemical survey requirements following demolition of facilities are defined in this functional area element. These activities are not presently identified as integral to the TWRS current mission.

\subsection{RELEASE CRITERIA}

\subsubsection{Performance Objective}

This functional area element includes requirements used to determine the long-term maintenance and controls for the site or release criteria for the reuse of the site following decommissioning. Release criteria associated with housekeeping activities are specified in the Radiation Protection Functional Area PO\&C.

\subsection{PREREQUISITES}

None. 


\subsection{SPECLAL APPROVALS}

None

\subsection{REFERENCES}

The following documents were used to create this D\&D section:

Comprehensive Environmental Response, Compensation, and Liability Act (CERCLA) of 1980, Public Law 96-510, 11 December 1980 as amended (42 USC 9601 et seq.).

National Environmental Policy Act (NEPA) of 1969, Public Law 91-190, 1 January 1970 as amended ( 42 USC 4321 et seq.).

Resource Conservation and Recovery Act (RCRA) of 1996, Public Law 94-580, 20 October 1976 (42 USC 6901 et seq.).

WHC-SD-MP-SRID-001, Tank Waste Remediation System Standards and Requirements Identification Document, 30 January 1996. 


\section{WASTE MANAGEMENT}

\subsection{PURPOSE}

This section provides waste management functional area elements, performance objectives, and criteria intended for use by Tank Farm operational activities to ensure compliance with applicable State and Federal Regulations and Department of Energy (DOE) Orders as defined in the Tank Waste Remediation System (TWRS) Standards and Requirements Identification Document (S/RID) and the Waste Management Program.

\subsection{SCOPE}

The performance objectives and criteria (PO\&C) apply to all Tank Farm facilities and organizations subject to evaluation under the TWRS Management Assessment Program.

\subsection{FUNCTIONAL AREA ELEMENTS}

The following are the waste management functional area elements. Each functional area element has performance objectives and subsequent criteria. The criteria are used to assess the objectives.

\subsection{WASTE CHARACTERIZATION AND CERTIFICATION}

\subsubsection{Performance Objective}

The physical, chemical, and radiological characteristics of all wastes managed at the facility are determined in accordance with all applicable DOE, Federal, state, and local requirements.

\section{Criteria}

3.1.1.1 A formal waste characterization and certification program is established that describes procedures and roles and responsibilities for identifying and characterizing all solid, hazardous, radioactive, and mixed waste streams. [DOE 5820.2A, Chapter II, Sections 3.a and 3.c, Chapter III, Sections 3.d and 3.e; 40 CFR 262, Part 11; 40 CFR 268, Part 7; WAC173-303-070, 081, 082, 090, and 100]

3.1.1.2 The waste characterization program is documented, regularly evaluated and updated, and is implemented through standard operating procedures 
(SOPs), including (where necessary) sampling and analysis procedures. [WAC-173-303, Sections 300 and 395; 40 CFR 265; 40 CFR 268]

3.1.1.3 The waste characterization and certification program includes quality assurance (QA) and control mechanisms, such as regular inspections and audits of activities and documentation. The program maintains current and accurate waste stream characterization information and requires updates to waste stream characterization after process changes. [40 CFR 265; WAC 173-303]

3.1.1.4 The facility has a training program for personnel involved in waste management activities addressing all aspects of facility operations that have a potential to affect waste certification. [WAC 173-303-330]

\subsection{PACKAGING AND LABELING COMPLIANCE}

\subsubsection{Performance Objective}

Markings and identifications meet the requirements of DOE, Federal, state, and local requirements.

\section{Criteria}

3.2.1.1 Labels are placed on containers and tanks to adequately identify the major risk(s) associated with the contents for employees, emergency response personnel, and the public. [WAC-173-303, Section 395; 40 CFR 761, Part 45]

3.2.1.2 Labels are not obscured, removed, or otherwise unreadable in the course of inspection required under WAC-173-303-320. [WAC-173-303, Section 395]

3.2.1.3 Polychlorinated biphenyls (PCB) articles, PCB storage areas, PCB transformer locations, transport vehicles, and $\mathrm{PCB}$ containers and $\mathrm{PCB}$ articles containers containing wastes are marked with the Environmental Protection Agency (EPA) PCB mark (ML) as prescribed by 40 CFR 761 . The PCB containers and $\mathrm{PCB}$ article containers containing wastes are marked with the container's out-of-service date. [40 CFR 761]

3.2.1.4 Labels are destroyed or otherwise removed from empty containers, unless the container will continue to be used for storing dangerous waste at the facility. [WAC-173-303, Section 395] 


\subsection{PLANS, RECORDS AND REPORTING}

\subsubsection{Performance Objective}

A system exists to ensure that required environmental program documentation is completed in accordance with DOE 5400.1.

\section{Criteria}

3.3.1.1 The responsibility for preparing and updating each of the required documents is defined and assigned to a responsible individual or organizational unit. [DOE 5400.1, Chapter III]

3.3.1.2 The methodology and requirements for preparation, review, and approval of each required document are formalized through controlled procedures and related documents. [DOE 5400.1, Chapter III]

3.3.1.3 Provisions are made to provide input to the Annual Environmental Report [DOE 5400.1, Chapter II]

3.3.1.4 Radioactive Effluent and On-Site Discharge Data Reports are prepared and submitted by April 1 of each year in accordance with the instructions of the Effluent Information System and On-Site Discharge Information System User's Manual. [DOE 5400.1, Chapter II]

3.3.1.5 Provisions are made to review the Waste Minimization Plan, inclusive of the Pollution Prevention Awareness Plan, annually and to update the plan as needed every 3 years as a minimum. [DOE 5400.1]

3.3.1.6 An Annual Document Log containing information prescribed in 40 CFR 761.180 is prepared by July 1 of each year for the previous calendar year [40 CFR 761]

\subsubsection{Performance Objective}

Records are maintained to demonstrate that waste are managed in an environmentally sound manner. Record keeping-related activities are performed in accordance with applicable DOE, Federal, state, and local requirements.

\section{Criteria}

3.3.2.1 TWRS storage areas meet regulatory requirements for establishing and maintaining, where appropriate, waste characterization records, including 
waste analysis and sampling results; daily and weekly inspection reports; personnel training records; release incident and follow-up reports; annual, biennial, and other summary reports; and standard operating records. [DOE 5820.2A, Chapter III; 40 CFR 265; 40 CFR 280; WAC 173-303; 40 CFR 761]

\subsection{WASTE MUNIMIZATION}

\subsubsection{Performance Objective}

The volume and toxicity of wastes are minimized to the greatest extent practical. Waste minimization related activities are performed in accordance with applicable DOE, Federal, state, and local requirements.

\section{Criteria}

3.4.1.1 A formalized waste minimization program has been developed and implemented. The program includes elements identified in DOE and state guidance documents, including the requirements of the Pollution Prevention Awareness Plan. [DOE 5820.2A, Chapter II, Section 3]

3.4.1.2 The signed waste manifest and the waste reporting program provides certification that a waste minimization program in place. [DOE 5820.2A, Chapter II, Section 3]

3.4.1.3 Annual waste minimization goals are established to reduce the amount of solid, hazardous, and radioactive waste generated at the facility. [DOE 5820.2A, Chapter III, Section 3]

\subsection{WASTE TREATMENT AND DISPOSAL TECHNOLOGY}

\subsubsection{Performance Objective}

Hazardous wastes are safely accumulated and stored using adequate facilities with a minimum potential for release of contaminants to the environment. The associated activities are performed in accordance with all applicable DOE, Federal, state, and local requirements.

\section{Criteria}

3.5.1.1 Satellite and 90-day accumulation areas are operated in accordance with 
approved procedures. The procedures identify regulatory requirements applicable to each area based on the types and volume of wastes maintained and the length of time the wastes are kept in the area.

[DOE 5820.2A, Chapter III, Section 3; DOE 5400.5; 40 CFR 262; 40 CFR 265; WAC-173-303, Section 395]

3.5.1.2 All plans, reports, and other documents (such as, waste analysis plans, emergency preparedness plans, and contingency plans) required for the operation of areas are prepared accurately. The operating document provisions are incorporated into procedures for operating the areas.

[DOE 5400.5; WAC-173-303]

3.5.1.3 Procedures are established to ensure that the technical and administrative standards for each waste area are met. These standards include compliance with accumulation time frames, correct container labeling, inspections, and facility design and operation, as well as contingency plans and emergency preparedness procedures. [40 CFR 265]

3.5.1.4 A training program is available for all personnel responsible for managing, operating, and overseeing waste staging and satellite accumulation areas.

[WAC 173-303-330]

3.5.1.5 The handling of radioactive and mixed wastes is conducted in accordance with a formal as low as reasonably achievable (ALARA) program. [DOE 5400.5 ; DOE 5820.2A]

\subsubsection{Performance Objective}

Wastes are safely and effectively treated or recycled with a minimum potential for release of contaminates to the environment. The waste treatment or recycle activities are performed in accordance with all applicable DOE, Federal, state, and local requirements.

Criteria

3.5.2.1 All waste potentially amenable to treatment are evaluated, selected, and labeled for treatment as required. Wastes potentially amenable to recycling are evaluated as part of the overall facility waste management plans (including waste minimization). [DOE 5400.5; DOE 5820.2A; 40 CFR 265; 40 CFR 268]

3.5.2.2 All wastes shipped for treatment or recycling are selected and prepared in accordance with the waste acceptance criteria or waste analysis plans. The plans are current and are routinely evaluated to determine if they are adequate. Inspections, testing, and $\mathrm{QA}$ /quality control (QC) are done in 
accordance with and at the frequency specified in the plans. [DOE 5820.2A; 40 CFR 265]

3.5.2.3 Procedures are established to ensure that the unit-specific and general facility technical standards are met during the design and operation of treatment and recycling units. Depending on the units regulated, the technical standards could include compliance with emissions limits, adoption of best available technology (BAT) for liquid radioactive waste streams, monitoring requirements, maintenance of secondary containment, and management of residuals. [40 CFR 265; DOE 5400.5]

3.5.2.4 The operation of units that treat or recycle wastes in accordance with specific exemptions are routinely evaluated to ensure that they and the wastes sent to the units are in compliance with the requirements specified under the exemption. [WAC-173-303]

3.5.2.5 Procedures are established to identify and, if necessary, collect and further manage all residuals that are subject to regulation. [40 CFR 265]

3.5.2.6 Personnel operating or overseeing treatment units have appropriate training for the particular job functions associated with the treatment processes, including waste handling, monitoring, $\mathrm{QA} / \mathrm{QC}$, and waste residual management. [40 CFR 265; WAC-173-330]

3.5.2.7 Waste subject to Resource Conservation and Recovery Act (RCRA) land disposal restrictions (LDRs) are identified prior to treatment, are treated in compliance with the LDRs, and certified as compliant with the LDR treatment standards prior to being sent to a disposal facility.

\section{[40 CFR 265]}

3.5.2.8 Waste is stored and labeled per the requirements of the applicable Federal, DOE, state, and local regulations. While in storage, wastes are not inadvertently released to the environment. [40 CFR 265]

3.5.2.9 Proper documentation of storage activities are maintained as required. [40 CFR 265]

\subsubsection{Performance Objective}

Wastes are safely disposed, using adequate facilities with a minimum potential for release of contaminates to the environment. The waste disposal-related activities are performed with applicable DOE, Federal, state, and local requirements.

3.5.3.1 All disposal areas are identified in TWRS waste management plans, and 
applicable regulatory requirements are known. [DOE 5400.5; DOE 5820.2A; 40 CFR 265; 40 CFR 268]

3.5.3.2 Waste accepted for disposal are in accordance with waste acceptance criteria or waste analysis plans. The plans are current and are routinely evaluated to determine if they are adequate. Inspections, testing, and $\mathrm{QA} / \mathrm{QC}$ are done in accordance with and at the frequency specified in the plans. [DOE 5820.2A; 40 CFR 265; WAC 173-303]

3.5.3.3 Personnel operating or overseeing RCRA disposal units have appropriate training for the particular job functions associated with the process, including waste handling, unit operations, and monitoring. [DOE 5820.2A; 40 CFR 265; WAC-173-330]

3.5.3.4 The disposal of radioactive and mixed wastes is conducted in accordance with a formal procedure, and records are maintained. [DOE 5820.2A]

\subsection{PREREQUISITES}

None.

\subsection{SPECIAL APPROVALS}

None 


\subsection{REFERENCES}

The following documents were used to create this WM section:

40 CFR 262, Standards Applicable to Generators of Hazardous Waste, as amended by 58 FR 34370, 25 June 1993.

40 CFR 265, Interim Status Standards for the Treatment, Storage, and Disposal of Hazardous Waste, as amended by 59 FR 48041, 19 September 1994.

40 CFR 268, EPA Regulations on Land Disposal Restrictions, as amended by 59 FR 48041, 19 September 1994.

40 CFR 761, Polychlorinated Biphenyls (PCBs) Manufacturing, Processing, Distribution in Commerce, and use Prohibitions, effective 9 December 1993.

DOE 5400.1, General Environmental Protection Program, 9 November 1988.

DOE 5400.5, Radiation Protection of the Public and Environment, 8 February 1990.

DOE 5820.2A, Radioactive Waste Management, 26 September 1988.

WAC-173-303, Dangerous Waste Regulations, 8 December 1993.

WHC-SD-MP-SRID-001, Tank Waste Remediation System Standards and Requirements Identification Document, 30 January 1996. 


\section{RESEARCH AND DEVELOPMENT AND EXPERIMENTAL ACTIVITIES}

\subsection{PURPOSE}

This section provides research and development and experimental activities functional area elements, performance objectives, and criteria intended for use by Tank Farm operational activities to ensure compliance with applicable State and Federal Regulations and Department of Energy (DOE) Orders as defined in the Tank Waste Remediation System (TWRS) Standards and Requirements Identification Document (S/RID) and research and development programs.

\subsection{SCOPE}

The performance objectives and criteria (PO\&C) apply to all Tank Farm facilities and organizations subject to evaluation under the TWRS Management Assessment Program.

\subsection{FUNCTIONAL AREA ELEMENTS}

Research and development and experimental activities are the responsibility of Battelle, Pacific Northwest National Laboratory. Some applied engineering are performed by TWRS to support the resolution of tank safety issues and characterization of tank waste. These activities are addressed in the engineering functional area PO\&C.

\subsection{PREREQUISITES}

None.

\subsection{SPECLAL APPROVALS}

None.

\subsection{REFERENCES}

The following document was used to create this R\&D\&E section:

WHC-SD-MP-SRID-001, Tank Waste Remediation System Standards and Requirements Identification Document, 30 January 1996. 


\section{NUCLEAR SAFETY}

\subsection{PURPOSE}

This section provides nuclear safety functional area elements, performance objectives, and criteria intended for use by Tank Farm operational activities to ensure compliance with applicable State and Federal Regulations and Department of Energy (DOE) Orders as defined in the Tank Waste Remediation System (TWRS) Standards and Requirements Identification Document (S/RID) and Nuclear Criticality Safety Program.

\section{$2.0 \quad$ SCOPE}

The Performance objectives and criteria (PO\&C) apply to all Tank Farm facilities and organizations subject to evaluation under the TWRS Management Assessment Program.

\subsection{FUNCTIONAL AREA ELEMENTS}

Sections 3.1 through 3.5 describe the nuclear safety functional area elements. Each functional area element has performance objectives and subsequent criteria. The criteria are used to assess the objectives.

\subsection{SAFETY ANALYSIS}

\subsubsection{Performance Objective}

A safety analysis has been performed that develops and evaluates the adequacy of the safety basis for each DOE nuclear facility. The safety basis includes management, design, construction, operation, and engineering characteristics necessary to protect the public, workers, and the environment from the safety and health hazards posed by the nuclear facility or nonfacility nuclear operations. A Safety Analysis Report (SAR) documenting the safety analyses for each DOE nuclear facility has been prepared and submitted to DOE for its approval. [DOE 5480.23, Section 8] 


\section{Criteria}

3.1.1.1 Detailed nuclear criticality safety analyses are performed for specific operations, storage arrangements, and the handling and transportation of fissionable materials. [DOE 5480.24, Section 7.c., Paragraph 1]

3.1.1.2 The level of analysis and documentation for each facility is commensurate with the magnitude of the hazards being addressed, the complexity of the facility and/or systems being relied on to maintain an acceptable level of risk, and the stage or stages of the facility life cycle for which DOE approval is sought. [DOE 5480.23, Section 8.a.(1)]

3.1.1.3 The SAR defines the safety basis, documents the logic of its derivation, demonstrates adherence to the safety basis, and justifies its adequacy.

[DOE 5480.23, Section 8.b.(1)]

3.1.1.4 The SAR includes thorough documentation of the assumptions employed in the safety analysis. [DOE 5480.23, Section 8.b.(2)]

3.1.1.5 The SAR includes the results of the safety analysis that identifies the dominant contributors to the risk of the facility so that these vulnerabilities can be better managed. [DOE 5480.23, Section 8.b.(3)]

3.1.1.6 A document control system is being maintained to ensure that all users of SARs and their supporting documentation have current editions.

[DOE 5480.23, Section 8.d]

3.1.1.7 The SAR is reviewed and updated annually to ensure that the information in each SAR is current and remains applicable. Revisions reflect all changes implemented up to 6 months prior to the filing of the updated SAR. [DOE 5480.23, Section 9.c.]

3.1.1.8 An analysis of criticality incident scenarios is used to determine the conditions of operation for criticality safety and their impact on health and safety of the workers and/or public. [DOE 5480.24, Section 7.c.(5)]

3.1.1.9 Safety analysis of nonfacility nuclear operations are documented and maintained in a form that is auditable by DOE. [DOE 5480.23 , Section 8]

\subsubsection{Performance Objective}

The consequences of unmitigated releases of radioactive and/or hazardous material are evaluated and classified by hazard categories. [DOE 5480.23, Section 8.c.(1)] 


\section{Criteria}

3.1.2.1 The hazard analysis is based on an inventory enveloping all radioactive and nonradioactive hazardous materials that are stored, utilized, or may be formed within a nuclear facility. [DOE 5480.23, Section 8.c.(2)]

3.1.2.2 The hazard analysis identifies energy sources or processes that might contribute to the generation or uncontrolled release of hazardous materials. The hazard analysis estimates the consequences of accidents in which the facility or process and/or materials in the inventory are assumed to interact, react, or be released in a manner to produce a threat or challenge to the health and safety of individuals onsite and offsite. [DOE 5480.23, Section 8.c.(3)]

3.1.2.3 The hazard analysis is submitted to DOE for approval in accordance with the Safety Analysis Plan and schedule. [DOE 5480.23, Section 8.c.(4)]

\subsection{TECHNICAL SAFETY REQUIREMENTS}

\subsubsection{Performance Objective}

Technical safety requirements (TSRs) are used to define the operating limits and surveillance requirements, the basis thereof, safety boundaries, and management or administrative controls necessary to protect the health and safety of the public and to minimize the potential risk to workers from the uncontrolled release of radioactive or other hazardous materials and from radiation exposure due to inadvertent criticality.

[DOE 5480.22, Section 9.b]

\section{Criteria}

3.2.1.1 TSRs are based on the facility SAR; however, in some cases (such as, surveillance intervals and acceptance criteria) national and international codes, standards, and guides are used as a basis. [DOE 5480.22, Section 9.b]

3.2.1.2 The written bases in the TSRs provide summary statements of the reasons for the operating limits and associated surveillance requirements. The TSR shows how the numeric value, the condition, or the surveillance fulfills the purpose derived from the safety documentation. [DOE 5480.22, Section 9.e.(6)]

3.2.1.3 The TSRs contain the Limiting Conditions of Operations (LCOs) and clearly specify limiting times and the actions to be taken if the LCOs are 
not met. [DOE 5480.22, Section 9.e.(3)(b)]

3.2.1.4 The facility is operated in accordance with the TSRs as approved by the Program Secretarial Officer (PSO). The TSRs are controlled documents. [DOE 5480.22, Section 9.a and h]

3.2.1.5

The TSR is kept current at all times and reflects the facility as it exists and as it is analyzed in the SAR. [DOE 5480.22, Section 9.f]

3.2.1.6

The TSRs are reviewed and updated annually to ensure that the information in each TSR is current and remains applicable. [DOE 5480.22, Section 9.g]

3.2.1.7 Provisions are established so that emergency actions that depart from the approved TSRs may be taken when needed to protect the health and safety of the public. If emergency actions are taken, verbal notification is made to the Manager, Richland Operations Office within 2 hours and by written reports to the PSO within 24 hours. [DOE 5480.22, Section 9.I]

\subsection{UNREVIEWED SAFETY QUESTIONS}

\subsubsection{Performance Objective}

Changes made to the facility that directly or indirectly affect the authorization basis are reviewed for Unreviewed Safety Questions (USQs). A situation involves a USQ if the following occurs:

The probability of occurrence or the consequences of an accident or malfunction of equipment important to safety previously evaluated in the facility safety analyses could be increased;

The possibility for an accident or malfunction of a different type than any evaluated previously in the facility safety analyses could be created; or

Any margin of safety, as defined in the bases of the TSRs, could be reduced.

[DOE 5480.21 Preamble, Section 10.c]

\section{Criteria}

3.3.1.1 A process exists by which sources of change can be integrated into the USQ review process. This process ensures that the need for completion of a safety evaluation is not overlooked and that this process is integrated into existing procedures or that new procedures are developed, as necessary. [DOE 5480.21, Chapter III, Section 2] 
3.3.1.2 Facility aspects and documents that constitute the authorization basis are defined and identified within the facility USQ procedures. [DOE 5480.21, Chapter III, Section 3.c]

3.3.1.3 Procedures have been developed that provide detailed guidance for the performance and review of USQ determinations. [DOE 5480.21, Chapter III, Section 5.a]

3.3.1.4 Personnel qualifications that are needed to perform or review a safety evaluation are defined in implementing procedures. Specific responsibilities of those performing or reviewing safety evaluations are also clearly defined. [DOE 5480.21, Chapter III, Section 5.d]

3.3.1.5 All personnel responsible for performing, reviewing, or approving USQ determinations receive initial training on the application of the order and of facility-specific procedures. [DOE 5480.21, Chapter III, Section 8]

3.3.1.6 Periodic updates of the SAR are submitted to DOE summarizing all situations for which a safety evaluation was required. The report indicates all "changes" considered in a safety evaluation and implemented 6 months or more before the submittal date of the report. [DOE 5480.21 Preamble, Section 10.e]

\section{$3.4 \quad$ NUCLEAR CRITICALITY SAFETY}

\subsubsection{Performance Objectives}

The basic elements and control parameters of programs for nuclear criticality safety satisfy the requirements of the mandatory American Nuclear Society's ANSI/ANS nuclear criticality safety standards. [DOE $\mathbf{5 4 8 0 . 2 4}$, Section 7.a. Introduction]

\section{Criteria}

3.4.1.1 Process designs incorporate sufficient factors of safety to require at least two unlikely, independent, and concurrent changes in process conditions before a criticality accident is possible. Protection is provided by either (a) the control of two independent process parameters (which is the preferred approach, if practical) or (b) a system of multiple (at least two) controls on a single parameter. In each case, no single failure may result in the potential for a criticality accident. The basis for selecting either approach is fully documented. [DOE 5480.24, Section 7.a.(2)(a)]

3.4.1.2 As a first priority, reliance is placed on equipment design in which 
dimensions of the contained fissionable material and spacing between equipment are limited via passive engineering controls. Where geometry control is not feasible, the preferred order of controls is other passive engineering controls, active engineering controls, and administrative controls. Feasibility is determined by weighing risk versus practicality/cost. [DOE 5480.24, Section 7.a.(2)(b)]

3.4.1.3 All dimensions, nuclear properties, and other features upon which reliance is placed is verified prior to beginning operations, and control is exercised to maintain them. The basis for not selecting geometry control is fully documented. [DOE 5480.24, Section 7.a.(2)(b)]

3.4.1.4 Structures, systems, and components that provide nuclear criticality safety are designed as safety class systems and are capable of performing their criticality safety functions during and following design basis accidents and events. [DOE 6430.1A, Section 1300-4, Paragraph 5]

3.4.1.5 A Safety Equipment List has been developed that identifies structures, systems, and components classified as safety class 1,2 , or 3 and identifies their required safety function(s). [WHC-CM-4-46, Chapter 9.0]

\subsection{MATERIALS CONTROL}

\subsubsection{Performance Objective}

A monitoring and surveillance program has been established to prevent accumulations of fissionable materials. The measurement control program is in accordance with the latest edition of 10 CFR 830. [DOE 5480.24, Section 7]

\section{Criteria}

3.5.1.1 A monitoring and surveillance program has been established to prevent accumulations of fissionable materials in, but not limited to, process equipment and storage, pipe, and ventilation systems. If unsafe accumulations are detected, corrective measures are taken to prevent criticality hazards. [DOE $\mathbf{5 4 8 0 . 2 4}$, Section 7.d]

3.5.1.2 A description of the technical practices and measurement control program (including reliability and operability characteristics) used in determining the quantities of fissionable material (or other materials such as soluble poisons to prevent accidental criticality) present in any location has been developed. The uncertainties of the measured values are defined. [DOE 5480.24, Section 7.c.(8)] 
3.5.1.3 Procedures are established for processing fissionable material, including descriptions of equipment; information on the chemical and physical form of the material; allowable quantities of material; spacing requirements; allowable methods of handling and transferring material; and methods for preventing criticality resulting from accumulation of material in scrap, waste, slag, solutions, machining residues, etc. [DOE 5480.24, Section 7.c.(2)]

\subsection{PREREQUISITES}

None.

\subsection{SPECIAL APPROVALS}

None.

\subsection{REFERENCES}

The following documents were used to create the NS section:

DOE 5480.21, Unreviewed Safety Questions, 24 December 1991.

DOE 5480.22, Technical Safety Requirements, 15 September 1992.

DOE 5480.23, Nuclear Safety Analysis Reports, 10 April 1992.

DOE 5480.24, Nuclear Criticality Safety, 12 August 1992.

DOE 6430.1A, General Design Criteria, 6 April 1989

WHC-CM-4-46, Safety Analysis Manual, 30 September 1988.

WHC-SD-MP-SRID-001, Tank Waste Remediation System Standards and Requirements Identification Document, 30 January 1996. 


\section{OCCUPATIONAL SAFETY AND HEALTH}

\subsection{PURPOSE}

The section provides functional area elements, performance objectives, and criteria intended for use by the Tank Farm operational activities to ensure compliance with applicable State and Federal Regulations and Department of Energy (DOE) Orders as defined in the Tank Farm Remediation System (TWRS) Standards and Requirements Identification Document.(S/RID), and Occupational Safety and Industrial Hygiene (OSH) Program.

\subsection{SCOPE}

The performance objectives and criteria (PO\&C) apply to all Tank Farm facilities and organizations subject to evaluation under the TWRS Management Assessment Program.

\subsection{FUNCTIONAL AREA ELEMENTS}

The following are the OSH functional area elements. Each functional area element has performance objectives and subsequent criteria. The criteria are used to assess the objectives.

\subsection{ORGANIZATION AND ADMINISTRATION}

\subsubsection{Performance Objective}

Facility organization and administration implements and controls the occupational safety and industrial hygiene programs.

\section{Criteria}

3.1.1.1 Line management ensures that a safety program is implemented to maintain workplaces free of safety hazards. [DOE 5480.6; DOE 5483.1A Section 7.d(1); DOE 6430.1A]

3.1.1.2 The occupational safety technical support staff has a direct line of communication with facility management. Reports and recommendations of the technical staff are not subject to inappropriate nontechnical management review and approval. [DOE 5480.6, Section 8.g] 
3.1.1.3 The staff responsible for the direction and operation of the occupational safety program at the facility are qualified and have time and authority to implement the established program.

3.1.1.4 Professional and technically qualified industrial hygienists are available to aid line management in the implementation of the industrial hygiene program. [DOE 5480.10, Section 9.d(1); DOE O 440.1, Attachment 2, 3 and $17(\mathrm{~K})]$

3.1.1.5 Information about the facility's occupational safety programs is communicated to top management, all segments of the organization concerned, the public, and regulatory agencies. [DOE O 232.1; DOE 5483.1A, 7.d(11); DOE 5484.1]

3.1.1.6 Resources are allocated and established to meet the operational requirements of the facility OSH Program. [DOE 5483.1A, Section 7.d(11)(a)]

3.1.1.7 Occupational safety issues at the facility are factors in establishing priorities for spending on capital improvements projects. [DOE 5480.9, Section 6.a; DOE 5483.1A, Section 7.d(11)(b)]

3.1.1.8 Management establishes specific goals and objectives for reducing the frequency and severity of occupational accidents and injuries.

[DOE 5480.19, Chapter I, Section C3; DOE 5483.1A, 7.d(11)]

3.1.1.9 A formal self-assessment program is used at the facility to evaluate the effectiveness of the OSH Program activities. [DOE 5482.1B, Paragraph 9]

\subsection{PROCEDURES AND DOCUMENTATION}

\subsubsection{Performance Objective}

Procedures and documentation provide direction, record generation, and support for the occupational safety programs and construction safety activities as they pertain to or potentially impact the safety of facility personnel.

\section{Criteria}

3.2.1.1 Operating procedures provide direction to ensure that potential hazards are identified for correction and that safety requirements are uniformly implemented. [DOE 5480.10, Section 9.a; DOE 5483.1A, Section 7.d(11)(b)] 
3.2.1.2 Written safety policies are readily available to all facility organization elements, periodically reviewed, and kept current. [DOE 5483.1A, 7.d(11)]

3.2.1.3 Occupational safety policy statements (as developed by the facility) are consistent with the requirements of applicable DOE Orders.

[DOE 5480.4; DOE 5483.1A, Section 7.d(11)(b)]

3.2.1.4 Policies and management directives define authority and responsibility at each level of the facility organization for the control of occupational safety concerns. [DOE 5480.10, Section 9.a]

3.2.1.5 Work permits identify potentially hazardous maintenance, construction, experiments, and other nonroutine activities. The work permits require application of safety expertise to plan and review the work.

[DOE 4330.4B Chapter I, Section 3.4 and Chapter II, Section 6.3; DOE 5480.10, Section 9.b; DOE 5480.19, Chapter I, VIII]

3.2.1.6 Current copies of DOE Orders, prescribed standards, and applicable codes and regulation are available at the facility. [DOE 5480.4, Attachment 2; DOE 5483.1A, 7.d(11)]

3.2.1.7 A facility program with required documentation is established to track the correction of identified deficiencies and deviations from prescribed standards. [DOE 232.1]

\subsection{OCCUPATIONAL SAFETY AND HEALTH CONCERNS}

\subsubsection{Performance Objective}

Safety concerns arising from physical, or other environmental stress in the workplace, are identified, evaluated, and controlled.

\section{Criteria}

3.3.1.1

A documented program identifies and evaluates existing and potential occupational safety and health concerns. [DOE 5480.10, Section 9.a and 9.b; DOE 5483.1A]

3.3.1.2

The need for specialized safety equipment and technical resources at the facility are identified, and this equipment is maintained.

[DOE 5483.1A] 
3.3.1.3 Occupational safety equipment is available, its use is enforced, and training for its use is provided. [DOE 5480.19, Chapter D; DOE 5483.1A, 7.d(11)]

3.3.1.4 Monitoring data is regularly obtained for potential safety and health concerns, and the information is used to determine the effectiveness of facility control measures. [DOE $5483.1 A$, Section 7.d(11)(d)]

3.3.1.5 Housekeeping practices and programs reflect a commitment to minimize contamination of areas and equipment and to minimize the risk of contamination and injury of personnel. [DOE 5483.1A, Section 7.d(11)(a)]

3.3.1.6 Laboratories, record storage, offices, and training areas at the facility are

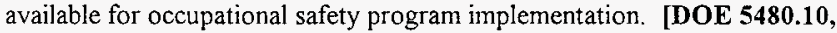
Section 9e; DOE 5483.1A, Section 7.d(11)(a)]

\subsection{SURVEILLANCE PROGRAMS}

\subsubsection{Performance Objective}

Surveillance of programs for reporting and investigating injuries, accidents, and illness is conducted as a measure of safety performance.

\section{Criteria}

3.4.1.1 A documented system is available for reporting injuries, accidents, illnesses, and unusual occurrences. [DOE O 232.1; DOE 5484.1]

3.4.1.2 Investigations are conducted for incidents and events that resulted, or could have resulted, in occupational injuries or death, to identify probable causes, and to identify corrective actions to prevent recurrence of similar accidents. [DOE O 232.1; DOE 5483.1A]

3.4.1.3 Analysis of facility injuries, accidents, and illnesses is performed to evaluate performance and identify trends and potential problem areas that should be brought to the management's attention. [DOE 5480.10, Section 9.a;

DOE 5483.1A]

3.4.1.4 Systems are available for facility employees to report potential occupational safety and health concerns. [DOE 5480.10, Section 9.a(5); DOE 5483.1A] 


\subsubsection{Performance Objective}

A documented and effective hazard identification process has been implemented to ensure that existing and potential chemical, physical, biological, and ergonomic hazards are identified and that the risk of associated worker injury or illness is evaluated.

\section{Criteria}

3.4.2.1 Initial or baseline surveys of all work areas or operations have been performed to identify and evaluate potential risks for the workers.

[DOE O 440.1, Attachment 2, 17. a]

3.4.2.2 Hazards in the workplace are identified. [DOE 5480.10, Section 9.b(1); DOE O 440.1, Attachment 2,9.a]

3.4.2.3 Periodic walkthrough surveys are conducted to identify potential hazards in the workplace. [DOE 5480.10, Sec 9.b(1); DOE O 440.1, Attachment 2, 17.c]

\subsubsection{Performance Objective}

Recognized exposure assessment methodologies are used to evaluate chemical, physical, and biological agents and ergonomic stressors.

\section{Criteria}

3.4.3.1 Workplace monitoring (personal, area, wipe, and bulk sampling), biological monitoring, and observations are used to document worker exposures.

[DOE 5480.10, Section 9.e; DOE O 440.1, Attachment 2, 9.b]

3.4.3.2 Equipment used for monitoring the workplace is appropriately calibrated and maintained. [DOE 5480.10, Section 9.e; DOE 5700.6C, Section 9.b(2)a; DOE O 440.1, Attachment 2, 17(j)]

3.4.3.3 Personal/area exposure monitoring samples are analyzed by an accredited industrial hygiene laboratory. [DOE O 440.1, Attachment 2, 17(d)]

3.4.3.4 The American Conference of Governmental Industrial Hygienists (ACGIH), "Threshold Limit Values for Chemical Substances and Physical Agents and Biological Exposure Indices" (most recent edition, as specified in the contract), are used when the ACGIH threshold limit values are lower (more protective) than the OSHA permissible exposure limits.

[DOE 5480.4, Attachment 2; DOE O 440.1, Attachment 2, 12(g)] 
3.4.3.5 When the ACGIH threshold limit values are used as exposure limits, facilities/projects nonetheless comply with the other provisions of applicable OSHA-expanded health standards. [DOE O 440.1, Attachment 2, 12(g)]

3.4.3.6 An effective system has been developed to maintain records of employee exposures to toxic materials or harmful physical agents, and the results are easily retrievable. [DOE 5480.10, Section 9.f (3); DOE 5483.1A, Chapter III, Section 2.b; DOE 5480.4, Attachment 2 [29 CFR 1910.20]; DOE 1324.2A, Attachment V-1 4.c and 4.d]

\subsubsection{Performance Objective}

A hazard prevention/abatement process has been implemented to ensure that all identified hazards are managed through final abatement and control.

\section{Criteria}

3.4.4.1 Appropriate engineering, administrative, work practice and/or personal protective control methods are used to limit hazardous exposures to acceptable levels. [DOE 5480.10, Section 9.b; DOE O 440.1, Attachment 2, 17(e)]

3.4.4.2 Control measures are implemented for existing hazards identified in the workplace. [DOE O 440.1, Attachment 2, 10(b)]

3.4.4.3 Controls (engineering, administrative, and/or personal protective equipment) are incorporated in the appropriate facility design or procedure for hazards identified during the facility design or during the development of procedures. [DOE O 440.1, Attachment 2, 10(a)]

3.4.4.4 The appropriate type of chemical protective clothing is used to prevent skin absorption of chemicals. [DOE $\mathrm{O} 440.1$, Attachment 2, 17(j)]

3.5 CHEMICAL, PHYSICAL, BIOLOGICAL, AND ERGONOMIC HAZARDS

\subsubsection{Performance Objective}

Personnel are adequately informed of chemical, physical, biological, and ergonomic hazards that may be encountered in their work environment. 


\section{Criteria}

3.5.1.1 A Hazard Communication Program in accordance with 29 CFR 1910.1200 has been implemented; this program is used to effectively communicate health hazards to facility/project personnel. [DOE 5480.4, Attachment 2; DOE 5480.10, Section 9.b(5); DOE 5483.1A; DOE O 440.1, Attachments 2 and 12]

3.5.1.2 Employees are encouraged to be involved with the development of Industrial Hygiene Program goals, objectives, and performance measures and in the identification and control of hazards in the workplace.

\section{[DOE O 440.1, Attachments 2 and 5]}

3.5.1.3 Employees and supervisors are informed of their rights and responsibilities and of the company and DOE resources available to resolve concerns about potential health hazards in their work environment. [DOE 5483 1A, Section 7.d(11)(b); DOE O 440.1, Attachment 2]

3.5.1.4 Employees are provided written notification of exposure monitoring results when it is indicated that their exposure(s) have exceeded the applicable exposure limits. [DOE 5480.10, Section 9.b(5); DOE O 440.1, Attachment 2, 6(g)]

\subsection{OSHA STANDARDS}

\subsubsection{Performance Objective}

Appropriate OSHA General Industry (and Construction when applicable) health and safety standards are implemented based on the identified facility/project hazards.

\section{Criteria}

3.6.1.1 The facility is clean, uncluttered, and free of safety concerns for tripping and falling on all walking and working surfaces as required by 29 CFR 1910, Subpart D. [DOE 5480.4, Attachment 2, Section 2.e(1)(c)]

3.6.1.2 Ladders, guard rails, and fall protection equipment are well maintained and meet standards prescribed in 29 CFR 1910, Subpart D. [DOE 5480.4, Attachment 2, Section 2.e(1)(c)]

3.6.1.3 Exits are properly marked, adequately lighted, and all means of egress are continuous and unobstructed from any point in a building in accordance with 29 CFR 1910, Subpart E. [DOE 5480.4, Attachment 2, Section 2.e(1)(c)] 
3.6.1.4 An Inspection and Preventative Maintenance Program has been established for powered platforms, hoisting and rigging devices, cranes, and other powered tools and machinery. Operational procedures are in compliance with the site Hoisting and Rigging manual, and 29 CFR 1910, Subparts F and N. [DOE 5480.4, Attachment 2, Section 2.e(1)(c)]

3.6.1.5 The ventilation requirements of 29 CFR 1910, Subpart $G$ have been implemented as appropriate. [DOE 5480.4, Attachment 2; DOE 440.1, Attachment 2, 12]

3.6.1.6 An effective Noise/Hearing Conservation Program that is in accordance with 29 CFR 1910, Subpart $G$ has been implement for facilities/projects with hazardous noise levels. [DOE 6430.1A, Section 1660-1(4)

3.6.1.7 An effective Process Safety Management Program that is in accordance with 29 CFR 1910, Subpart $H$ has been implemented when applicable. [DOE 5480.4 Attachment 2; DOE O 440.1 Attachment 2, 12]

3.6.1.8 An effective Hazard Waste Operations and Emergency Response Program that is in accordance with 29 CFR 1910, Subpart $H$ has been implemented for facilities/projects that are involved in hazardous waste operations or Resource, Conservation, and Recovery Act (RCRA) treatment, storage, disposal facilities activities. [DOE 6430.1A, Section 1660-1(4)]

3.6.1.9 Compressed gas containers and other high pressure systems are inspected, stored, and maintained to minimize occupational safety concerns in accordance with 29 CFR 1910, Subparts H and M. [DOE 5480.4, Attachment 2, Section 2.e(1)(c)]

3.6.1.10 Programs exist (as appropriate) for the handling, processing, storing, transporting, and shipping of explosive materials in accordance with the DOE explosives safety manual, and 29 CFR 1910, Subpart H. [DOE 5480.4, Attachment 2, Section 2.e(1)(c), 2.e(6)(a)]

3.6.1.11 An effective Respiratory Protection Program that is in accordance with 29 CFR 1910, Subpart I and ANSI Z88.2 has been implemented. [DOE 5480.4, Attachment 2; DOE O 440.1, Attachments 2 and 12 (a and I), and 17(h)]

3.6.1.12 An effective Permit Required Confined Space Program that is in accordance with 29 CFR 1910, Subpart J has been implemented for facilities/projects with permit required confined spaces. [DOE 5480.4, Attachment 2; DOE 0 440.1 Attachments 2 and 12]

3.6.1.13 Appropriate danger, warning, and safety information signs are available 
throughout the facility in accordance with 29 CFR 1910, Subpart J.

[DOE 5480.4, Attachment 2; DOE $O$ 440.1 Attachments 2 and 12]

3.6.1.14 Personnel are aware of and follow procedures for lockout and tagout to prevent accidental contact with energized electrical circuits and other hazardous energy sources, in accordance with 29 CFR 1910, Subpart J. [DOE 5480.4, Attachment 2, Section 2.e(1)(c)]

3.6.1.15 Guarding is available and established as specified in 29 CFR 1910, Subpart $O$ for machines and tools with moving and rotating parts that may present workplace safety concerns. [DOE 5480.4, Attachment 2, Section 2.e(1)(c)]

3.6.1.16 Hand and portable power tools, and other hand-held equipment meet the requirements of 29 CFR 1910, Subpart P. [DOE 5480.4, Attachment 2, Section 2.e(1)(c)]

3.6.1.17 Welding, cutting, and brazing operations are conducted in accordance with 29 CFR 1910, Subpart Q. [DOE 5480.4, Attachment 2, Section 2.e(1)(c)]

3.6.1.18 Electrical safety procedures and rules are established in accordance with 29 CFR 1910 Subpart S. [DOE 5480.4, Attachment 2, Section 2.e(1)(c)]

3.6.1.19 An effective Asbestos Program that is in accordance with 29 CFR 1910, Subpart $Z$ has been implemented for facilities/projects involved in asbestos or asbestos containing material work activities. [DOE 5480.4, Attachment 2; DOE 0 440.1, Attachments 2 and 12]

3.6.1.20 An effective Lead Program that is in accordance with 29 CFR 1910, Subpart $Z$ has been implemented for facilities/projects involved in lead or lead containing material work activities. [DOE 5480.4, Attachment 2; DOE $O$ 440.1, Attachments 2 and 12]

3.6.1.21 An effective Bloodborne Pathogens Program that is in accordance with 29 CFR 1910, Subpart $Z$ has been implemented for facilities/projects with employees potentially exposed to blood or other potentially infectious materials. [DOE 5480.4, Attachment 2; DOE O 440.1, Attachments 2 and 12]

3.6.1.22 An effective Laboratory Standard that is in accordance with 29 CFR 1910, Subpart $Z$ has been implemented for facilities/projects engaged in the laboratory use of hazardous chemicals. [DOE 5480.4, Attachment 2; DOE $O$ 440.1, Attachments 2 and 12] 
3.6.1.23 Safety rules and requirements for the use of motorized equipment and motor vehicles are in use. Personnel understand and comply with these safety rules. [DOE 5480.4, Attachment 2, Section 2.g(2)]

3.6.1.24 An effective Carcinogen Control Program has been implemented that mitigates the risk from identified and potential OSHA/ACGIH carcinogens. [DOE 5480.10, Section 9.c; DOE O 440.1, Attachment 2, 17(I)]

3.6.1.25 An effective Heat Stress Program has been implemented to control exposures to heat stress conditions in accordance with guidelines of the ACGIH. [DOE 5480.4, Attachment 2; DOE O 440.1, Attachment 2, 12(h)]

\subsection{TRAINING}

\subsubsection{Performance Objective}

Facility personnel are informed of safety and health training and awareness programs.

\section{Criteria}

3.7.1.1 Information on employee occupational safety rights and obligations are visibly posted at the facility. [DOE 5483.1A]

3.7.1.2 Occupational safety awareness among facility personnel is promoted by a documented program for communicating knowledge of the known safety concerns to all persons on the facility. [DOE 5483.1A]

3.7.1.3 A facility occupational safety training program includes activities that motivate, educate, and train all employees to recognize, correct, or report safety and health concerns, and hazards in the workplace. [DOE 5480.10, Section 9b(5); DOE 5483.1A]

3.7.1.4 Occupational safety training programs for all facility employees include indoctrination on safe work practices and procedures. [DOE 5480.20, Chapter 1; DOE 5483.1A]

\subsection{MEDICAL SURVEILLANCE PROGRAM}

\subsubsection{Performance Objective}

Facility/project personnel are enrolled in the appropriate medical surveillance program 
based on the applicable OSHA and DOE requirements.

\section{Criteria}

3.8.1.1 Employee job task analysis and hazard analysis information that outline physical and mental requirements and potential exposures and hazards of a specific job are provided to the occupational medical contractor. [DOE 5480.8A, Section 11, 2 and 3; DOE O 440.1, Attachment 2, 18(c)(2)(a)]

3.8.1.2 A summary of the potential work site exposures of employees is provided to the occupational medical contractor prior to mandatory health examinations. [DOE 5480.8A, Section 11, 2 and 3; DOE 0440.1 , Attachment 2, 18(c)(2)(b)]

\subsection{PREREQUISITES}

None.

\subsection{SPECIAL APPROVALS}

None. 


\subsection{REFERENCES}

The following documents were used to create this OS\&H section:

10 CFR 1910, Occupational Safety and Health Standards, 1 July 1993.

DOE $\mathrm{O} 232.1$, Occurrence Reporting and Processing of Operating Information, 25 September 1995.

DOE O 440.1, Worker Protection Management for DOE Federal and Contractor Employees, 30 September 1995.

DOE 4330.4B, Maintenance Management Program, 10 February 1994.

DOE 5480.4, Environmental Protection, Safety, and Health Protection Standards, 15 May 1984.

DOE 5480.6, Safety of Department of Energy Owned Nuclear Reactors, 23 September 1986.

DOE 5480.8A, Contractor Occupational Medical Program, 26 June 1992.

DOE 5480.9, Construction Safety and Health Program, 18 November 1987.

DOE 5480.10, Contractor Industrial Hygiene Program, 26 June 1985.

DOE 5480.19, Conduct of Operations Requirements for DOE Facilities, 19 May 1992.

DOE 5482.1B, Environment Safety, and Health Appraisal Program, 18 November 1991.

DOE 5483.1 A, Occupational Safety and Health Program for DOE Contractor Employees at Government-Owned Contractor-Operated Facilities, 22 June 1983.

DOE 5484.1, Environmental Protection, Safety and Health Protection Information Reporting Requirements, 24 February 1981.

DOE 5700.6C, Quality Assurance, 21 August 1991.

DOE 6430.1A, General Design Criteria, 6 April 1981.

Resource Conservation and Recovery Act (RCRA) of 1996, Public Law 94-580, 20 October 1976 (42 USC 6901 et seq.)

WHC-SD-MP-SRID-001, Tank Waste Remediation System Standards and Requirements Identification Document, 30 January 1996. 


\section{ENVIRONMENTAL PROTECTION}

\subsection{PURPOSE}

This section provides environmental protection functional area elements, performance objectives, and criteria intended for use by Tank Farm operational activities to ensure compliance with applicable State and Federal Regulations and Department of Energy (DOE) Orders as defined in the Tank Waste Remediation System (TWRS) Standards and requirements Identification Document (S/RID) and the Environmental Protection Program.

\section{$2.0 \quad$ SCOPE}

The performance objectives and criteria (PO\&C) apply to all Tank Farm facilities and organizations subject to evaluation under the TWRS Management Assessment Program.

\subsection{FUNCTIONAL AREA ELEMENTS}

The following are the waste management functional area elements. Each functional area element has performance objectives and subsequent criteria. The criteria are used to assess the objectives.

\subsection{ENVIRONMENTAL POLICY MANAGEMENT}

\subsubsection{Performance Objective}

A program and system are established to ensure compliance with the National Environmental Policy Act (NEPA)/State Environmental Policy Act (SEPA) so that appropriate NEPA/SEPA documentation is issued before initiating detailed design, procurement, start of construction, operation, or testing concerning a proposed action.

\section{Criteria}

3.1.1.1 A formal program is in place that establishes responsibilities and requirements for the implementation of, and compliance with, contractor requirements of NEPA/SEPA. [40 CFR 1501; WAC 197-11; 10 CFR 1021]

3.1.1.2 Procedures and plans are implemented to conduct NEPA/SEPA-level evaluation/reviews, to develop and distribute appropriate NEPA 
documentation, and provide approval that the requirements of NEPA/SEPA are satisfied and that proposed actions can proceed. [40 CFR 1501; 10 CFR 1021; WAC 197-11]

3.1.1.3 A training program is established with appropriate documentation to ensure proper NEPA/SEPA training of appropriate personnel. [10 CFR 1021; WAC 173-303-330]

\subsubsection{Performance Objective}

A program is implemented to develop response action alternatives at appropriate times in the Resource Conservation and Reclaimation Act (RCRA)/Comprehensive Environmental Restoration, Compensation, and Liability Act (CERCLA) process, to screen the alternatives to identify appropriate alternatives for detailed analysis, and to select and implement the remedy.

\section{Criteria}

3.1.2.1 Alternatives that meet remedial action objectives for all exposure pathways are developed, screened as necessary to reduce them to a workable number for final consideration, and evaluated against appropriate remedy selection criteria. [WAC 197-11; 40 CFR 1501 and 1505]

3.1.2.2 All activities taken during remedial design and remedial action (RA) or corrective measures implementation conform, for CERCLA sites, to record of decision (ROD) or to the conditions of an explanation of significant differences or ROD Amendment or, for RCRA sites, to the signed remedy selection document. Any changes to these agreements are prepared in accordance with the appropriate notice, community relations, and response to comments requirements. [40 CFR 1505 and 1506]

\subsection{PERMITS}

\subsubsection{Performance Objective}

Liquid effluent discharges have received the necessary discharge permits from appropriate Federal, State, or local agencies.

\section{Criteria}

3.2.1.1 A program has been implemented to verify that discharge permits are obtained, or applied for, prior to commencing construction of a facility or 
modification of a facility for which a discharge permit is required. [DOE 5400.1]

3.2.1.2 The facility has a National Pollutant Discharge Elimination System (NPDES) permit for existing discharges to surface waters pursuant to 40 CFR 122 and 123. [WAC 173-216; DOE 5400.1, Chapter IV]

3.2.1.3 The facility has a permit from the Washington State Department of Health for on-site sewage systems. For sewage systems with a design capacity greater than 14,500 gallons per day, the permit is issued through Ecology under WAC 173-216-240. [WAC 246-272]

3.2.1.4 There are requirements and schedules for the documented periodic inspection of drain lines and sewers to ascertain that wastes are directed to the correct discharge point. [WAC 246-272]

\subsubsection{Performance Objective}

All discharge limitations mandated by site specific NPDES permits, pretreatment requirements established by local sanitary authorities, Federal Facility Compliance Agreements, consent orders, multiparty compacts, or other contractual obligations that may establish permit type requirements are being complied with on a consistent basis.

\section{Criteria}

3.2.2.1 Monitoring is being performed to ensure facilities meet permit requirements, including analysis of samples utilizing methods specified in the permits. [WAC 246-272; DOE 5400.1]

3.2.2.2 Specific reporting requirements in the permits are followed. Reports are complete and are reviewed by qualified environmental personnel prior to being forwarded. [WAC 246-272; DOE 5400.1]

3.2.2.3 A program exists to notify regulatory agencies of changes or alterations to the facility that could change the nature or increase the quantity of pollutants released. [WAC 246-272]

\subsubsection{Performance Objective}

Controls are established to prevent or phase out the discharge of radioactively contaminated liquids to soil columns. 


\section{Criteria}

3.2.3.1 The program includes a mechanism to review all operational changes, new facilities, and facility modifications to determine if they increase an ongoing soil-column release, create a new one, or discharge uncontaminated liquid to an inactive soil-column release area. [WAC 173-218; DOE 5440.1; DOE 5400.5, Chapter III; 10 CFR 1021]

3.2.3.2 The program contains a mechanism that ensures new or increased discharges of radionuclides in liquid waste to active or virgin soil columns are prohibited. [WAC 173-218; DOE 5400.5, Chapter II]

3.2.3.3 The program implements a mechanism that ensures liquid discharges, even through uncontaminated, are prohibited in inactive release areas.

[WAC 173-218; DOE 5400.5, Chapter II]

\subsubsection{Performance Objective}

Permits to construct or modify and permits to operate various air pollutant sources are obtained or renewed in a timely manner.

\section{Criteria}

3.2.4.1 A program is in effect to ensure that permits to construct or modify and permits to operate are obtained or reviewed for applicable sources of air pollutants in a timely manner. [40 CFR 61; WAC 246-247; DOE 5400.1]

3.2.4.2 The facility has obtained a permit or a permit exemption for existing discharges to the atmosphere pursuant to upper tier requirements.

[WAC 246-247; 40 CFR 61; DOE 5400.1]

\subsubsection{Performance Objective}

RCRA permit applications, reports, and notifications to regulatory agencies are prepared and submitted in accordance with all applicable Federal, State, and local requirements.

\section{Criteria}

3.2.5.1 Permit applications, notifications of interim status, changes to existing interim status, and any other required notifications to regulatory agencies are prepared and submitted by the statutory or other deadlines established in agreements, plans, or orders in effect at the facility. [WAC 173-303; 40 CFR 265] 
3.2.5.2 Reports required under statue, regulation, orders, agreements, permits, or plans that provide information to the regulators or others about the regulatory compliance and operating status of the facility are prepared and submitted in a timely manner. These reports are complete and accurate and, when submitted, reflect the operating conditions at the facility.

[WAC 173-303; 40 CFR 265]

\subsection{ENVIRONMENTAL MONITORING, SURVEILLANCE, AND INSPECTIONS}

\subsubsection{Performance Objective}

The Environmental Monitoring Program is established to demonstrate compliance with limits for radiation exposure to the public by documentation of an appropriate combination of measurements and calculations

\section{Criteria}

3.3.1.1 Measured and calculated doses to the public have not exceeded the limits of DOE 5400.5 and other applicable regulations. [DOE 5400.1; DOE 5400.5, Chapter II]

3.3.1.2 Dose evaluations consider all potential pathways and are supported with documentation, including the recording of all parametric values. [DOE 5400.5, Chapter I, Section 10]

3.3.1.3 The reporting and record retention requirements of DOE 5400.1 and DOE 5400.5 are met. [DOE 5400.1; DOE 5484.1]

\subsubsection{Performance Objective}

Waste management facilities are monitored in accordance with applicable DOE Federal, State, and local requirements.

\section{Criteria}

3.3.2.1 A system is in place to accurately monitor environmental media that are potentially affected by waste facilities. The monitoring program is implemented in conformance with a formal plan. [40 CFR 265, DOE 5400.1; DOE 5820.2A]

3.3.2.2 Facility specific information is included in the Environmental Monitoring Plan (EMP) to address required wastewater and surface water monitoring 
and reporting needs. [DOE 5400.1, Chapter IV; DOE 5400.5; DOE/EH-173T]

3.3.2.3 The EMP contains the information necessary for users to understand and perform their activities. [DOE 5400.1, Chapter IV; DOE 5400.5; DOE/EH-173T]

3.3.2.4 Assessments are performed by persons not directly involved in the monitoring and reporting programs to ensure that the program is following the plan and that the plan addresses all permit requirements. [DOE 5400.1, Chapter IV; DOE/EH-173T]

\subsubsection{Performance Objective}

Underground storage tanks (UST) are managed to minimize the potential for releases to the environment and to ensure compliance with all applicable DOE, Federal, state, and local requirements.

\section{Criteria}

3.3.4.1 General operating requirements delineated in standard operating procedures (SOPs) ensure that only substances compatible with the UST system are stored; that corrosion protection equipment is inspected and maintained, and records are kept; and that any repairs to the UST system are made in accordance with manufacturers' specifications and EPA, state, or local requirements. [WAC 173-360]

3.3.4.2 Release detection requirements are met for all new USTs. A compliance schedule has been developed for all USTs installed prior to December 1988 to meet release detection requirements by the required dates. In addition, records of leak detection testing and install are maintained. [WAC 173360]

3.3.4.3 Daily inventory control (or another test of equivalent performance) are conducted in a manner capable of detecting a release of at least 1.0 percent of flow-through plus 130 gallons on a monthly basis. [WAC 173-360]

3.3.4.4 A groundwater monitoring network is in place so that the effects of operations on groundwater quality can be determined and documented. The monitoring-well network consists of sufficient stations to determine the quality of the groundwater entering and leaving the site. [40 CFR 165; DOE 5400.1]

3.3.4.5 SOPs are established to detail procedures and equipment in place to 
3.3.4.6 Following immediate response activities for releases, corrective actions are taken to prevent further releases and further migration, and to evaluate the extent of the release. Required follow-up reports are made to appropriate agencies. [WAC 173-360]

\subsubsection{Performance Objective}

Sampling and analysis of environmental media are conducted to provide representative defensible data.

\section{Criteria}

3.3.5.1 Field and laboratory activities are conducted in accordance with controlled, validated procedures. [DOE 5400.1, Chapter IV]

3.3.5.2 Sampling is conducted to ensure collection of a representative sample, and precautions are taken to maintain sampling integrity. [DOE 5400.1, Chapter [V]

3.3.5.3 Sample chain-of-custody is maintained. [DOE 5400.1, ChapterIV]

3.3.5.4 Analytical results receive independent, documented review. [DOE 5400.1, Chapter IV]

3.3.5.5 An Instrument Control Program, including such requirements as calibration, preventive maintenance, and efficiency, functional, and background checks, is established. [DOE 5400.1, Chapter IV]

\subsubsection{Performance Objective}

A Radiological Environmental Monitoring Program is established to provide accurate and complete surveillance of the radiological effects of facility operations on the environment.

\section{Criteria}

3.3.6.1 An Environmental Surveillance Program is being conducted that reflects facility characteristics, hazard potential, and quantities and concentrations of materials released. [DOE 5400.1; DOE/EH-173T, Chapter 5]

3.3.6.2 The extent and use of affected air, land, and water, and specific local or public interest or concerns are identified, documented, used as a part of the program basis, and periodically reevaluated. [DOE 5400.1, Chapter IV] 
3.3.6.3 All analytical data undergo documented review that includes comparison with pre-established lower limits of detection and action levels. [DOE/EH-173T, Chapter 6]

3.3.6.4 All operational changes, new facilities, and facility modifications are evaluated to determine their impact on the program and are modified as needed. [DOE 5400.1, Chapter IV]

3.3.6.5 Environmental studies and pre-operational surveillances are conducted prior to startup of a new site, facility, or process that has the potential for significant adverse environmental impact. [DOE 5400.1, Chapter IV]

3.3.6.6 The environmental monitoring plan is the primary document that defines the program, its basis, and its implementation. A mechanism is established to ensure that the plan is reviewed and updated every 3 years. [DOE 5400.1, Chapter IV, Section 10.C]

\subsubsection{Performance Objective}

An effective program is established to provide verification of the effectiveness of the environmental protection activities and adherence to the quality assurance (QA) program.

\section{Criteria}

3.3.7.1

Programs for environmental self-assessments and oversight activities are defined in controlled documents and are comprehensive in scope. [DOE 5482. 1B]

Appraisals are conducted on a regular, planned basis, utilizing approved and controlled procedures performed by trained, qualified personnel. [DOE 5400.1, Chapter IV]

A formal system is in place to document responses, investigations, and corrective actions related to audits, appraisals, and surveillance. Findings and observations are formally documented and communicated to management and staff personnel for corrective actions and root cause determinations (when required). [DOE 5400.1, Chapter IV] 


\subsection{ENVIRONMENTAL CONTROL STANDARDS}

\subsubsection{Performance Objective}

Emissions to the atmosphere of regulated pollutants are inventoried and maintained at levels that are below allowable standards, and in the case of radionuclides, emissions are controlled to the extent that potential exposures to members of the public are as low as reasonably achievable (ALARA).

\section{Criteria}

3.4.1.1 All exhaust stacks and vents, as well as sources of fugitive emissions, are inventoried and evaluated to determine which sources need engineering and/or administrative controls to minimize emissions to the atmosphere. This inventory and evaluation are documented, including the basis for a decision to not control specific sources. [DOE 5400.5; WAC 173-400; 40 CFR 61]

3.4.1.2 Emission control systems or administrative controls are in place and are operated in a manner that ensures effective control of emissions to the atmosphere. SOPs are available that describe operational requirements for emission-control equipment or that details steps needed to implement administrative controls. [DOE 5400.1; WAC 173-400]

\subsubsection{Performance Objectives}

Environmental surveillance monitoring is in place to ascertain the effects, on-site and offsite, of airborne emissions of pollutants or hazardous materials from DOE activities.

\section{Criteria}

3.4.2.1 Air surveillance monitoring for all pollutants and hazardous materials emitted by each facility is formalized in a plan and has appropriate review and approval. [DOE 5400.1; 40 CFR 61; DOE/EH-173T; WAC 173400]

3.4.2.2 Operating procedures for monitoring or sampling equipment and laboratory analyses for the pollutant being monitored are developed, reviewed, and approved. [DOE/EH-137T; DOE 5400.1; DOE 5400.5; 40 CFR 61]

3.4.2.3 Non-radiological regulated pollutants and hazardous materials emitted from the facility are identified in an approved monitoring plan. The plan defines all those pollutants and hazardous materials that require 
surveillance monitoring, and documents the basis for not monitoring specific pollutants. [DOE 5400.1, Chapter IV]

\subsection{RECORDKEEPING, REPORTS, AND NOTIFICATIONS}

\subsubsection{Performance Objective}

A program is established to identify, report, classify, investigate, and take remedial action when spills or unplanned releases of hazardous substances, extremely hazardous substances, oil, or waste occur.

\section{Criteria}

3.5.1.1 Plans and procedures are established that outline the specific responsibilities for identifying, responding to emergencies, and promptly reporting environmental occurrences including spills and unplanned releases and the submission of required reports (initial and follow-up). [40 CFR 355; WAC 173-303; DOE 5400.1]

\subsubsection{Performance Objective}

A program is established to comply with the notification procedures for continuous releases of hazardous substances, including procedures to identify such potential releases, evaluate the nature and magnitude of such releases with appropriate statistical certainty, and submit required annual reports.

\section{Criteria}

3.5.2.1 Plans and procedures are established that outline the specific responsibilities for identifying, responding to emergencies, and promptly reporting environmental occurrences including spills and unplanned releases, and the submission of required reports (initial and follow-up). [40 CFR 355]

\subsection{PREREQUISITES}

None. 


\subsection{SPECIAL APPROVALS}

None.

\subsection{REFERENCES}

The following documents were used to create this EP section:

10 CFR 1201, National Environmental Policy Act Implementing Procedures, FR 55 (213): 46444-46464, 2 November 1990.

40 CFR 61, National Emission Standards for Hazardous Air Pollutants, 15 July 1994.

40 CFR 265, Interim Status Standards for the Treatment, Storage, and Disposal of Hazardous Waste, as amended by 59 FR 48041, 19 September 1994.

40 CFR 1501, NEPA and Agency Planning.

40 CFR 1505, NEPA and Agency Decisionmaking.

40 CFR 1506, Other Requirements of NEPA.

DOE/EH 173T, Environmental Regulatory Guide for Radiological Effluent Monitoring and Environmental Surveillance, January 1991.

DOE 5400.1, General Environmental Protection Program, 9 November 1988.

DOE 5400.5, Radiation Protection of the Public and Environment, 8 February 1990.

DOE 5484.1, Environmental Protection, Safety, and Health Protection Information Reporting Requirements, 24 February 1981.

DOE 5820.2A, Radioactive Waste Management, 26 September 1988.

WAC 173-216, State Waste Discharge Permit Program, 23 October 1993.

WAC 173-218, Underground Injection Control Program, 30 March 1984.

WAC 173-303, Dangerous Waste Regulations, 8 December 1993.

WAC 173-360, Underground Storage Tank Regulations, 31 January 1994.

WAC 246-272, On-Site Sewage Systems, 9 March 1994. 
WHC-SD-MP-SRID-001, Tank Waste Remediation System Standards and Requirements Identification Document, 30 January 1996. 
WHC-SD-TWR-SRID-003

September 30, 1996

Rev. 0

\section{ATTACHMENT 3 WHC-SD-TWR-SRID-003, Rev. 0 Page i of 31}

Att. $3-i$ 
WHC-SD-TWR-SRID-003

September 30, 1996 Rev. 0

\section{TABLE OF CONTENTS}

$1.0 \quad$ S/RID Phase 2 Evaluation Chart $\ldots \ldots \ldots \ldots \ldots \ldots \ldots \ldots \ldots \ldots .1$

2.0 S/RID Phase 2 Detailed Tables $\ldots \ldots \ldots \ldots \ldots \ldots \ldots \ldots \ldots \ldots .3 .2$

Att. $3-i j$ 
- Total Reg. Reviewed $\triangle$ Proc.Compliant/Y $\bigotimes$ Proc.Compliant/N $⿴$ Cont. Improvement Chks 394 392 72 109

Total Procedures Reviewed: 573

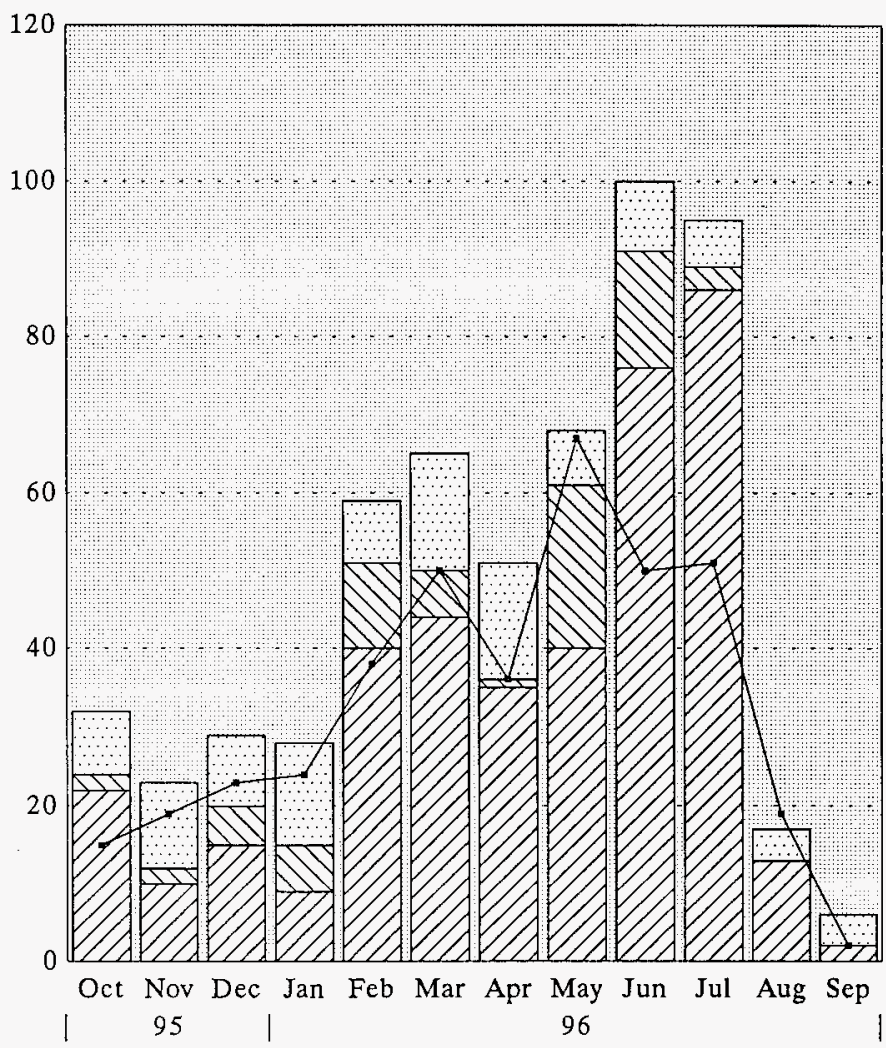

\begin{tabular}{|l|c|c|c|c|c|c|c|c|c|c|c|c|}
\hline Cont. Improvement Chks & 8 & 11 & 9 & 13 & 8 & 15 & 15 & 7 & 9 & 6 & 4 & 4 \\
\hline Proc.Compliant/N & 2 & 2 & 5 & 6 & 11 & 6 & 1 & 21 & 15 & 3 & 0 & 0 \\
\hline Proc.Compliant/Y & 22 & 10 & 15 & 9 & 40 & 44 & 35 & 40 & 76 & 86 & 13 & 2 \\
\hline Total Proc. Reviewed & 32 & 23 & 29 & 28 & 59 & 65 & 51 & 68 & 100 & 95 & 17 & 6 \\
\hline Total Req. Reviewed & 15 & 19 & 23 & 24 & 38 & 50 & 36 & 67 & 50 & 51 & 19 & 2 \\
\hline
\end{tabular}




\section{Assessments from 0ctober 1995 to 0ctober 1996 - WEST TANK FARMS}

\begin{tabular}{|c|c|c|c|c|c|c|c|}
\hline Month & $\begin{array}{c}\text { Int/Ext } \\
\text { I/E }\end{array}$ & As50s5or & Topic & Requirements & Implementing Procedure & $\begin{array}{c}\text { Compliant } \\
\text { Y/N }\end{array}$ & $\begin{array}{c}\text { C/A's } \\
\text { Complete }\end{array}$ \\
\hline Oct & $\mathbf{E}$ & $\begin{array}{l}\text { DOE } \\
\text { SJ BARAY } \\
\text { C MOGAN }\end{array}$ & $\begin{array}{l}\text { ROUTINE MONTHLY INSPECTION } \\
\text { QA ASSESSMENT OF SY EXHAUSTER } \\
\text { REPLACEMENT }\end{array}$ & $\begin{array}{l}\text { DOE ORDER 5OO0.3B, ANSI/ANG-3.2 } \\
\text { SECT 5.3.2 PAGE } 1 \text { SENT 1; DOE- } \\
\text { STD-1073-93 CH } 2 \text { SECT } 2.12 \text { PARA } \\
\text { 6 SENT 2-4; } \\
\text { 1OCFR830 PART } 120 \text { (c) (2) }(111):\end{array}$ & $\begin{array}{l}\text { WHC-IP-0731; WHC-CM-1-5; } \\
\text { WHC-CM-6-1 EP-3-3; } \\
\text { WHC-CM-2-1, PP-4.4 EP-1.6; }\end{array}$ & $\begin{array}{l}Y \\
Y\end{array}$ & \\
\hline Nov & E & $\begin{array}{l}\text { C HOGAN } \\
\text { MCCLUSKY }\end{array}$ & $\begin{array}{l}\text { QA ASSESSMENT OF IF PROCEDURAL CONTROL } \\
\text { SYSTEM } \\
\text { ROUTINE MONTHLY INSPECTIONS }\end{array}$ & 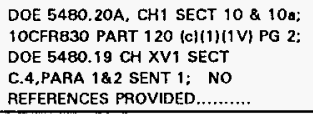 & $\begin{array}{l}\text { WHC-IP-O842, VOL 1, SECT. } 2.1 \\
\text { REV 1; WHC-IP-O842, VOL } 2 \text {. } \\
\text { SECT. } 4.16 .2 \text { REV1A; WHC-CM-3- } \\
\text { 5. SECT } 12.7 \\
\text { NO REFERENCES PROVIDED........ }\end{array}$ & $\begin{array}{l}Y \\
Y\end{array}$ & \\
\hline Dec & 1 & C HOGAN & QA ASSESSMENT OF USO PROCESS & $\begin{array}{c}\text { DOE } 5480.21 \text { PQEAMBLE SECT 10a; } \\
\text { DOE 5480.21 PAEAMBLE SECT 10b; } \\
" . \quad \text { " }\end{array}$ & $\begin{array}{l}\text { WHC-IP-O842, VOL 4, SECT. } 5.4 \\
\text { REV 7; WHC-CM-1-3, SECT. MRP } \\
5.12 \text { REV 2; WHC-CM-1-5 SECT } \\
\text { 7.3: }\end{array}$ & $\begin{array}{l}\mathrm{N} \\
\text { In- } \\
\text { progress }\end{array}$ & \\
\hline Jan & $\begin{array}{l}1 \\
1 \\
1\end{array}$ & $\begin{array}{l}\text { PETE OWEN } \\
\text { DEL SCOTT } \\
\text { CHOGAN } \\
\text { GUSTAVSON }\end{array}$ & $\begin{array}{l}\text { OPEAATOR AID } \\
\text { REQUIRED READING } \\
\text { QA ASSESSMENT OF VENDOR INFO REO'MENTS } \\
\text { ENVIRONMENTAL ASSESSMENT OF 241-T: }\end{array}$ & $\begin{array}{l}\text { NO REFERENCES PGOVIDED........ } \\
\text { DOE-STD1073-CH } 2 \text { SECT 2.1.2 PARA } \\
6 \text { SENT 2-4; } \\
\text { WAC-246-247-040; } \\
\text { WAC- 173-303-320; } \\
\text { WAC- 173-303-350; }\end{array}$ & $\begin{array}{l}\text { NO REFERENCES } \\
\text { PQOVIDED......... } \\
\text { WHC-CM-6-1, EP 3-3; } \\
\text { WHC-CM-7-5/WHC-EP-0438-1; } \\
\text { NO REFERENCES..... } \\
\text { DOE-RL-93-75; WHC IP-0971: } \\
\text { WHC-CM-4-3 }\end{array}$ & $\begin{array}{l}\text { Y } \\
\mathrm{N} \\
\text { in- } \\
\text { progress }\end{array}$ & \\
\hline Feb & $\begin{array}{l}\text { E } \\
1\end{array}$ & $\begin{array}{l}\text { DOE } \\
\text { KG WADE } \\
\text { C HOGAN }\end{array}$ & $\begin{array}{l}\text { EMISSION MONITORING } \\
\text { OA ASSESSMENT OF } \\
\text { LOCK AND TAG }\end{array}$ & $\begin{array}{l}\text { STANDING ORDER }: 1995-3330-\text {-SO- } \\
\text { OO3 } \\
\text { STANDING ORDER } \because 95-02 \text { REV } 1 \text {; }\end{array}$ & $\begin{array}{l}\text { WHC-IP-0718; WHC-IP-O842; } \\
\text { WHC-IP-OB42, SECT 4.9.1, PARA } \\
\text { 4.2.5; }\end{array}$ & $\begin{array}{l}Y \\
Y\end{array}$ & \\
\hline
\end{tabular}

Att. $3-2$ 
WHC-SO-IWR-SRIO-OO

September 30, 39 Rev.

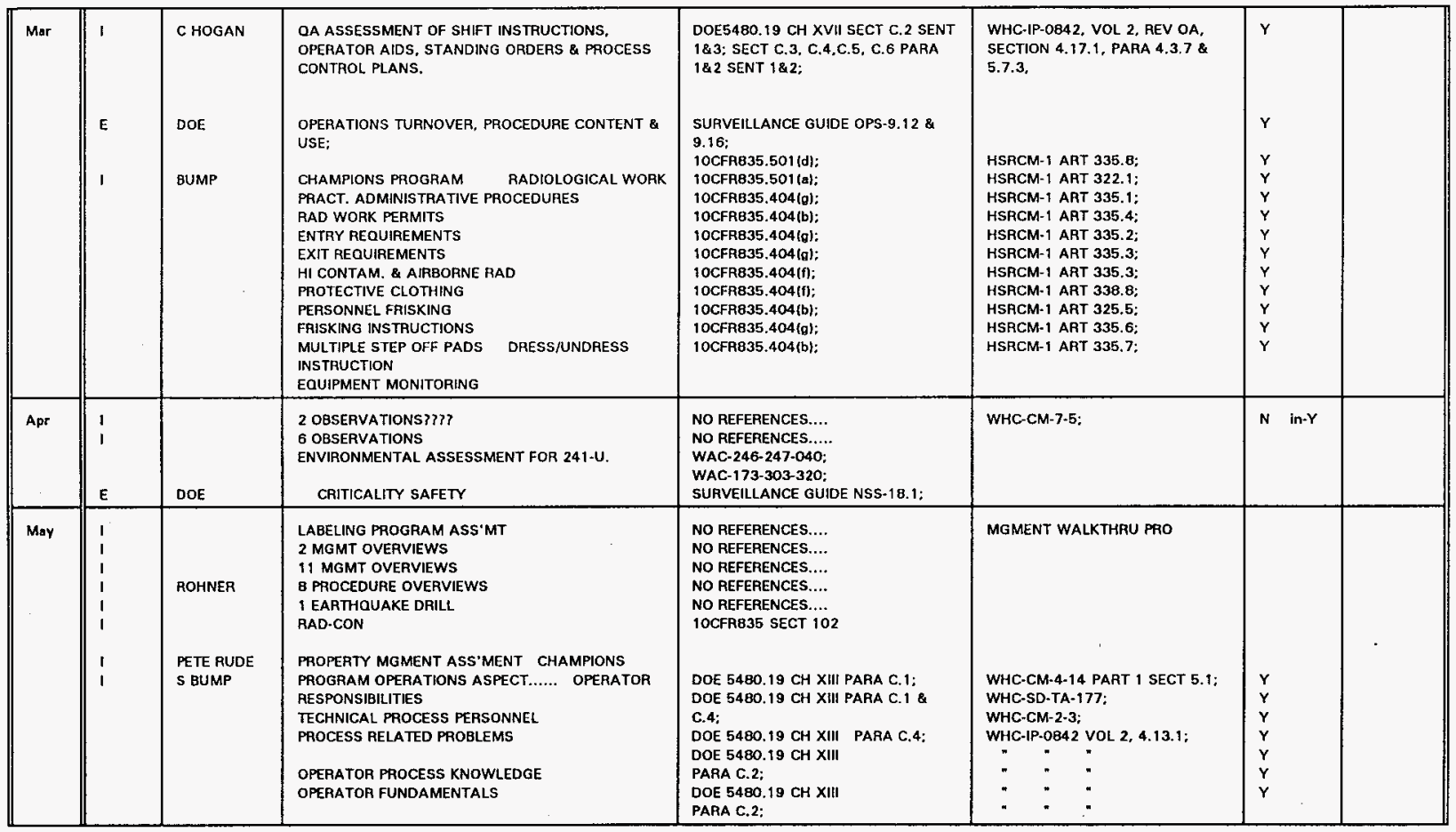

Att. $3-3$ 
$W H C-S D-I W K-S K I D-00$

September 30, 199 Rev.

\begin{tabular}{|c|c|c|c|c|c|c|}
\hline June & $\begin{array}{l}1 \\
1 \\
1 \\
1 \\
1 \\
1\end{array}$ & $\begin{array}{l}\text { C MERCADO } \\
\text { ROHNER } \\
\text { C HOGAN } \\
\text { DOE } \\
\text { DOE } \\
\text { DOE }\end{array}$ & $\begin{array}{l}10 \text { MANAGEMENT OVERVIEWS } \\
15 \text { PROCEOURE OBSERVATIONS } \\
2 \text { DRILLS (POWER OUTAGE SY FARM \& ACCIDENT } \\
\text { DRILLAT B COMPLEX. } \\
\text { MANAGEMENT ASSESSMENT } \\
\text { RAD-CON } \\
\text { OA ASSESSMENT OF HAZARDOUS WASTE } \\
\text { HANDLING \& PACKAGING: } \\
\text { ERGONOMICS } \\
\text { HEAT STRESS } \\
\text { PRESSURE SAFETY }\end{array}$ & $\begin{array}{l}\text { TOCFR835 SECT 102; } \\
\text { SURVEILLANCE GUIDE OSS 19.7; } \\
\text { SURVELLANCE GUIDE OSS-19.8; } \\
\text { SURVEILLANCE GUIDE OSS-19.4: }\end{array}$ & $\begin{array}{l}\text { NO REFERENCES... } \\
\text { NO REFERENCES... } \\
\text { NO REFERENCES... } \\
\text { WHC-IP-0842; } \\
\text { WHC-SD-TA-177; WHC-CM-4-14, } \\
\text { PART 1. SECT 5.1: } \\
\text { TO-100-045 REV. C-1; T0-100-65. } \\
\text { REV B-0; }\end{array}$ & $\begin{array}{l}Y \\
Y \\
Y \\
Y \\
Y \\
Y \\
Y\end{array}$ \\
\hline July & 1 & R SWALLOW & $\begin{array}{l}\text { CHAMPIONS PROGRAM } \\
\text { INDEPENDENT VERIFICATION COMP'S REQ'G IND. } \\
\text { VERIFIC } \\
\text { CRITERIA FOR INDEPENDENT VERIFICATION } \\
\text { OGCASIONS REOUIRING INDEPENDENT } \\
\text { VERIFICATION } \\
\text { VERIFICATION TECHNIQUES } \\
\text { INDEPENDENCE } \\
\text { SURVEILLANCE TESTING } \\
\text { OPERATIONS SELF ASSESSMENT } \\
\text { INDEPENDENT VERIFICATION } \\
\text { PROCEDURES } \\
\text { DOCUMENTATION IDENTIFICATION } \\
\text { DESIGNATING INDIVIDUALS } \\
\text { REVIEW \& COMPLETON } \\
\text { IMMEDIATE READING } \\
\text { MATERIAL AVAILABILITY } \\
\text { COMPLETION OF READING DOC } \\
\text { REQ'D READING REVIEWS }\end{array}$ & 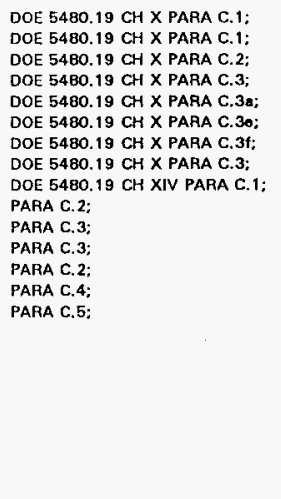 & $\begin{array}{l}\text { WHC-IP-0842 VOL 2; } \\
\vdots \\
\vdots \\
\vdots \\
\vdots \\
\vdots \\
\vdots \\
:\end{array}$ & $\begin{array}{l}Y \\
Y \\
Y \\
Y \\
Y \\
Y \\
Y \\
Y \\
Y \\
Y \\
Y \\
Y \\
Y \\
Y \\
Y \\
Y\end{array}$ \\
\hline
\end{tabular}

Att. $3-4$ 
家

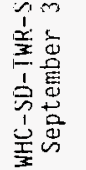

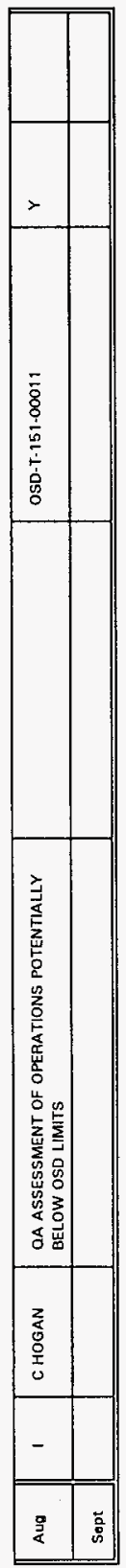

0
$m$
+
+ 
Assessments from October 1995 to October 1996 - WEST TANK FARMS

\begin{tabular}{|c|c|c|c|c|c|c|c|}
\hline Month & $\begin{array}{c}\text { Int/Ext } \\
\text { I/E }\end{array}$ & Assessor & Topic & Requirements & Implementing Procedures & $\begin{array}{c}\text { Compliant } \\
\text { Y/N }\end{array}$ & $\begin{array}{c}\mathrm{C} / \mathrm{A}^{\circ} \mathbf{\mathrm { s }} \\
\text { Complate }\end{array}$ \\
\hline July & 1 & $\begin{array}{l}\text { PL OWEN } \\
\text { R } \\
\text { MALHAN }\end{array}$ & $\begin{array}{l}\text { CHAMPIONS PROGRAM } \\
\text { EOUIPIPIPE LABELING } \\
\text { ABBREVIATIONS/NOMENCLATURE } \\
\text { LABELING PROCEDURES } \\
\text { TEMPORARY LABEL APPROVAL ROUTINE } \\
\text { ACTIVITIES } \\
\text { LABELING OEFICIENCIES } \\
\text { TEMPORARY LABEL VERIFICATION } \\
\text { LABEL ATTACHMENT/READABLE } \\
\text { PIPING SYSTEM LABELS } \\
\text { MATERIAL COMPATIBILITY } \\
\text { LABEL PLACEMENT } \\
\text { COMPONENTS REO'G LABELING } \\
\text { LABEL REQUIREMENTS } \\
\text { TRAINING REQUIREMENTS } \\
\text { ONSHIFT TRNG REOUIREMENTS } \\
\text { OUALIFICATION PROGRAM APP } \\
\text { TRAINEE PROFICIENCY } \\
\text { TRAINEE MONITORING } \\
\text { OATA RECORDING } \\
\text { ONE TO ONE INSTRUCTION } \\
\text { NUMBER OF TRAINEES } \\
\text { QUALIFICATION DOCUMENT. } \\
\text { SUSPENSION OF TRAINING } \\
\text { OPERATOR INSTRUC OUALIF'N } \\
\text { ON SHIFT INSTRUCTOR }\end{array}$ & $\begin{array}{l}\text { DOE 5480.19 CH XVIII PARA C. 2; } \\
\text { PARA C.4; } \\
\text { PARA C.4b; } \\
\text { PARA C.4a; } \\
\text { PARA C.4b; } \\
\text { PARA C.4b; } \\
\text { PARA C. 2; } \\
\text { PARA C. 2; } \\
\text { PARA C. 2; } \\
\text { PARA C.3; } \\
\text { PARA C.1; } \\
\text { PARA C.2; } \\
\text { DOE 5480.19 CH V PARA C.1: } \\
\text { PARA C.1: } \\
\text { PARA C.4; } \\
\text { PARA C.3; } \\
\text { PARA C.3; } \\
\text { PARA C.3; } \\
\text { PARA C.4; } \\
\text { PARA C. } 7 ; \\
\text { PARA C.5; } \\
\text { PARA C.6; } \\
\text { PARA C. 2; } \\
\text { PARA C. 2; }\end{array}$ & $\begin{array}{l}\text { WHC-IP-0842, VOL 4; 6TF- } \\
\text { 100:WHC-SP-0708 } \\
\vdots \\
\vdots \\
\text { WHC-IP-0842 VOL2\&3; } \\
\text { WHC-SP-0708: } \\
\text { WHC-CM-2-15; } \\
\text { WHC-IP-0842 VOL 2; } \\
\quad ; \\
\quad ; \\
\text { WHC-IP-0842 VOL283. } \\
\text { WHC-SP-0708; } \\
\text { WHC-IP-0842 VOL 2\&3. } \\
\text { WHC-CM-2-15. } \\
\text { WHC-SP-0708; } \\
\text { WHC-IP-0842 VOL283, } \\
\text { WHC-SP-0708; ' } \\
\text { " }\end{array}$ & $\begin{array}{l}Y \\
Y \\
Y \\
Y \\
Y \\
Y \\
Y \\
Y \\
Y \\
Y \\
Y \\
Y \\
Y \\
Y \\
Y \\
Y \\
Y \\
Y \\
Y \\
Y \\
Y \\
Y \\
Y \\
Y \\
Y \\
Y\end{array}$ & \\
\hline
\end{tabular}

Att. $3-6$ 
Assessments from 0ctober 1995 to 0ctober 1996 - WEST TANK FARMS

\begin{tabular}{|c|c|c|c|c|c|c|c|}
\hline Month & $\begin{array}{c}\text { Int/Ext } \\
\text { I/E }\end{array}$ & Assessor & Topic & Requirements & Implementing Procedures & $\begin{array}{c}\text { Complient } \\
Y / N\end{array}$ & $\begin{array}{c}\text { C/A's } \\
\text { Complete }\end{array}$ \\
\hline July & 1 & $\begin{array}{l}\text { R SWALLOW } \\
\text { A MALHAN }\end{array}$ & $\begin{array}{l}\text { CHAMPIONS PROGRAM } \\
\text { INDEPENDANT VERIFICATION COMPONENTS } \\
\text { REQ IND. VERIF CRITERIA FOR IND. VERIF } \\
\text { OCCAISIONS REQ IND VERIF } \\
\text { OPERATOR AID APPROVAL } \\
\text { OPRTOR AID APPROVAL CRIT. } \\
\text { OPERATOR AID USE } \\
\text { OPERATOR AID DEVELOPMENT } \\
\text { OP AIDIPROCED INTERFACE } \\
\text { OPERATOR AID POSTING } \\
\text { OPERATOR AID LISTING } \\
\text { OPERATOR AID REFERENCE } \\
\text { OPERATOR AID UPDATE } \\
\text { OPERATOR AIDS CURRENT } \\
\text { OPERATOR AID REVIEWS } \\
\text { UNAPPROVED OPERATOR AIDS } \\
\text { STATUS CHANGE AUTHORIZATION } \\
\text { OPERATIONAL LIMITS COMPLIANCE } \\
\text { SHIFT ACTIVITY AUTHORIZATION } \\
\text { TEMP MODIFICATION CONTROL STATUS } \\
\text { CHANGE REPORTING } \\
\text { EQUIP DEFIC. REPORTING } \\
\text { EQUIP\& SYSTEM ALIGNMENT } \\
\text { EQUIP LOCK \& TAG } \\
\text { OPERATIONAL LIMITS DOCUM } \\
\text { POST MAINTENANCE TESTING } \\
\text { TRAINING } \\
\text { FLARM STATUS } \\
\text { ENGINEERING DRAWINGS } \\
\text { FUNCTIONAL TESTING } \\
\text { ONA }\end{array}$ & 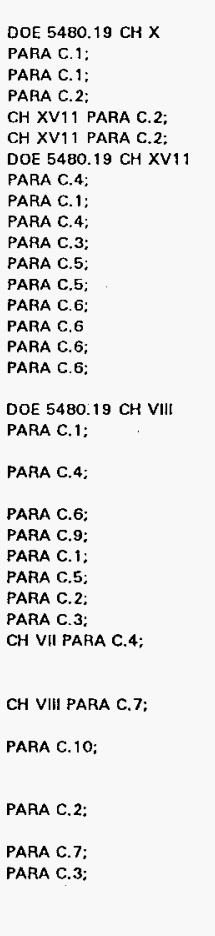 & 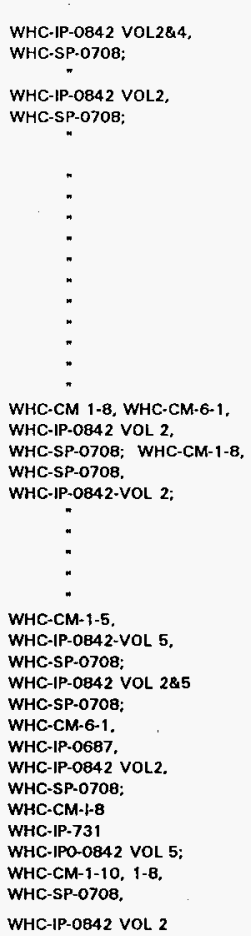 & $\begin{array}{l}Y \\
Y \\
Y \\
Y \\
Y \\
Y \\
Y \\
Y \\
Y \\
Y \\
Y \\
Y \\
Y \\
Y \\
Y \\
Y \\
Y \\
Y \\
Y \\
Y \\
Y \\
Y \\
Y \\
Y \\
Y \\
Y \\
Y \\
Y \\
Y \\
Y \\
Y \\
Y\end{array}$ & \\
\hline
\end{tabular}




\section{Assessments from October 1995 to 0ctober 1996 - WEST TANK FARMS}

\begin{tabular}{|c|c|c|c|c|c|c|c|}
\hline Month & $\begin{array}{c}\operatorname{Int} / \mathrm{Ext} \\
1 / \mathrm{E}\end{array}$ & Assessor & Topic & Requirements & Implementing Procedures & $\begin{array}{c}\text { Compliant } \\
Y / N\end{array}$ & $\begin{array}{c}\text { C/A's } \\
\text { Complete }\end{array}$ \\
\hline July & 1 & $\begin{array}{l}\text { R SWALLOW } \\
\text { R MALHAN }\end{array}$ & $\begin{array}{l}\text { CHAMPIONS PROGRAM } \\
\text { INDEPENDANT VERIFICATION COMPONENTS } \\
\text { REO IND. VERIF CRITERIA FOR IND. VERIF } \\
\text { OCCAISIONS REQ IND VERIF } \\
\text { OPERATOR AID APPROVAL } \\
\text { OPRTOR AID APPROVAL CRIT. } \\
\text { OPERATOR AID USE } \\
\text { OPERATOR AID DEVELOPMENT } \\
\text { OP AID/PROCED INTERFACE } \\
\text { OPERATOR AID POSTING } \\
\text { OPERATOR AID LISTING } \\
\text { OPERATOR AID REFERENCE } \\
\text { OPERATOR AID UPDATE } \\
\text { OPERATOR AIDS CURRENT } \\
\text { OPERATOR AID REVIEWS } \\
\text { UNAPPROVED OPERATOR AIDS } \\
\text { STATUS CHANGE AUTHORIZATION } \\
\text { OPERATIONAL LIMITS COMPLIANCE } \\
\text { SHIFT ACTIVITY AUTHORIZATION } \\
\text { TEMP MODIFICATION CONTROL STATUS } \\
\text { CHANGE REPORTING } \\
\text { EOUIP DEFIC. REPORTING } \\
\text { EOUIP\& SYSIEM ALIGNMENT } \\
\text { EOUIP LOCK \& TAG } \\
\text { OPERATIONAL LIMITS DOCUM } \\
\text { FULSTIONAL TESTING } \\
\text { PLARM STATUS } \\
\text { POST MAINTENANCE TESTING } \\
\text { TRAINING }\end{array}$ & 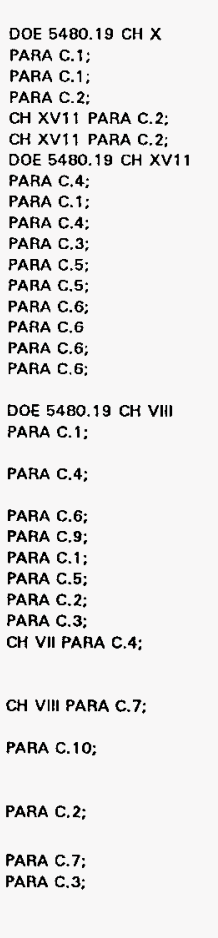 & $\begin{array}{l}\text { WHC-IP-0842 VOL2\&4, } \\
\text { WHC-SP-0708; } \\
\text { WHC-IP-0842 VOL2, } \\
\text { WHC-SP-0708; } \\
\quad ; \\
\quad \vdots \\
\quad ; \\
\quad ; \\
\quad ; \\
\text { WHC-CM 1-8, WHC-CM-6-1, } \\
\text { WHC-IP-0842 VOL 2, } \\
\text { WHC-SP-0708; WHC-CM-1-8, } \\
\text { WHC-SP-0708, } \\
\text { WHC-IP-0842-VOL 2: } \\
\quad ; \\
\quad ; \\
\quad:\end{array}$ & $\begin{array}{l}Y \\
Y \\
Y \\
Y \\
Y \\
Y \\
Y Y \\
Y \\
Y \\
Y \\
Y \\
Y \\
Y \\
Y \\
Y \\
Y \\
Y \\
Y \\
Y \\
Y \\
Y \\
Y \\
Y \\
Y \\
Y \\
Y \\
Y\end{array}$ & \\
\hline
\end{tabular}


Assessments from October 1995 to October 1996 - WEST TANK FARMS

\begin{tabular}{|c|c|c|c|c|c|c|c|}
\hline Month & $\begin{array}{l}\text { Int/Ext } \\
I / E\end{array}$ & Assessor & Topic & Requirements & Implementing Procedures & $\begin{array}{c}\text { Compliant } \\
Y / N\end{array}$ & $\begin{array}{c}\text { CA's } \\
\text { Complete }\end{array}$ \\
\hline July & $\mathbf{I}$ & R BROOKS & $\begin{array}{l}\text { CHAMPIONS PROGRAM } \\
\text { LOCKOUTS \& TAGOUTS } \\
\text { LOCKOUT/TAGOUT PROGRAM } \\
\text { LOCKOUT/TAGOUT PROCEDURES } \\
\text { APPLICATION LOCKOUT/TAGOUT } \\
\text { LOCKOUT/TAGOUT REMOVAL } \\
\text { CAUTION TAG CONTROL } \\
\text { CAUTION TAG ISSUANCE } \\
\text { LOCKOUT TAGOUT DOCUMENT. } \\
\text { VERIFICATION OF INSTALLATION } \\
\text { SHIFT/PEPSONNEL CHANGES } \\
\text { TAG PLACEMENT } \\
\text { PROTEC. MAT'LS \& HOWARE } \\
\text { TAGOUT DEVICES } \\
\text { RELEASE FROM L } \text { T OUTS } \\
\text { TEMP REMOVAL OF L\&T OUTS } \\
\text { EXCEPTION OF DOCUMENTAT'N } \\
\text { PERIODIC INSPECTIONS } \\
\text { CAUTION TAG REVIEW } \\
\text { NOTIFICATION OF PERSONNEL } \\
\text { OUTSIDE CONTRACTORS } \\
\text { GROUP L \& T OUTS } \\
\text { TRAINING } \\
\text { LOCK \& TAG LIMITATIONS } \\
\text { RETRAINING }\end{array}$ & 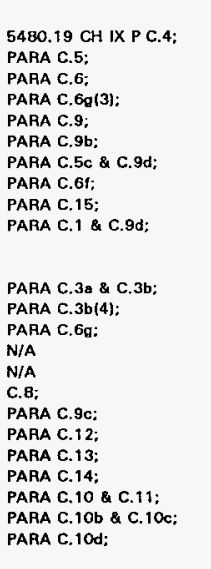 & $\begin{array}{l}\text { WHC-IP-0842 VOL } 2 . \\
\text { WHC-SP-0708; } \\
\vdots \\
\vdots \\
\text { WHC-IP-0842 VOL 2, } \\
\text { WHC-CM-1-10. } \\
\text { WHC-SP-0708; } \\
\vdots \\
\vdots \\
: \\
: \\
\vdots \\
: \\
:\end{array}$ & $\begin{array}{l}Y \\
Y \\
Y \\
Y \\
Y \\
Y \\
Y \\
Y \\
Y \\
Y \\
Y \\
Y \\
Y \\
Y \\
Y \\
N / A \\
N / A \\
Y \\
Y \\
Y \\
Y \\
Y \\
Y \\
Y \\
Y \\
Y\end{array}$ & \\
\hline
\end{tabular}




\section{East Tank Farm Transition Project Fiscal Year 1996 Assessments October 1995 to September 1996}

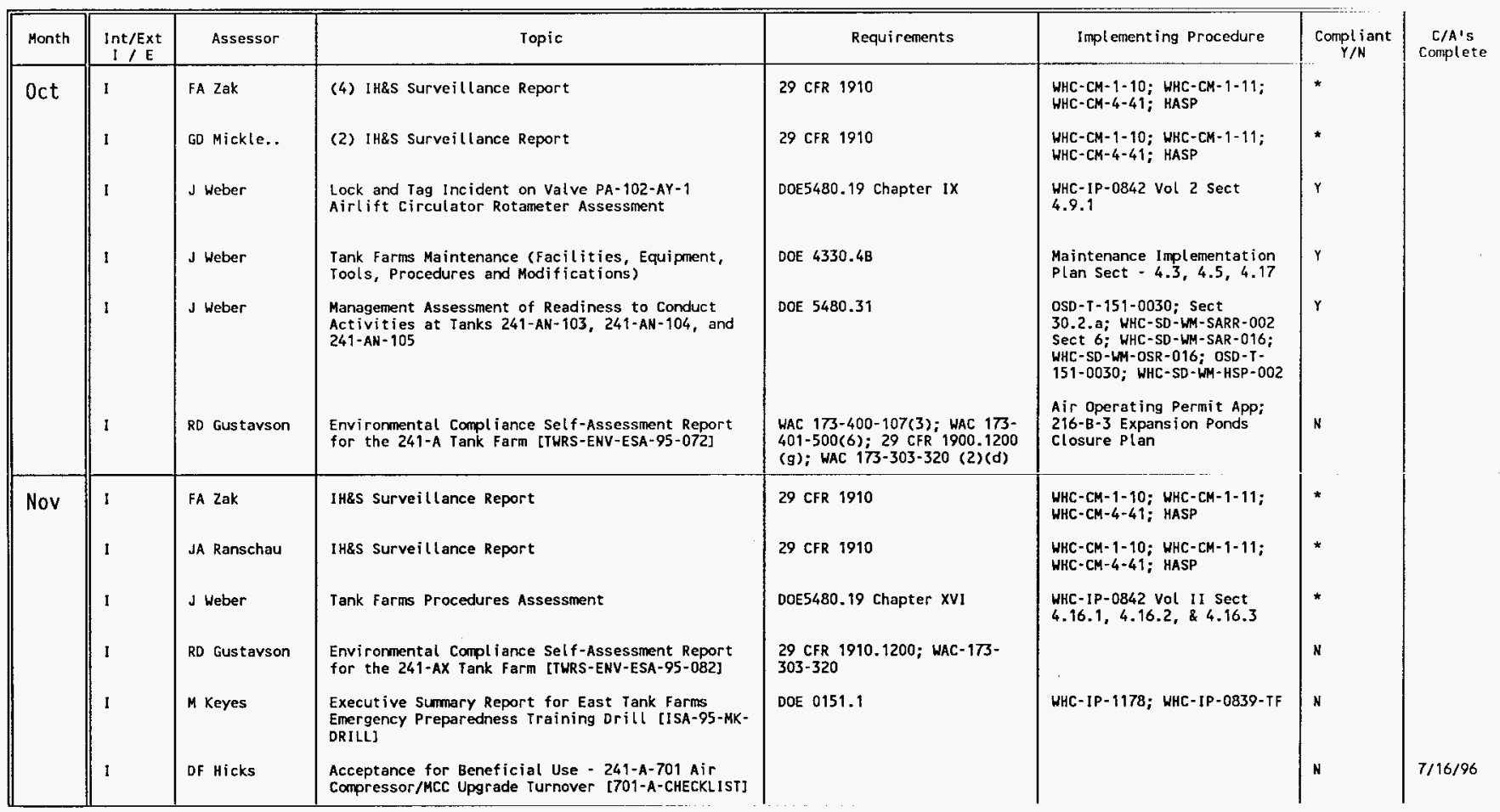




\section{East Tank Farm Transition Project Fisca! Year 1996 Assessments October 1995 to September 1996}

\begin{tabular}{|c|c|c|c|c|c|c|c|}
\hline Month & $\begin{array}{l}\text { Int/Ext } \\
I / E\end{array}$ & Assessor & Topic & Requi rements & Implement ing Procedure & $\underset{Y / N}{\text { Compl iant }}$ & $\begin{array}{c}\text { C/A's } \\
\text { Complete }\end{array}$ \\
\hline \multirow[t]{6}{*}{ Dec } & ! & FA Zak & IH\&S Surveillance Report & 29 CFR 1910 & $\begin{array}{l}\text { WHC }-C M-1-10 ; \text { WHC-CM-1-11; } \\
\text { WHC-CM-4-41; HASP }\end{array}$ & * & \\
\hline & ! & JA Ranschau & (4) IH\&S Surveillance Report & 29 CFR 1910 & $\begin{array}{l}\text { HHC-CM-1-10; HHC-CM-1-11; } \\
\text { WHC-CM-4-41; HASP }\end{array}$ & * & \\
\hline & I & JS King & $\begin{array}{l}\text { Facility Monitoring Program Assessment of } \\
\text { Logkeeping at CASS [ISA-95-CASS-JK] }\end{array}$ & DOE 5480.19 chapter XI & $\begin{array}{l}\text { WHC-1P-0842 Vol II Sect } \\
4.11 .1\end{array}$ & * & \\
\hline & I & JE Andrews & $\begin{array}{l}\text { Conduct of Operations Assessment: Operator Aid } \\
\text { Postings [ISA-CONOPS-AID-JA] }\end{array}$ & DOE 5480.19 Chapter XVII & $\begin{array}{l}\text { WHC-IP-0842 Vol II Sect } \\
4.17 .1\end{array}$ & y & \\
\hline & I & J Weber & $\begin{array}{l}\text { Tank Waste Remediation System Corrective Action } \\
\text { Commi tment Implementation Assessment }\end{array}$ & $\begin{array}{l}\text { DOE } 5480.19 \text { Chapter XVI, } \\
\text { Sect C.5.d }\end{array}$ & WHC-IP- 0842 Vol I Sect 2.4 & N & \\
\hline & I & RD Gustavson & $\begin{array}{l}\text { Enviromental Compl iance Self-Assessment Report } \\
\text { for the 241-B Tank Farm [TWRS-ENV-ESA-96-010] }\end{array}$ & $\begin{array}{l}\text { WAC } 246-247-040 \text {; WAC } 173- \\
303-320\end{array}$ & WHCC-SD-LM- IP-006 & N & \\
\hline
\end{tabular}




\section{East Tank Farm Transition Project Fiscal Year 1996 Assessments October 1995 to September 1996}

\begin{tabular}{|c|c|c|c|}
\hline Month & $\begin{array}{l}\text { Int/Ext } \\
\mathrm{I} / \mathrm{E}\end{array}$ & Assessor & Topic \\
\hline \multirow[t]{11}{*}{ Jan } & 1 & ETF Personnel & (4) IH\&S Surveillance Reports \\
\hline & 1 & JA Ranschau & (4) IH\&S Surveillance Report \\
\hline & I & GD Mickle & (3) IH\&S Surveillance Report \\
\hline & 1 & ETF Personnel & $\begin{array}{l}\text { (10) Safety and Housekeeping Inspection } \\
\text { Checklists }\end{array}$ \\
\hline & 1 & RP Raven.. & 241-AN Facility Surveillance Worksheet \\
\hline & 1 & ETf Personnel & (9) Procedure observation Checkl ists \\
\hline & 1 & ETF Managers & $\begin{array}{l}\text { (8) Review and update of conditions in corrective } \\
\text { action databases }\end{array}$ \\
\hline & I & DW Medley & $\begin{array}{l}\text { ETfTP High Radiation Area Postings and Physical } \\
\text { Access Controls [ISA-ETF-POSTING-96] }\end{array}$ \\
\hline & I & $\mathrm{CL}$ Caldwell & $\begin{array}{l}\text { 10CFR835 Assessments performed by RADCON for } \\
\text { period of 01/96 (Planning Radiological Work, } \\
\text { Radiologically Controlled Areas Postings, High } \\
\text { Radiation Areas, \& Radioactive Source Controls. } \\
\text { [ISA-RADCON-ACT-PLAN-96] }\end{array}$ \\
\hline & 1 & TW Bohan & $\begin{array}{l}\text { Conduct of Operations Assessment: Required } \\
\text { Reading [ISA-CONOPS-REQ-READ-TB] }\end{array}$ \\
\hline & $E$ & JK McClusky & $\begin{array}{l}\text { Performance Evaluation of WHC Waste Storage } \\
\text { Division Tank Farm Operations Project Division } \\
\text { for Novenber } 1995 \text { through January } 1996 \text { [THS-roP- } \\
96-01]\end{array}$ \\
\hline
\end{tabular}

\begin{tabular}{|c|c|c|}
\hline Requi rements & Implementing Procedure & $\underset{Y / N}{C}$ \\
\hline 29 CFR 1910 & $\begin{array}{l}\text { HHC-CM-1-10; WHC-CM-1-11; } \\
\text { WHC-CM-4-41; HASP }\end{array}$ & * \\
\hline 29 CFR 1910 & $\begin{array}{l}\text { WHC-CM-1-10; WHC-CM-1-11; } \\
\text { WHC-CM-4-41; HASP }\end{array}$ & * \\
\hline 29 CFR 1910 & $\begin{array}{l}\text { WHC-CM-1-10; HHC-CM-1-11; } \\
\text { WHC-CM-4-41; HASP }\end{array}$ & * \\
\hline 29 CFR 1910 & WHC-CM-1-10 & * \\
\hline $\begin{array}{l}29 \text { CFR 1910; } 10 \text { CFR 835; DOE } \\
5480.19\end{array}$ & & * \\
\hline DOE 5480.19 Chapter XVI & & * \\
\hline $\begin{array}{l}\text { DOE } 5480.19 \text { chapter XVI, } \\
\text { Sect C.5.d }\end{array}$ & & * \\
\hline 10 CFR $835.502 / 835.603$ & $\begin{array}{l}\text { HSRCM Articles 231, 334, \& } \\
\text { Appendix } 3-B\end{array}$ & $\mathbf{Y}$ \\
\hline 10 CFR 835 & HSRCM-1 & Y \\
\hline DOE 5480.19 Chapter XIV & WHC-IP-0842 Vol $2,4.14 .1$ & N \\
\hline $\begin{array}{l}29 \text { CFR 1910; } 29 \text { CFR 1926; } \\
\text { DOE } 5480.19 \text { Chapter v; } 10 \\
\text { CFR } 835\end{array}$ & & r \\
\hline
\end{tabular}




\section{East Tank Farm Transition Project Fiscal Year 1996 Assessments October 1995 to September 1996}

WHC-SD-TWR-SR I $[1-00]$

September 30, I99!

Rev. :

\begin{tabular}{|c|c|c|c|c|c|c|c|}
\hline Month & $\begin{array}{l}\text { Int/Ext } \\
I / E\end{array}$ & Assessor & Topic & Requi rements & Implement ing Procedure & $\begin{array}{l}\text { Compl iant } \\
Y / N\end{array}$ & $\begin{array}{l}\text { C/A's } \\
\text { Complete }\end{array}$ \\
\hline \multirow[t]{13}{*}{ Feb } & 1 & GD Mickle.. & (5) IH\&S Surveillance Report & 29 CFR 1910 & $\begin{array}{l}\text { WHC-CM-1-10; WHC-CM-1-11; } \\
\text { WHC-CM-4-41; HASP }\end{array}$ & $*$ & \\
\hline & 1 & FA Zak & IH\&S Surveillance Report & 29 CFR 1910 & $\begin{array}{l}\text { WHC-CM-1-10; WHC-CM-1-11; } \\
\text { WHC-CM-4-41; HASP }\end{array}$ & * & \\
\hline & 1 & ETF Managers & Review of IMX matrixes & DOE $5480.20 \mathrm{~A}$ & & * & \\
\hline & 1 & ETf Personnel & (9) Procedure Observation Checklists & DOE 5480.19 Chapter XVI & & * & \\
\hline & 1 & J Weber & Safety/Authorization Basis Assessment & $\begin{array}{l}\text { DOE 5480.22; WHC-SD-WM-1SB- } \\
001\end{array}$ & $\begin{array}{l}\text { WHC-SD-WM-OSR-004; WHC-SD- } \\
\text { WM-OSR-05; WHC-SD-LWM-OSR- } \\
016 ; \text { WHC-CM-1-5; WHC-CM-3- } \\
5 \text {; WHC-CM-6-1; WHC-1P-0842 } \\
\text { Vol IV Sect } 5.4\end{array}$ & N & \\
\hline & I & J Weber & Lock and Tag Assessment [ISA-QA-LOCKTAG-96] & DOE 5480.19 , Chapter IX & $\begin{array}{l}\text { WHC-IP-0842 Vol } 11 \text { Sect } \\
4.9 .1\end{array}$ & N & \\
\hline & I & HP Fox & $\begin{array}{l}\text { TFIP Interfaces with the Characterization Project } \\
\text { Activities [TFTP-CP-Report-96] }\end{array}$ & DOE 5480.19 ; DOE $4330.4 B$ & WHC-IP-0842; WHC-CH-1-8 & $Y$ & \\
\hline & 1 & Ro Gustavson & $\begin{array}{l}\text { Environmental Compliance Self-Assessment Report } \\
\text { for the } 241-\mathrm{C} \text { Tank Farm [TWRS-ENV-ESA-96-018] }\end{array}$ & $\begin{array}{l}\text { WAC } 246-247-030 ; 040, \& 130 ; \\
\text { WAC } 173-400-075 ; 40 \text { CFR } 61 ; \\
\text { WAC } 173-303-320 ; \text { WAC } 173- \\
400-105\end{array}$ & & $\mathbf{N}$ & \\
\hline & 1 & DW Medley & $\begin{array}{l}\text { Tank farm Ventilation Upgrade } W-030 \text { Project } \\
\text { Assessment for RADCON Readiness Review [ISA- } \\
\text { RADCON-RA-W030] }\end{array}$ & 10 CFR 835 & HSRCM- 1 & $\mathbf{Y}$ & \\
\hline & I & J Weber & TWRS Design Control Assessment & DOE 5480.21 & $\begin{array}{l}\text { WHC-CM-6-1 EP-2.2; WHC-IP- } \\
0842 \text { Vol IV Sect ion } 5.4 \text {; } \\
\text { WHC-CM-4-2 QI } 15.1\end{array}$ & $\mathbf{N}$ & \\
\hline & 1 & $\mathrm{~J}$ Weber & $\begin{array}{l}\text { Standing Orders/Shift Instructions, Operator } \\
\text { Aids, \& Process Control Plans Assessment }\end{array}$ & DOE 5480.19 & $\begin{array}{l}\text { WHC-IP-0842 Vol } 11, \text { Sect } \\
4.17 .1,4.15 .1, \& 4.8 \text {. }\end{array}$ & $\mathbf{Y}$ & \\
\hline & I & DH Medley & $\begin{array}{l}\text { Summary of Self-Assessment Evaluation of ETFTP } \\
\text { Radiological conduct of Operations at AA Valve } \\
\text { Pit Job [ISA-RADCON-AA-Valve-96] }\end{array}$ & 10 CFR 835 & HSRCM- 1 & $Y$ & \\
\hline & E & JK MeClusky & $\begin{array}{l}\text { Evaluation Report of UHC Tank Farm Operations } \\
\text { during February } 1996 \text { [S- } 96 \text {-TOP-TANKFARM] }\end{array}$ & 10 CFR 835 & WHC-CM-4-14; PSCP-3-002 & $\gamma$ & \\
\hline
\end{tabular}




\section{East Tank Farm Transition Project Fiscal Year 1996 Assessments October 1995 to September 1996}

\begin{tabular}{|c|c|c|c|c|c|c|}
\hline Month & $\begin{array}{c}\text { Int } / \text { Ext } \\
I / E\end{array}$ & Assessor & Topic & Requirements & Implementing Procedure & $\underset{Y / N}{\text { Compliant }}$ \\
\hline \multirow[t]{13}{*}{ Mar } & I & FA Zak & IH\&S Surveillance Report & 29 CFR 1910 & $\begin{array}{l}\text { WHC-CM-1-10; WHC-CM-1-11; } \\
\text { WHC-CM-4-41; HASP }\end{array}$ & * \\
\hline & $!$ & JA Ranschau & (4) IH\&S Surveillance Report & 29 CFR 1910 & $\begin{array}{l}\text { WHC-CM-1-10; WHC-CM-1-11; } \\
\text { WHC-CM-4-41; HASP }\end{array}$ & $*$ \\
\hline & I & PG O'Connor... & $\begin{array}{l}\text { C-Farm Housekeeping Safety Inspection [ISA- } \\
\text { HOUSEKEEPING-CFARM-96] }\end{array}$ & 29 CFR 1910 & $\begin{array}{l}\text { WHC-CM-1-10 WKS 9, WKS } 18 \text {, } \\
\& \text { WKS } 25\end{array}$ & * \\
\hline & 1 & CH Saunders.. & $\begin{array}{l}\text { Mo-393, M0- } 996, \text { Mo- } 266, \text { mo-267, M0- } 268 \\
\text { Housekeeping Safety inspection [I SA-HOUSEKEEPING- } \\
\text { TRAILERS-96] }\end{array}$ & 29 CFR 1910 & $\begin{array}{l}\text { WHC-CM-1-10 WKS } 9 \text {, WKS } 18 \\
\& \text { WKS } 25\end{array}$ & * \\
\hline & 1 & DW Medley.. & $\begin{array}{l}\text { Quarterly Self-Assessment Evaluation of ETFTP } \\
\text { Radiological Postings and Labeling(1st qtr }-96 \text { ) }\end{array}$ & 10 CFR 835 & HSRCM- 1 & N \\
\hline & ! & ETf Personnel & (10) Procedure Observation Checklists & DOE 5480.19 Chapter XVI & & * \\
\hline & $!$ & WE ROSs & Iechnical Assist Data Sheet & & $10-020-820$ & * \\
\hline & 1 & CE Upchurch & $\begin{array}{l}\text { Cont amination, High Contamination, and Airborne } \\
\text { Radioactivity Areas [1SA-RADCON-CONTAM [NATION-CU] }\end{array}$ & 10 CFR 835 & HSRCM- 1 ; WHC-CM-4- 14 & Y \\
\hline & 1 & VE Mehrer & $\begin{array}{l}\text { Assessment of East Tank Farm \& 242+A Evaporator } \\
\text { Standing Orders }\end{array}$ & DOE 5480.19 Chapter XV & WHC-IP-0842 Vol $2,4.15 .1$ & $\mathbf{Y}$ \\
\hline & I & KR Farrell & $\begin{array}{l}\text { Conduct of Operations Assessment: Notifications } \\
\text { [ISA-CONOPS-NOTIFICATIONS-KF] }\end{array}$ & DOE 5480.19 Chapter VII & $\begin{array}{l}\text { WHC-IP-0842 Vol } 2,4.6 .2 \text {; } \\
\text { WHC-IP-0262-IF }\end{array}$ & Y \\
\hline & 1 & KR Farrell & $\begin{array}{l}\text { Conduct of Operations Assessment: Investigation } \\
\text { of Abnormal Events [ISA-CONOPS-INVEST IGATE-KF] }\end{array}$ & DOE 5480.19 Chapter VI & WHC- $1 \mathrm{P}-0842$ Vol $2,4.6 .2$ & N \\
\hline & $\mathbf{E}$ & CA Ashley & $\begin{array}{l}\text { Rad-Con Issues Between 209-E and Tank Farm RCT's } \\
\text { ident ified during Facil ity Representative } \\
\text { walkdown [ISA-96-CAA-209E] }\end{array}$ & 10 CFR 835 & HSRCM-1 & r \\
\hline & $\mathbf{E}$ & JK McClusky & $\begin{array}{l}\text { Evaluation Report of WHC Tank Farm Operations } \\
\text { During March } 1996 \text { and request for corrective } \\
\text { action [S-96-TOP-TANKFARM] }\end{array}$ & 29 CFR 1910.180 & $\begin{array}{l}\text { WHC-IP-0718; WHC-IP-0842 } \\
\text { Vol VI, } 5.1 ; \text { WHC-1P-0842 } \\
\text { Vol } 11,4.2 .1\end{array}$ & N \\
\hline
\end{tabular}




\section{East Tank Farm Transition Project Fiscal Year 1996 Assessments October 1995 to September 1996}

\begin{tabular}{|c|c|c|c|c|c|c|c|}
\hline Month & $\begin{array}{c}\text { Int/Ext } \\
\mathrm{I} / \mathrm{E}\end{array}$ & Assessor & Topic & Requi rements & Impl ement ing Procedure & $\begin{array}{c}\text { Compl iant } \\
Y / N\end{array}$ & $\begin{array}{c}\text { C/A's } \\
\text { Complete }\end{array}$ \\
\hline Apr & $\begin{array}{l}\text { I } \\
\text { I } \\
1 \\
\text { I }\end{array}$ & $\begin{array}{l}\text { VS Trainor.. } \\
\text { FA Zak } \\
\text { JA Ranschau } \\
\text { All Personnel } \\
\text { ETF Managers } \\
\text { MR Kembel } \\
\text { CN Hogan } \\
\text { RADCON } \\
\text { RADCON } \\
\text { RADCON } \\
\text { WL Smoot } \\
\text { J Jens } \\
\text { WE Ross } \\
\text { JK McClusky }\end{array}$ & $\begin{array}{l}\text { (2) IH\&S Surveillance Report } \\
\text { IH\&S Surveillance Report } \\
\text { (5) IH\&S Surveill ance Report } \\
\text { (76) office Safety Checkl ists } \\
\text { (3) Procedure observation checkl ists } \\
\text { Assessment of the current temporary modifications } \\
\text { in place } \\
\text { Hazardous Waste Handl ing and Packaging Assessment } \\
\text { Radiologically Controlled Area Postings of } 200 \\
\text { East Perimeter Fence } \\
\text { Selection and Use of Respiratory Protection } \\
\text { Including Medical Assessment } \\
\text { Radiological Work Controls } \\
\text { Conduct of Operations Walkdown of A-Complex } \\
\text { Procedure, RHP, and Work Practice Adherence } \\
\text { Assessment } \\
\text { Operational Readiness Review/Readiness Assessment } \\
\text { for project W-320 [H320-FP-1.1.5 P/L \#1] } \\
\text { Evaluation Report of HHC Tank Farm Operations } \\
\text { during April 1996 [S-96-TOP-TANKFARM; TOP- } 96-04- \\
01]\end{array}$ & $\begin{array}{l}29 \text { CFR } 1910 \\
29 \text { CFR } 1910 \\
29 \text { CFR } 1910 \\
29 \text { CFR } 1910 \\
\text { DOE } 5480.19 \text { Chapter XVI } \\
\text { DOE } 5480.19 \text { Chapter VI1! } \\
\text { WAC- } 173-303 \\
10 \text { CFR } 835 \text {; DOE } 5480.19 \\
\text { DOE } 5480.19 \text { Chapter XVI } \\
\text { DOE } 6430.1 \mathrm{~A} \\
10 \text { CFR } 835\end{array}$ & 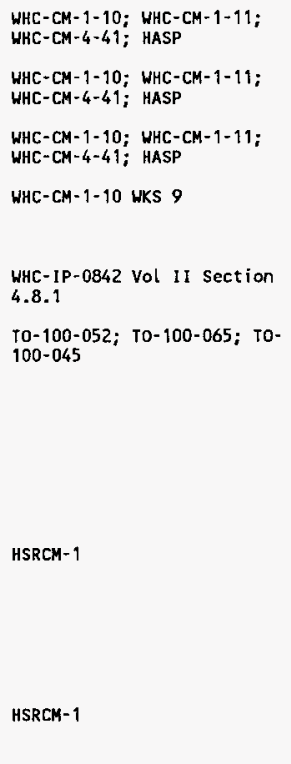 & $\begin{array}{l}\text { * } \\
\text { * } \\
\text { * } \\
\text { * } \\
\text { * } \\
\text { * } \\
\text { Y }\end{array}$ & \\
\hline
\end{tabular}




\section{East Tank Farm Transition Project Fiscal Year 1996 Assessments October 1995 to September 1996}

\begin{tabular}{|c|c|c|c|c|c|c|c|}
\hline Month & $\begin{array}{c}\text { Int/Ext } \\
\mathrm{I} / \mathrm{E}\end{array}$ & Assessor & Topic & Requi rements & Implementing Procedure & $\underset{Y / N}{C}$ & $\begin{array}{c}\text { C/A's } \\
\text { Complete }\end{array}$ \\
\hline May & I & $\begin{array}{l}\text { FA Zak } \\
\text { ETF Personnel } \\
\text { ETF Personnel } \\
\text { ETF Personnel } \\
\text { HM Chafin } \\
\text { ETF Managers } \\
\text { DW Medley } \\
\text { E. C. Dahlin } \\
\text { LA Tusler } \\
\text { WL Smoot } \\
\text { TM Horner } \\
\text { IM Blaak }\end{array}$ & $\begin{array}{l}\text { (2) IH\&S Surveillance Report } \\
\text { (4) Procedure Observation Checklists } \\
\text { (42) Safety and Housekeeping Inspection } \\
\text { Checkl ists/Office Safety Checkl ist } \\
\text { (6) Personnel Contamination Survey Evaluation } \\
\text { Checklists } \\
\text { Inspection/Surveillance Report for AY/AZ } \\
\text { Calibration Equipment } \\
\text { (18) Self Assessment of the Label ing Program } \\
\text { Self-Assessment Evaluation of ETFIP Radiation } \\
\text { Exposure Control/Use of External Dosimetry } \\
\text { Property Management Walk-Through [PMH-96-016] } \\
\text { Second quarter Fiscal year 1996 Tank Farms } \\
\text { Criticality Safety Inspection [CRITI-SAF-TRN-96] } \\
\text { Conduct of Operations Review of AN-Farm [ISA- } \\
\text { CONOP-ANFARM-WS] } \\
\text { Second Quarter } 1996 \text { Operator-Aid Audit } \\
\text { Conduct of Operations Assessment: Operations } \\
\text { Aspects of Facility Chemistry and Unique } \\
\text { Processes [ISA-CONOPS-CHEMISTRY-TB] }\end{array}$ & $\begin{array}{l}29 \text { CFR } 1910 \\
\text { DOE } 5480.19 \text { Chapter XVI } \\
29 \text { CFR } 1910 \\
10 \text { CFR } 835 \\
10 \text { CFR } 830.120 \\
\text { DOE } 5480.19 \text { Chapter XVIII } \\
10 \text { CFR } 835 \\
\text { DOE } 2200.6 \text {; Prime Contract } \\
\text { DOE } 5480.5 \\
10 \text { CFR } 835 \text {; DOE } 5480.19 \\
\text { DOE } 5480.19 \text { Chapter XVI! } \\
\text { DOE } 5480.19 \text { Chapter XIII }\end{array}$ & $\begin{array}{l}\text { UHC-CM-1-10; WHC-CM-1-11; } \\
\text { WHC-CM-4-41; HASP } \\
\text { WHC-CM-1-10 } \\
\text { HSRCM-1 } \\
\text { WHC-SO-WM-CAPP-018; WHC-CM- } \\
4-2 \text { OR } 12.0 \\
\text { WHC-IP-0842 VoL } 4 \text { SeCt } 3.3 ; \\
6-T F-100 \\
\text { RWPS TF-007 \& TF-012 } \\
\text { WHC-CM-2-3, } 6.5 \\
\text { WHC-CM-4-29; WHC-IP-0842 } \\
\text { Vol IV, } 5.3 \\
\text { HSRCM-1 } \\
\text { WHC-IP-0842 Vol II } 4.17 .1 \\
\text { WHC-IP-0842 Vol II } 4.13 .1\end{array}$ & $\begin{array}{l}* \\
\star \\
Y \\
Y \\
Y \\
\star \\
Y \\
Y \\
Y \\
Y \\
Y \\
Y\end{array}$ & \\
\hline
\end{tabular}




\section{East Tank Farm Transition Project Fiscal Year 1996 Assessments October 1995 to September 1996}

\begin{tabular}{|c|c|c|c|c|c|c|}
\hline Month & $\begin{array}{l}\text { Int } / \text { Ext } \\
I / E\end{array}$ & Assessor & Topic & Requi rements & Implementing Procedure & $\begin{array}{l}\text { Compl iant } \\
Y / N\end{array}$ \\
\hline \multirow[t]{10}{*}{ Jun } & I & FA Zak & IH\&S Surveillance Report for A Farm & 29 CFR 1910 & $\begin{array}{l}\text { WHC-CM-1-10; } \text { WHC-CM-1-11; } \\
\text { WHC-CM-4-41; HASP }\end{array}$ & * \\
\hline & I & ETF Personnel & (8) Procedure observation Checklists & DOE 5480.19 Chapter XVI & & * \\
\hline & I & Eng Personnel & $\begin{array}{l}\text { (7) Safety and Housekeeping inspection } \\
\text { Checkl ists/Housekeeping Inspection Checklist }\end{array}$ & 29 CFR 1910 & WHC-CM- $1-10$ & * \\
\hline & I & DW Medley & $\begin{array}{l}\text { Quarterly self-Assessment Evaluation of ETFTP } \\
\text { Radiological Postings and Label ing( } 2 \text { nd qt }-96 \text { ) } \\
\text { [ISA-RAD-96-DM] }\end{array}$ & 10 CFR 835 & HSRCM- 1 & Y \\
\hline & I & JW Hagan & $\begin{array}{l}\text { Assessment of Operations Potentially Below OSD } \\
\text { Limits }\end{array}$ & DOE 5480.22 & $\begin{array}{l}\text { OSD-T-151-00017; OSD-T-151- } \\
\text { D0013; OSD-T-151-00007 }\end{array}$ & N \\
\hline & I & RL Legg & $\begin{array}{l}\text { Post-Maintenance Testing Assessment [ISA-MAINT- } \\
\text { POSIMAINT-RL] }\end{array}$ & DOE $4330.4 \mathrm{~B}$ & $\begin{array}{l}\text { WHE-IP-0842, Vol 5, 7.2; } \\
\text { WHC-IP-1217 }\end{array}$ & Y \\
\hline & I & GP Hopkins & $\begin{array}{l}\text { Conduct of Operations Assessment: Lockouts \& } \\
\text { Tagouts [ISA-CONOP-LOCK/TAG] }\end{array}$ & DOE 5480.19 Chapter IX & WHC-IP-0842, vol 2, 4.9.1 & $\gamma$ \\
\hline & I & RD Gustavson & $\begin{array}{l}\text { Enviromental Compl iance Self-Assessment Report } \\
\text { for the } 241 \text {-AN Tank Farm [TWRS-ENV-ESA-241-AN] }\end{array}$ & $\begin{array}{l}\text { WAC } 173-400-075 ; 40 \text { CFR-61; } \\
\text { WAC } 173-303-640(2) ; \text { WAC } 173- \\
303-320(2)\end{array}$ & $\begin{array}{l}\text { UHC-SD-HM-PD-047; WHC-CM-4- } \\
41 ; \text { WHC-IP-0842 Vol } 1,4.4\end{array}$ & N \\
\hline & i & RD Gustavson & $\begin{array}{l}\text { Enviromental Compl iance Self-Assessment Report } \\
\text { for the } 241 \text {-AP Tank Farm [TURS-ENV-ECSS-96-001] }\end{array}$ & $\begin{array}{l}\text { WAC } 173-303-320(2)(d) ; \text { WAC } \\
173-303-640(6) ;\end{array}$ & TF-OR-A-03; WHC-CM-7-5 & N \\
\hline & $\varepsilon$ & CA Ashley & $\begin{array}{l}\text { Walkthrough of A-Complex and AP Tank Farm: } \\
\text { Observations [A-Complex-Walkthrough] }\end{array}$ & 29 CFR 1910 & $\begin{array}{l}\text { WHC-CM-1-10; } \text { WHC-CM-1-11; } \\
\text { WHC-CM-4-41; HASP }\end{array}$ & * \\
\hline
\end{tabular}




\section{East Tank Farm Transition Project Fiscal Year 1996 Assessments \\ October 1995 to September 1996}

\begin{tabular}{|c|c|c|c|c|c|c|c|}
\hline Month & $\begin{array}{c}\text { Int/Ext } \\
\mathrm{I} / \mathrm{E}\end{array}$ & Assessor & Topic & Requirements & Implement ing Procedure & $\underset{Y / N}{\text { Compl iant }}$ & $\begin{array}{c}\text { C/A's } \\
\text { Complete }\end{array}$ \\
\hline Jul & $\begin{array}{l}1 \\
1\end{array}$ & $\begin{array}{l}\text { ML Delahunt.. } \\
\text { ETF Personnel } \\
\text { EIf Personnel } \\
\text { PL Ireadway } \\
\text { CL Caldwell } \\
\text { CA Widhalm } \\
\text { TM Horner } \\
\text { JE Pieper.. } \\
\text { MR Kembel } \\
\text { BK Norris }\end{array}$ & $\begin{array}{l}\text { (2) IH\&S Surveillance Report } \\
\text { (5) Procedure Observation Checkl ists } \\
\text { (19) Housekeeping Inspection Checklist } \\
\text { Lock \& Tag Surveillance for 204AR, 244AR, \& } \\
\text { inter-farm tags } \\
\text { Response of East and West Tank Farms to "High } \\
\text { Radiation Area Entry Control" } \\
\text { Technical Procedure Path Forward Action Plan [E- } \\
\text { PROC-PATHFRW] } \\
\text { Conduct of Operations Assessment: Independent } \\
\text { Verification } \\
\text { ETF Sel f-Assessment Report: Contamination } \\
\text { Control Hork Practices [ISA-RAD-HORK-PRACIICE-JP] } \\
\text { Conduct of Operations Assessment: Control of } \\
\text { Equipment and System Status [ISA-CONOPS-EQUIP-MK] } \\
\text { Conduct of Operations Assessment: Equipment and } \\
\text { Piping Label ing [ISA-CONOPS-LABEL-BN] }\end{array}$ & $\begin{array}{l}29 \text { CFR } 1910 \\
\text { DOE } 5480.19 \text { Chapter XVI } \\
29 \text { CFR } 1910 \\
\text { DOE } 5480.10 \text { Chapter IX } \\
10 \text { CFR } 835 \\
\text { DOE } 5480.19 \text { Chapter XVI } \\
\text { DOE } 5480.19 \text { Chapter X } \\
\text { 10 CFR } 835 \\
\text { DOE } 5480.19 \text { Chapter VIII } \\
\text { DOE } 5480.19 \text { Chapter XVIII }\end{array}$ & $\begin{array}{l}\text { WHC-CM-1-10; WHC-CM-1-11; } \\
\text { HHC-CM-4-41; HASP } \\
\text { WHC-CM-1-10 } \\
\text { WHC-IP-0842 Vol } 2,4.9 .1 \\
\text { HSRCM-1; WHC-1P-0842 Vol } 7 \text {; } \\
2.2 ; \text { WHC-IP-0842 Vol } 5,7.1 \\
\text { WHC-IP-0842, Vol } 2,4.16 .1 \text {; } \\
4.16 .2, \& 4.16 .3 \\
\text { WHC-IP-0842, Vol } 2,4.10 .1 \\
\text { HSRCM-1 } \\
\text { WHC-IP-0842, Vol 2, 4.8.1 } \\
\text { WHC-IP-0842, Vol } 4,3.3 ; 6 \text { - } \\
\text { TF-100 }\end{array}$ & $\begin{array}{l}* \\
* \\
* \\
* \\
Y \\
Y \\
Y \\
Y \\
Y \\
Y\end{array}$ & \\
\hline
\end{tabular}




\section{East Tank Farm Transition Project Fiscal Year 1996 Assessments October 1995 to September 1996}

WHC-SD-IWR-SKID-003 September 30 , 1996

Rev. C

\begin{tabular}{|c|c|c|c|c|c|c|c|}
\hline Month & $\begin{array}{l}\text { Int/Ext } \\
\mathrm{I} / \mathrm{E} \\
\end{array}$ & Assessor & Topic & Requirements & Implementing Procedure & $\begin{array}{c}\text { Compl i ant } \\
Y / \mathbb{N}\end{array}$ & \multirow[t]{10}{*}{$\begin{array}{l}\text { C/A's } \\
\text { Complete }\end{array}$} \\
\hline \multirow[t]{7}{*}{ Aug } & I & & () IH\&S Surveillance Report & 29 CFR 1910 & $\begin{array}{l}\text { WHC-CM-1-10; WHC-CM-1-11; } \\
\text { WHC-CM-4-41; HASP }\end{array}$ & * & \\
\hline & 1 & ETF Personnel & (15) Procedure Observation Checklists & DOE 5480.19 Chapter XVI & & * & \\
\hline & ! & TL Jennings & $\begin{array}{l}\text { Conduct of operations Assessment: Control of On- } \\
\text { Shift Training [ISA-CONOPS-ON-SHIFT-TRAINING-TJ] }\end{array}$ & DOE 5480.19 Chapter $V$ & HHC-IP-0842, Vol $2,4.5 .1$ & Y & \\
\hline & I & CA Widhalm & $\begin{array}{l}\text { Technical Procedure Path forward Action Plan } \\
\text { (Rev. 1) [E-PROC-PATHFRH] }\end{array}$ & DOE 5480.19 Chapter XVI & $\begin{array}{l}\text { WHC-IP-0842, vol 2, 4.16.1, } \\
4.16 .2, \& 4.16 .3\end{array}$ & Y & \\
\hline & I & DL Sparks & $\begin{array}{l}\text { Packaging and Transportation Operations } \\
\text { Assessment [ISA-ETF-P\&T-96-1] }\end{array}$ & $\begin{array}{l}\text { DOE } 5480.3 ; \text { DOE } 1540.1 A_{1} .2 \\
\& .3 A_{0} ; 49 \text { CFR } 172.700-704\end{array}$ & WHC-CM-2-14 & r & \\
\hline & $\mathrm{t}$ & CA widhalm.. & $\begin{array}{l}\text { Occupational Safety and Heal th Assessment [ISA- } \\
\text { ETF-0SHA-1996-1] }\end{array}$ & $\begin{array}{l}\text { DOE } 5480.6 ; \text { DOE } 5483.1 \text { A DOE } \\
6430.1 A ; \text { DOE } 5480.10 ; \text { DOE } \\
440.1 ; \text { DOE } 232.1 ; \text { DOE } \\
5484.1 ; \text { DOE } 5480.9 ; \text { DOE } \\
5480.19 ; \text { DOE } 5482.18 ;\end{array}$ & $\begin{array}{l}\text { WHC-CM-1-10; WHC-SD-WM-HSP- } \\
002 ; \text { WHC-IP-0030; WHC-IP- } \\
0842 \text { Vol } 1,2.10 ; \text { WHC-CM-1- } \\
11 \text {; WHC-CM-4-40 }\end{array}$ & r & \\
\hline & I & CA Hidhalm.. & $\begin{array}{l}\text { Shift Rout ines and Operating Practices [ISA- } \\
\text { CONOPS-OP-1996-1] }\end{array}$ & DOE 5480.19 Chapter II & $\begin{array}{l}\text { HHC-IP-0842 Vol } 2,4.2 .1 \& \\
4.2 .2\end{array}$ & Y & \\
\hline \multirow[t]{2}{*}{ Sep } & ! & & (2) IH\&S Surveillance Report & 29 CFR 1910 & $\begin{array}{l}\text { WHC-CM-1-10; } \text { HHC-CM-1-11; } \\
\text { WHC-CM-4-41; HASP }\end{array}$ & * & \\
\hline & I & RP Raven & $\begin{array}{l}\text { Shift Rout ines and operating Practices [ISA- } \\
\text { CONOPS-ROUTINES-RR] }\end{array}$ & DOE 5480.19 chapter 2 & $\begin{array}{l}\text { WHC-IP-0B42 Vol } 2,4.2 .1 \& \\
4.2 .2\end{array}$ & $r$ & \\
\hline
\end{tabular}

* These assessments do not evaluate the whole program. They strictly perform spot checks of programmatic areas. Only when many of these assessments have been performed, and the results evaluated can a program be evaluated for compliance or not. 


\section{EVAPORATOR Assessments from October 1995 to October 1996}

\begin{tabular}{|c|c|c|c|c|c|c|c|}
\hline Month & 1 or $E$ & Assessor & Topic & Requirements & Procedure & $\begin{array}{l}\text { Compli. } \\
Y / \mathbb{N}\end{array}$ & $\begin{array}{l}\text { CA's } \\
\text { Complete }\end{array}$ \\
\hline oct & $\begin{array}{l}\text { Internal } \\
\text { Internal }\end{array}$ & $\begin{array}{l}\text { OA } \\
\text { Industrial } \\
\text { Safety }\end{array}$ & $\begin{array}{l}\text { Assessment of the lockout and tagout } \\
\text { program } \\
\text { IH\&S Surveillance Report }\end{array}$ & $\begin{array}{l}\text { DOE } 5480.19 \text { CHAPTER IX } \\
29 \text { CFR } 1910\end{array}$ & $\begin{array}{l}\text { WHC-CM-4-3 SEC G- } \\
\text { WHC-1P-0842 SEC } 4.9 .1 \\
\text { HHC-CM-1-10, WHC-CM-1-11, WHC- } \\
\text { CM-4-41, HASP }\end{array}$ & $\begin{array}{l}\text { y } \\
y\end{array}$ & \\
\hline Nov & Internal & Ind. Safety & $\begin{array}{l}\text { Tank farms Procedures } \\
\text { IS\&H Surveil lance Report }\end{array}$ & $\begin{array}{l}10 \text { CFR } 830 \text { PART } 120(\mathrm{C}) \text { ( } 1 \text { (1) (iv) } \\
\text { DOE } 4430.4 \mathrm{~B} \text { CHAP II SEC } 6.36 \\
\text { PAR } 9 \text { XVI SEC C.1 PAR } 1 \text { \& } 2 \\
\text { CHAP XVI SEC } \\
\text { DOE } 5480.19 \text { ( } 92518) \text { CHAP XVI, } \\
\text { SEC C.2.A SENTENCE } 1 \text { \& } 3 \\
29 \text { CFR } 1910\end{array}$ & $\begin{array}{l}\text { WHC-1P-0842, vol. 1, sec } 2.1 \\
\text { rev-1 } \\
\text { WHC-1P-0842 Vol. 11, Sec } 4.16 .2 \\
\text { reV 1a } \\
\text { WHC-CM-3-5 SEC } 12.7 \\
\text { WHC-CM-1-10, WHC-CM1-11, WHC-CM- } \\
4-41, \text { HASP }\end{array}$ & $\begin{array}{l}Y \\
Y \\
Y \\
Y \\
Y\end{array}$ & \\
\hline Dec & Internal & $\begin{array}{l}\text { Champions } \\
\text { from the } \\
\text { facility }\end{array}$ & $\begin{array}{l}\text { Champion Program - } \\
\text { Operator Aid Use } \\
\text { Operator Aid Development } \\
\text { Operator Aid/Procedure Interface } \\
\text { Operator Aid Approval } \\
\text { Operator Aid Approval Criteria }\end{array}$ & $\begin{array}{l}\text { DOE } 5480.19 \text { Chap XVII } \\
\text { para. } .4 \text {. } \\
\text { c. } 1 \\
\text { c. } 4 \\
\text { c. } 2 \\
\text { c. } 2\end{array}$ & $\begin{array}{l}\text { WHC-IP-0842 VOL } 2 \text { SEC } 4.17 .1 \\
\text { NO REQ } \\
\text { WHC-IP-0842 SEC } 4.17 .1 \\
\text { WHC-IP-0842 VOL } 2 \\
\text { SAME AS ABOVE }\end{array}$ & $\begin{array}{l}Y \\
Y \\
Y \\
Y\end{array}$ & \\
\hline Jan & Internal & $\begin{array}{l}\text { 242-A } \\
\text { personnel } \\
\text { THRS OA }\end{array}$ & $\begin{array}{l}\text { Facility Monitoring - safety, } \\
\text { housekeeping, materials condition. AP tank } \\
\text { farm AN tank farm, evap. control room } \\
\text { areas } \\
\text { Tank Waste Remediation System Corrective } \\
\text { Action Commitment implementation } \\
\text { assessment }\end{array}$ & $\begin{array}{l}\text { DOE } 5480.19 \text { CHAPTER XVI } \\
29 \text { CFR } 1910 \\
\text { S/RIDS chapter } 9 \text { sec. } 9.11 \\
\text { (cond of ops) }\end{array}$ & $\begin{array}{l}\text { WHC-CM-1-10 } \\
\text { TANK FARMS UPGRADE PROGRAM PLAN } \\
\text { HHCF-EP-0392 \& HHC-SD-HM-HP-072 }\end{array}$ & Y & \\
\hline
\end{tabular}


EVAPORATOR

Assessments from October 1995 to October 1996

\begin{tabular}{|c|c|c|c|c|c|c|}
\hline Feb & $\begin{array}{l}\text { Internal } \\
\text { Internal }\end{array}$ & $\begin{array}{l}\text { Evap } \\
\text { personnel } \\
\text { Facility } \\
\text { Champions }\end{array}$ & $\begin{array}{l}\text { Facility Monitoring-242-A control room } \\
\text { log review, key control review, } \\
\text { housekeeping inspections \& prejob safety } \\
\text { meetings. } \\
\text { Champions Program - } \\
\text { 1) Root Cause Determination } \\
\text { 2) Corrective Act ion Management } \\
\text { 3) Iimel iness of Reporting } \\
\text { 4) Investigator Qualification } \\
\text { 5) Lessons Learned } \\
\text { 6) Event Training } \\
\text { 7) Event Trending } \\
\text { 8) Notification Procedure } \\
\text { 9) Notification Responsibility } \\
\text { 10) Notifications - Names \& Phone Numbers } \\
\text { 11)Documentation } \\
\text { 12) Notification Equipment } \\
\text { Lock and Tag }\end{array}$ & 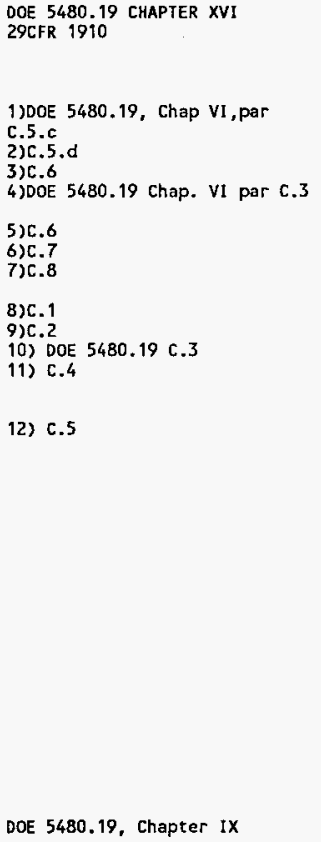 & 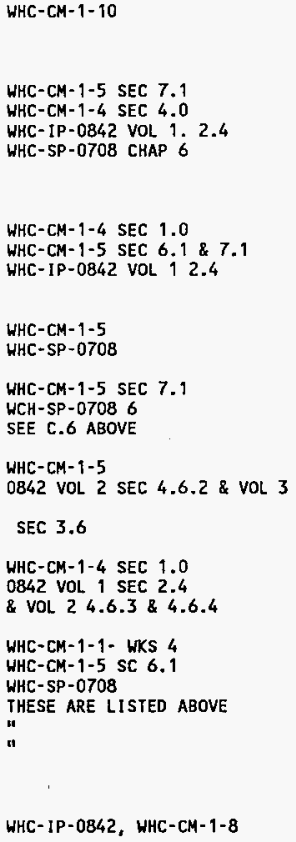 & $\begin{array}{l}y \\
y \\
y \\
y \\
y\end{array}$ \\
\hline
\end{tabular}




\section{EVAPORATOR Assessments from October 1995 to October 1996}

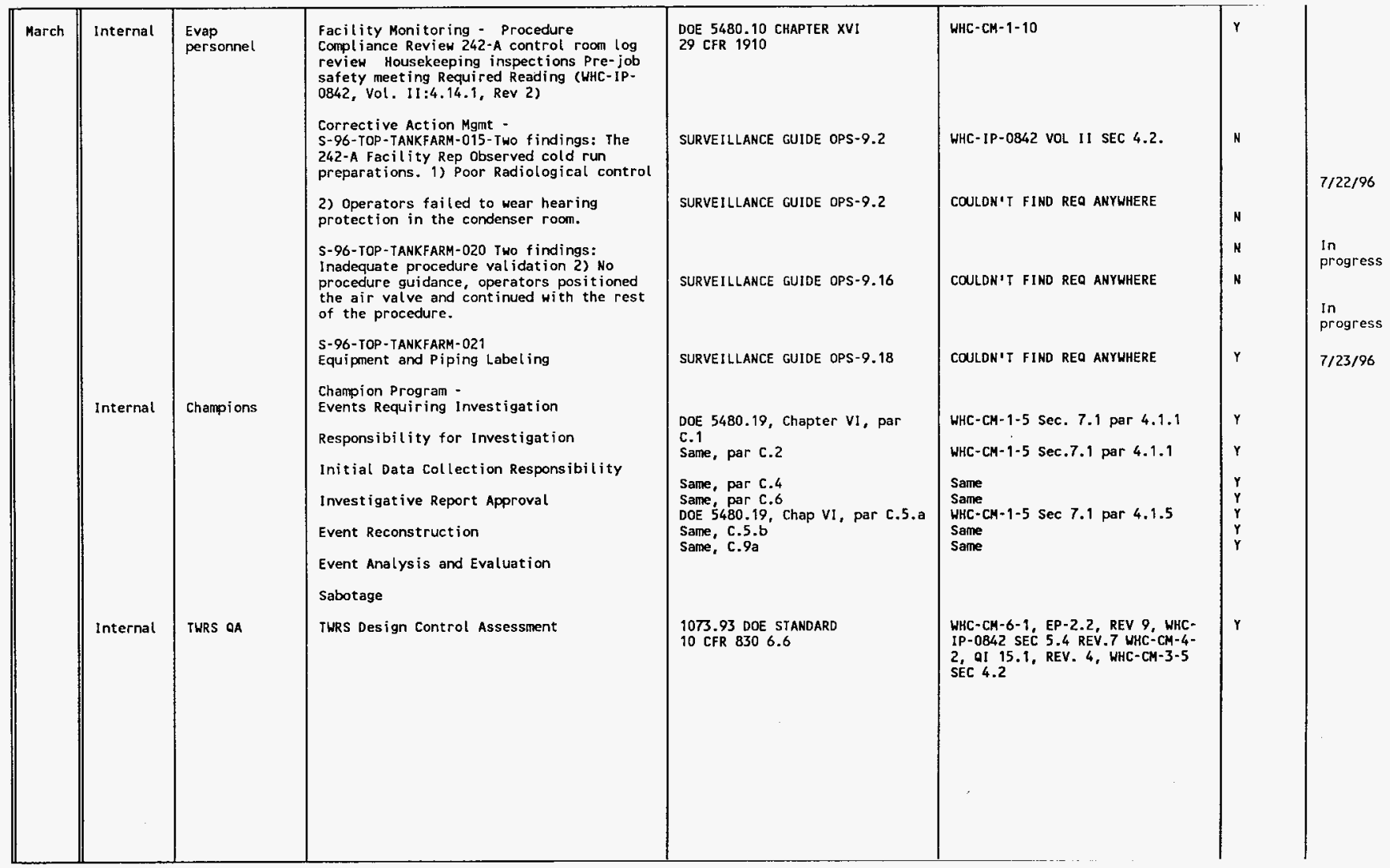




\section{EVAPORATOR \\ Assessments from October 1995 to October 1996}

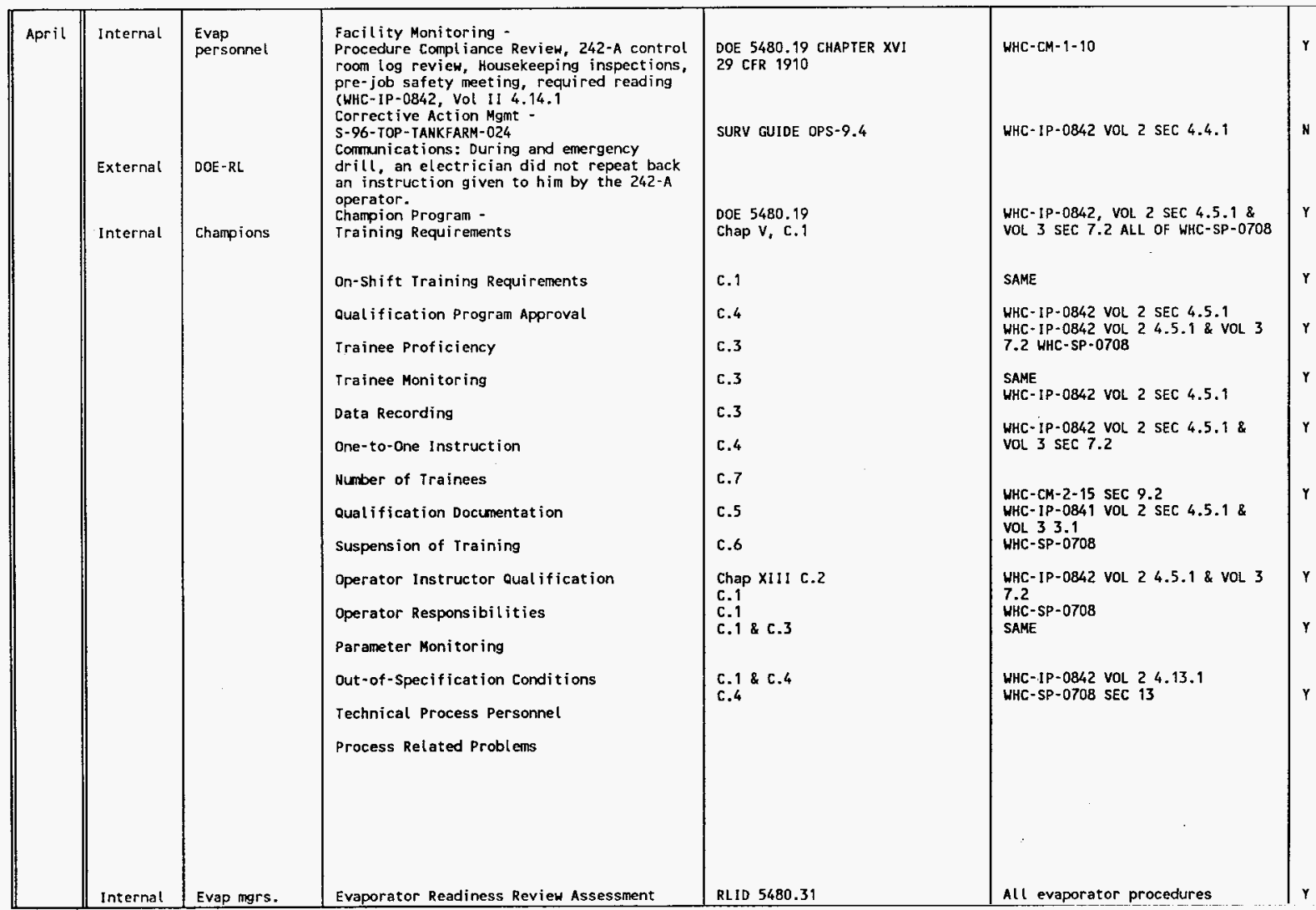


EVAPORATOR

Assessments from October 1995 to October 1996

\begin{tabular}{|c|c|c|c|c|c|}
\hline May & Internal & $\begin{array}{l}\text { Evap } \\
\text { personnel } \\
\text { CHAMPIONS }\end{array}$ & $\begin{array}{l}\text { Facility Monitoring- Procedure } \\
\text { Compliance Review } 242-\mathrm{A} \text { control room log } \\
\text { review } \\
\text { Housekeeping inspections, Pre-job safety } \\
\text { meeting, Required Reading } \\
\text { Champion Program - } \\
\text { Operator Process Knowledge } \\
\text { Operator Fundamentals }\end{array}$ & $\begin{array}{l}\text { DOE } 5480.19 \text { CHAPTER XVI } \\
29 \text { CFR } 1910 \\
\text { DOE } 5480.19 \text {, Chapter XIII, para } \\
\text { C. } 2 \\
\text { C. } 2\end{array}$ & $\begin{array}{l}\text { WHC-CM-1-10 } \\
\text { WHC-IP-0842 VOL } 24.13 .1 \\
\text { WHC-SP-0708 }\end{array}$ \\
\hline
\end{tabular}

WHC-SD-TWR-SRIO-00?

September 30 , 199

Rev. I 


\section{EVAPORATOR Assessments from October 1995 to October 1996}

\begin{tabular}{|c|c|c|c|c|c|c|}
\hline June & Internal & $\begin{array}{l}\text { Evap } \\
\text { personnel }\end{array}$ & $\begin{array}{l}\text { Facility Monitoring- Procedure } \\
\text { Compliance Review, } 242-A \text { control room log } \\
\text { review } \\
\text { Housekeeping inspections, Pre-job safety } \\
\text { meeting, required Reading } \\
\text { Corrective Action Mgnt- } \\
\text { S- } 96-\text { TOP-IANKFARM-037-F01 } \\
\text { Process Memo EE-96-015 was not written in } \\
\text { accordance with the writer's guide } \\
\text { requirements. } \\
\text { Fo2- The } 242 \text {-A control room operator } \\
\text { placed one steam condensate basin in } \\
\text { service and placed another out of service } \\
\text { without referring to the "continuous use" } \\
\text { procedure. } \\
\text { Champions Program - } \\
\text { Lockout/Iagout Program } \\
\text { Lockout/Tagout Procedures } \\
\text { Application of Lockout/Tagout } \\
\text { Lockout/Tagout Device Removal } \\
\text { Caution Tag Control } \\
\text { Caution Iag Issuance } \\
\text { Lockout/Tagout Documentation } \\
\text { Verification of Installation } \\
\text { Shift of Personnel Changes } \\
\text { Iag Placement } \\
\text { Protective Materials and Hardware } \\
\text { Iagout Devices } \\
\text { Release from Lockout/Tagout } \\
\text { Temporary Removal of Lockout/Tagout } \\
\text { Exceptions for Documentation } \\
\text { Periodic Inspections } \\
\text { Caution Tag Review }\end{array}$ & 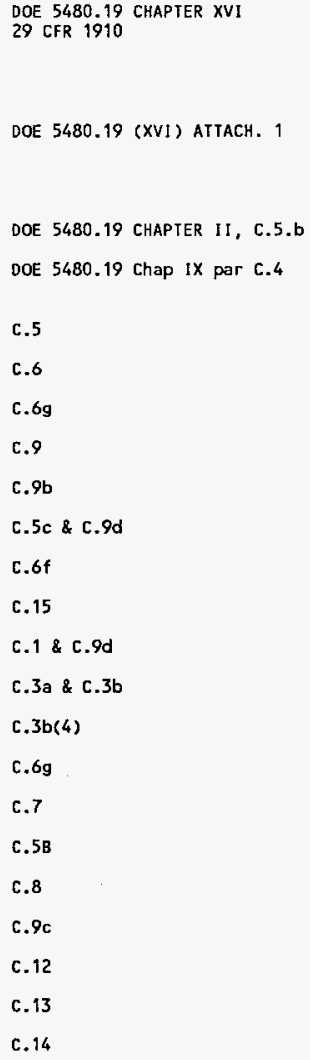 & $\begin{array}{l}\text { WHC-CM-3-5, WHC-IP-0731, WHC-IP- } \\
\text { OB42 VOL } 2 \text { SEC } 4.16 .2 \\
\text { WHC-IP-0842 VOL. } 2 \text { SEC } 4.2 .1 \\
\text { WHC-CM-1-10 WKS } 8.1 \\
\text { WHC-IP-0842 VOL } 14.9 .1 \\
\text { WHC-SP-0709 SEC } 9 \\
\text { SAME AS ABOVE } \\
\text { SAME AS ABOVE } \\
\text { SAME AS ABOVE } \\
\text { SAME AS ABOVE } \\
\text { SAME AS ABOVE } \\
\text { SAME AS ABOVE } \\
\text { SAME AS ABOVE } \\
\text { SAME AS ABOVE } \\
\text { SAME AS ABOVE } \\
\text { SAME AS ABOVE } \\
\text { SAME AS ABOVE } \\
\text { SAME AS ABOVE } \\
\text { SAME AS ABOVE } \\
\text { SAME AS ABOVE } \\
\text { SAME AS ABOVE } \\
\text { SAME AS ABOVE } \\
\text { SAME AS ABOVE } \\
\text { SAME AS ABOVE }\end{array}$ & $\begin{array}{l}\text { N } \\
Y \\
Y \\
Y \\
Y \\
Y \\
Y \\
Y \\
Y \\
Y \\
Y \\
Y \\
Y \\
Y \\
Y \\
Y \\
Y \\
Y \\
Y \\
Y\end{array}$ \\
\hline
\end{tabular}


Assessments from October 1995 to October 1996

\begin{tabular}{|c|c|c|c|c|c|c|}
\hline June & & & $\begin{array}{l}\text { Training } \\
\text { Lock and Tag Limitations } \\
\text { Retraining }\end{array}$ & $\begin{array}{l}5480.19 \text {, Chap IX, C. } 10 \mathrm{a} \& \text { C.11 } \\
\text { C. } 10 \mathrm{~b} \& 10 . \mathrm{c} \\
\text { c. } 10 \mathrm{~d}\end{array}$ & $\begin{array}{l}\text { WHC-CM-1-10 WKS B.1, WHC-IP-0842 } \\
\text { VOL. } 11,4.9 .1, \text { WHC-SP-0708 SEC9 } \\
\text { SAME } \\
\text { SAME }\end{array}$ & $\begin{array}{l}Y \\
Y \\
Y\end{array}$ \\
\hline July & Internal & Champions & $\begin{array}{l}\text { Champions Program - } \\
\text { Material Compatibility } \\
\text { Label Placement } \\
\text { Components Requiring Labeling } \\
\text { Label Requirements }\end{array}$ & $\begin{array}{l}5480.19 \text { Chap XV11 C. } 2 \\
\text { c. } 3 \\
\text { c. } 1 \\
\text { c. } 2\end{array}$ & $\begin{array}{l}\text { WHC-IP-0842 VOL. } 11 \text { SEC } 4.17 .1 \\
\text { WHC-SP-0708 SEC } 17 \\
\text { SAME } \\
\text { SAME } \\
\text { SAME }\end{array}$ & $\begin{array}{l}Y \\
Y \\
Y \\
Y\end{array}$ \\
\hline
\end{tabular}


EVAPORATOR

Assessments from October 1995 to October 1996

\begin{tabular}{|c|c|c|c|c|c|}
\hline July & Internal & Champions & $\begin{array}{l}\text { Champions Program- } \\
\text { Status Change Authorization } \\
\text { Operational Limits Compliance } \\
\text { Shift Activity Authorization } \\
\text { Temporary Modification Control } \\
\text { Components Requiring Independent } \\
\text { Verification } \\
\text { Criteria for Independent Verification } \\
\text { Occasions Requiring Independent } \\
\text { Verification } \\
\text { Verification Techniques } \\
\text { Independence } \\
\text { Surveillance Testing } \\
\text { Operations Self-Appraisal } \\
\text { Independent Verification Training } \\
\text { Abbreviations and Homenclature } \\
\text { Label ing Procedures } \\
\text { Tenporary Label Approval } \\
\text { Routine Activities } \\
\text { Label ing Deficiencies } \\
\text { Temporary Label Verification } \\
\text { Label Attachnent and Readability } \\
\text { Piping System Labels Material Placement }\end{array}$ & 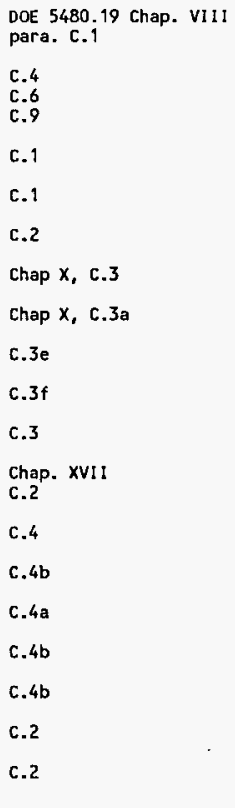 & $\begin{array}{l}\text { WHC-CM- } 9-8 \text { ENTIRE DOCUMENT } \\
\text { WHC-CM- }-1 \text { SEC } 2 \\
\text { WHC-1P-0842 VOL } 2 \text { SEC } 4.8 .1 \\
4.8 .3 \text { \& VOL } 4 \text { SEC } 5.5 \\
\text { SAME } \\
\text { SAME } \\
\text { SAME } \\
\text { SAME } \\
\text { WHC-1P-0842 VOL } 2 \text { SEC } 4.10 .1 \\
\text { WHC-SP-0708 SEC } 10 \\
\text { SAME } \\
\text { SAME } \\
\text { SAME } \\
\text { SAME } \\
\text { WHC-IP-0842 VOL } 2 \text { SEC } 4.17 .1 \\
\text { WHC-SP-0708 SEC } 17 \\
\text { SAME } \\
\text { SAME } \\
\text { SAME } \\
\text { SAME } \\
\text { SAME } \\
\text { SAME } \\
\text { SAME }\end{array}$ \\
\hline
\end{tabular}


Assessments from October 1995 to October 1996 - CPO

\begin{tabular}{|c|c|c|c|c|c|c|c|}
\hline Month & $\begin{array}{l}\text { Int/Ext } \\
\text { II/E }\end{array}$ & Assessor & ropic & Requirements & Implementing Procedures & $\begin{array}{c}\text { Compliant } \\
\text { Y/N }\end{array}$ & $\begin{array}{c}\mathrm{C} / \mathrm{A} ' \mathrm{~s} \\
\text { Complete }\end{array}$ \\
\hline \multicolumn{8}{|l|}{ Oct } \\
\hline \multicolumn{8}{|l|}{ Nov } \\
\hline Dec & $\mathbf{E}$ & DOE-RL & TWS-TOP-95.10 & $\begin{array}{l}\text { DOE } 5000.38 \\
\text { WAC } 173-303-200 \\
\text { HSRCM-1, Art. } 235 \text { (OK) } \\
\text { DOE 5480.19. Att. 1, eh. 8, sec. C. } 1 \text { (OK): } \\
\text { HSRCM- }- \text { Art. 123, Art. 335, part 1, Art. } 8 \\
\text { part 1, Art. } 234\end{array}$ & $\begin{array}{l}\text { WHC-SD-SM-ISB-OO1, P. 6-9; } \\
\text { No formal maint. procedure, inaccurate } \\
\text { config. control, no formal method, for } \\
\text { grouping conditions: } \\
\text { WHC-SD-WM-OSR-003 and -016 and -001: } \\
\text { WHC-SD-WM-ISB-001: WHC-EP-0182-89; } \\
\text { WHC-SD-GN-SWO-20008, } 9 / 7 / 95 \\
\text { NOTE: were in HATS - all is sues complete } \\
\text { as of 7/96 }\end{array}$ & $\begin{array}{l}\mathrm{N} / Y \\
\mathrm{~N} / Y \\
\mathrm{~N} / Y \\
\mathrm{~N} / Y \\
\mathrm{~N} / Y \\
\mathrm{~N} / Y \\
\mathrm{~N} / \mathrm{Y} \\
\mathrm{N} / \mathrm{Y} \\
\mathrm{N} / \mathrm{Y}\end{array}$ & $\begin{array}{l}\text { All complete by } \\
7 / 31 / 96\end{array}$ \\
\hline \multicolumn{8}{|l|}{ Jan } \\
\hline \multicolumn{8}{|l|}{ Feb } \\
\hline Mar & 1 & Champions & $\begin{array}{l}\text { CPO 751XX } \\
\text { RAD WORK PRACTICES: CONTAMINA TION } \\
\text { AREAS, J.Harvey, 3/20/96: Contamination, } \\
\text { High Contamination, and Airbome Radioactivity } \\
\text { Aroas } \\
\text { 1. Management Leadership } \\
\text { 2. Employee Involvement } \\
\text { 3. Work Site Analysis } \\
\text { 4. Prevention \& Control }\end{array}$ & $\begin{array}{l}\text { 10 CFR 835.501(a): } \\
\text { 10 CFR 835.501(d): } \\
10 \text { CFR } 835.404 \text { (b)(f)(g) }\end{array}$ & $\begin{array}{l}\text { HSACM-1. Art. 335.8: } \\
\text { Art.322.2. } \\
\text { Art. 335.1; } \\
\text { Art. } 232.1 ; \\
\text { Art. 335.2: } \\
\text { Art. 325.1: } \\
\text { Art. 335.3; } \\
\text { Atr. 335.4: } \\
\text { Art. 338.8; } \\
\text { Art. 325.6: } \\
\text { Art. 335.5; } \\
\text { Art. 335.7 }\end{array}$ & $\begin{array}{l}Y \\
Y \\
Y \\
Y \\
Y \\
Y \\
Y \\
Y \\
Y \\
Y \\
Y \\
Y \\
Y\end{array}$ & \\
\hline Apr & 1 & TFTP $(778 x x)$ & $\begin{array}{l}\text { TFTP-778XX } \\
\text { S-96-TOP-TANKFARM-006-01 }\end{array}$ & CAM CALIBRATION PROCEDURE & WHC-IP-0842, Vol. V, Sec. $3.10(6 / 12 / 96)$ & $\mathrm{N} / \mathrm{V}$ & $7 / 1 / 96$ \\
\hline
\end{tabular}




\section{Assessments from October 1995 to October 1996 - CPO}

\begin{tabular}{|c|c|c|c|c|c|c|}
\hline May & E & DOE-ADAMS & $\begin{array}{l}\text { PAD-AS-96-007 } \\
\text { [CPO - } 751 \times X]\end{array}$ & 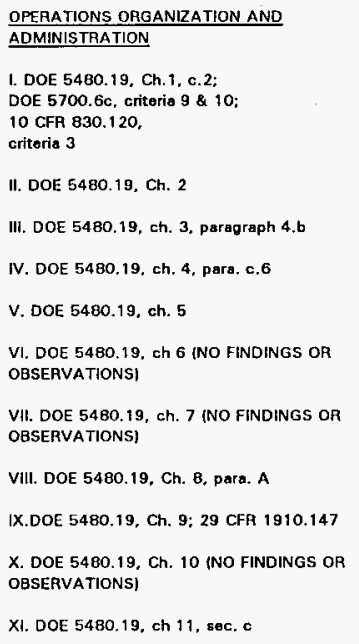 & 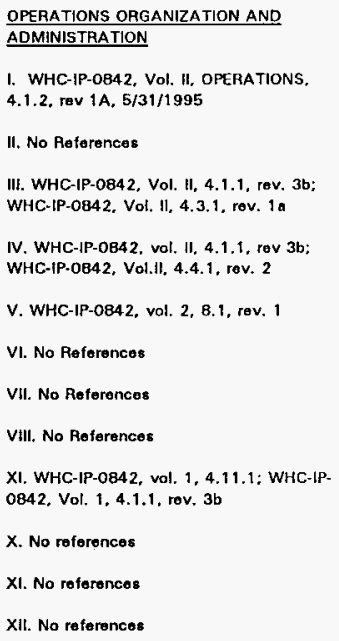 & $\begin{array}{l}\text { I. N } \\
\text { III.Y } \\
\text { III. N } \\
\text { N } \\
\text { IV. Y } \\
Y \\
\text { V.Y Y } \\
\text { VI.Y Y } \\
\text { VII.Y } \\
\text { VII. N } \\
\text { IX. N } \\
\text { N } \\
\text { X.Y Y } \\
\text { XI. N } \\
\text { XII.Y }\end{array}$ \\
\hline
\end{tabular}




\begin{tabular}{|c|c|c|c|c|c|c|}
\hline May & E & DOE-ADAMS & PAD-AS-96-007 & $\begin{array}{l}\text { XII. DOE 5480.19, ch. } 12 \text { (NO FINDINGS) } \\
\text { XIII. DOE 5480.19. Ch. } 13 \text {, para. 4b } \\
\text { XIV. DOE } 5480.19, \text { ch } 14 \\
\text { XV. ? } \\
\text { XVI. ? } \\
\text { XVI. DOE } 5480.19, \text { Ch } 17 \\
\text { (NO FINDINGS OR OBSERVATIONS) } \\
\text { XVIII. DOE 54BO.19, ch. } 18 \text { (NO FINDINGS OR } \\
\text { OBSERVATIONS) }\end{array}$ & 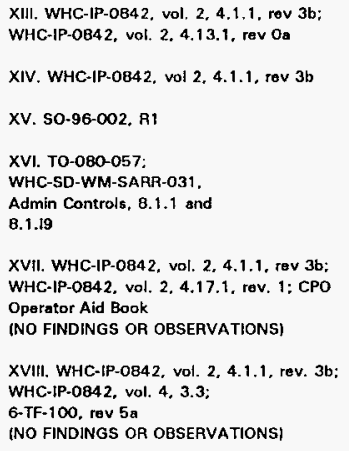 & $\begin{array}{l}\text { XIII. N } \\
N \\
\text { XIV.Y } \\
X V . Y \\
X V I ! Y \\
Y \\
Y \\
Y \\
X \text { XVII. Y } \\
Y \\
Y \\
\\
X V I I H . Y \\
Y \\
Y\end{array}$ \\
\hline May & E & DOE-ADAMS & PAD-AS-96-007 & 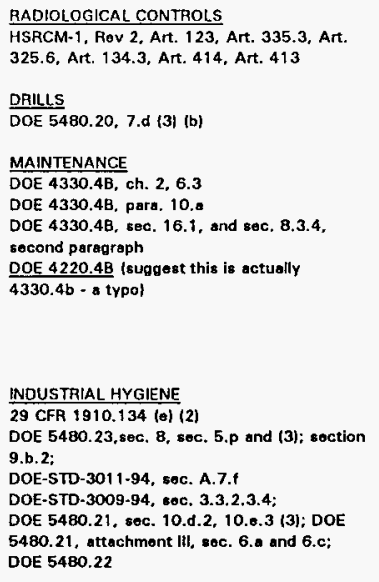 & 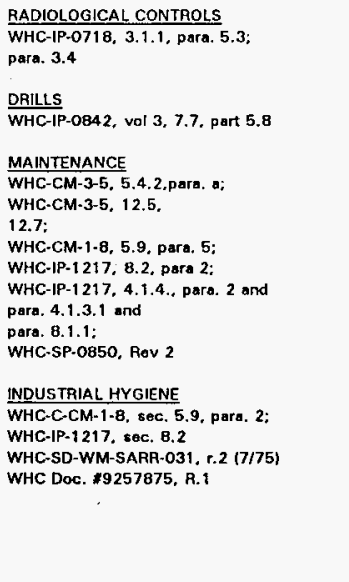 & $\begin{array}{l}n \\
N \\
N \\
N \\
N \\
N \\
N \\
N \\
N \\
N \\
N \\
N \\
N \\
N \\
N \\
N \\
N\end{array}$ \\
\hline
\end{tabular}




\section{Assessments from October 1995 to October 1996 - CPO}

WHC-SD-IWR-SRID-003

September 30,1996

Rev. 0

\begin{tabular}{|c|c|c|c|c|c|c|c|}
\hline June & I & $\begin{array}{l}\text { TFTP ENGIN. } \\
\text { 74XXX } \\
\text { TFTP 778XX }\end{array}$ & $\begin{array}{l}\text { ISA-96-004-JGP } \\
\text { WSD-GOP-31996-FO1 }\end{array}$ & $\begin{array}{l}\text { No references } \\
\text { No References } \\
\text { No roferences } \\
\text { No references }\end{array}$ & $\begin{array}{l}\text { TF MAINT PROCEDURES } \\
\text { WHC-SD-WM-RPT-220 [3/5/96) } \\
\text { WHC-IP-0842, Vol. 3, Soc. } 10.7(7 / 96) \\
\text { WHC-1P-0842, Vol. 4, Sec. } 5.4(8 / 96) \\
\text { Procodure Hold Points }(778 \times x) \\
\text { Procedures Not specific enough }(751 \mathrm{xx})\end{array}$ & $\begin{array}{l}\mathrm{N} / \mathrm{N} \\
\mathrm{N} / \mathrm{Y} \\
\mathrm{N} / \mathrm{H} \\
\mathrm{N} / 2\end{array}$ & $\begin{array}{l}\begin{array}{l}\text { To bo } \\
\text { completed } \\
9 / 30 / 96\end{array} \\
7 / 22 / 96 \\
7 / 22 / 96 \\
6 / 6 / 96 \\
6 / 17 / 96 \\
\end{array}$ \\
\hline July & 1 & $751 \times x$ & $\begin{array}{l}\text { PCC-96-KST-CPO-CO1 } \\
\text { PCC-96-KST-CPO-CO2 } \\
\text { PCC-96-KST-CPO-CO3 }\end{array}$ & No roferences & $\begin{array}{l}\text { RMCX AIR PERMIT MOD } \\
\text { CONTAM. EQUIP. MGT PLAN } \\
\text { LOUA TAPS PERMIT }\end{array}$ & $\begin{array}{l}\mathrm{N} \\
\mathrm{N} \\
\mathrm{N}\end{array}$ & $\begin{array}{l}\text { Sched. for } \\
\text { completion } \\
10 / 2 / 96 \text { and } \\
12 / 1 / 96\end{array}$ \\
\hline Aug & & & & & & & \\
\hline Sept & & & & & & & \\
\hline
\end{tabular}

